\author{
UNIVERSIDADE DE SÃO PAULO \\ ESCOLA DE ENGENHARIA DE SÃO CARLOS \\ DEPARTAMENTO DE ENGENHARIA ELÉTRICA
}

PEDRO IVO DE CASTRO OYAMA

Método para classificação de café em grãos por imagens digitais pelo uso de atributos selecionados de morfologia, cor e textura

São Carlos

2014 



\title{
Método para classificação de café em grãos por imagens digitais pelo uso de atributos selecionados de morfologia, cor e textura $^{1}$
} textura

\begin{abstract}
Dissertação apresentada à Escola de Engenharia de São Carlos da Universidade de São Paulo como parte dos requisitos para obtenção do título de Mestre em Ciências, Programa de Engenharia Elétrica
\end{abstract}

Área de concentração: Processamento de Sinais e Instrumentação

Orientador: Prof. Dr. Evandro Luis Linhari Rodrigues

\section{São Carlos}

2014

\footnotetext{
${ }^{1}$ Trata-se da versão corrigida da dissertação. A versão original se encontra disponível na EESC/USP que aloja o Programa de Pós-Graduação de Engenharia Elétrica.
} 
AUTORIZO A REPRODUÇÃO TOTAL OU PARCIAL DESTE TRABALHO, POR QUALQUER MEIO CONVENCIONAL OU ELETRÔNICO, PARA FINS DE ESTUDO E PESQUISA, DESDE QUE CITADA A FONTE.

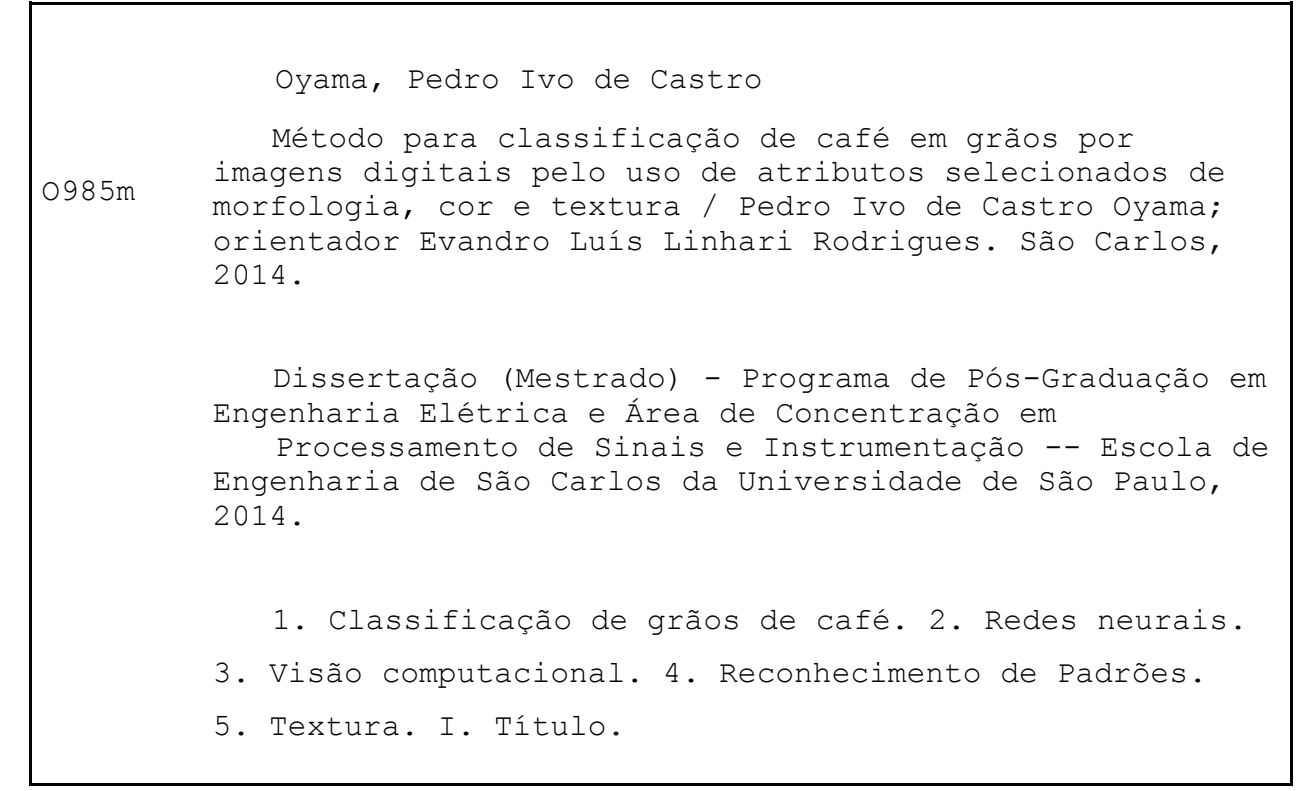




\section{FOLHA DE JULGAMENTO}

Candidato: Engenheiro PEDRO IVO DE CASTRO OYAMA.

Título da dissertação: Método para classificação de café em grãos por imagens digitais pelo uso de atributos selecionados de morfologia, cor e textura".

Data da defesa: $31 / 07 / 2014$

\section{Comissão Julgadora:}

Resultado:

Prof. Associado Evandro Luis Linhari Rodrigues

(Orientador)

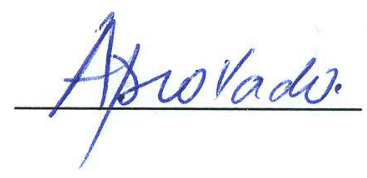

(Escola de Engenharia de São Carlos/EESC)

Dr. Lúcio André de Castro Jorge

(Empresa Brasileira de Pesquisa Agropecuária/EMBRAPA)

Anavado

Dr. Ednaldo José Ferreira

(Empresa Brasileira de Pesquisa Agropecuária/EMBRAPA)

Aprovado

Coordenador do Programa de Pós-Graduação em Engenharia Elétrica:

Prof. Titular Denis Vinicius Coury

Presidente da Comissão de Pós-Graduação:

Prof. Associado Paulo César Lima Segantine 



\section{AGRADECIMENTOS}

Ao Prof. Dr. Evandro, pela orientação e por todo seu apoio.

Ao Dr. Lúcio, pelas oportunidades concedidas e pela coorientação.

À Escola de Engenharia de São Carlos, por toda estrutura oferecida para o desenvolvimento do mestrado.

À Cooxupé, pelo apoio financeiro concedido por intermédio da Fundação para o Incremento da Pesquisa e do Aperfeiçoamento Industrial.

À Embrapa Instrumentação, pela disponibilização de recursos, de pessoal e do laboratório.

À minha família e aos meus amigos, pelo apoio constante em toda minha vida. 



\section{RESUMO}

OYAMA, P.I.C. Método para classificação de café em grãos por imagens digitais pelo uso de atributos selecionados de morfologia, cor e textura. 2014. Dissertação (Mestrado) Escola de Engenharia de São Carlos, Universidade São Paulo, São Carlos, 2014.

A análise da qualidade de grãos é um dos gargalos encontrados na cadeia produtiva do setor cafeeiro, tendo em vista que atualmente é feita de forma manual. Buscando uma solução para o problema, este trabalho apresenta um método baseado em visão computacional e redes neurais artificiais para identificar vinte e uma classes de grãos de café em amostras. No total, 421 atributos de três diferentes naturezas - morfologia, cor e textura - foram reunidos para compor o conjunto de características utilizado pela rede neural. Os atributos morfológicos são: Descritores de Fourier, Descritores Genéricos de Fourier, Momentos de Zernike, elementos do Modelo Autorregressivo e um conjunto de atributos diversos. Após avaliar duas abordagens para os atributos de cor - histogramas de frequências de cor e atributos estatísticos desses histogramas - a segunda foi escolhida e, assim, os atributos de cor adotados foram: média, variância, obliquidade, energia, curtose, entropia e suavidade de histogramas globais de cor, calculados para os espaços de cor RGB, HSV, $\mathrm{I}_{1} \mathrm{I}_{2} \mathrm{I}_{3}$ e CIELAB. Visando um melhor desempenho, os descritores de Haralick foram modificados para que dois pixels de referência fossem utilizados no cálculo da matriz de coocorrência. A versão modificada dos descritores superou as originais, e assim, seus valores calculados com o espaço de cor $\mathrm{I}_{1} \mathrm{I}_{2} \mathrm{I}_{3}$ (aquele que apresentou melhor eficácia em testes) foram utilizados como atributos de textura. O conjunto de atributos foi arranjado em cinco subconjuntos, cada um contendo diferentes combinações das distintas naturezas de atributos e sendo associado a uma análise. Para cada subconjunto selecionaram-se os melhores elementos pelas técnicas chi-quadrado, ganho de informação e PCA (Principal Component Analysis). O resultado dessa seleção determinou as entradas para três processos classificatórios, que foram avaliados a fim de se determinar o mais efetivo. Após as avaliações, e sendo determinada a melhor configuração, o processo classificatório escolhido proporcionou a acurácia de $85,08 \%$, superando trabalhos correlatos.

palavras-chave: classificação de grãos de café, redes neurais, visão computacional, reconhecimento de padrões, textura 



\section{ABSTRACT}

OYAMA, P.I.C. Method for coffee beans classification through digital images using selected morphological, colour and textural attributes. 2014. Dissertation (Master) - Escola de Engenharia de São Carlos, Universidade São Paulo, São Carlos, 2014.

The quality asssessment of beans is one of the bottlenecks found in the production chain of the coffee industry, as nowadays it is done manually. Seeking a solution for the problem, this work presents a method based on computer vision with neural networks to identify twenty-one classes of coffee beans in samples. In total, 421 features of three different types - morphological, colour and textural - were gathered to compose the feature set used by the neural network. The morphological features were Fourier Descriptors, Generic Fourier Descriptors, Zernike Moments, elements from Autoregressive Model and a miscellaneous set. After evaluating two approaches of colour features - colour frequency histograms and statistics from those histograms - the latter was chosen and the colour features comprised the mean, variance, skewness, kurtosis, energy, entropy and smoothness of global histograms calculated for the channels of the RGB, HSV, $\mathrm{I}_{1} \mathrm{I}_{2} \mathrm{I}_{3}$ and CIELAB colour spaces. Seeking better performance the Haralick features were modified, so two pixels were used as reference in the computation of the Grey Level Co-occurrence Matrix. The modified versions of the features outperformed the original ones and their computations with the $\mathrm{I}_{1} \mathrm{I}_{2} \mathrm{I}_{3}$ colour space (the one that provided the best results in tests) were used as textural features. The feature set was then rearranged in five intersecting subsets, each one containing different combinations of the feature types and being associated with an analysis. For each subset the best elements were selected using the techniques PCA (Principal Component Analysis), chi-squared and information gain. The resulting selections were used to determine the inputs to three classification processes, which were evaluated in order to select the most effective. After all evaluations, and having determined the best configuration, the selected classification process yielded an overall accuracy of $85.08 \%$, outperforming related works.

Keywords: coffee bean classification, neural networks, computer vision, pattern recognition, texture 



\section{LISTA DE FIGURAS}

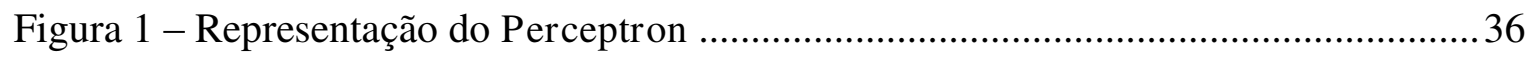

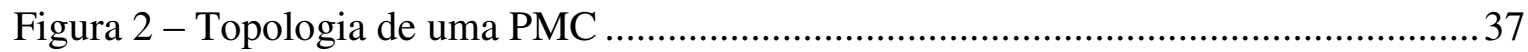

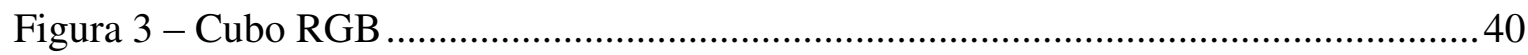

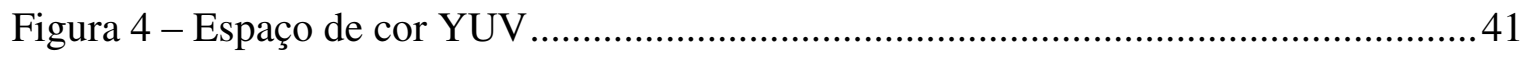

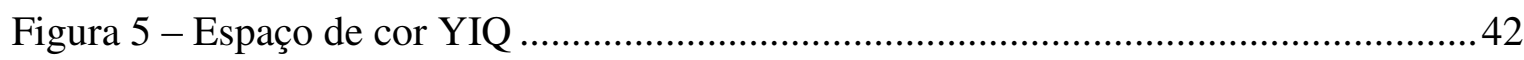

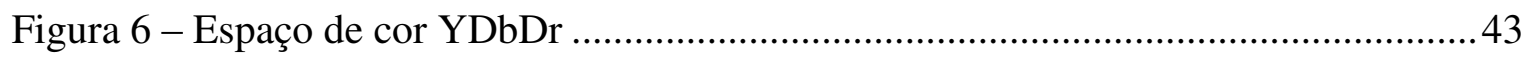

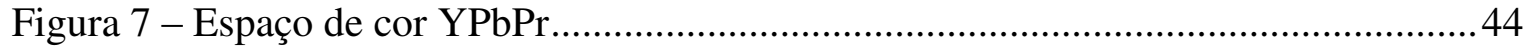

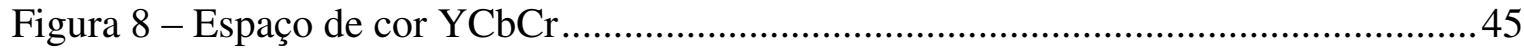

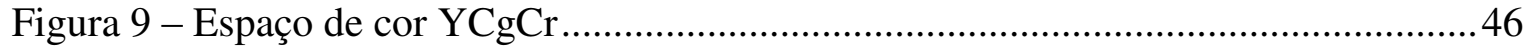

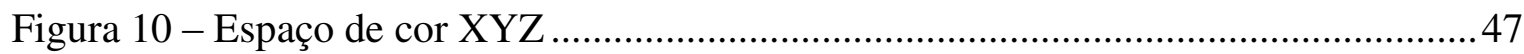

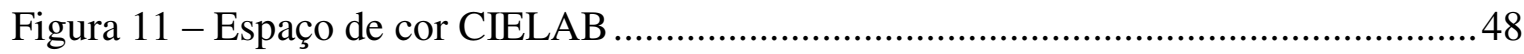



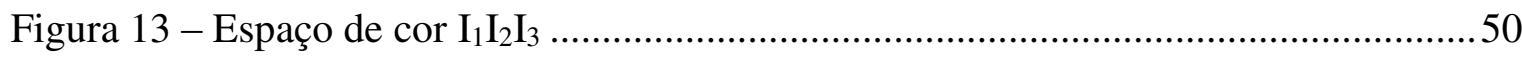

Figura 14 - Espaço de cor rgb por duas perspectivas.......................................................51

Figura 15 - Mapeamento de coordenadas utilizado pelo DGF. ........................................53

Figura 16 - Orientação do objeto e sistema alternativo de coordenadas.............................58

Figura 17 - Relação entre o pixel de referência $(P R)$ e o pixel vizinho $\left(P V_{i}\right)$ para $d=1$..60

Figura 18 - Formato de uma GLCM para uma imagem com 3 níveis de cinza.................61

Figura 19 - Função de densidade da distribuição $\chi^{2}$, para vários graus de liberdade k.......68

Figura 20 - Função distribuição acumulada da distribuição $\chi^{2}$, para vários graus de liberdade $\mathrm{k}$

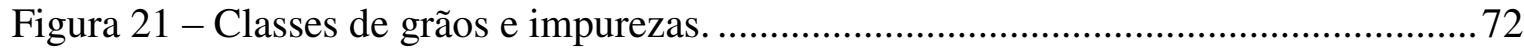

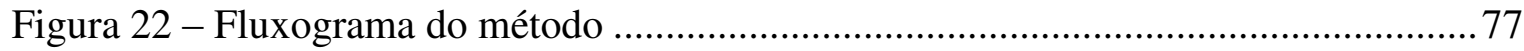

Figura 23 - Estrutura interna do aparato de captura de imagens....................................... 80

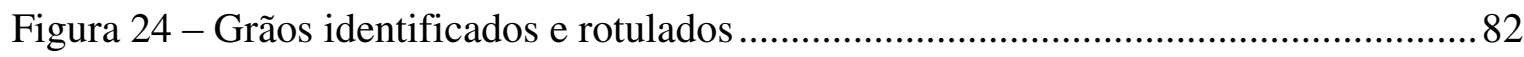

Figura 25 - Utilização de dois pixels de referência para o cálculo da GLCM ...................90

Figura 26 - GLCM para 2 níveis de cinza utilizando a abordagem de dois pixels de referência.

Figura 27 - Comparação de simetrias no cálculo das GLCM............................................92

Figura 28 - As três configurações de simetria para a GLCM utilizando dois pixels de referência. 
Figura 29 - Simetria diagonal para os pixels PV_8, PV_0, PV_3 e PV_5 93

Figura 30 - Processo classificatório envolvendo análises paralelas de cor, morfologia e



Figura 31 - Treinamento e avaliação do processo classificatório $\mathrm{P}_{\mathrm{M}+\mathrm{C}+\mathrm{T}}$ …………......... 109

Figura 32 - Acurácias das classificações utilizando os melhores atributos de cada técnica de seleção de atributos para a análise $\mathrm{A}_{\mathrm{MCT}}$..... 122 


\section{LISTA DE GRÁFICOS}

Gráfico 1 - Distribuição do número de amostras por classe .74

Gráfico 2 - Distribuição do número de amostras de grãos perfeitos por peneira 75

Gráfico 3 - Distribuição das amostras por classe, para o banco de atributos morfológicos 101

Gráfico 4 - Distribuição das amostras da classe Ovalado por classe original, para o banco de atributos morfológicos 101

Gráfico 5 - Distribuição das amostras da classe Perfeito por peneira, para o banco de atributos morfológicos 101

Gráfico 6 - Distribuição das amostras da classe Irregular por classe original, para o banco de atributos morfológicos 102

Gráfico 7 - Distribuição das amostras por classe, para os bancos de cor e textura 102

Gráfico 8 - Distribuição das amostras da classe fundida Perfeito por classe original e peneira, para os bancos de cor e textura..... 103

Gráfico 9 - Distribuição das amostras das classes fundidas Marinheiro e Casca por classe original, para os bancos de cor e textura 103

Gráfico 10 - Distribuição das amostras por classe, para o banco de atributos morfológicos, de cor e de textura.

Gráfico 11 - Distribuição das amostras da classe Perfeito por peneira, para o banco de atributos morfológicos, de cor e de textura 104

Gráfico 12 - Acurácias das classificações utilizando os melhores atributos de cada técnica de seleção de atributos para a análise $A_{M}$. 116

Gráfico 13 - Acurácias das classificações utilizando os melhores atributos de cada técnica de seleção de atributos para a análise $A_{C}$

Gráfico 14 - Acurácias das classificações utilizando os melhores atributos de cada técnica de seleção de atributos para a análise $\mathrm{A}_{\mathrm{T}}$.

Gráfico 15 - Acurácias das classificações utilizando os melhores atributos de cada técnica de seleção de atributos para a análise $\mathrm{A}_{\mathrm{CT}}$. 



\section{LISTA DE TABELAS}

Tabela 1 - Distribuição do número de amostras por classe 73

Tabela 2 - Distribuição do número de amostras de grãos perfeitos por peneira. 75

Tabela 3 - Acurácias para cada espaço de cor, das classificações utilizando histogramas de frequências normalizadas das cores do grão como vetor de características .....

Tabela 4 - Acurácias (em \%), para cada vetor de características avaliado, das classificações utilizando descritores de Haralick

Tabela 5 - Atualização da GLCM para cada posição do pixel vizinho 93

Tabela 6 - Acurácias (em \%), para cada vetor de características avaliado, das classificações utilizando descritores de Haralick com 2 pixels de referência. Comparadas com as respectivas acurácias dos descritores calculados com 1 pixel de referência 98

Tabela 7 - Relação das classes discrimináveis em cada análise 99

Tabela 8 - Classes fundidas para cada análise 100

Tabela 9 - Classes de cada análise

Tabela 10 - Número de amostras disponíveis para cada análise..... 104

Tabela 11 - Acurácias para cada espaço de cor, das classificações utilizando histogramas de frequências normalizadas das cores do grão como vetor de características

Tabela 12 - Comparação das acurácias obtidas pelas duas abordagens de cálculo dos descritores de Haralick: com 1 e 2 pixels de referência

Tabela 13 - Comparação das precisões médias obtidas pelas duas abordagens de cálculo dos descritores de Haralick: com 1 e 2 pixels de referência

Tabela 14 - Comparação dos recalls médios obtidos pelas duas abordagens de cálculo dos descritores de Haralick: com 1 e 2 pixels de referência 113

Tabela 15 - Comparação das F-Measures médias obtidas pelas duas abordagens de cálculo dos descritores de Haralick: com 1 e 2 pixels de referência

Tabela 16 - Quinze primeiros atributos das ordenações por chi-quadrado e por ganho de informação (G.I.) para cada análise.

Tabela 17 - Acurácias (em \%) das classificações utilizando os melhores atributos de cada técnica de seleção de atributos para a análise $\mathrm{A}_{\mathrm{M}}$. 115

Tabela 18 - Acurácias (em \%) das classificações utilizando os melhores atributos de cada técnica de seleção de atributos para a análise $A_{C}$. 
Tabela 19 - Acurácias (em \%) das classificações utilizando os melhores atributos de cada técnica de seleção de atributos para a análise $\mathrm{A}_{\mathrm{T}}$.

Tabela 20 - Acurácias (em \%) das classificações utilizando os melhores atributos de cada técnica de seleção de atributos para a análise $\mathrm{A}_{\mathrm{CT}}$.

Tabela 21 - Acurácias (em \%) das classificações utilizando os melhores atributos de cada

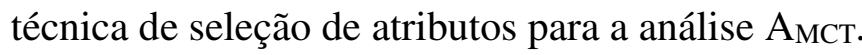

Tabela 22 - Resumo do processo de seleção de atributos

Tabela 23 - Recalls das classes dos Processos Classificatórios

Tabela 24 - Matriz de confusão do processo classificatório proposto. 126

Tabela 25 - Recalls do processo classificatório proposto. 126

Tabela 26 - Dez maiores confusões entre classes.

Tabela 27 - Notação dos atributos utilizada nas tabelas de ordenações

Tabela 28 - Ordenação dos atributos da análise $A_{M}$ pelos algoritmos Ganho de Informação e chi-quadrado.....

Tabela 29 - Ordenação dos atributos da análise $A_{C}$ pelos algoritmos Ganho de Informação e chi-quadrado.....

Tabela 30 - Ordenação dos atributos da análise $\mathrm{A}_{\mathrm{T}}$ pelos algoritmos Ganho de Informação e chi-quadrado. 141

Tabela 31 - Ordenação dos atributos da análise $A_{C T}$ pelos algoritmos Ganho de Informação e chi-quadrado.....

Tabela 32 - Ordenação dos atributos da análise $\mathrm{A}_{\mathrm{MCT}}$ pelos algoritmos Ganho de Informação e chi-quadrado 145 


\section{LISTA DE SIGLAS}

CIE XYZ

CIELAB

DGFs

GLCM

HSV

$\mathrm{I}_{1} \mathrm{I}_{2} \mathrm{I}_{3}$

PCA

PMC

RGB

$\mathrm{rgb}$

TPFM

$\mathrm{YCbCr}$

$\mathrm{YCgCr}$

$\mathrm{YDbDr}$

YIQ

$\mathrm{YPbPr}$

YUV
Espaço de cor cujos canais são X, Y e Z

Espaço de cor cujos canais são L, a* e b*

Descritores Genéricos de Fourier

Matriz de co-ocorrência de níveis de cinza, do inglês Grey

Level Co-occurrence Matrix

Espaço de cor cujos canais são H, S e V

Espaço de cor cujos canais são $\mathrm{I}_{1}, \mathrm{I}_{2}$ e $\mathrm{I}_{3}$

Análise de Componentes Principais, do inglês Principal

Component Analysis

Perceptron Multicamadas

Espaço de cor cujos canais são R, G e B

Espaço de cor RGB normalizado cujos canais são r, g e b

Transformada Polar de Fourier Modificada

Espaço de cor cujos canais são $\mathrm{Y}, \mathrm{Cb}$ e $\mathrm{Cr}$

Espaço de cor cujos canais são $\mathrm{Y}, \mathrm{Cg}$ e $\mathrm{Cr}$

Espaço de cor cujos canais são Y, Db e Dr

Espaço de cor cujos canais são Y, I e Q

Espaço de cor cujos canais são $\mathrm{Y}, \mathrm{Pb}$ e $\mathrm{Pr}$

Espaço de cor cujos canais são Y, U e V 



\section{SUMÁRIO}

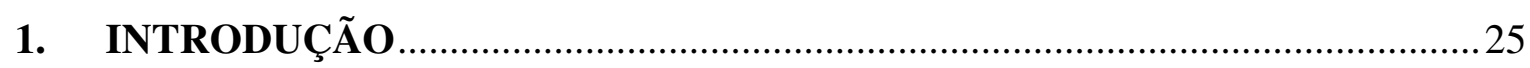

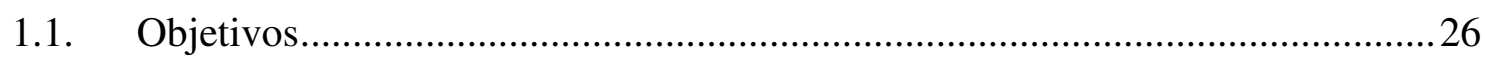

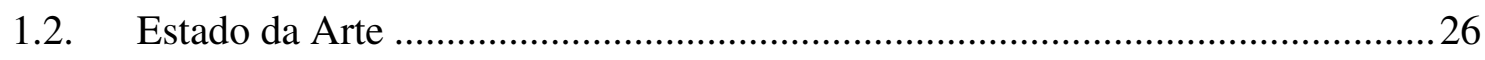

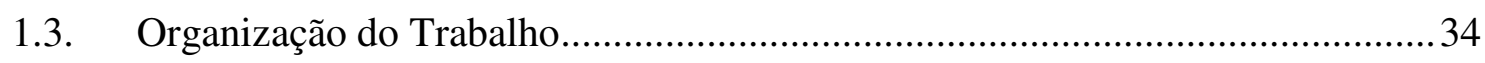

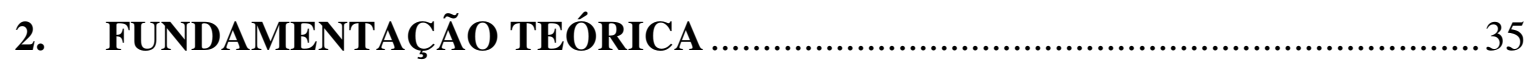

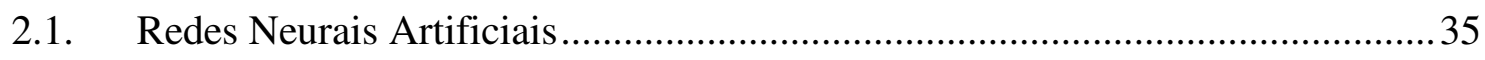

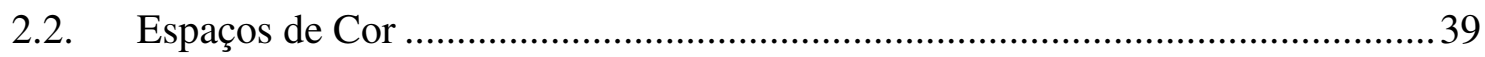

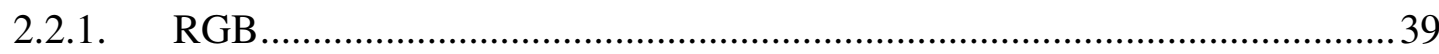

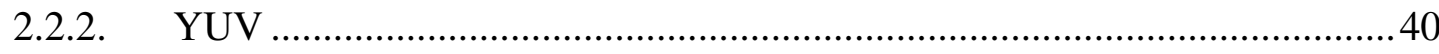

2.2.3. YIQ

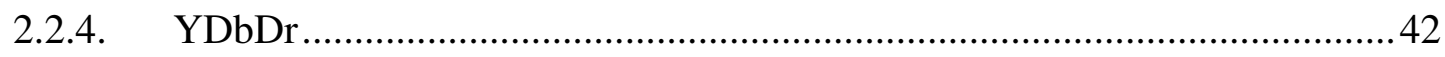

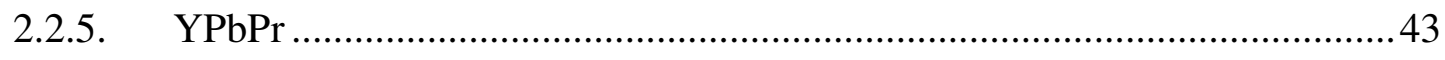

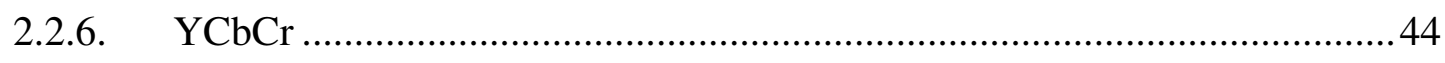

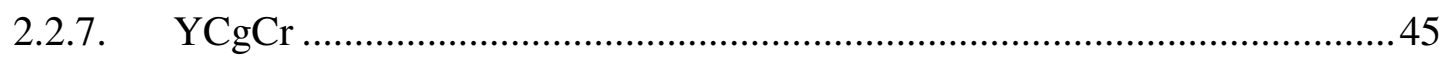

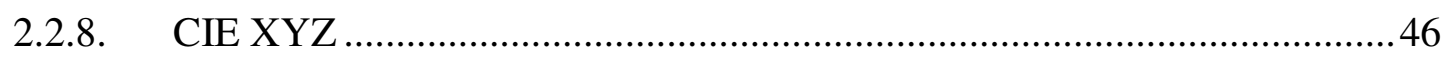



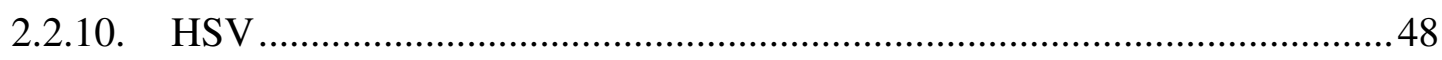



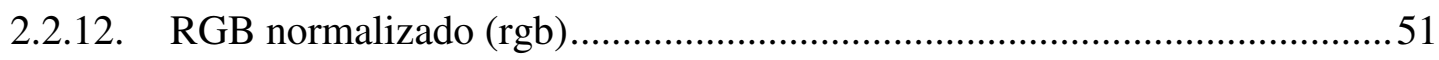

2.3. Atributos Morfológicos …………………………………………………....

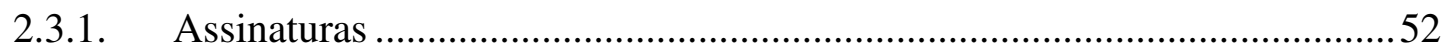

2.3.2. Descritores de Fourier ........................................................................52

2.3.3. Descritores Genéricos de Fourier (DGFs)...................................................53

2.3.4. Modelo Autorregressivo...........................................................................5

2.3.5. Momentos de Zernike.............................................................................56 




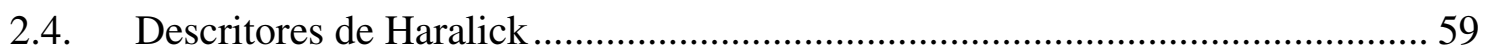

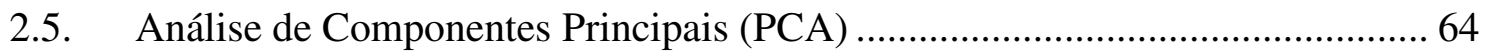

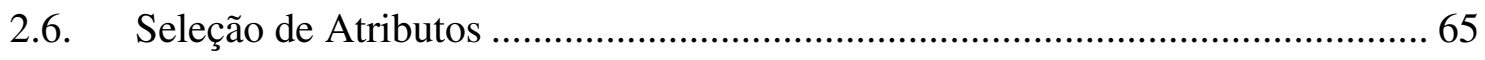

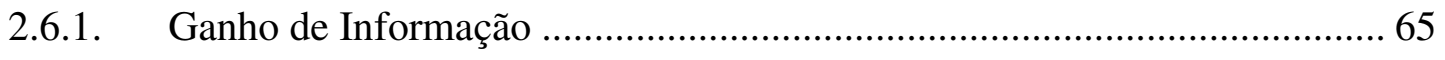

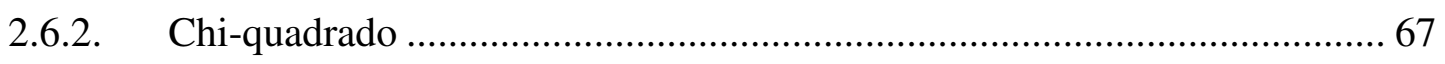

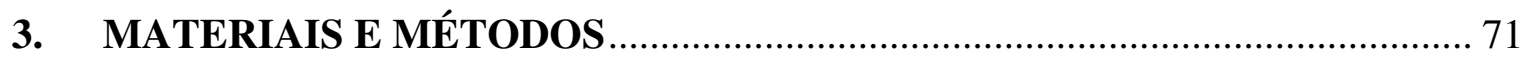



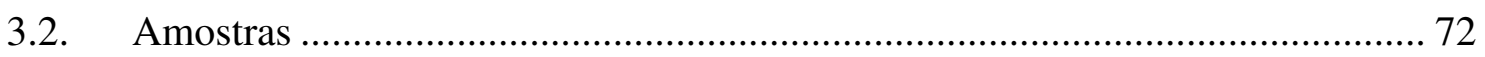

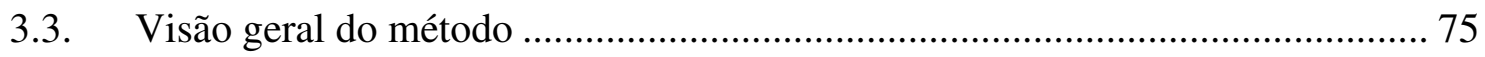

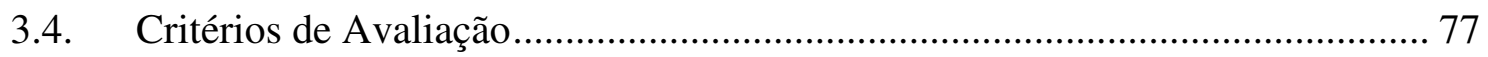

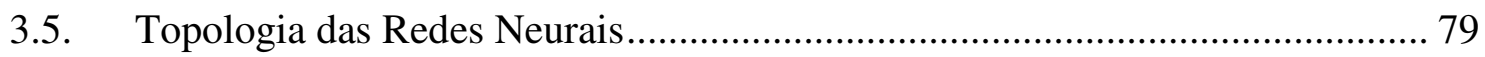

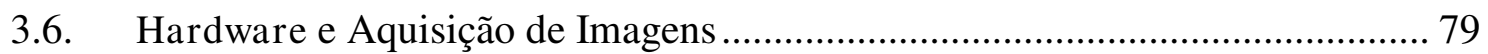

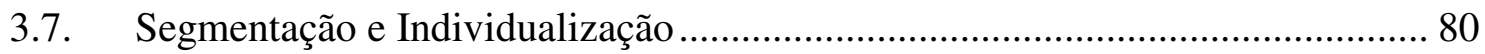

3.8. Criação de um Banco de Dados de Amostras ................................................. 82

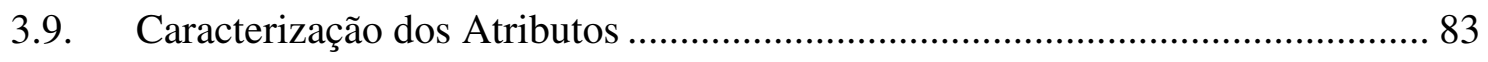



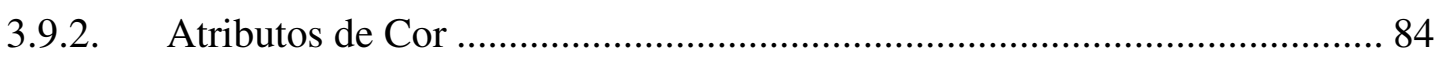

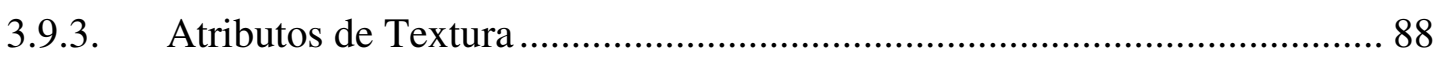

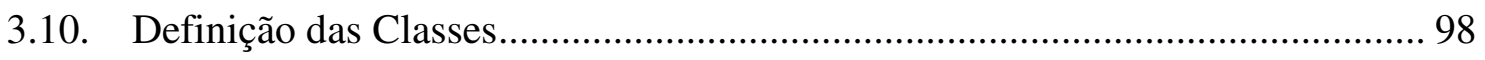

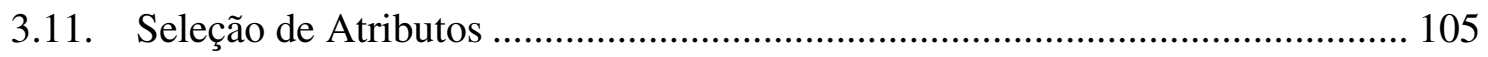

3.12. Definição do Processo Classificatório ......................................................... 106

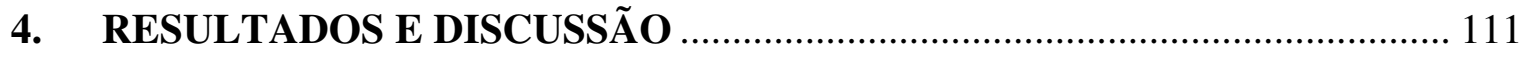

4.1. Classificação por Histogramas de Frequências Normalizadas de Cores ......... 111

4.2. Modificaçãa dos Descritores de Haralick ...................................................... 112

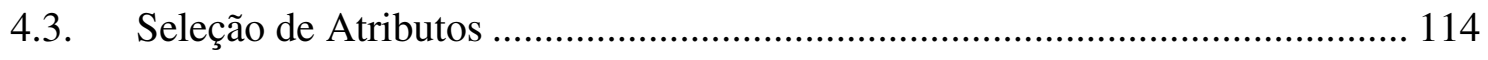

4.4. Definição do Processo Classificatório ......................................................... 124 
5. CONCLUSÕES

129

6. TRABALHOS PUBLICADOS

131

REFERÊNCIAS BIBLIOGRÁFICAS

133

APÊNDICE

137 



\section{INTRODUÇÃO}

Desde o século XIX o Brasil tem se destacado na produção e exportação do café, e atualmente ocupa a primeira posição mundial tanto na produção como na exportação do produto, contando com cerca de $30 \%$ do total das exportações mundiais do café (INTERNATIONAL COFFEE ORGANIZATION, 2014a; b). Devido à alta exigência do mercado internacional por produtos de qualidade, o café brasileiro exportado necessita passar por um rígido controle de qualidade, o qual deve ser preciso e rápido, dado o grande volume do produto que deve ser avaliado. Esse controle diz respeito tanto ao café em pó quanto ao grão antes da torrefação e da moagem.

Um dos desafios que as cooperativas de café enfrentam atualmente é avaliar a qualidade das safras de seus associados no ritmo imposto pelo processo produtivo, de modo que eles saibam prontamente o valor do seu produto. Essa informação deve ser obtida rapidamente, já que o preço pelo qual essas commodities são negociadas podem ser muito voláteis. A qualidade de uma safra geralmente é avaliada pela análise de pequenas amostras, visando identificar e quantificar grãos defeituosos e impurezas, os quais podem depreciar sobremaneira o sabor e o aroma da bebida produzida, e consequentemente seu valor. Grãos defeituosos são aqueles que apresentam alterações físicas e químicas comprometedoras, e podem ser provenientes de diversos fatores ocorridos durante o ciclo de vida do café, do cultivo e da colheita, ao beneficiamento e armazenamento. Impurezas são qualquer corpo estranho que não é café encontrado junto dos grãos. A qualidade da amostra é dada de maneira quantitativa ao se computar o número de ocorrências dos diversos tipos de defeitos e impurezas, os quais geralmente têm pesos diferentes na contagem, já que podem depreciar a bebida em proporções distintas.

Atualmente, a avaliação de qualidade é feita visualmente por especialistas e apresenta as seguintes desvantagens: a análise é dependente da intepretação subjetiva do avaliador, de modo que diferentes avaliadores podem dar diferentes diagnósticos para a mesma amostra; é um processo lento, já que cada grão deve ser avaliado individualmente; e a qualidade da análise se deprecia ao decorrer do turno de trabalho, por fatores envolvendo, principalmente, a fadiga. 
Essas questões fazem dessa análise um processo caro e não totalmente confiável, dadas as subjetividades envolvidas.

Em geral, os métodos automáticos de classificação aparecem em máquinas e sistemas para aplicação no processo de produção de beneficiadoras de sementes. No laboratório, a análise de amostras continua sendo feita de forma subjetiva e manual.

Neste contexto, o presente trabalho propõe um método para análise de amostras de café em grãos pela análise de imagens digitais, a fim de se aumentar a velocidade e reduzir as subjetividades envolvidas no atual processo manual de classificação.

\subsection{0bjetivos}

O objetivo deste trabalho foi desenvolver um método para a classificação de grãos de café em uma amostra por meio de processamente de imagem digital.

Dada a imagem de uma amostra, com grãos que não se tocam, cada um dos objetos deve receber uma classificação, de acordo com as regras de análise comumente adotadas pela indústria de café, com a maior acurácia possível.

\subsection{Estado da Arte}

Apesar de o problema já ter sido explorado por grupos que desenvolveram produtos e patentes relacionados, não há muitos trabalhos acadêmicos tratando a classificação de café por processamento digital de imagens na literatura. Por outro lado, muitos trabalhos abordando problemas correlatos de classificação de grãos e sementes têm sido desenvolvidos dentro e fora do país. Problemas desse tipo têm sido alvo de estudos há pelo menos quatro décadas e, a fim de se traçar um panorama geral sobre o que tem sido desenvolvido, um breve resumo englobando alguns trabalhos publicados ao decorrer desse período será apresentado nesta seção.

Brogan e Edison (1974) apresentaram um dos trabalhos pioneiros no uso de visão computacional na classificação de grãos. Eles utilizaram os atributos morfológicos comprimento, largura e espessura, e algumas de suas combinações, como por exemplo largura/comprimento, para determinar a composição de amostras de grãos. As amostras podiam 
conter grãos de milho, trigo, soja, cevada, aveia e centeio. Mesmo sendo um dos trabalhos precursores da área, seu método obteve bons resultados, com a acurácia de cerca de $98 \%$.

Neuman et al. (1989a) analisaram amostras de 10 diferentes variedades de sementes de trigo, arranjadas em 6 categorias mais abrangentes. Com um lote de sementes, calcularam os valores médios dos canais $\mathrm{R}, \mathrm{G}$ e B para cada variedade, assim como as respectivas variâncias. Com os resultados, constatou-se a possibilidade de se discriminar as sementes de diferentes categorias por meio dos valores médios dos elementos do sistema RGB. Na continuação do trabalho (NEUMAN et al., 1989b), os valores obtidos no primeiro estudo foram utilizados para gerar funções discriminantes. Um segundo lote de sementes foi utilizado para validar o método. Aplicando-se o método para diferenciar grãos em uma amostra contendo apenas sementes de duas categorias distintas (realizando um experimento para cada uma das 30 combinações possíveis) obteve-se uma acurácia média de $88 \%$ em relação a todos os experimentos. Classificando-se uma amostra contendo sementes de todas as seis categorias a acurácia foi de $66,6 \%$.

Chtioui et al. (1996) classificaram sementes em amostras contendo quatro espécies diferentes: rumex, aveia selvagem, alfafa e vicia. A classificação foi realizada analisando atributos morfológicos, como Descritores de Fourier e momentos invariantes, totalizando 25 atributos. Também foram utilizados atributos de textura calculados a partir de histogramas locais (média, variância, energia, entropia, curtose e obliquidade) e cinco dos descritores de Haralick (HARALICK; SHANMUGA.K; DINSTEIN, 1973) (energia, contraste, correlação, entropia e momento inverso de diferenças). Os atributos de textura foram calculados para os três canais do modelo RGB e para o modelo em tons de cinza, totalizando, portanto, 44 atributos. Esse conjunto de atributos foi então utilizado em dois métodos de classificação: análise discriminante stepwise (MCLACHLAN, 2004) e redes neurais perceptron multicamadas (PMC). Em classificações-teste o primeiro método obteve 98,4\% de acurácia e o segundo $100 \%$.

Ahmad et al. (1999) utilizaram um sistema de visão computacional para discriminar grãos de soja sintomáticos (dentre oito doenças) e não sintomáticos. De cada semente foi extraída uma janela amostral (de 15x15 pixels), com as quais foram calculadas seis características de cor - valores máximo e mínimo, média, variância, mediana e desvio padrão - para cada um dos componentes RGB. Com o uso da correlação de Pearson, o conjunto de características foi reduzido pela metade, eliminando-se variáveis com alta correlação. Os atributos mantidos 
foram os mínimos, médias e variâncias. Com eles foram gerados classificadores pela análise discriminante stepwise. Os testes revelaram, no melhor caso, uma acurácia de 67,16\%.

No trabalho de Majumdar e Jayas (2000a) foram utilizadas características de forma para diferenciar sementes em amostras contendo duas variedades de trigo, uma de cevada, uma de aveia e uma de centeio. De um lote de sementes, foram calculadas 23 características para cada grão, das quais foram selecionadas as 10 mais significativas pela análise discriminante stepwise. Dentre as selecionadas estavam: maior e menor raios, os primeiros momentos invariantes e o primeiro Descritor de Fourier. A classificação foi realizada utilizando-se análise discriminante com o conjunto de características selecionadas. A acurácia do método foi de $96 \%$.

O trabalho anterior foi estendido por Majumdar e Jayas (2000b), tratando o mesmo problema com métodos análogos, porém com o uso de características de cores. De 18 atributos de cor extraídos das sementes (média, variância e intervalo de variação das componentes RGB e HSI), foram determinadas as 10 mais significativas, as quais foram utilizadas na classificação pela análise discriminante. O resultado foi uma acurácia de $94,88 \%$.

Majumdar e Jayas (2000c) deram continuidade aos métodos descritos anteriormente, realizando a classificação por atributos de textura. Alguns parâmetros definidos para análise de textura foram variados para encontrar sua melhor combinação. Foi avaliado o uso de diferentes números máximos de tons de cinza: 32, 16, 8 e 4. Além disso, diferentes canais de cor pelas quais são calculados os descritores foram testados: os canais do modelo RGB e algumas combinações entre elaes, por exemplo, $(\mathrm{R}+\mathrm{G}+\mathrm{B}) / 3$. Um total de 25 atributos de textura foram utilizados, dentre eles atributos derivados de matrizes de coocorrência de níveis de cinza, apresentados por Haralick, Shanmuga e Dinstein (1973) e atributos derivados de matrizes de comprimento de primitiva a nível de cinza, desenvolvidos por Galloway (1975). O número de atributos foi reduzido para 15 aplicando a análise discriminante stepwise, e estes atributos foram utilizados no classificador baseado em análise discriminante. Uma bateria de classificações foi conduzida contemplando todas as combinações de parâmetros. O melhor resultado foi obtido fazendo a análise no canal G com um máximo de 8 tons, gerando a acurácia de 91,94\%.

Um estudo avaliando combinações das três abordagens anteriores foi conduzido por Majumdar e Jayas (2000d). Foram realizados testes de classificação utilizando todas as possíveis combinações de dois conjuntos de atributos: morfologia e textura (combinação A); morfologia e cor (combinação B); e textura e cor (combinação C). Também foi testada a combinação de todos os conjuntos - morfologia, cor e textura (combinação D). No caso de combinações de dois conjuntos, as classificações foram realizadas pelo uso dos 15 atributos 
mais discriminantes, enquanto que quando todos os conjuntos foram considerados os 20 atributos mais discriminantes foram adotados. As acurácias obtidas com as combinações A, B, C e D foram, respectivamente, 98,6\%, 99,4\%, 98,4 e 99,7\%. Assim, para o problema apresentado, a classificação mostrou-se mais acurada para a combinação D, ou seja, utilizando a combinação de todos os tipos de atributos.

Carter, Yan e Tomlins (2006) publicaram um trabalho de análise de amostras de grãos de arroz por imagens digitais. Nele é apresentado um procedimento de visão computacional para determinar em uma amostra o número de grãos de arroz de cada um dos três possíveis tipos (em porcentagem). De um conjunto de amostras de sementes foram extraídas diversas características morfológicas de cada grão, incluindo razão de aspecto, e maior e menor eixos. Com esses dados foram calculados seus respectivos histogramas (com cinco intervalos) e seus valores médios para cada classe, gerando uma base de dados. Depois da aplicação da PCA (Principal Component Analysis) (JOLLIFFE, 2005) foram selecionadas as seis componentes principais mais discriminantes dentre as resultantes. Essas componentes principais foram definidas como as variáveis de entrada de um sistema fuzzy (COX et al., 1998), e para cada uma delas foi desenvolvida uma função de pertinência. $O$ software desenvolvido utilizou as funções para classificar individualmente os grãos de uma amostra. Várias classificações de amostras contendo combinação de dois tipos de sementes em proporções típicas foram realizadas para avaliar a eficácia do método, e foram obtidos resultados com erros situados entre $5 \%$ e $10 \%$.

Khatchatourian e Padilha (2008) utilizaram redes neurais artificiais do tipo PMC para classificação de 8 variedades de soja por imagens digitais. Aplicando um método de detecção de bordas pelo filtro de Prewitt e operações morfológicas para eliminação de ruídos, amostras de grãos de soja foram segmentadas de uma imagem de fundo preto. Os grãos foram então individualizados e identificados. Cada um deles foi transcrito em uma matriz 130x130, dimensões previamente avaliadas para comportar qualquer grão, de modo que um elemento de valor 1 representa um pixel do grão e um elemento de valor 0 representa um pixel do fundo. Estas matrizes foram então transformadas em vetores de dimensão 16.900 para servirem como vetores de características. Uma rede neural que contava com três camadas escondidas com 90, 70 e 60 neurônios, foi treinada com 280 amostras. Utilizando a rede neural na classificação de um conjunto de amostras diferentes das utilizadas no treinamento, os autores obtiveram a acurácia de 57,5\%. 
Choudhary, Paliwal e Jayas (2008) utilizaram técnicas de visão computacional para diferenciar sementes em amostras contendo duas variedades de trigo, uma de cevada, uma de aveia e uma de centeio. O método utilizou 51 características morfológicas, 93 de cor, 56 de textura e 135 relacionadas a wavelets. Wavelets são uma ferramenta de análise de sinais que, dentre outras possibilidades, permite caracterizar texturas em múltiplas resoluções por meio de sucessivas decomposições (GONZALEZ; WOODS, 2008a). Os pixels das sementes foram passados para os distintos canais de três espaços de cor - RGB, HSI, e CIELAB. Em cada um dos canais foi aplicada uma transformada wavelet discreta, decompondo a imagem original em três outras de resoluções diferentes. Para cada uma das decomposições foram calculadas 3 características de energia e 3 de correlação. Assim, foram obtidos os 135 atributos de wavelet. As características morfológicas, de cor e de textura foram obtidas de maneira semelhante aos calculados em outros artigos citados anteriormente. Com classificadores baseados em análise discriminante foram comparadas combinações diferentes de conjuntos de características de naturezas distintas. $\mathrm{O}$ melhor resultado foi obtido quando todos os conjuntos foram utilizados ao mesmo tempo, proporcionando uma acurácia de 97,0\%. Apesar de a classificação utilizando somente os atributos wavelet ter gerado o pior resultado - acurácia de 75,1\% - dois de seus elementos foram listados entre as 20 características mais discriminantes pela análise discriminante stepwise.

No trabalho de Carrillo e Peñaloza (2009) foram utilizados classificadores baseados na distância de Mahalanobis (MAHALANOBIS, 1936) para identificar seis classes de café em grão em uma amostra. A distância de Mahalanobis permite calcular a distância entre um grupo de valores e outro, ou entre um valor e um grupo de valores. Essa distância é calculada utilizando a covariância entre os grupos de valores e suas médias. Com um conjunto de amostras, foram extraídos os valores RGB de todos os pixels dos grãos presentes e estes foram agrupados por classes. A classificação foi então testada calculando-se a distância de Mahalanobis de cada pixel de um grão com cada um dos agrupamentos de pixels representativos das classes. O pixel recebeu a classificação do agrupamento que proporcionou a menor distância e, após a classificação de todos os pixels, ao grão foi atribuída a classe que possuía maior número de pixels. O recall médio desse método foi de $67,7 \%$.

Chen et al. (2010) desenvolveram um método para classificação de grãos de milho de cinco variedades diferentes com imagens capturadas com um digitalizador de mesa. Inicialmente foram extraídas características geométricas, de cor e de forma, totalizando 58 atributos. Os atributos geométricos incluem área, perímetro, comprimento e larguras dos grãos em diferentes 
pontos. Os de forma abrangem, entre outros, momentos invariantes e os primeiros coeficientes de Fourier. A cor foi tratada transformando-se o espaço RGB em outros quatro: RGB normalizado, YCbCr, $\mathrm{I}_{1} \mathrm{I}_{2} \mathrm{I}_{3}$ e HSV. As características de cor utilizadas foram desvios padrões e médias de componentes desses espaços de cor. Com o objetivo de melhorar a eficiência e a eficácia do método, o número de atributos foi reduzido utilizando a análise discriminante stepwise. O processo de classificação foi dividido em duas etapas, sendo que na primeira foram separadas três classes de grãos por intermédio de um classificador baseado no cálculo de distâncias Mahalanobis. A segunda etapa utilizou uma rede neural do tipo PMC para separar uma das classes determinadas no processo anterior em três outras. A acurácia obtida com o método foi de $94,8 \%$.

Ahmad et al. (2010) apresentaram uma máquina para realizar a separação automática de grãos de café por visão computacional. O problema consistia em diferenciar entre quatro tipos de grãos, sendo três deles caracterizados pelo tamanho e o quarto (grão defeituoso), podendo ser definido por tamanho ou cor. Foram utilizados três atributos morfológicos (área, comprimento e perímetro), dois atributos de cor (citados pelos autores como índices de vermelho e verde) e mais um atributo definido como área defeituosa. 2000 amostras, uniformemente distribuídas entre as classes, foram utilizadas para treinar uma PMC, e 500 outras amostras, também uniformemente distribuídas, constituíram o conjunto de testes para avaliação do método. O resultado foi uma acurácia de 78,32\%.

No trabalho de Arefi, Motlagh e Teimourlou (2011) foi realizada a identificação de quatro variedades de trigo iraniano em amostras. Para tanto foram utilizados atributos morfológicos e de cor, calculados a partir das representações das sementes em cinco espaços de cor distintos: RGB, HSI, RGB normalizado, $\mathrm{YCrCgCb}, \mathrm{I}_{1} \mathrm{I}_{2} \mathrm{I}_{3}$ e CIELAB. Para cada grão de um conjunto de treinamento foram calculados os valores de média, desvio padrão, variância, obliquidade e curtose de cada um dos canais dos espaços de cores e foram escolhidos seis atributos para serem utilizados como entrada para uma rede neural, a saber: média(CIE-a*), curtose(CIE-a*), média(R-B), média(R-G), obliquidade(G) e variância(R-G). Dentre 10 atributos morfológicos foram escolhidos 6 para comporem o conjunto de entrada da rede neural: área, área/eixo maior, área/perímetro, $\frac{4 \pi \text { área }}{\text { perímetro }^{2}}$, eixo maior/ eixo menor e diâmetro do círculo de mesma área / eixo maior. Treinando uma rede neural artificial do tipo PMC com 280 amostras e classificando amostras-teste foi obtida a acurácia de $95,86 \%$.

Faridah, Parikesit e Ferdiansjah (2013) apresentam um método para classificar amostras de café como um todo, ao invés de classificar seus grãos componentes individualmente. As 
amostras deviam ser classificadas como pertencentes a uma dentre as sete possíveis categorias, de acordo com sua aparência. Foram utilizadas as médias dos canais R, G e B, juntamente com quatro descritores de Haralick (energia, entropia, contraste e homogeneidade) como entrada para redes neurais PMC. Os recalls obtidos para cada uma das categorias foram $100 \%, 80 \%$, $60 \%, 40 \%, 100 \%, 40 \%$ e $100 \%$, resultando no recall médio de $74,29 \%$.

No trabalho de Delwiche, Yang e Graybosch (2013) é proposto um método para avaliação de grãos de trigo por meio de imagens tomadas de ângulos distintos. O objetivo do estudo foi discriminar os grãos entre duas classes: bons e defeituosos, sendo os possíveis defeitos a presença de bolor, ponta preta ou brotos. Com o uso de um jogo de espelhos, três imagens de perspectivas diferentes eram capturadas de grãos em queda-livre. De cada uma das imagens de um grão foram calculados os oito atributos morfológicos seguintes: área, perímetro, maior e menor eixos, excentricidade, solidez (área dividida pela área do menor polígono convexo a envolver o grão) e a razão maior eixo/ menor eixo e sua inversa. Também foram calculados cinco dos descritores de Haralick: contraste, correlação, energia, homogeneidade e entropia. Para cada um desses atributos foram calculados os valores máximo, mínimo e médio entre as três imagens para compor o conjunto de atributos. Os descritores de Fourier elípticos (KUHL; GIARDINA, 1982) foram calculados para apenas uma das imagens, e os coeficientes dos seus 10 primeiros harmônicos, e os valores das suas 5 primeiras componentes principais dos coeficientes simétricos foram adicionados ao conjunto, juntamente com o volume da revolução da elipse dada pelas médias dos eixos menores e maiores das três imagens. Utilizando a análise discriminante stepwise foram selecionados os atributos mais discriminantes - dois morfológicos e quatro de textura - e eles foram avaliados por dois métodos, análise discriminante stepwise e K-nearest neighbours. Os resultados proporcionaram acurácias entre $91 \%$ e $94 \%$.

Valiente-Gonzalez et al. (2014) apresentaram um equipamento para a avaliação automática da qualidade de grãos de milho por imagem. O método proposto visava classificar grãos individualizados como "aceito" ou "rejeitado". A análise foi realizada em duas etapas: na primeira pixels eram avaliados entre "bons" e "defeituosos", e na segunda avaliava-se a proporção de pixels ruins no grão para determinar sua classificação. O vetor de características utilizado para classificar um pixel era composto pelas coordenadas do espaço de cor adotado de cada um dos pixels que compreendem uma janela $3 \times 3$. Com um conjunto de amostras de treinamento (somente de grãos "aceitos") calcularam-se os valores médios de cada um dos elementos do vetor de características e os vetores de características foram então transformados 
para que ficassem centrados na média de seus valores. Aplicou-se então a PCA nos vetores de características transformados, de modo que o resultado seria o modelo de pixels "bons". A distribuição de Hotelling $\left(\mathrm{T}^{2}\right)$, que determina a variação do pixel para o modelo, foi calculada para cada um dos pixels do conjunto de treinamento. Um threshold foi definido para $\mathrm{T}^{2}$ para que $\tau \%$ dos pixels de treinamento tivessem seus $\mathrm{T}^{2}$ menores que o threshold, e os pixels com valores maiores seriam considerados defeituosos. A segmentação dos grãos foi feita de modo semelhante à determinação dos pixels defeituosos, pelo método conhecido como eigenbackgrounds (OLIVER; ROSARIO; PENTLAND, 2000). A porcentagem de pixels defeituosos $(\varepsilon)$ em cada um dos grãos do conjunto de treinamento foi calculada, e então calculou-se a média $\bar{\varepsilon}$ dessas porcentagens. Definiu-se, então, um parâmetro $\alpha$, de modo que se um grão apresentasse $\varepsilon>\alpha \bar{\varepsilon}$ ele seria considerado "rejeitado". A partir desse método, utilizaram-se amostras de testes (200 grãos "aceitos" e 200 grãos "rejeitados") para determinar os melhores valores para os parâmetros, o espaço de cor mais eficaz (entre RGB, HSV e CIELAB), e consequentemente a capacidade do método. O melhor resultado obtido foi $92 \%$ de acurácia, $92 \%$ de precisão e $91 \%$ de recall com o espaço de cor HSV, $\tau=95 \%$ e $\alpha=1,2$.

A abordagem adotada neste trabalho para tratar o problema de classificação de grãos de café foi extrair um conjunto de atributos morfológicos, de cor e de texura, e então agrupá-los em subconjuntos $(\{$ morfológicos $\},\{$ cor $\},\{$ textura $\},\{$ cor e textura $\}$ e $\{$ morfológicos, cor e textura\}), associando cada um deles a uma análise baseada em redes neurais. Os atributos morfológicos eram: Descritores de Fourier, Descritores Genéricos de Fourier, Momentos de Zernike, elementos do Modelo Autorregressivo e um conjunto de atributos diversos. Os atributos de cor eram estatísticas extraídas de histogramas de cor de quatro espaços de cor. Os atributos de textura eram descritores de Haralick modificados para utilizar dois pixels de referência no cálculo das matrizes de co-ocorrência. Para cada subconjunto aplicaram-se técnicas de seleção, a fim de se definir os melhores atributos de cada análise. As análises foram combinadas em três diferentes configurações e avaliadas, determinando o método de classificação proposto. 


\subsection{0rganização do Trabalho}

No Capítulo 2 são detalhados os fundamentos teóricos envolvidos nas técnicas e ferramentas utilizadas neste trabalho, abordando redes neurais artificiais, espaços de cores, os atributos utilizados e conceitos utilizados para seleção de atributos.

O método desenvolvido é apresentado no Capítulo 3, sendo definidos o material utilizado, os processos de captura de imagens, segmentação e individualização dos grãos. Também são definidos os atributos utilizados e como foram selecionados e o processo para definir o procedimento de classificação.

Os resultados dos experimentos realizados para avaliar o método são apresentados e discutidos no Capítulo 4.

O Capítulo 5 traz as conclusões obtidas do trabalho realizado e comentários gerais.

E, finalmente, o Capítulo 6 apresenta os trabalhos publicados em decorrência deste trabalho. 


\section{FUNDAMENTAÇÃO TEÓRICA}

Neste capítulo serão expostos brevemente os conceitos que contextualizam o problema abordado e o método proposto. Será apresentada a rede neural do tipo PMC, o classificador utilizado como base para as classificações. Também serão apresentados os espaços de cor utilizados para derivar os atributos de cor: RGB, YUV, YIQ, YDbDr, YPbPr, YCbCr, YCgCr, CIE XYZ, CIELAB, HSV, $\mathrm{I}_{1} \mathrm{I}_{2} \mathrm{I}_{3}$ e RGB normalizado. Também os atributos morfológicos utilizados no método: assinaturas, Descritores de Fourier, Modelo Autorregressivo, Momentos de Zernike, Descritores Genéricos de Fourier (DGF) e um conjunto de descritores compostos por somente um elemento. Serão apresentados os 14 descritores de Haralick, desenhados para representação de textura e modificados no método proposto visando se avaliar macro-texturas. Por fins, serão apresentados os conceitos utilizados para promover seleção de atributos: PCA (Principal Component Analysis), Ganho de Informação e Chi-quadrado.

\subsection{Redes Neurais Artificiais}

Redes neurais artificiais do tipo Perceptron Multicamadas são modelos computacionais inspirados no modelo biológico de interligação entre neurônios, e visam promover o aprendizado de máquina. Dentre outras aplicações, elas são amplamente utilizadas na classificação de padrões, ou seja, indicar a que classe pertencem os dados de entrada. As PMCs são redes neurais cujo aprendizado é supervisionado, e, portanto, antes de realizar qualquer classificação é necessário um processo de treinamento no qual vários exemplos de dados préclassificados são apresentados. As PMCs são constituídas de várias camadas de neurônios artificiais, os Perceptrons, os quais são ilustrados na Figura 1. (SILVA; SPATTI; FLAUZINO, 2010) 


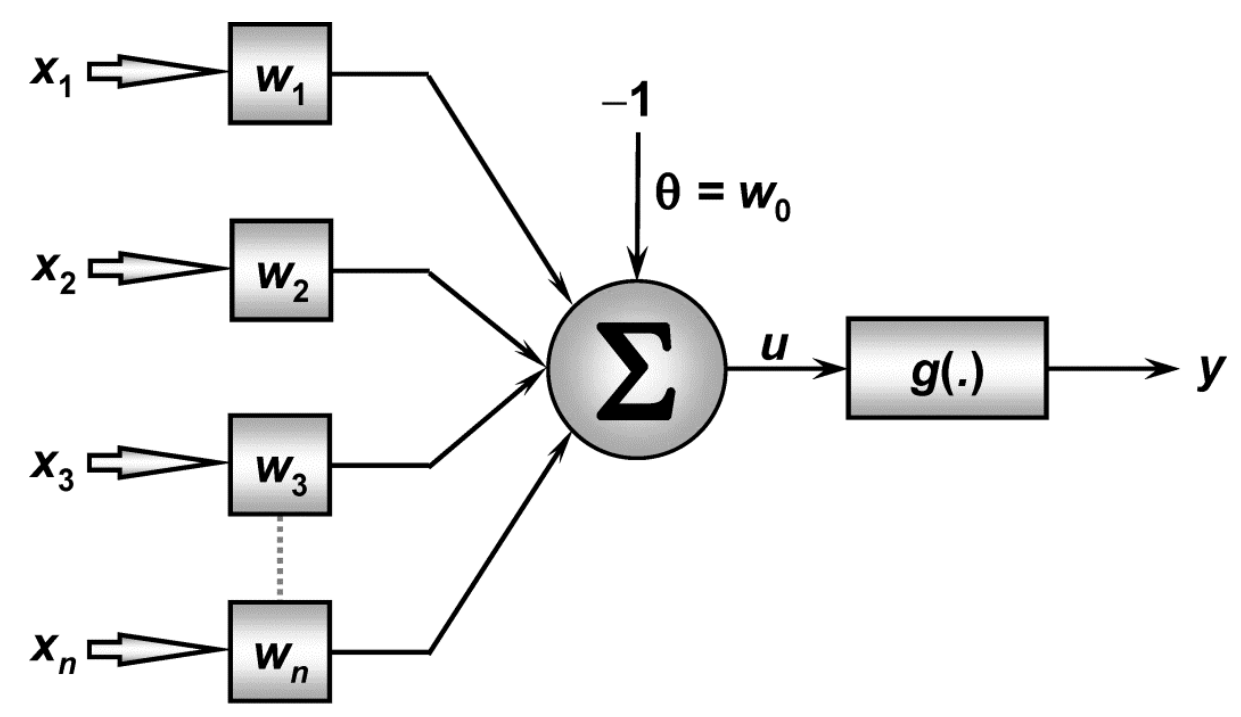

Figura 1 - Representação do Perceptron

(SILVA; SPATTI; FLAUZINO, 2010)

O Perceptron recebe um conjunto de sinais de entrada $\left(x_{1}, x_{2}, \ldots, x_{n}\right)$ e os transforma em um único sinal de saída y. Cada um dos sinais de entrada é multiplicado por seu respectivo peso sináptico $\left(w_{1}, w_{2}, \ldots, w_{n}\right)$, e os resultados dessas operações são somados junto com o produto do limiar de ativação $(\theta)$ e seu peso sináptico $\left(w_{0}\right)$, cujo valor é -1 , como determinado pela Equação (2.1). O resultado do somatório, chamado de potencial de ativação (u), é passado como argumento para a função de ativação $(g(\cdot))$, a qual definirá a saída y (Equação (2.2)). Os pesos sinápticos são ajustados automaticamente pelo processo de treinamento e, assim, o Perceptron é capaz de associar uma saída a um conjunto de valores de entrada, conforme o comportamento entrada-saída apresentado no treinamento.

$$
\begin{gathered}
u=\sum_{i=1}^{n} w_{i} \cdot x_{i}-\theta \\
y=g(u)
\end{gathered}
$$

As camadas de neurônios de uma PMC, e como elas são interligadas, são ilustrados na Figura 2. Há uma camada de entrada, por onde dados são fornecidos, uma de saída, por onde os resultados são apresentados, e pelo menos uma camada escondida (intermediária). As saídas de neurônios de uma camada são utilizadas como entrada para os neurônios da camada posterior, de forma sucessiva até o sinal chegar à camada de saída. O número de camadas 
escondidas e o número de neurônios em cada uma devem ser definidos de acordo com a aplicação, e influenciam na taxa de sucesso da classificação (SILVA; SPATTI; FLAUZINO, 2010).

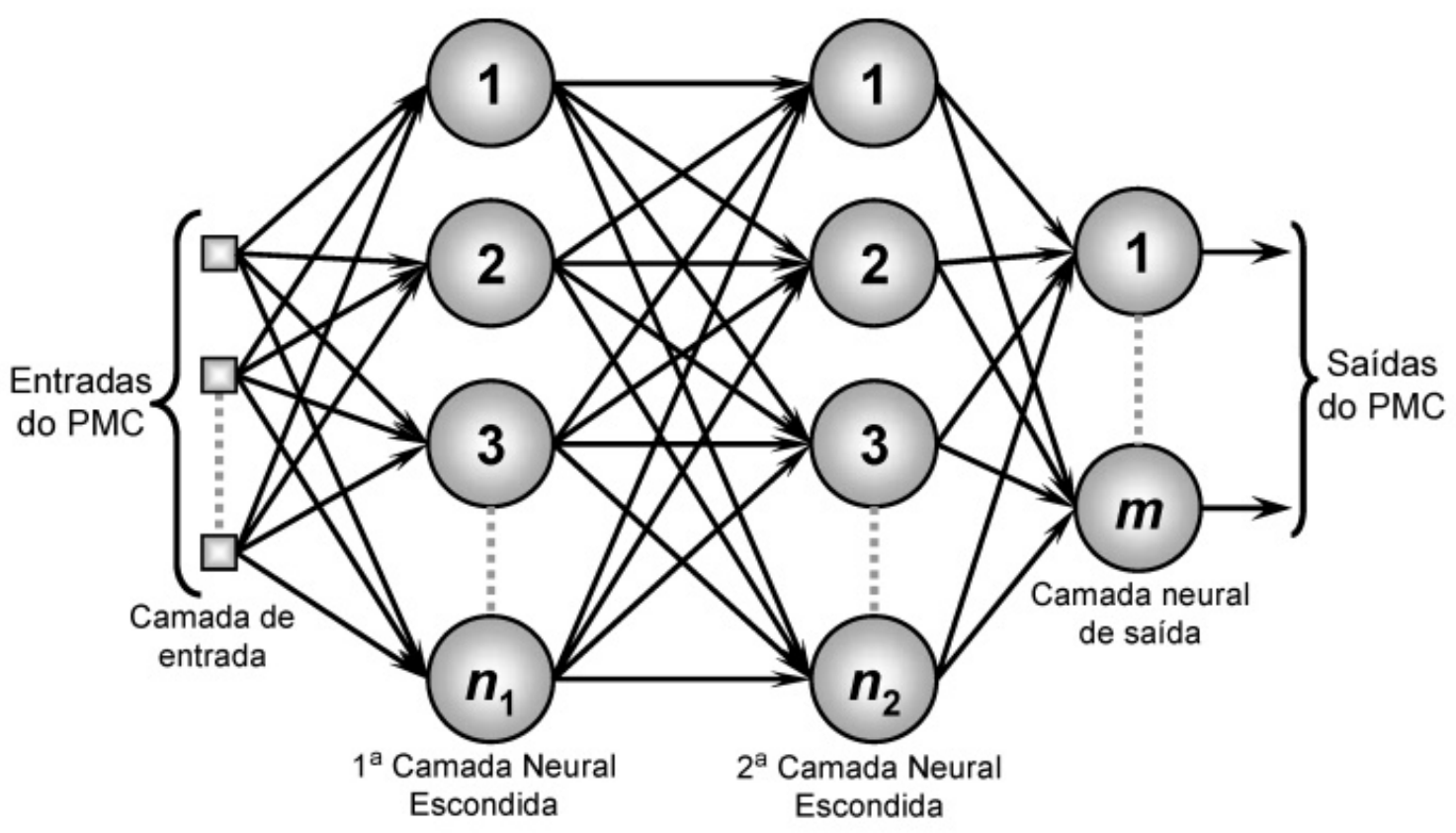

Figura 2 - Topologia de uma PMC

(SILVA; SPATTI; FLAUZINO, 2010)

$\mathrm{O}$ algoritmo de treinamento de uma PMC mais comumente utilizado é o backpropagation (RUMELHART; HINTON; WILLIAMS, 1985). Ele exige um conjunto de amostras, as quais contêm valores de entrada e as respectivas saídas desejadas. Para cada amostra o conjunto de sinais de entrada é passado à rede neural e o conjunto de valores de saída é produzido como normalmente seria no modo de operação. As saídas são comparadas aos valores esperados e o erro obtido é retropropagado sucessivamente, camada a camada, ajustando-se os pesos sinápticos no processo a fim de se minimizar o erro. Uma execução desse processo para todo o conjunto de amostras é chamada de época. $\mathrm{O}$ algoritmo repete sucessivamente a execução de épocas até que um determinado critério de parada seja atingindo, o qual pode ser a obtenção de um erro satisfatoriamente pequeno ou a conclusão da execução de certo número de épocas.

Os principais parâmetros que devem ser especificados no treinamento pelo backpropagation são o critério de parada, a taxa de aprendizado $(\eta)$ e o momentum $(\alpha)$. Os dois últimos parâmetros podem ser melhor entendidos pelas Equações (2.3) e (2.4), adaptadas de Haykin (1999). 


$$
\begin{gathered}
w_{j i}(n+1)=w_{j i}(n)+\Delta w_{j i}(n) \\
\Delta w_{j i}(n)=\alpha \Delta w_{j i}(n-1)-\eta \frac{\partial \varepsilon(n)}{\partial w_{j i}(n)}
\end{gathered}
$$

Onde $w_{j i}(n)$ é o peso sináptico na iteração $\mathrm{n}$ do neurônio j que está conectado ao neurônio i da camada anterior. $\frac{\partial \varepsilon(n)}{\partial w_{j i}(n)}$ é o gradiente do erro na iteração n, que indica a direção de maior variação do erro. Uma iteração do treinamento é caracterizada como processamento de uma única amostra, e não deve ser confundida com o conceito de época.

Analisando as equações, primeiramente sem o uso do momentum $(\alpha=0)$, constata-se que a taxa de aprendizado determina a magnitude com a qual o gradiente do erro é utilizado na atualização. Taxas de aprendizagem altas garantem que a cada atualização os pesos sinápticos sofram maiores alterações em direção ao erro mínimo, aumentando a velocidade do aprendizado, mas podem causar instabilidade e impossibilitar que um erro menor que um certo limite seja alcançado, uma vez que um grande incremento pode fazer com que o valor resultante vá além do valor que proporciona o erro mínimo. Por outro lado, taxas de aprendizagem baixas diminuem a possibilidade de instabilidade, mas exigem a execução de um número de épocas muito maior e torna o aprendizado mais suscetível a mínimos locais.

O momentum é um parâmetro responsável por tornar a aprendizagem mais eficiente. Quando ele é adotado, o algoritmo de aprendizagem passa a utilizar tanto a taxa de aprendizagem quanto o momentum para atualizar os pesos sinápticos. Para uma melhor compreensão de seu mecanismo, a Equação (2.4) pode ser reescrita em forma de série para $\alpha \neq$ 0, conforme a Equação (2.5).

$$
\Delta w_{j i}(n)=-\eta \sum_{t=0}^{n} \alpha^{n-t} \frac{\partial \varepsilon(t)}{\partial w_{j i}(t)}
$$

Nota-se que quando o momentum é utilizado, a atualização do peso sináptico não é influenciada somente pelo valor do gradiente na iteração corrente, mas também por todos os seus valores em iterações anteriores. Como $0 \leq|\alpha|<1$, os valores do gradiente têm seus pesos diminuídos exponencialmente conforme a distância entre suas correspondentes iterações e a iteração corrente aumenta. Como constatado por Jacobs (1988), pela Equação (2.5) pode-se 
perceber que quando o gradiente mantém o mesmo sinal em atualizações consecutivas, o resultado do somatório aumenta em módulo, e consequentemente o ajuste do peso torna-se mais significativo, enquanto que quando os sinais do gradiente se opõem em atualizações consecutivas, o ajuste do peso é menos significativo.

\subsection{Espaços de Cor}

Os seres humanos percebem cores por meio de células sensíveis a luz presentes na retina do olho. Essas células são denominadas cones e bastonetes, sendo os primeiros muito mais eficazes em proporcionar distinção de cores que os últimos, que são mais relacionados à visão noturna por serem mais sensíveis a baixos níveis de iluminação. Existem três tipos de cones, diferenciados pelo comprimento de onda que são capazes de estimulá-los. Os cones do tipo L são sensíveis a comprimentos de onda longos, referentes ao espectro de cores avermelhadas; os de tipo M são sensíveis a médios comprimentos de onda, referentes ao espectro de cores esverdeadas; e finalmente os de tipo S são sensíveis a comprimentos de onda curtos, referentes ao espectro de cores azuladas. Assim, as cores que percebemos estão relacionadas ao número de cones sensibilizados de cada tipo. Por exemplo, quando há muitos cones $\mathrm{S}$ sensibilizados, e poucos dos outros tipos, vemos uma cor de tonalidade azul.

Esta é a forma como o olho humano capta as cores. Para lidarmos matematicamente ou computacionalmente com elas, algum sistema semelhante deve ser utilizado, e esses sistemas são chamados de espaços de cor. Existem diversos deles na literatura, sendo que suas eficácias são dependentes da aplicação em que estão sendo empregadas. A seguir são apresentados os espaços de cor utilizados neste trabalho.

\subsubsection{RGB}

O modelo RGB trata as cores da mesma forma como o olho humano as capta. As cores são representadas pelos canais $\mathrm{R}, \mathrm{G}$ e $\mathrm{B}$, que definem respectivamente intensidade com a qual as cores primárias vermelho, verde e azul estão presentes. Desta forma, ele é um modelo aditivo, já que a cor é representada pela soma dos valores de seus canais. Este espaço de cor pode ser representado por um cubo (conforme o apresentado na Figura 3), já que cada um dos canais variam de 0 a 255 (ou 0 a 1 em algumas representações). O RGB é importante porque é um dos principais espaços de cor utilizados no processo de captura de imagens das câmeras digitais, e assim sendo a grande maioria das imagens são armazenadas utilizando-o. 


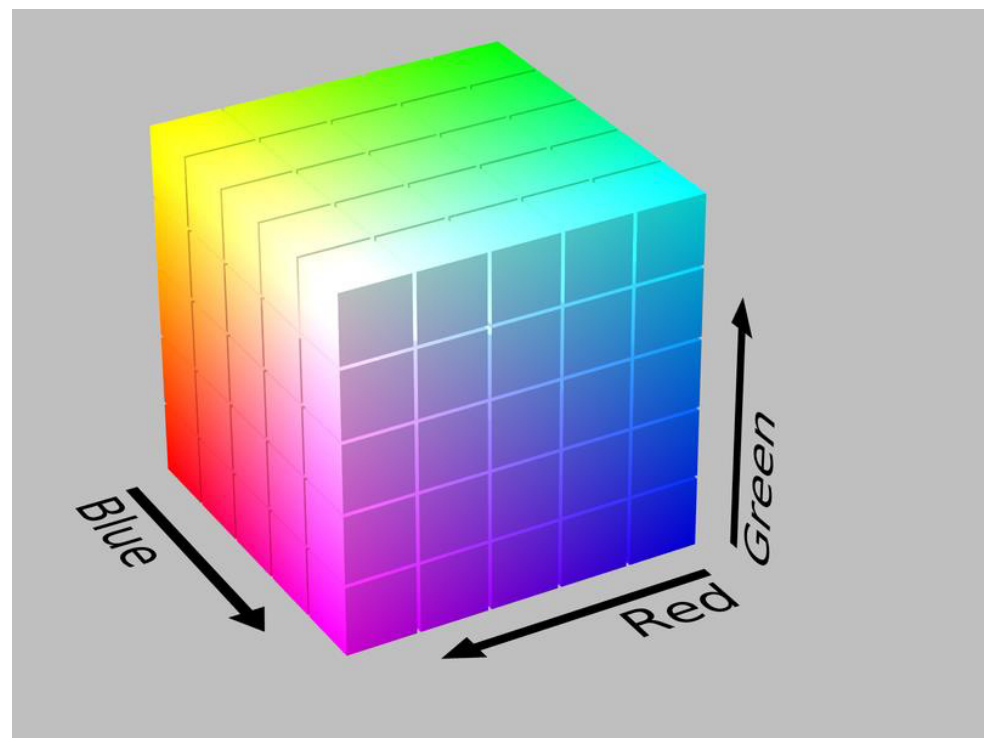

Figura 3 - Cubo RGB

(extraído de http://en.wikipedia.org/wiki/HSL_and_HSV )

Os espaços de cor definidos abaixo - YUV, YIQ, YDbDr, YPbPr, YCbCr e YCgCr - foram desenvolvidos para serem utilizados em sistemas eletrônicos de display, como televisores e telas de computadores. Eles separam a informação de cor em três canais - um de luminância e dois de crominância. Com o intuito se minimizar gastos nas transmissões, e dado que a visão humana é mais sensível a variações de luminância que de crominância, os canais destinadas a esta última contam com menor resolução.

\subsubsection{YUV}

Este modelo é o adotado pelo padrão PAL de transmissão de sinais analógicos televisivos, os quais são utilizados pela maioria dos países. Seu primeiro canal de crominância (U) determina a diferença entre o azul e a luminância (B -Y) enquanto o segundo canal (V) determina a diferença entre o vermelho e a luminância (R-Y). Seus canais podem ser calculados a partir dos valores RGB pelas Equações (2.6)-(2.8) (JACK, 2007). O espaço YUV está representado na Figura 4. 


$$
\begin{gathered}
Y=0,299 R+0,587 G+0,114 B \\
\mathrm{U}=-0,147 \mathrm{R}-0,289 \mathrm{G}+0,436 \mathrm{~B} \\
\mathrm{~V}=0,615 \mathrm{R}-0,515 \mathrm{G}-0,1 \mathrm{~B}
\end{gathered}
$$

Em que: $\mathrm{R}, \mathrm{G}, \mathrm{B}, \mathrm{Y} \in[0,1], U \in[-0,436,+0,436], V \in$ $[-0,615,+0,615]$

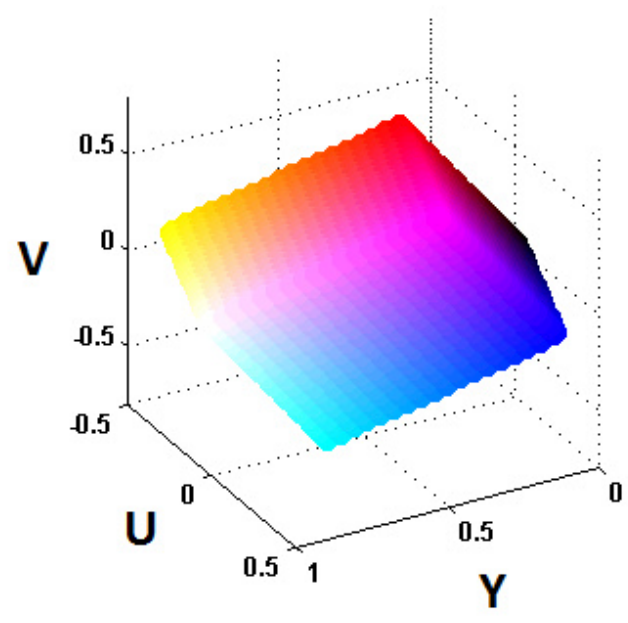

Figura 4 - Espaço de cor YUV

\subsubsection{YIQ}

O padrão NTSC de transmissão analógica de TV foi inicialmente proposto com o modelo YUV, mas foi substituído pelo YIQ, pois este exige uma menor largura de banda na transmissão (PRATT, 2007). Os canais de crominância I e Q são um remapeamento do sistema YUV, com os eixos $\mathrm{U}$ e $\mathrm{V}$ rotacionados de $33^{\circ}$ (FORD; ROBERTS, 1998). A transformação do espaço RGB para o YIQ é dada pelas Equações (2.9)-(2.11) (JACK, 2007). O espaço é mostrado na Figura 5.

$$
\begin{aligned}
& Y=0,299 R+0,587 G+0,114 B \\
& I=0,596 R-0,275 G-0,321 B \\
& Q=0,212 R-0,523 G+0,311 B
\end{aligned}
$$

Em que: $\mathrm{R}, \mathrm{G}, \mathrm{B}, \mathrm{Y} \in[0,1], I \in[-0,5957,+0,5957], Q \in[-0,5226,+0,5226]$ 


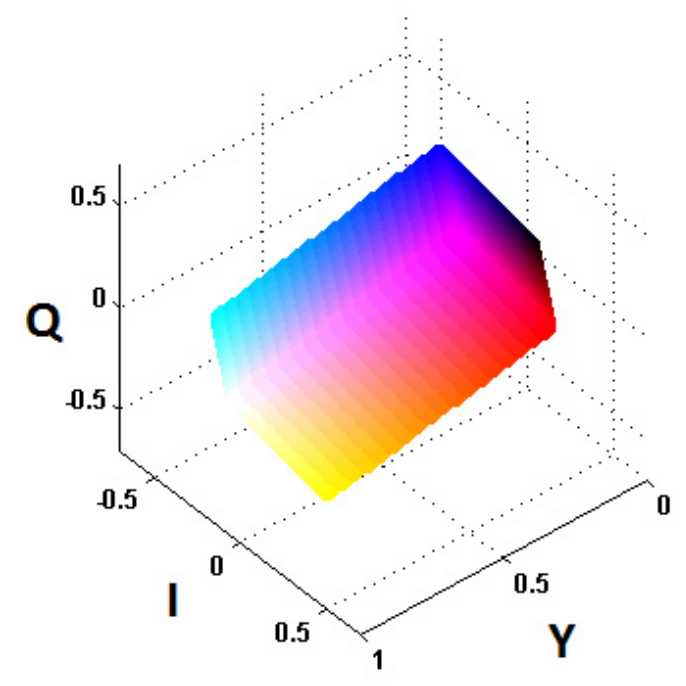

Figura 5 - Espaço de cor YIQ

\subsubsection{YDbDr}

É o modelo empregado pelo padrão SECAM de transmissão de TV, adotado basicamente pela França, Rússia e alguns países do leste europeu. Seus canais de crominância também definem a diferença entre o azul e a luminância e a diferença entre o vermelho e a luminância. Os canais podem ser calculados pelas Equações (2.12) - (2.14) (SHI; SUN, 2008) e o espaço de cor é ilustrado na Figura 6.

$$
\begin{aligned}
Y & =0,299 R+0,587 G+0,114 B \\
D b & =-0,450 R-0,883 G+1,333 B \\
D r & =-1,333 R+1,116 G-0,217 B
\end{aligned}
$$

Em que: $\mathrm{R}, \mathrm{G}, \mathrm{B}, \mathrm{Y} \in[0,1], D b, D \operatorname{Pr} \in[-1333,+1,333]$ 


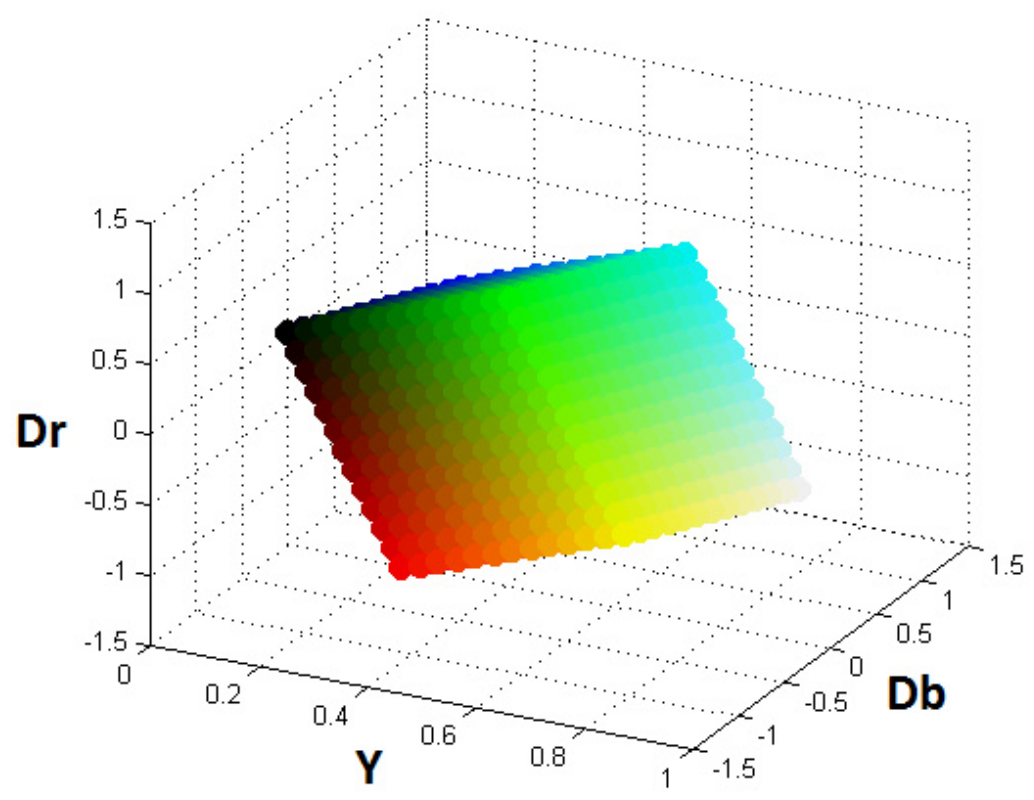

Figura 6 - Espaço de cor YDbDr

\subsection{5. $\mathrm{YPbPr}$}

Este é um espaço de cor utilizado na transmissão analógica de vídeo. Ele é derivado dos sinais de vídeo composto (NTSC, PAL), que utilizam os espaços de cor YUV e YIQ, e foi desenvolvido para requerer menor largura de banda sem prejudicar a qualidade da imagem. Por isso é capaz de transmitir vídeos em alta definição (JACK, 2007). Assim como no YUV, os canais de crominância $\mathrm{Pb}$ e $\mathrm{Pr}$ determinam a diferença entre o azul e a luminância e a diferença entre o vermelho e a luminância, respectivamente. $\mathrm{O}$ cálculo de $\mathrm{Y}, \mathrm{Pb}$ e $\mathrm{Pr}$ é dado pelas Equações (2.15)-(2.17) (JACK, 2007). O espaço de cor é representado na Figura 7.

$$
\begin{gathered}
Y=0,299 R+0,587 G+0,114 B \\
P b=-0,169 R-0,331 G+0,5 B \\
P r=0,5 R-0,419 G-0,081 B
\end{gathered}
$$

Em que: $\mathrm{R}, \mathrm{G}, \mathrm{B}, \mathrm{Y} \in[0,1], \quad \operatorname{Pb}, \operatorname{Pr} \in[-0,5,+0,5]$ 


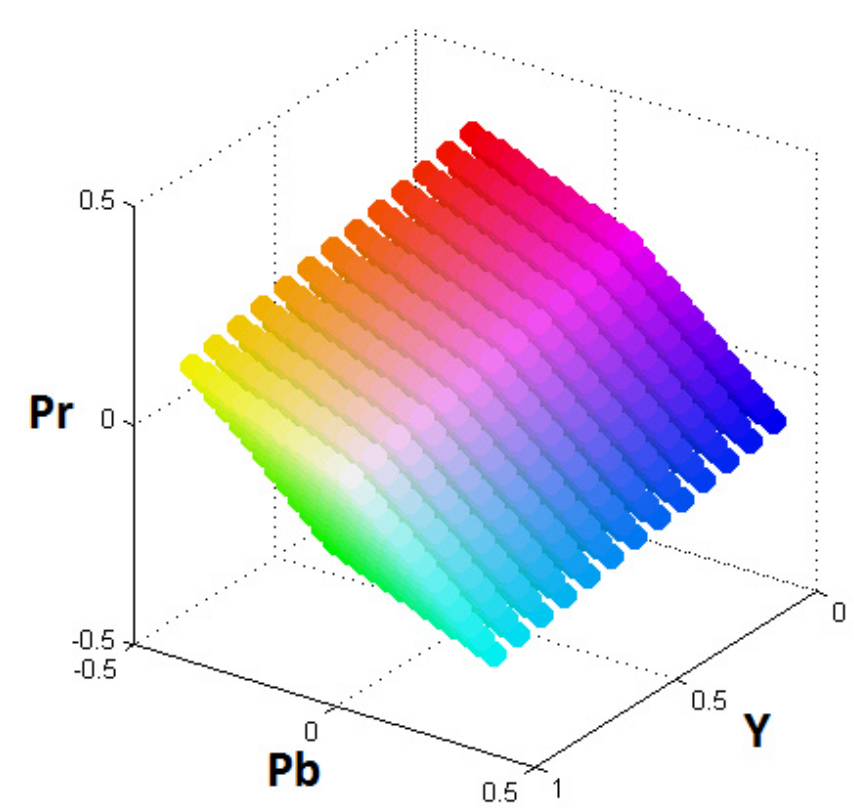

Figura 7 - Espaço de cor YPbPr

\subsection{6. $\mathrm{YCbCr}$}

YCbCr é a versão digital do modelo YPbPr, com resolução de 8 bits para cada canal. Por se tratar de um espaço de cor para aplicações digitais, ele teve que ser redimensionado e deslocado em relação ao YPbPr para garantir uma escala com valores inteiros e não-negativos. Assim sendo, a obtenção dos canais $\mathrm{YCbCr}$ a partir do espaço $\mathrm{YPbPr}$ é dada pelo conjunto de Equações (2.18)-(2.20) (JACK, 2007). O espaço de cor é ilustrado na Figura 8.

$$
\begin{gathered}
Y=A R R E D O N D A(219 Y+16) \\
C b=A R R E D O N D A(224 P b+128) \\
C r=A R R E D O N D A(224 P r+128)
\end{gathered}
$$

Em que: $Y \in[16,235], \quad C b, C r \in[16,240]$ 


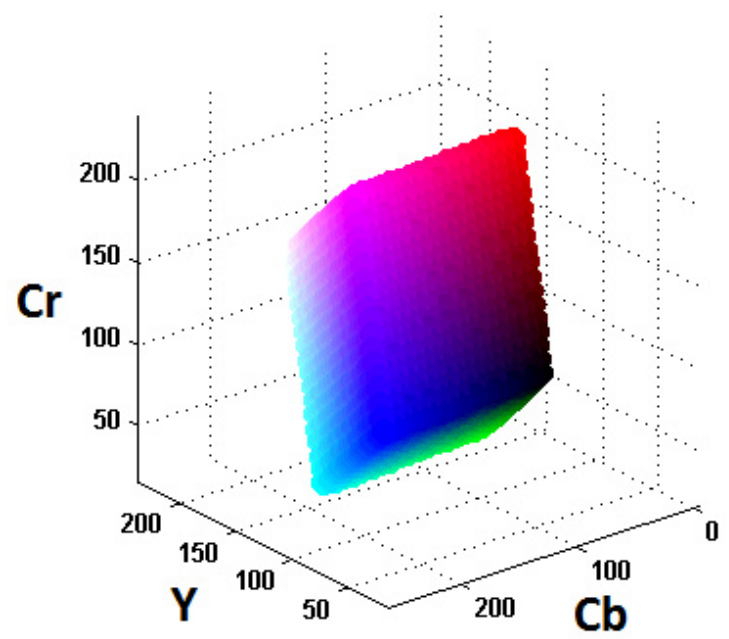

Figura 8 - Espaço de cor $\mathrm{YCbCr}$

\subsection{7. $\mathrm{YCgCr}$}

Este espaço é uma variação do YCbCr e foi apresentado por De Dios e García (2003) na segmentação de faces. Ao invés de utilizar um canal de crominância para a diferença entre o azul e a luminância $(\mathrm{Cb})$, o $\mathrm{YCgCr}$ utiliza um canal para a diferença entre o verde e a luminância (Cg). Os canais são calculados pelas Equações (2.21)-(2.23). O espaço $\mathrm{YCgCr}$ é representado na Figura 9.

$$
\begin{gathered}
Y=16+65,481 R+128,553 G+24,966 B \\
C g=128-81,085 R+112 G-30,915 B \\
C r=128+112 R-93,768 G-18,214 B
\end{gathered}
$$

Em que: $\mathrm{R}, \mathrm{G}, \mathrm{B} \in[0,1], \quad Y \in[16,235], \quad \operatorname{Cg}, \operatorname{Cr} \in[16,240]$ 


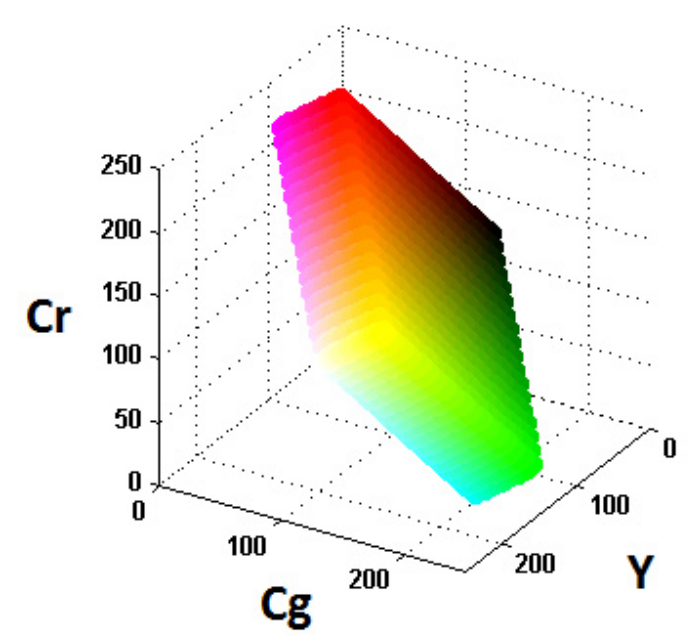

Figura 9 - Espaço de cor $\mathrm{YCgCr}$

\subsubsection{CIE XYZ}

A CIE (Commission internationale de l'éclairage), órgão internacional de padronização de cor e luz, desenvolveu em 1931 o sistema de cor XYZ baseando-se em um experimento para analisar como os seres humanos percebem a cor. Neste experimento um observador deveria formar uma dada cor por meio da projeção de três fontes de luz de cores diferentes - vermelho, verde e azul - em uma tela. Cores diferentes eram formadas variando-se a intensidade das fontes. Porém algumas cores não podiam ser formadas desta maneira, a menos que se utilizassem intensidades negativas das fontes. O espaço de cor XYZ foi desenvolvido como um esforço de se criar um sistema que utilizasse apenas combinações de valores positivos de cores primárias para a representação de qualquer cor. Essas cores primárias são X, Y e Z. Os canais do espaço de cor são obtidos a partir das Equações (2.24)-(2.26) (PRATT, 2007) e o espaço é representado na Figura 10.

$$
\begin{gathered}
X=0,49018626 R+0,30987954 G+0,19993420 B \\
Y=0,17701522 R+0,81232418 G+0,01066060 B \\
Z==0,01007720 G+0,98992280 B
\end{gathered}
$$

Em que: $R, G, B, X, Y, Z \in[0,1]$ 


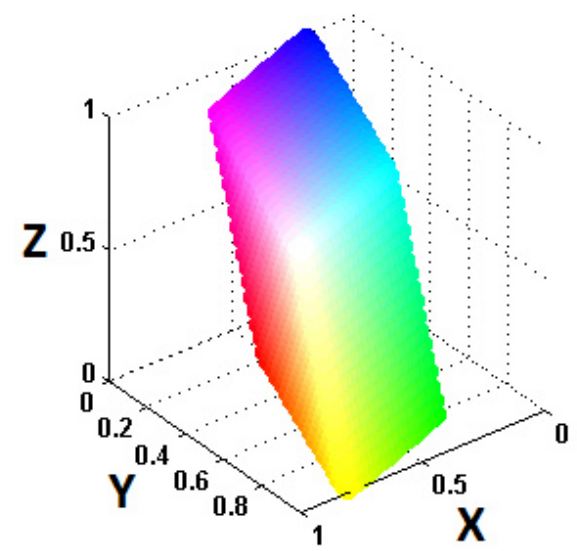

Figura 10 - Espaço de cor XYZ

\subsubsection{CIELAB}

O CIELAB, também conhecido como CIE L a* b*, é um espaço de cor definido pela CIE como um esforço de se criar um modelo de cor perceptualmente uniforme, já que o CIE XYZ não o é (BILLMEYER; SALTZMAN, 1981). Ser perceptualmente uniforme garante que uma mudança nos valores das componentes gere uma mudança proporcional na percepção humana das cores resultantes. Este modelo de cor é amplamente utilizado no tratamento de cores de frutos e hortaliças (JORGE et al., 2011). O CIELAB é especificado por três canais - L, a* e b*. L representa o brilho da cor, $\mathrm{a}^{*}$ representa uma escala de matiz que varia de verde (valores negativos) a magenta (valores positivos), e b* representa uma escala de matiz que varia de azul (valores negativos) a amarelo (valores positivos).

Os valores dos canais deste modelo são calculados a partir de valores do espaço de cor CIE XYZ, como apresentado pelas Equações (2.27)-(2.30). O espaço de cor é ilustrado na Figura 11.

$$
\begin{gathered}
L=116 f\left(Y / Y_{n}\right)-16 \\
a^{*}=500\left[f\left(X / X_{n}\right)-f\left(Y / Y_{n}\right)\right] \\
b^{*}=200\left[f(Y / Y)-f\left(Z / Z_{n}\right)\right]
\end{gathered}
$$

Sendo: 


$$
f(k)=\left\{\begin{array}{cl}
k^{\frac{1}{3}} & \text {, se } k>\left(\frac{6}{29}\right)^{3} \\
\frac{1}{3}\left(\frac{29}{6}\right)^{2} k+\frac{4}{29} & , \text { caso contrário }
\end{array}\right.
$$

$X_{n}, Y_{n}$ e $Z_{n}$ são os valores CIE XYZ para o iluminante referência, que neste trabalho foi o D65, caracterizado por $X_{n}=95,047, Y_{n}=100,000$ e $Z_{n}=108,883$.

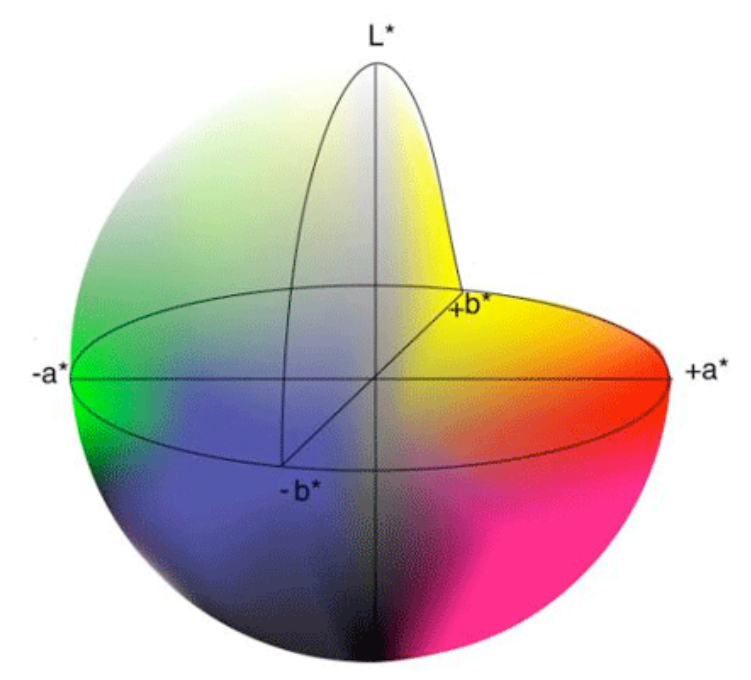

Figura 11 - Espaço de cor CIELAB (extraído de www.flexoglobal.com)

\subsubsection{HSV}

O modelo HSV decompõe uma cor em três canais: matiz (hue - H), saturação (saturation S) e valor (value - V). O matiz traz a informação da cor em si, definindo se ela é vermelha, verde, amarela, etc.. Seus valores variam de $0^{\circ}$ a $360^{\circ}$. A saturação indica a pureza da cor, de modo que quanto menor seu valor, menos se percebe a presença do matiz na cor, de tal forma que as cores que apresentam saturação 0 constituem o conjunto de cores da escala de cinza. $\mathrm{O}$ valor determina o brilho, sendo que cores claras possuem altos valores de $\mathrm{V}$, ao passo que cores escuras possuem baixos valores. Tanto a saturação quanto o brilho variam de 0 a $100 \%$. Os valores de H, S e V podem ser obtidos pelas Equações (2.31)-(2.33) (CHAVES-GONZALEZ et al., 2010). O espaço HSV é apresentado na Figura 12. 


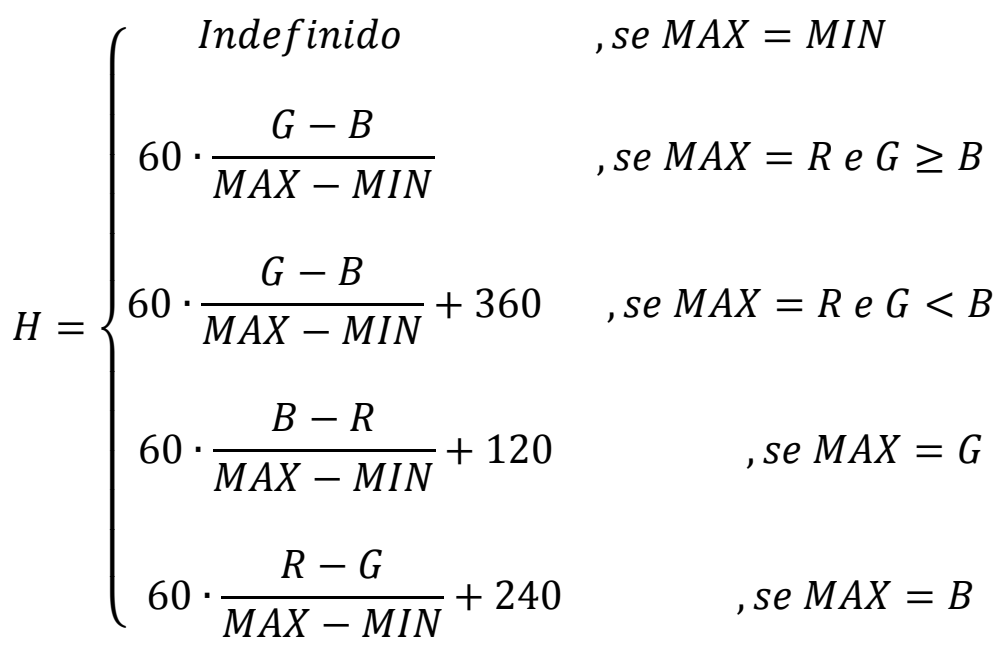

$$
\begin{aligned}
& S= \begin{cases}0, & \text {, se } M A X=0 \\
1-\frac{M I N}{M A X} & , \text { se } M A X \neq 0\end{cases} \\
& V=M A X
\end{aligned}
$$

Em que: $\mathrm{R}, \mathrm{G}, \mathrm{B}, \mathrm{S}, \mathrm{V} \in[0,1], \mathrm{H} \in[0,360], \mathrm{MAX}=\mathrm{MÁXIMO}(\mathrm{R}, \mathrm{G}, \mathrm{B}) \mathrm{e}$

$$
\text { MIN = MÍNIMO }(R, G, B)
$$



Figura 12 - Espaço de cor HSV

(extraído de http://en.wikipedia.org/wiki/HSL_and_HSV) 


\subsubsection{1. $\quad \mathbf{I}_{1} \mathbf{I}_{2} \mathbf{I}_{3}$}

O espaço $I_{1} I_{2} I_{3}$ foi proposto por Ohta, Kanade e Sakai (1980) com o intuito de se determinar um espaço de cor eficiente na segmentação de imagens. Para cada uma das imagens selecionadas foi calculada a transformada de Karhunen-Loève (RAO; YIP, 2001) dos canais RGB dos pixels da região a ser segmentada. Desta forma, para cada imagem foi obtido um espaço de cor cujos canais são descorrelacionados, e apresentam variâncias máximas. Ao analisarem os resultados obtidos em cada uma das imagens, os autores perceberam um padrão nas transformações que levavam do espaço RGB aos novos espaços de cor. Esse padrão se aproximava ao que então propuseram como o $\mathrm{I}_{1} \mathrm{I}_{2} \mathrm{I}_{3}$, e que é apresentado pelas Equações (2.34). (2.36). O espaço de cor é ilustrado na Figura 13. No trabalho citado o $\mathrm{I}_{1} \mathrm{I}_{2} \mathrm{I}_{3}$ foi comparado com vários outros espaços de cor na segmentação por thresholding recursivo e obteve bons resultados.

$$
\begin{gathered}
I_{1}=\frac{1}{3}(R+G+B) \\
I_{2}=\frac{1}{2}(R-B) \\
I_{3}=\frac{1}{4}(-R+2 G-B)
\end{gathered}
$$

Em que: $\mathrm{R}, \mathrm{G}, \mathrm{B}, I_{1} \in[0,1], I_{2}, I_{3} \in[-0,5,0,5]$

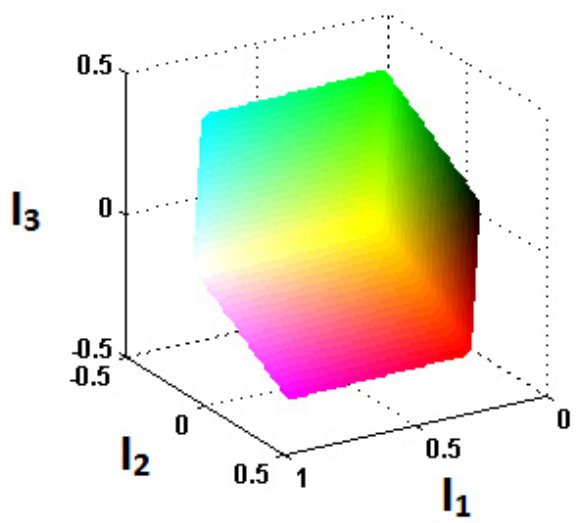

Figura 13 - Espaço de cor $\mathbf{I}_{1} \mathbf{I}_{2} \mathbf{I}_{3}$ 


\subsubsection{RGB normalizado (rgb)}

Visando reduzir a sensibilidade a variações de iluminação, o espaço RGB pode ser normalizado conforme as Equações (2.37)-(2.39) (BROWN; CRAW; LEWTHWAITE, 2001). Deve-se notar que a normalização, exatamente por remover informações de luminosidade, reduz significativamente o volume do espaço de cor, como pode ser observado na representação do espaço de cor na Figura 14.

$$
\begin{aligned}
& r=R /(R+G+B) \\
& g=G /(R+G+B) \\
& b=B /(R+G+B)
\end{aligned}
$$

Em que: $R, G, B, r, g, b \in[0,1]$
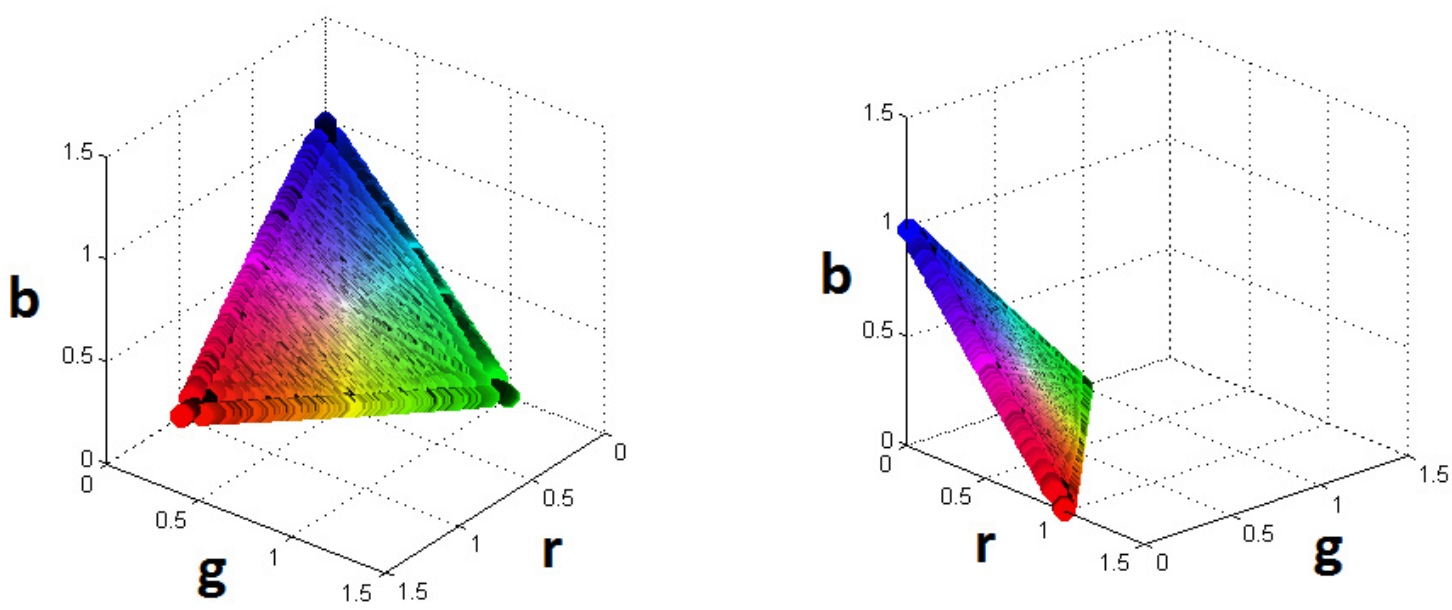

Figura 14 - Espaço de cor rgb por duas perspectivas

\subsection{Atributos Morfológicos}

Um dos desafios da visão computacional é conseguir definir formas de objetos por meio de representações matemáticas de maneira concisa, mas que ainda assim consigam expor informações intrínsecas da forma. Essas representações podem ser denominadas de atributos morfológicos. Inúmeras técnicas já foram apresentadas e suas eficiências dependem da aplicação e de que características da forma se deseja exaltar. Outro critério muito relevante 
envolvendo os atributos é o custo computacional exigido nos cálculos, que sendo muito alto, pode comprometer algumas aplicações. A seguir são apresentados os atributos utilizados neste trabalho.

\subsubsection{Assinaturas}

Assinaturas são funções 1D calculadas a partir dos pontos do contorno de uma forma. Geralmente elas são normalizadas para se obter invariância a escala. Existem várias abordagens para calculá-las, como, por exemplo, a tangente do ângulo, a área, comprimento da corda e a distância do centroide (ZHANG; LU, 2004). Esta última foi a utilizada neste trabalho.

As coordenadas $(\bar{x}, \bar{y})$ do centroide de uma figura representada por uma região contendo $\mathrm{N}_{\mathrm{p}}$ pixels de coordenadas $\left(\mathrm{x}_{\mathrm{i}}, \mathrm{y}_{\mathrm{i}}\right)\left(\mathrm{com} \mathrm{i}=1, \ldots, \mathrm{N}_{\mathrm{p}}\right)$ são dadas por (2.40) e (2.41) (JAIN, 1989).

$$
\begin{aligned}
& \bar{x}=\frac{1}{N_{p}} \sum_{i=1}^{N_{p}} x_{i} \\
& \bar{y}=\frac{1}{N_{p}} \sum_{i=1}^{N_{p}} y_{i}
\end{aligned}
$$

Portanto, para uma forma contendo $\mathrm{N}_{\mathrm{pb}}$ pixels de borda, cujas coordenadas são $\left(\mathrm{x}_{\mathrm{k}}, \mathrm{y}_{\mathrm{k}}\right)$ (com $\mathrm{k}=1, \ldots, \mathrm{N}_{\mathrm{pb}}$ ), tem-se o k-ésimo elemento da sua assinatura dado pela Equação (2.42).

$$
z(k)=\sqrt{\left(x_{k}-\bar{x}\right)^{2}+\left(y_{k}-\bar{y}\right)^{2}}
$$

\subsubsection{Descritores de Fourier}

Utilizando-se a transformada de Fourier é possível representar qualquer sinal como uma soma de senoides multiplicadas por diferentes coeficientes, tendo cada senoide uma frequência distinta. Essa transformada é amplamente utilizada na área de análise de sinais por permitir uma visualização do sinal no domínio da frequência, fornecendo possibilidades não alcançadas no domínio do tempo (GONZALEZ; WOODS, 2008b). 
A transformada de Fourier também pode ser utilizada na representação de forma, bastando tratar um conjunto de assinaturas como sendo um sinal e aplicar sobre ele a transformada. Os coeficientes das senoides obtidas passam então a ser chamados de Descritores de Fourier. Características típicas dos Descritores de Fourier são que geralmente a forma geral da figura é relativamente bem definida a partir de alguns dos termos de menor ordem da expansão, e as magnitudes dos termos são invariantes a rotação.

Os descritores de Fourier $\mathrm{F}(\mathrm{u})$ de um conjunto de $\mathrm{N}_{\mathrm{a}}$ assinaturas $\mathrm{z}(\mathrm{k})$ são obtidos pela equação (2.43) (GONZALEZ; WOODS, 2008b):

$$
F(u)=\frac{1}{N_{a}} \sum_{k=0}^{N_{a}-1} z(k) e^{-j 2 \pi u k / N_{a}}
$$

Para $\mathrm{u}=0,1, \ldots, \mathrm{N}_{\mathrm{a}}-1$.

\subsubsection{Descritores Genéricos de Fourier (DGFs)}

Uma das desvantagens da transformada de Fourier 2D é que ela não é invariante a rotação, pois girar uma imagem em $\theta$ acarreta a mesma rotação $\theta$ no espectro da frequência. Os Descritores Genéricos de Fourier (DGFs) (ZHANG; LU, 2002) foram propostos para contornar esse problema, utilizando-se de coordenadas polares ao invés de retangulares.

Desta forma, para se calcular os DGFs, primeiramente é aplicada uma Transformada Polar de Fourier Modificada (TPFM) sobre a forma. Essa transformada trata uma forma descrita em coordenadas polares como se fosse uma forma em coordenadas retangulares, como ilustrado na Figura 15. Então aplica-se a transformada de Fourier 2D discreta sobre ela.



(b)

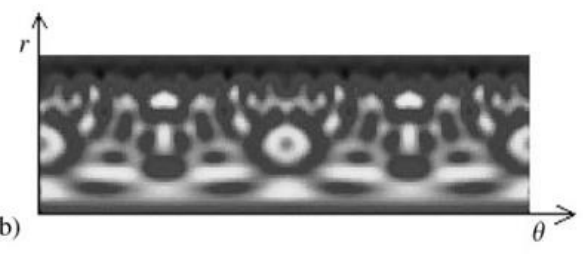

Figura 15 - Mapeamento de coordenadas utilizado pelo DGF.

Retirada de (ZHANG E LU, 2002) (a) Uma imagem em coordenadas polares (b) a mesma imagem em coordenadas polares tratada como coordenadas retangulares. 
Dessa forma, a TPFM é dada pela Equação (2.44):

$$
\operatorname{TPFM}(\rho, \varphi)=\sum_{r} \sum_{i} f\left(r, \theta_{i}\right) e^{-j 2 \pi\left(\frac{r}{R} \rho+\frac{2 \pi i}{T} \varphi\right)}
$$

Onde $\rho$ e $\varphi$ são, respectivamente, as frequências radial e angular. Sendo $0 \leq r<R, \theta_{i}=$ $\frac{i 2 \pi}{T}(0 \leq i<T)$ e $f\left(r, \theta_{i}\right)$ é a representação da imagem em coordenadas polares. $0 \leq \rho<R$ e $0 \leq \varphi<T$. R e T são, respectivamente, as resoluções radiais e angulares.

Para se obter invariância a translação a imagem deve ser transladada de modo a fazer o centroide $(\bar{x}, \bar{y})$ da forma ser a origem da imagem. Tem-se então:

$$
\begin{gathered}
r=\sqrt{(x-\bar{x})^{2}+(y-\bar{y})^{2}} \\
\theta=\operatorname{arctg}\left(\frac{y-\bar{y}}{x-\bar{x}}\right)
\end{gathered}
$$

Para se obter invariância quanto a rotação e escala, uma normalização se faz necessária. Assim, os DGFs são definidos como segue:

$$
\operatorname{DGF}(\rho, \varphi)= \begin{cases}\frac{\operatorname{TPFM}(\rho, \varphi)}{\mathrm{A} r e a} & , \text { se } \rho=0 \text { e } \varphi=0 \\ \frac{\operatorname{TPFM}(\rho, \varphi)}{\operatorname{TPFM}(0,0)} & \text {, caso contrário }\end{cases}
$$

Para $\rho=0, \ldots$, m e $\varphi=0, \ldots, \mathrm{n}$. Sendo Área a área do círculo que circunscreve a forma e m e n, respectivamente, os números máximos de frequências radiais e angulares escolhidos para compor o conjunto de descritores.

\subsubsection{Modelo Autorregressivo}

O Modelo Autorregressivo (DUBOIS; GLANZ, 1986) é uma técnica de representação de forma invariante a translação, rotação e escala. Ele representa as distâncias dos pontos da borda ao centroide da forma (que são chamadas de raio) como uma série temporal, de modo que cada 
raio é definido como uma combinação linear dos raios anteriores. Primeiramente é definido o número de raios $\left(\mathrm{N}_{\mathrm{R}}\right)$ a serem utilizados. Os $\mathrm{N}_{\mathrm{R}}$ raios são então coletados de forma que duas amostras vizinhas sejam separadas por um mesmo ângulo $\Delta \varphi=2 \pi / \mathrm{N}_{R}$.

O modelo determina que o conjunto de amostras de raios $\left(r_{t}\right)$ pode ser dado pela seguinte combinação linear:

$$
r_{t}=\alpha+\sum_{j=1}^{m_{A R}} \gamma_{j} r_{t-j}+\sqrt{\beta} w_{t} \quad t=1, \ldots, N_{R}
$$

Sendo,

$\mathrm{m}_{\mathrm{AR}}$ : Ordem do modelo

$r_{t}:$ Amostra do raio corrente

$r_{t-j}$ : Raio situado j posições anteriores ao raio corrente

$\gamma_{1}, \ldots, \gamma_{m_{A R}}:$ Coeficientes da autorregressão a serem estimados

$\sqrt{\beta}$ : Constante a ser estimada

$\alpha$ : Constante a ser estimada

$\left\{w_{t}\right\}$ : Uma sequencia aleatória de amostras independentes com média 0 e variância 1

Considera-se $r_{t}$ uma função periódica, de modo que $r_{t}=r_{t+N_{R}}$.

Os parâmetros do modelo são determinados segundo as Equações (2.49) e (2.50).

$$
\begin{aligned}
& \beta=\frac{1}{N_{R}} \sum_{t=1}^{N_{R}}\left(r_{t}-\alpha-\sum_{j=1}^{m_{A R}} \gamma_{j} r_{t-j}\right)^{2} \\
& {\left[\begin{array}{c}
\gamma_{1} \\
\vdots \\
\gamma_{m_{A R}} \\
\alpha
\end{array}\right]=\left[\begin{array}{cccc}
\sum_{t=1}^{N_{R}} r_{t-1}^{2} & \cdots & \sum_{t=1}^{N_{R}} r_{t-1} r_{t-m_{A R}} & \sum_{t=1}^{N_{R}} r_{t-1} \\
\vdots & \ddots & \vdots & \vdots \\
\sum_{t=1}^{N_{R}} r_{t-m_{A R}} r_{t-1} & & & \sum_{t=1}^{N_{R}} r_{t-m_{A R}} \\
\sum_{t=1}^{N_{R}} r_{t-1} & \cdots & \sum_{t=1}^{N_{R}} r_{t-m_{A R}} &
\end{array}\right]^{-1}\left[\begin{array}{c}
\sum_{t=1}^{N_{R}} r_{t-1} r_{t} \\
\vdots \\
\sum_{t=1}^{N_{R}} r_{t-m_{A R}} r_{t} \\
\sum_{t=1}^{N} r_{t}
\end{array}\right]}
\end{aligned}
$$


A razão $\alpha / \sqrt{\beta}$ pode ser interpretada como a relação sinal-ruído da forma, e os parâmetros $\left\{\gamma_{1}, \ldots, \gamma_{m}\right\}$ estabelecem a função que determina o seu contorno. Assim sendo, o conjunto $\left\{\frac{\alpha}{\sqrt{\beta}}, \gamma_{1}, \ldots, \gamma_{m}\right\}$ pode ser utilizado como um vetor de características para descrever o contorno de uma forma.

\subsubsection{Momentos de Zernike}

Os Momentos de Zernike (TEAGUE, 1979) são um conjunto de momentos complexos formados pela projeção de uma função $\mathrm{f}(\mathrm{x}, \mathrm{y})$, mapeada no círculo unitário $x^{2}+y^{2} \leq 1$, em uma família de polinômios complexos - os polinômios de Zernike.

As principais características dos Momentos de Zernike são que eles são invariantes a rotação, e por se tratarem de momentos ortogonais, contam com um mínimo de redundância de informação. O cálculo dos Momentos de Zernike para uma imagem digital f(x, y) quadrada de lado L, é definido pela Equação (2.51):

$$
Z_{n_{Z}, m_{Z}}=\frac{n_{Z}+1}{\pi(L-1)} \sum_{x=1}^{L} \sum_{y=1}^{L} f(x, y) V_{n_{Z}, m_{Z}}(\rho, \theta)
$$

Com $\rho=\frac{\sqrt{x^{2}+y^{2}}}{L}$ e $\theta=\tan ^{-1}(y / x)$. $\mathrm{n}_{\mathrm{Z}}$ é um número natural chamado de ordem do momento e $m_{Z}$ é denominado repetição, sendo que $n_{Z}-\left|m_{Z}\right|$ é par e $\left|m_{Z}\right|<n_{Z}$.

$V_{n_{Z}, m_{Z}}$ é a família de polinômios de Zernike, definida por (2.52).

$$
V_{n_{Z}, m_{Z}}(\rho, \theta)=R_{n_{Z}, m_{Z}}(\rho) e^{-j m_{Z} \theta}
$$

Com

$$
R_{n_{Z}, m_{Z}}(\rho)=\sum_{s=0}^{n_{Z}-\frac{\left|m_{Z}\right|}{2}}(-1)^{s} \frac{\rho^{n_{Z}-2 s}\left(n_{Z}-s\right) !}{s !\left[\frac{n_{Z}+\left|m_{Z}\right|}{2}-s\right] !\left[\frac{n_{Z}-\left|m_{Z}\right|}{2}-s\right] !}
$$


Para seu uso como atributos morfológicos, são utilizadas as magnitudes dos momentos de até certa ordem pré-definida. $\mathrm{O}$ número de momentos da ordem 0 até a ordem $\mathrm{n}_{\mathrm{Z}}$ é dada por $\left(\frac{\mathrm{nZ}}{2}+1\right)\left(\mathrm{n}_{\mathrm{Z}}+1\right)$.

\subsubsection{Atributos Unitários}

Os atributos morfológicos desta seção foram chamados de unitários por não serem constituídos de um conjunto de valores como os atributos morfológicos apresentados anteriormente. Cada um dos atributos unitários é definido por apenas um valor.

Os atributos unitários utilizados neste estudo são: área, perímetro, eixo maior, eixo menor, excentricidade, spread, slenderness e mais outros cinco atributos derivados dos anteriores $\left(\mathrm{A}_{1}\right.$, $\mathrm{A}_{2}, \mathrm{~A}_{3}, \mathrm{~A}_{4} \mathrm{e} \mathrm{A}_{5}$ ). Os dois primeiros são diretamente obtidos pelo contorno da forma, enquanto o cálculo dos outros são apresentados a seguir.

Para o cálculo dos atributos citados deve-se determinar primeiramente certos momentos centrais. Temos que os momentos centrais de ordem $(\mathrm{p}, \mathrm{q})$ de uma forma representada pelos pixels de coordenadas $\left(\mathrm{x}_{\mathrm{i}}, \mathrm{y}_{\mathrm{i}}\right)\left(\mathrm{com} \mathrm{i}=1, \ldots, \mathrm{N}_{\mathrm{p}}\right)$ são calculados pela Equação (2.54).

$$
\mu_{p, q}=\sum_{i=1}^{N_{p}}\left(x_{i}-\bar{x}\right)^{p}\left(y_{i}-\bar{y}\right)^{q}
$$

Sendo $\bar{x}$ e $\bar{y}$ as coordenadas do centroide.

Conforme descrito por Jain (1989), para o cálculo dos eixos maior e menor de uma forma deve-se calcular sua orientação, ou seja, o ângulo $\theta$ (Figura 16) com o qual ele possui o menor momento de inércia. $\theta$ é dado pela Equação (2.55).

$$
\theta=\arctan \left(\frac{\mu_{1,1}}{\mu_{2,0}-\mu_{0,2}}\right)
$$

Pode-se adotar um sistema alternativo de coordenadas, eixos $\alpha$ e $\beta$, que sejam respectivamente paralelo e perpendicular à orientação do objeto, como ilustrado na Figura 16. 


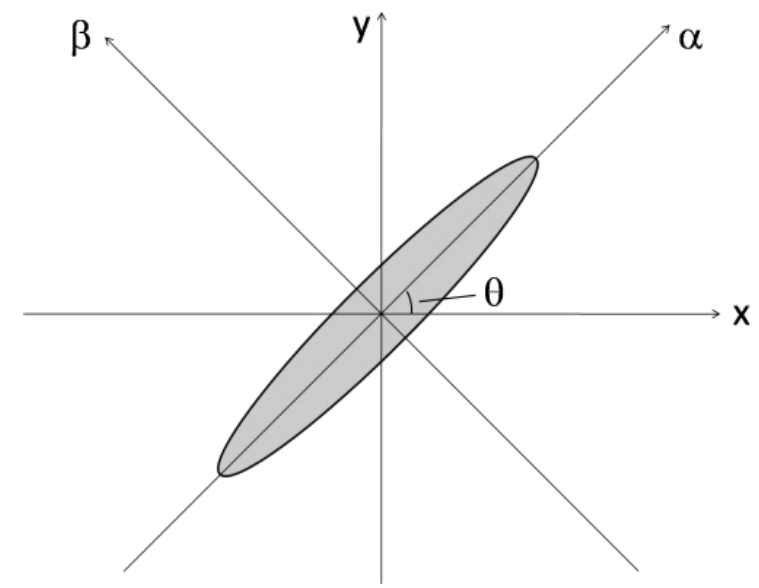

Figura 16 - Orientação do objeto e sistema alternativo de coordenadas

Imagem adaptada de (JAIN, 1989)

Assim, as coordenadas $\alpha$ e $\beta$ podem ser calculadas a partir das coordenadas x e y aplicandose uma operação de rotação de $\theta$ :

$$
\left[\begin{array}{l}
\alpha \\
\beta
\end{array}\right]=\left[\begin{array}{cc}
\cos \theta & \operatorname{sen} \theta \\
-\operatorname{sen} \theta & \cos \theta
\end{array}\right]\left[\begin{array}{l}
x \\
y
\end{array}\right]
$$

Transformando todos os pixels da forma para o sistema de coordenadas $(\alpha, \beta)$, e determinando o menor e maior valores de $\alpha$ ( $\alpha_{\min }$ e $\alpha_{\max }$ respectivamente) e o menor e maior valores de $\beta$ ( $\beta_{\min }$ e $\beta_{\max }$ respectivamente) pode-se definir os eixos maior e menor:

$$
\begin{aligned}
& \text { Eixo menor }=\operatorname{MIN}\left(\alpha_{\max }-\alpha_{\min }, \beta_{\max }-\beta_{\text {min }}\right) \\
& \text { Eixo maior }=\operatorname{MAX}\left(\alpha_{\max }-\alpha_{\min }, \beta_{\max }-\beta_{\text {min }}\right)
\end{aligned}
$$

A excentricidade de uma forma é calculada pela Equação (2.59) (JAIN, 1989). Os outros atributos derivados são apresentados por Symons e Fulcher (1988) e Shouche et al. (2001) na classificação de grãos de trigo e são dados pelas Equações (2.60)-(2.66).

$$
\begin{gathered}
\text { excentricidade }=\frac{\left(\mu_{2,0}-\mu_{0,2}\right)^{2}+4 \mu_{1,1}}{\text { Área }} \\
\text { spread }=\mu_{2,0}+\mu_{0,2}
\end{gathered}
$$




$$
\begin{gathered}
\text { slenderness }=\sqrt{\left(\mu_{2,0}-\mu_{0,2}\right)^{2}+4 \mu_{1,1}^{2}} \\
A_{1}=\frac{4 \pi \text { Área }}{\text { Perímetro }^{2}} \\
A_{2}=\frac{\text { Eixo maior }}{\text { Área }} \\
A_{3}=\frac{\text { Área }}{(\text { Eixo maior })^{3}} \\
A_{4}=\frac{\text { Área }}{\pi(\text { Eixo maior } / 2)^{2}} \\
A_{5}=\frac{\text { Área }}{\pi(\text { Eixo maior } / 2)(\text { Eixo menor } / 2)}
\end{gathered}
$$

\subsection{Descritores de Haralick}

Em 1973 Robert Haralick e seus colaboradores publicaram um artigo (HARALICK; SHANMUGA.K; DINSTEIN, 1973) descrevendo métodos matemáticos para descrever texturas de imagens digitais. Esse artigo apresenta 14 características que podem ser extraídas de uma imagem para representar texturas. Elas ficaram conhecidas como descritores de Haralick, os quais são uma das principais referências para aplicações que envolvem análise de texturas por imagens digitais. O estudo de Haralick baseia-se na utilização de matrizes de coocorrência de níveis de cinza (GLCM, do inglês Grey Level Co-occurrence Matrix).

A GLCM é uma representação matricial da frequência com que diferentes combinações de brilho (níveis de cinza) ocorrem em uma imagem. A relação entre combinações de brilho é determinada comparando-se um pixel de referência a um pixel vizinho. O pixel vizinho é determinado por dois parâmetros: a distância d e o ângulo $\theta$ em relação ao pixel de referência. 
Devido a simetria, considera-se apenas quatro valores de $\theta: 0^{\circ}, 45^{\circ}, 90^{\circ}$ e $135^{\circ}$. A relação entre o pixel de referência e o pixel vizinho é ilustrada na Figura 17, para $\mathrm{d}=1$.

Desta forma, se, por exemplo, o pixel vizinho for escolhido com $\mathrm{d}=1$ e $\theta=0^{\circ}$, as combinações de brilho serão determinadas comparando-se o pixel de referência ao pixel à sua direita e ao pixel à sua esquerda. A contagem das diferentes combinações é feita percorrendose todos os pixels da imagem, com cada um deles sendo o pixel de referência da vez.

\begin{tabular}{|c|c|c|}
\hline $\begin{array}{c}\mathrm{PV}_{3} \\
\left(d=1, \theta=135^{\circ}\right)\end{array}$ & $\begin{array}{c}\mathrm{PV}_{2} \\
\left(d=1, \theta=90^{\circ}\right)\end{array}$ & $\begin{array}{c}\mathrm{PV}_{1} \\
\left(d=1, \theta=45^{\circ}\right)\end{array}$ \\
\hline $\begin{array}{c}P V_{4} \\
\left(d=1, \theta=0^{\circ}\right)\end{array}$ & $P R$ & $\begin{array}{c}\mathrm{PV}_{0} \\
\left(d=1, \theta=0^{\circ}\right)\end{array}$ \\
\hline $\begin{array}{c}\mathrm{PV}_{5} \\
\left(d=1, \theta=45^{\circ}\right)\end{array}$ & $\begin{array}{c}\mathrm{PV}_{6} \\
\left(d=1, \theta=90^{\circ}\right)\end{array}$ & $\begin{array}{c}\mathrm{PV}_{7} \\
\left(d=1, \theta=135^{\circ}\right)\end{array}$ \\
\hline
\end{tabular}

Figura 17 - Relação entre o pixel de referência $(P R)$ e o pixel vizinho $\left(P V_{i}\right)$ para $d=1$

Todas as possíveis combinações de níveis de cinza são contadas e formatadas em uma matriz, a GLCM. Supondo uma imagem com apenas três níveis de cinza (0,1 ou 2), a GLCM referente a ela teria o formato apresentado na Figura 18. Sendo que $V_{i, j}$ indica quantas ocorrências de pixels de referência com nível de cinza i cujo pixel vizinho apresenta nível de cinza j há na imagem. 


\begin{tabular}{|c|c|c|c|c|}
\hline & \multicolumn{3}{|c|}{ Valor do pixel vizinho } \\
\hline & & 0 & 1 & 2 \\
\hline \multirow{3}{*}{  } & 0 & $V_{(0,0)}$ & $V_{(0,1)}$ & $V_{(0,2)}$ \\
\hline & 1 & $V_{(1,0)}$ & $V_{(1,1)}$ & $V_{(1,2)}$ \\
\hline & 2 & $V_{(2,0)}$ & $V_{(2,1)}$ & $V_{(2,2)}$ \\
\hline
\end{tabular}

Figura 18 - Formato de uma GLCM para uma imagem com 3 níveis de cinza

É necessário que a GLCM seja normalizada, apresentando probabilidades de ocorrência de combinações, ao invés de números absolutos de ocorrências. Essas probabilidades $\mathrm{P}_{\mathrm{i}, \mathrm{j}}$ são calculadas segundo a Equação (2.67), para $\mathrm{N}_{\mathrm{NC}}$ níveis de cinza.

$$
P_{i, j}=\frac{V_{i, j}}{\sum_{p=0}^{N_{N C}-1} \sum_{q=0}^{N_{N C^{-1}}} V_{p, q}}
$$

Cada um dos 14 descritores de Haralick é calculado utilizando-se os valores da GLCM de uma forma diferente. Antes de se calcular os descritores é preciso determinar alguns valores auxiliares, os quais são definidos pelas Equações (2.68)-(2.74). Os 14 descritores são dados pelas Equações (2.75)-(2.88). Nos cálculos envolvendo logaritmos soma-se $\varepsilon$, um valor arbitrário positivo muito pequeno, ao argumento do $\log$, a fim de se evitar a indefinição $\log (0)$.

$$
\begin{gathered}
P_{x}(i)=\sum_{j=0}^{N_{N C}-1} P_{i, j} \\
P_{y}(j)=\sum_{i=0}^{N_{N C^{-1}}} P_{i, j} \\
P_{x+y}(k)=\sum_{i=0}^{N_{N C^{-1}}} \sum_{j=0}^{N_{N C^{-1}}} P_{i, j}
\end{gathered}
$$


Com $\mathrm{i}+\mathrm{j}=\mathrm{ke} \mathrm{k}=0,1, \ldots, 2 \mathrm{~N}_{\mathrm{NC}}-2$.

$$
P_{x-y}(k)=\sum_{i=0}^{N_{N C^{-1}}} \sum_{j=0}^{N_{N C^{-1}}} P_{i, j}
$$

Com $\mid \mathrm{i}-\mathrm{jl}=\mathrm{ke} \mathrm{k}=0,1, \ldots, \mathrm{N}_{\mathrm{NC}}-1$.

$$
\begin{aligned}
& H X Y 1=-\sum_{i=0}^{N_{N C^{-1}}} \sum_{j=0}^{N_{N C^{-1}}} P_{i, j} \log \left(P_{x}(i) P_{y}(j)+\varepsilon\right) \\
& H X Y 2=-\sum_{i=0}^{N_{N C^{-1}}} \sum_{j=0}^{N_{N C^{-1}}} P_{x}(i) P_{y}(j) \log \left(P_{x}(i) P_{y}(j)+\varepsilon\right) \\
& Q(i, j)=\sum_{k=0}^{N_{N C^{-1}}} \frac{P_{i, k} P_{j, k}}{P_{x}(i) P_{y}(j)} \\
& \text { Segundo Momento Angular }=f_{1}=\sum_{i=0}^{N_{N C^{-1}}} \sum_{j=0}^{N_{N C^{-1}}} P_{i, j}^{2} \\
& \text { Contraste }=f_{2}=\sum_{n=0}^{N_{N C^{-1}}} n^{2}\left(\sum_{i=0}^{N_{N C^{-1}}} \sum_{j=0}^{N_{N C^{-1}}} P_{i, j}\right) \\
& \text { Correlação }=f_{3}=\frac{\sum_{i=0}^{N_{N C}-1} \sum_{j=0}^{N_{N C^{-1}}} P_{i, j}-\mu_{x} \mu_{y}}{\sigma_{x} \sigma_{y}}
\end{aligned}
$$

Onde $\mu_{x}, \sigma_{x}, \mu_{y}$, e $\sigma_{y}$ são, respectivamente, a média e o desvio padrão de $\mathrm{P}_{\mathrm{x}}$ e a média e o desvio padrão de $\mathrm{P}_{\mathrm{y}}$.

$$
\text { Variância }=f_{4}=\sum_{i=0}^{N_{N C^{-1}}} \sum_{j=0}^{N_{N C^{-1}}}(i-\mu)^{2} P_{i, j}
$$

Sendo $\mu$ a média dos níveis de cinza presentes na imagem. 


$$
\text { Momento Inverso da Diferença }=f_{5}=\sum_{i=0}^{N_{N C}-1} \sum_{j=0}^{N_{N C}-1} \frac{P_{i, j}}{1+(i-j)^{2}}
$$

$$
\text { Média da Soma }=f_{6}=\sum_{i=2}^{2 N_{N C}} i P_{x+y}(i-2)
$$

$$
\text { Variância da Soma }=f_{7}=\sum_{i=2}^{2 N_{N C}}\left(i-f_{8}\right)^{2} P_{x+y}(i-2)
$$

$$
\text { Entropia da Soma }=f_{8}=-\sum_{i=0}^{2 N_{N C^{-2}}} P_{x+y}(i) \log \left(P_{x+y}(i)+\varepsilon\right)
$$

$$
\text { Entropia }=f_{9}=-\sum_{i=0}^{N_{N C^{-1}}} \sum_{j=0}^{N_{N C^{-1}}} P_{i, j} \log \left(P_{i, j}+\varepsilon\right)
$$

$$
\text { Variância da Diferença }=f_{10}=\operatorname{Variância~de~}\left(P_{x-y}\right)
$$

$$
\text { Entropia da Diferença }=f_{11}=-\sum_{i=0}^{N_{N C^{-1}}} P_{x-y}(i) \log \left(P_{x-y}(i)+\varepsilon\right)
$$

$$
\text { Medida de Correlação } 1=f_{12}=\frac{f_{9}-H X Y 1}{\operatorname{MAX}(H X, H Y)}
$$

Sendo HX e HY as entropias de $\mathrm{P}_{\mathrm{x}}$ e $\mathrm{P}_{\mathrm{y}}$.

$$
\text { Medida de Correção } 2=f_{13}=\left(1-e^{-2\left(H X Y 2-f_{9}\right)}\right)^{1 / 2}
$$




\subsection{Análise de Componentes Principais (PCA)}

Muitas vezes, ao se trabalhar com um conjunto de características, percebe-se que ele apresenta grande redundância de informações, ou seja, as características têm altos coeficientes de correlação. Em geral, essa redundância é indesejável, pois limita o poder discriminatório das características. A Análise de Componentes Principais (PCA, do inglês Principal Component Analysis) é uma técnica que de um conjunto de características gera outras novas, cujas covariâncias são mínimas, e, portanto, têm máximas variâncias, de modo que essas novas características são perfeitamente descorrelacionadas (COSTA; CESAR, 2000). O conjunto de novas características, chamadas de componentes principais, é obtido por uma transformação linear aplicada nas características originais.

Dado um conjunto de $\mathrm{m}$ amostras expressas em $\mathrm{n}$ características, ele pode ser representado por uma matrix $\mathbf{F}_{\mathrm{mxn}}$. Sendo $\mathbf{K}=\mathbf{F}^{\mathrm{T}} \mathbf{F}$, então $\mathbf{K}$ é a matriz de covariância de $\mathbf{F}$ multiplicada por um escalar arbitrário e $\mathbf{K}$ é positiva definida, tendo, portanto, todos os seus autovalores positivos. Define-se os autovalores de $\mathbf{K}$ como $\lambda_{\mathrm{i}}(\mathrm{i}=1, \ldots, \mathrm{n})$, de modo que $\lambda_{1} \geq \lambda_{2} \geq \cdots \geq \lambda_{\mathrm{n}}$ $\geq 0$. Associado a cada autovalor $\lambda_{i}$ há um autovetor $\mathbf{v}_{\mathbf{i}}$. Como os autovalores $\lambda_{\mathrm{i}}$ foram ordenados de forma decrescente, tem-se que os autovetores vi estão sequenciados em ordem decrescente da variância apresentada pelos dados através dos eixos que eles representam. Além disso, dado que os autovetores são ortogonais por definição, os vi podem ser, então, definidos como as componentes principais propostas pelo método.

Define-se, assim, $\mathbf{L}$ como sendo a matriz que transforma o conjunto de dados expressos pelas características originais no mesmo conjunto expresso pelas componentes principais. $\mathbf{L}$ é uma matriz cujas colunas são os autovetores $\mathbf{V}_{\mathbf{i}}$ :

$$
L=\left[\begin{array}{lll}
v_{1} & \cdots & v_{n}
\end{array}\right]
$$

Então o conjunto de dados transformados pela PCA $(\widetilde{\boldsymbol{F}})$ é dado por

$$
\widetilde{\boldsymbol{F}}=\boldsymbol{F} \boldsymbol{L}
$$

A PCA pode ser utilizada para a compressão de dados. Para tanto, basta eliminar as componentes principais relacionadas a autovalores muito pequenos, já que elas apresentam 
variâncias muito baixas e, portanto, não proporcionam uma perda muito grande de informações quando omitidas.

\subsection{Seleção de Atributos}

Ao se definir um conjunto de atributos para realizar classificações, é possível que nem todos eles contribuam no processo discriminatório ou que contribuam muito pouco, de forma a aumentar injustificadamente o custo computacional envolvido. É possível, também, que certos atributos possam até prejudicar o resultado da classificação. Existem na literatura muitas técnicas que propõem contornar esse problema, fazendo uma filtragem, de modo a determinar um subconjunto dos atributos, o qual contém apenas aqueles com maior poder discriminante. Uma técnica de redução de dimensionalidade, que pode ser utilizada de modo similar a um seletor de atributos, é utilizar a PCA, descrita na Seção 2.5, para transformar os atributos, e então eliminar as componentes principais com baixas variâncias, ou seja, aquelas relacionadas aos menores autovalores.

Outra técnica é avaliar individualmente cada um dos atributos, e então ordená-los segundo um determinado critério de avaliação. Este critério deve ser um procedimento que calcula o poder discriminante de um atributo, mesurado por um valor, ao analisar sua relação com todo conjunto de amostras. A seleção pode ser feita, então, determinando um valor de corte para os valores relacionados aos poderes discriminantes, de forma a manter somente atributos com valores acima dele. Outra possibilidade é manter um determinado número de atributos, os quais são selecionados entre os mais bem posicionados. Dois critérios de avaliação de atributos foram utilizados neste trabalho, e serão escritos abaixo: ganho de informação e chi-quadrado.

\subsubsection{Ganho de Informação}

Em teoria da informação, o termo entropia representa a incerteza associada a uma variável aleatória, de forma que quanto maior a entropia, maior a quantidade de informação necessária para se prever o valor dessa variável. A entropia é máxima quando a variável apresenta uma distribuição uniforme (MACKAY, 2003).

O conceito de entropia pode ser usado na área de classificação de padrões para se determinar o ganho de informação que um atributo proporciona à classificação, conforme descrito por 
Setiono e Liu (1996). Dado um conjunto $\mathbf{S}$ contendo $\mathrm{N}_{\mathrm{am}}$ amostras, as quais são categorizadas em classes, definidas pela variável $\mathrm{C} \in\left\{\mathrm{c}_{1}, \ldots, \mathrm{c}_{\mathrm{n}}\right\}$, e sendo $\mathrm{N}\left(\mathrm{c}_{\mathrm{i}}\right)$ o número de amostras da classe $\mathrm{c}_{\mathrm{i}}$, então a entropia da classificação do conjunto $\mathbf{S}$ é dada por:

$$
H(\boldsymbol{S})=-\sum_{i=1}^{n} \frac{N\left(c_{i}\right)}{N_{a m}} \log _{2} \frac{N\left(c_{i}\right)}{N_{a m}}
$$

Tendo as amostras de $\mathbf{S}$ um atributo $A \in\left\{\mathrm{a}_{1}, \ldots, \mathrm{a}_{\mathrm{m}}\right\}$, então $\mathbf{S}$ pode ser dividido de modo que cada subconjunto $\mathbf{S}_{\mathbf{j}}$ resultante tenha apenas amostras com $A=a_{j}(j=1, \ldots, m)$. Sendo $N\left(a_{j}\right)$ o número de amostras com $\mathrm{A}=\mathrm{a}_{\mathrm{j}} \mathrm{e} \mathrm{N}\left(\mathrm{c}_{\mathrm{i}}, \mathrm{a}_{\mathrm{j}}\right)$ o número de amostras com $\mathrm{C}=\mathrm{c}_{\mathrm{i}} \mathrm{e} \mathrm{A}=\mathrm{a}_{\mathrm{j}}$, então a entropia da classificação do conjunto $\mathbf{S}_{\mathbf{j}}$ é calculada pela Equação (2.92).

$$
H\left(\boldsymbol{S}_{\boldsymbol{j}}\right)=-\sum_{i=1}^{n} \frac{N\left(c_{i}, a_{j}\right)}{N\left(a_{j}\right)} \log _{2} \frac{N\left(c_{i}, a_{j}\right)}{N\left(a_{j}\right)}
$$

A entropia de $\mathbf{S}$ quando suas amostras são arranjadas pelos valores de A pode ser calculada pela soma das entropias dos subconjuntos $\mathbf{S}_{\mathbf{j}}$, ponderada pelo número de elementos nos subconjuntos, conforme a Equação (2.93).

$$
H(\boldsymbol{S}, \mathrm{A})=\sum_{j=1}^{m} \frac{N\left(a_{j}\right)}{N_{a m}} H\left(\boldsymbol{S}_{\boldsymbol{j}}\right)
$$

O ganho de informação que o atributo A oferece na classificação do conjunto de amostras $\mathbf{S}$ é dado pela redução observada na entropia ao se arranjar as amostras de $\mathbf{S}$ pelos valores de A. O ganho de informação é dado pela equação abaixo.

$$
G(\boldsymbol{S}, \mathrm{A})=H(\boldsymbol{S})-H(\boldsymbol{S}, \mathrm{A})
$$

Como o valor de $G(\boldsymbol{S}, \mathrm{A})$ é sensível ao número de diferentes valores que A pode assumir, uma normalização se faz necessária para que os ganhos de informação de diferentes atributos possam ser comparados de modo consistente. A normalização pode ser feita pela entropia do 
atributo em relação a seus valores $(\widetilde{H}(\boldsymbol{S}, \mathrm{A}))$. Dessa forma, calculamos o ganho de informação normalizado segundo a Equação (2.95).

$$
G_{N}(\boldsymbol{S}, \mathrm{A})=\frac{G(\boldsymbol{S}, \mathrm{A})}{\widetilde{H}(\boldsymbol{S}, \mathrm{A})}
$$

Com

$$
\widetilde{H}(\boldsymbol{S}, \mathrm{A})=\sum_{j=1}^{m} \frac{N\left(a_{j}\right)}{N_{a m}} \log _{2} \frac{N\left(a_{j}\right)}{N_{a m}}
$$

Os cálculos descritos acima pressupõem que o atributo A seja uma variável discreta. Caso ele seja definido por uma variável contínua, algum método de discretização deve ser previamente aplicado.

\subsubsection{Chi-quadrado}

Este critério avalia um atributo baseando-se na estatística $\chi^{2}$. O $\chi^{2}$ é amplamente utilizado para se verificar ou refutar uma hipótese de dependência entre duas variáveis, atribuindo ao resultado um grau de confiabilidade estatístico.

Primeiramente deve-se compreender o conceito da distribuição $\chi^{2}$ (WALCK, 2007). Dado um conjunto de variáveis aleatórias independentes $\mathrm{Z}_{\mathrm{p}}(\mathrm{p}=1, \ldots, \mathrm{k})$ com distribuição normal com média zero e variância $1\left(\mathrm{Z}_{\mathrm{p}} \sim \mathrm{N}(0,1)\right)$, e definindo uma variável aleatória $Q=\sum_{r=1}^{k} Z_{r}^{2}$, então $\mathrm{Q}$ apresenta uma distribuição chi-quadrado com $\mathrm{k}$ graus de liberdade $\left(\mathrm{Q} \sim \chi_{k}^{2}\right)$. A função de densidade de $\chi_{k}^{2}$ é dada pela Equação (2.97) e sua curva está traçada na Figura 19 para alguns graus de liberdade.

$$
f_{k}(x)=\left\{\begin{aligned}
\frac{x^{\left(\frac{k}{2}-1\right)} e^{-\frac{x}{2}}}{2^{\frac{k}{2}} \Gamma\left(\frac{k}{2}\right)} & , \quad x \geq 0 \\
0, & x<0
\end{aligned}\right.
$$

Onde $\Gamma(\cdot)$ é a função gama definida pela Equação (2.98). 


$$
\Gamma(z)=\int_{0}^{\infty} t^{z-1} e^{-t} d t
$$

A função distribuição acumulada de $\chi_{k}^{2}$ é dada pela Equação (2.99) e sua curva está traçada na Figura 20 para alguns graus de liberdade.

$$
F_{k}(x)=\frac{\gamma\left(\frac{k}{2}, \frac{x}{2}\right)}{\Gamma\left(\frac{k}{2}\right)}
$$

Sendo $\gamma(\cdot)$ a função gama incompleta definida pela Equação (2.100)

$$
\gamma(s, x)=\int_{0}^{x} t^{s-1} e^{-t} d t
$$

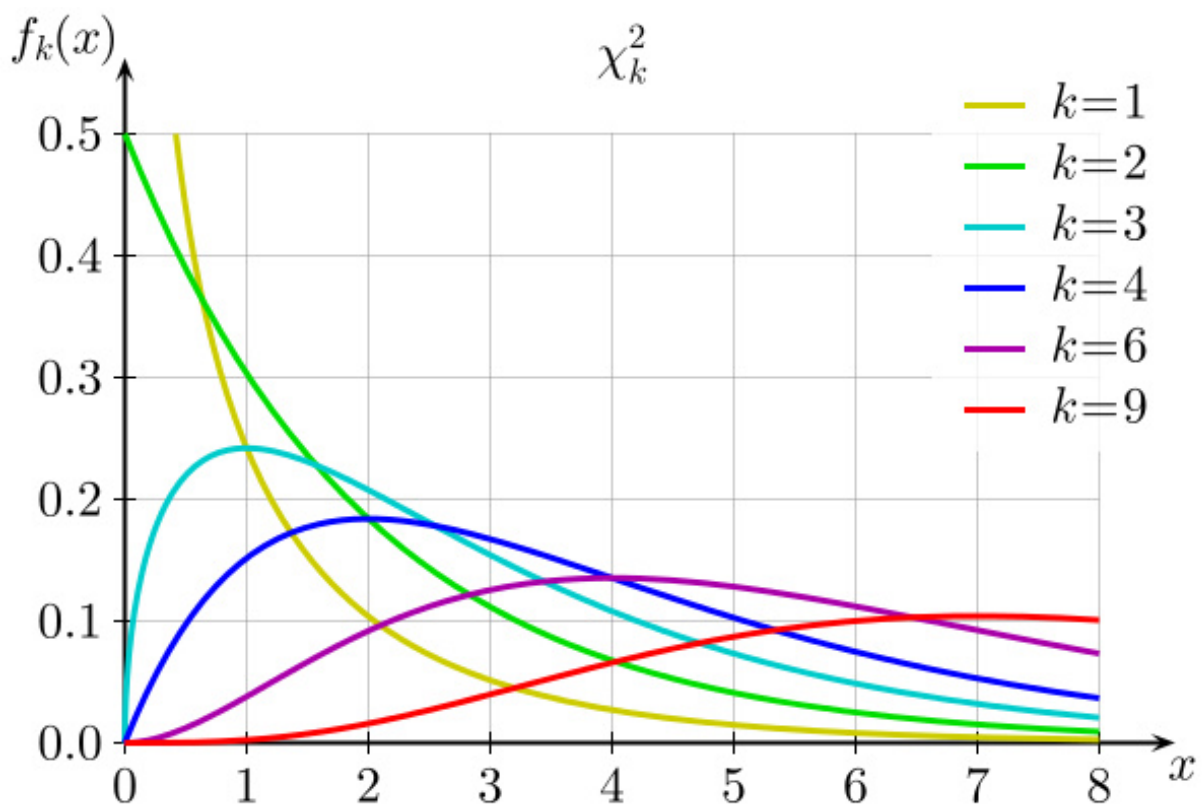

Figura 19 - Função de densidade da distribuição $\chi^{2}$, para vários graus de liberdade $k$ Figura retirada de http://en.wikipedia.org/wiki/Chi-squared_distribution 




Figura 20 - Função distribuição acumulada da distribuição $\chi^{2}$, para vários graus de liberdade $\mathbf{k}$

Figura retirada de http://en.wikipedia.org/wiki/Chi-squared_distribution

Em problemas de classificação de padrões, pode-se avaliar a dependência entre a classe de uma amostra, definida pela variável $\mathrm{C} \in\left\{\mathrm{c}_{1}, \ldots, \mathrm{c}_{\mathrm{n}}\right\}$ e um atributo da amostra, definido pela variável discreta $A \in\left\{a_{1}, \ldots, a_{m}\right\}$. Primeiramente são definidas duas hipóteses: a hipótese nula $\left(\mathrm{H}_{0}\right)$, a qual será avaliada pelo teste, e a hipótese alternativa $\left(\mathrm{H}_{\mathrm{a}}\right)$, que será estatisticamente comprovada caso a hipótese nula não seja sustentada. Então são definidos dois conjuntos de valores:

$\mathrm{O}_{\mathrm{ij}}$ : Número de amostras observadas com $\mathrm{C}=\mathrm{c}_{\mathrm{i}}$ e $\mathrm{A}=\mathrm{a}_{\mathrm{j}}$.

$\mathrm{E}_{\mathrm{ij}}$ : Número de amostras esperadas com $\mathrm{C}=\mathrm{c}_{\mathrm{i}}$ e $\mathrm{A}=\mathrm{a}_{\mathrm{j}}$, se a hipótese $\mathrm{H}_{0}$ for verdadeira. $\operatorname{Com~} \mathrm{i}=1, \ldots, \mathrm{n}$ e $\mathrm{j}=1, \ldots, \mathrm{m}$.

O atributo estatístico X² é então dado pela Equação (2.101) (MENDENHALL; BEAVER; BEAVER, 2013).

$$
X^{2}=\sum_{i=1}^{n} \sum_{j=1}^{m} \frac{\left(O_{i j}-E_{i j}\right)^{2}}{E_{i j}}
$$

$\mathrm{Se} \mathrm{H}_{0}$ for verdadeira, $\mathrm{X}^{2}$ terá um valor próximo de zero. Se $\mathrm{X}^{2}$ apresentar um valor elevado é provável que $\mathrm{H}_{0}$ não seja verdadeira e, consequentemente, a hipótese $\mathrm{H}_{\mathrm{a}}$ seja mais plausível. É possível se atribuir um nível de confiabilidade estatístico no descarte ou na permanência da 
hipótese $\mathrm{H}_{0}$. Como para um número suficientemente grande de amostras, em repetidos experimentos $\mathrm{X}^{2}$ apresenta uma distribuição próxima de $\chi_{k}^{2} \operatorname{com} \mathrm{k}=(\mathrm{m}-1)(\mathrm{n}-1)$ (MENDENHALL; BEAVER; BEAVER, 2013), é possível calcular a probabilidade de $\mathrm{H}_{0}$ ser verdadeira a partir da função distribuição acumulada da Equação (2.99). Sendo x o valor calculado de $\mathrm{X}^{2}$, a probabilidade de se obter $\mathrm{X}^{2} \geq \mathrm{x}\left(\mathrm{P}\left(\mathrm{X}^{2} \geq \mathrm{x}\right)\right)$, sendo $\mathrm{H}_{0}$ verdadeira é $1-\mathrm{F}_{\mathrm{k}}(\mathrm{x})$ e, portanto, essa é a probabilidade de $\mathrm{H}_{0}$ ser verdadeira.

No problema de classificação de padrões, para se avaliar a importância de um atributo, pode-se assumir a hipótese nula $\mathrm{H}_{0}$ como sendo a total independência entre a classe e o atributo. A partir dessa hipótese pode-se estimar os valores esperados para as amostras $\hat{E}_{i j}$. Sendo $\hat{p}_{c i}$ a probabilidade estimada de uma amostra pertencer à classe $\mathrm{c}_{\mathrm{i}}$, e $\hat{p}_{a j}$ a probabilidade estimada de o atributo da amostra ter valor $\mathrm{a}_{\mathrm{j}}$, então:

$$
\begin{gathered}
\hat{p}_{c i}=\frac{\begin{array}{c}
\text { Número de amostras } \\
\text { da classe } c_{i}
\end{array}}{\text { Número total de amostras }}=\frac{\sum_{r=1}^{m} O_{i r}}{N_{a m}} \\
\hat{p}_{a j}=\frac{\begin{array}{c}
\text { Número de amostras } \\
\text { com atributo } a_{j}
\end{array}}{\text { Número total de amostras }}=\frac{\sum_{r=1}^{n} O_{r j}}{N_{a m}} \\
\hat{E}_{i j}=\hat{p}_{c i} \hat{p}_{a j}=\frac{\left(\sum_{r=1}^{m} O_{i k}\right)\left(\sum_{r=1}^{n} O_{k j}\right)}{N_{a m}}
\end{gathered}
$$

Faz-se, então, $E_{i j}=\hat{E}_{i j}$ e calcula-se $\mathrm{X}^{2}$ pela Equação (2.101). Quanto maior for $\mathrm{X}^{2}$, maior a importância do atributo. É necessário se salientar, que para calcular $\mathrm{X}^{2}$, o atributo deve ser uma variável discreta. Se esse não for o caso, uma método de discretização deve ser aplicado. 


\section{MATERIAIS E MÉTODOS}

Este capítulo apresentará o método desenvolvido para a classificação de amostras de café em grãos, assim como todo material utilizado no processo. Na Seção 3.1 serão apresentados o software utilizado no auxílio do desenvolvimento das rotinas envolvidas no método e o ambiente de desenvolvimento. A Seção 3.2 caracterizará o conjunto de amostras e impurezas no qual foi baseado o desenvolvimento do método, e a forma como foi construído um banco de dados para armazenar suas informações é descrita na Seção 3.8. O método é apresentado de maneira sucinta na Seção 3.3 e detalhado nas seções seguintes. Os critérios adotados para se avaliar o método são apresentados na Seção 3.4. A configuração das redes neurais utilizadas e os parâmetros dos processos de avaliação são dados na Seção 3.5. O hardware adotado para realizar a captura de imagens de amostras é descrito na Seção 3.6 e a segmentação e individualização dos grãos das imagens na Seção 3.7. A Seção 3.9 caracteriza os atributos que compuseram os diferentes vetores de características avaliados, sendo que na Seção 3.9.3.2 será explanado como os descritores de Haralick foram modificados para serem utilizados como atributos de textura dos vetores de características. A Seção 3.10 definirá as classes a serem identificadas em cada etapa dos processos classificatórios avaliados. O processo de seleção de atributos utilizado para reduzir o número de características empregadas é descrito na Seção 3.11. E finalmente, a Seção 3.12 detalha como foi definido o processo classificatório.

\subsection{Especificação do Software}

O desenvolvimento do software que realiza todos os passos englobados no método proposto foi realizado em linguagem Java, utilizando a IDE NetBeans ${ }^{1}$ na versão 7.2 e com o auxílio de bibliotecas de manipulação de imagens, como $\mathrm{JAI}^{2}$ (Java Advanced Imaging) e Image ${ }^{3}$. Para o manuseio das redes neurais e aplicação da PCA foi utilizado um pacote de ferramentas de mineração de dados chamado WEKA $^{4}$ (WITTEN; FRANK; HALL, 2011), contendo

${ }^{1}$ Disponível em http://www.netbeans.org/downloads/. Acessado em 16/05/2014.

2 Disponível em http://www.oracle.com/technetwork/java/download-1-0-2-140451.html. Acessado em 16/05/2014.

${ }^{3}$ Disponível em http://rsbweb.nih.gov/ij/download.html. Acessado em 16/05/2014.

${ }^{4}$ Disponível em http://www.cs.waikato.ac.nz/ml/weka/. Acessado em 16/05/2014. 
implementações de algoritmos relacionados à PMC e a outras redes neurais. Também foram utilizadas as implementações dos algoritmos de seleção de atributos fornecidas pelo WEKA.

\subsection{Amostras}

As categorias de classificação de café adotadas neste trabalho foram as utilizadas pela Cooperativa Regional de Cafeicultores de Guaxupé Ltda. (Cooxupé), que forneceu amostras de grãos contendo grãos prefeitos, com defeitos e impurezas já separados e classificados por especialistas da cooperativa. Essas amostras foram utilizadas como referências para o desenvolvimento do método e sua validação. As diferentes classes de grãos e impurezas a serem identificadas neste trabalho são apresentadas Figura 21.

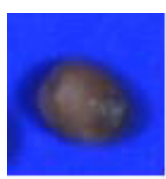

(a)

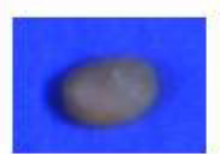

(b)

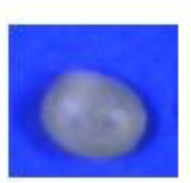

(h)



(o)

(i)

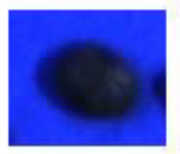

(p)
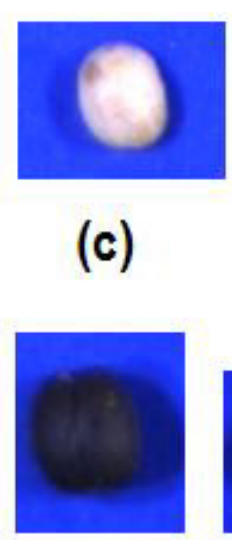

(c)
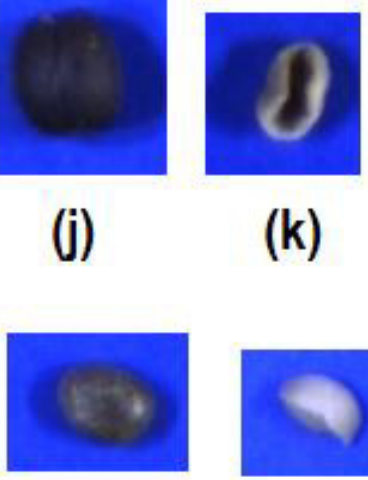

(q)

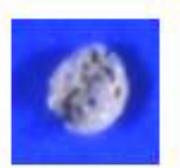

(d)

(k)

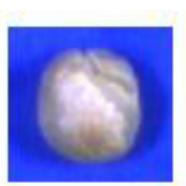

(e)

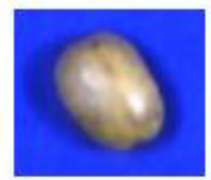

(I)

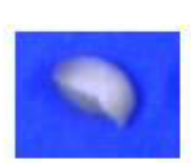

(r)

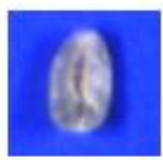

(s)

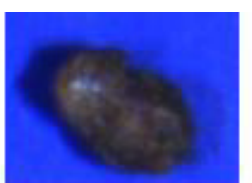

(f)



(m)

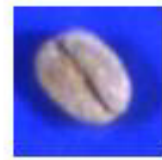

(t)

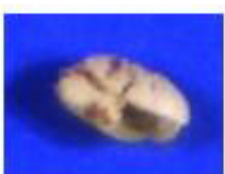

(g)

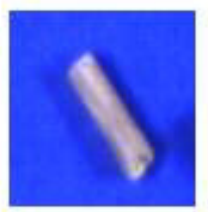

(n)



(u)

Figura 21 - Classes de grãos e impurezas.

(a) ardido, (b) barrento, (c) branco, (d) brocado, (e) cabeça, (f) casca, (g) casca de marinheiro, (h) perfeito, (i) chocho, (j) coco, (k) concha, (l) marinheiro, (m) melado, (n) pau, (o) pedra, (p) preto, (q) preto-verde, (r) quebrado, (s) triângulo, (t) velho, (u) verde

Os defeitos são: ardido, barrento, branco, brocado, cabeça, chocho, concha, marinheiro, melado, preto, preto-verde, quebrado, triângulo, velho e verde. As impurezas são: casca, casca 
de marinheiro, coco, pau e pedra. Portanto, com a classe de grãos perfeito, tem-se um total de 21 classes.

No total foram utilizadas 15.773 amostras, distribuídas por classe de acordo com a Tabela 1, que está ilustrada no Gráfico 1.

\begin{tabular}{cc} 
Tabela 1 - Distribuição do número de amostras por classe \\
\hline Classe & Quantidade \\
\hline Perfeito & 2585 \\
Ardido & 518 \\
Barrento & 788 \\
Branco & 667 \\
Brocado & 710 \\
Cabeça & 698 \\
Casca & 496 \\
Casca de marinheiro & 499 \\
Chocho & 798 \\
Coco & 544 \\
Concha & 588 \\
Marinheiro & 547 \\
Melado & 502 \\
Pau & 637 \\
Pedra & 710 \\
Preto & 577 \\
Preto Verde & 746 \\
Quebrado & 920 \\
Triângulo & 820 \\
Velho & 633 \\
Verde & 790 \\
\hline
\end{tabular}




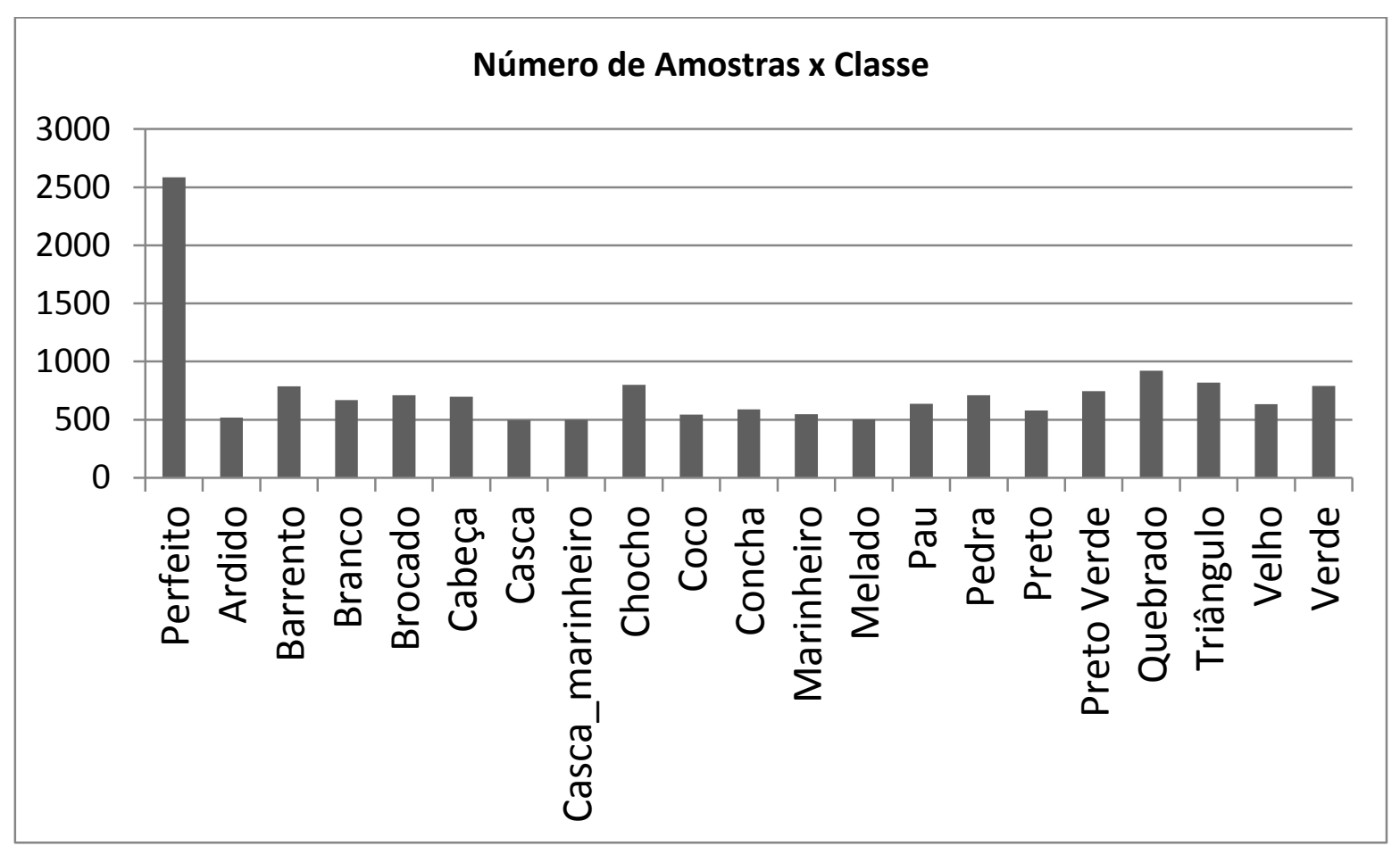

Gráfico 1 - Distribuição do número de amostras por classe

Percebe-se que há uma distribuição razoavelmente uniforme entre as classes, com exceção da classe perfeito, que apresenta um número muito maior de amostras. Isso se deve ao fato de que esta classe é subdividida em nove outras - as peneiras - uma classificação adicional utilizada pelas cooperativas que agrupa grãos de acordo com seus tamanhos. Essa classificação remete ao processo de separação dos grãos por tamanho, onde são utilizadas peneiras com crivos de medidas distintas. As medidas dos crivos das peneiras são dadas em frações de 1/64 de polegada e o número da peneira corresponde ao numerador da fração. Por exemplo: a peneira 19 está associada ao crivo de 19/64 de polegada. Como grãos perfeitos devem ser identificados independentemente de sua peneira, uma quantidade significante de cada peneira deve ser utilizada.

As 2585 amostras de grãos perfeitos estão distribuídas entre as nove peneiras de acordo conforme a Tabela 2 e o Gráfico 2. 
Tabela 2 - Distribuição do número de amostras de grãos perfeitos por peneira

\begin{tabular}{cc}
\hline Peneira & Quantidade \\
\hline MK11 & 278 \\
MK12 & 257 \\
PN13 & 295 \\
PN14 & 293 \\
PN15 & 309 \\
PN16 & 319 \\
PN17 & 300 \\
PN18 & 270 \\
PN19 & 264 \\
\hline
\end{tabular}

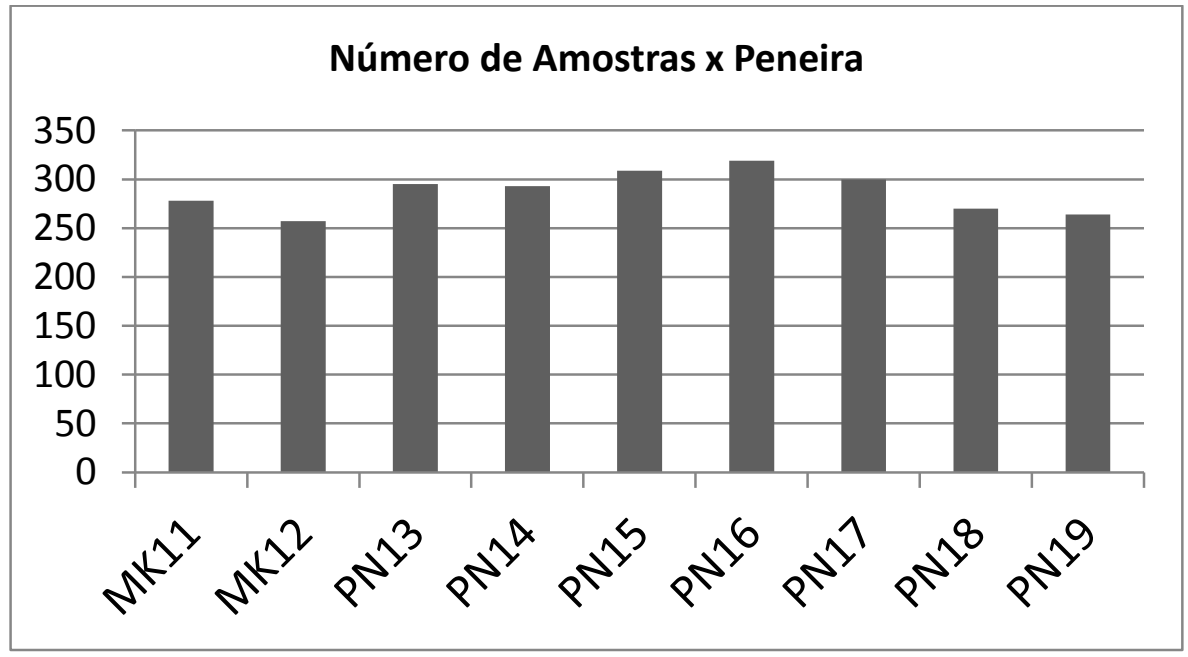

Gráfico 2 - Distribuição do número de amostras de grãos perfeitos por peneira

\subsection{Visão geral do método}

O método adotado neste trabalho é apresentado resumidamente nesta seção. Primeiramente, imagens das amostras foram adquiridas, então definiu-se uma técnica de segmentação dos grãos, possibilitando a separação dos objetos de interesse do fundo das imagens. Com isso foi possível criar um banco de dados de amostras pré-classificadas, e então extrair diversos atributos de cor, morfológicos e de textura.

Posteriormente foram avaliados métodos para se realizar a classificação em si. Para tanto, foram definidas cinco análises: utilizando somente atributos morfológicos $\left(\mathrm{A}_{\mathrm{M}}\right)$; utilizando somente atributos de cor $\left(\mathrm{A}_{\mathrm{C}}\right)$; utilizando somente atributos de textura $\left(\mathrm{A}_{\mathrm{T}}\right)$; utilizando somente 
atributos de cor e textura $\left(\mathrm{A}_{\mathrm{CT}}\right)$; e utilizando todos os atributos juntos $\left(\mathrm{A}_{\mathrm{MCT}}\right)$. Cada uma dessas análises consiste na classificação do grão por uma rede neural previamente treinada com os atributos associados a ela. A determinação de quais atributos foram utilizados para as redes neurais foi feita por meio de um processo de seleção de atributos. Para cada análise são definidas diferentes classes a serem identificadas, as quais são a fusão das classes originais do problema (impurezas e defeitos).

Finalmente, foram avaliados três processos de classificação, os quais se utilizam das análises descritas:

$\boldsymbol{P}_{\text {MCT }}$ : Classificar diretamente a partir da análise $\mathrm{A}_{\text {MCT. }}$

$\boldsymbol{P}_{\boldsymbol{M}+\boldsymbol{C}+\boldsymbol{T}}$ : Realizar as análises $\mathrm{A}_{\mathrm{M}}, \mathrm{A}_{\mathrm{C}}$ e $\mathrm{A}_{\mathrm{T}}$ paralelamente e cruzar os resultados para definir a classificação final.

$\boldsymbol{P}_{\boldsymbol{M}+\boldsymbol{C} \boldsymbol{T}}$ : Realizar as análises $\mathrm{A}_{\mathrm{M}}$ e $\mathrm{A}_{\mathrm{CT}}$ paralelamente e cruzar os resultados para definir a classificação final.

A Figura 22 apresenta o método em linhas gerais, por meio de um fluxograma. O processo representado pelo bloco A é detalhado na Seção 3.6. O processo do bloco B é apresentado na Seção 3.7. O processo do bloco C é discutido na Seção 3.8. Os atributos extraídos no processo do bloco D são descritos na Seção 3.9. O processo definido pelo conjunto de blocos E é detalhado na Seção 3.11. Finalmente, os processos dos blocos F e G são descritos na Seção 3.12 . 


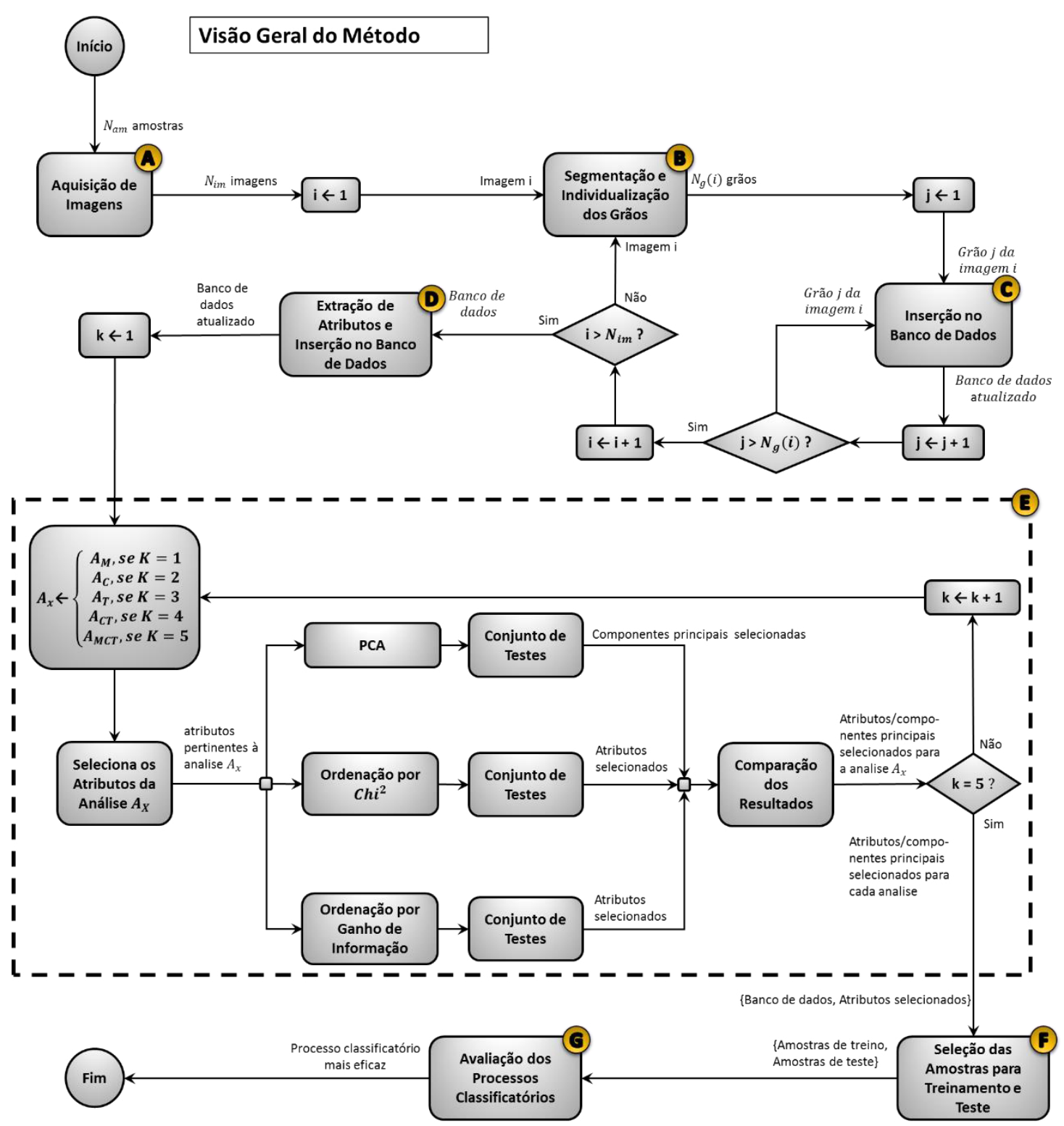

Figura 22 - Fluxograma do método

\subsection{Critérios de Avaliação}

O principal critério de comparação de resultados foi a acurácia (Equação (3.1)), critério esse adotado pela maioria dos trabalhos apresentados na Introdução.

$$
\text { Acurácia }=\frac{\text { Número de instâncias corretamente classificadas }}{\text { Total de instâncias classificadas }}
$$


Outros critérios também foram utilizados: precisão, recall e F-Measure. O conceito de precisão define a proporção de acertos ao se atribuir uma certa classe aos objetos sendo classificados. O conceito de recall define a proporção de acerto ao se classificar objetos de uma certa classe. A F-Measure é uma forma de avaliar tanto a precisão quanto o recall utilizando uma só medida. Para tanto, é realizada a média harmônica entre os dois critérios.

Para calcular esses critérios deve-se definir os seguintes conceitos:

Número de verdadeiros positivos da classe C: VP $(C)=$ Número de vezes que a classe $C$ foi corretamente atribuída a um objeto

Número de falsos positivos da classe C: FP $(C)$ = Número de vezes que a classe $C$ foi erroneamente atribuída a um objeto

Número de falsos negativos da classe $\mathrm{C}$ : $\mathrm{FN}(\mathrm{C})$ = Número de vezes que a um objeto foi erroneamente atribuída a classe $\mathrm{C}$

Então a precisão, o recall e a F-Measure para uma classe C são dados pelas equações abaixo:

$$
\begin{gathered}
\operatorname{precisão}(C)=\frac{V P(C)}{V P(C)+F P(C)} \\
\operatorname{recall}(C)=\frac{V P(C)}{V P(C)+F N(C)} \\
F-\operatorname{Measure}(C)=\frac{2 \operatorname{precisão}(C) \operatorname{recall}(C)}{\text { precisão }(C)+\operatorname{recall}(C)}
\end{gathered}
$$

O recall médio das classes pode ser utilizado para verificar se o valor da acurácia é consiste, não sendo fruto de um classificador viciado, que tende a indicar a classe mais recorrente, por exemplo, no caso de não uniformidade de distribuição de instâncias entre as classes. Valores de acurácia e de recall médio muito diferentes podem ser um indício dessa condição. 


\subsection{Topologia das Redes Neurais}

Redes neurais do tipo PCM, treinadas com o algoritmo backpropagation, foram os classificadores adotados neste trabalho. Os parâmetros de treinamentos utilizados foram: taxa de aprendizagem $\eta=0,1$, momentum $\alpha=0,5$ e como critério de parada a execução de 5.000 épocas. As topologias são a mesma para todas as redes, com três camadas: uma de entrada (com um neurônio para cada elemento do vetor de características), uma de saída (um neurônio para cada uma das classes a serem identificadas), e uma escondida. Como o trabalho exigiu a comparação de resultados de classificações com números diferentes de dados de entrada e de saída, padronizou-se o número de neurônios da camada escondida em função do número de entradas e saídas. Dessa forma, o número de neurônios da camada escondida $N_{c e}$ é calculado para cada rede, segundo a Equação (3.5), arredondando para baixo.

$$
N_{c e}=\left(N_{e}+N_{s}\right) / 2
$$

Onde:

$N_{e}$ : Número de neurônios na camada de entrada.

$N_{s}$ : Número de neurônios na camada de saída.

A maioria das classificações das redes neurais foi avaliada utilizando-se a validação cruzada pelo método k-folds (HASTIE; TIBSHIRANI; FRIEDMAN, 2009). Por esse método o conjunto de amostras é dividido em k subconjuntos mutualmente exclusivos de tamanhos iguais (quando possível). Então são realizadas k iterações de um processo que consiste no treinamento de uma rede neural seguido da sua utilização na classificação de um conjunto de amostras de validação. Em cada iteração um subconjunto diferente é utilizado para realizar a validação e os (k-1)

subconjuntos restantes são utilizados para o treinamento. É feita a média dos resultados da classificação do conjunto de validação de cada iteração para definir um resultado final.

\subsection{Hardware e Aquisição de Imagens}

Para se poder capturar imagens das amostras de café por um método sistemático, com o qual todas as condições que afetam a foto pudessem ser reproduzidas exatamente da mesma forma a cada processo de aquisição, uma câmara foi desenvolvida (representação esquemática 
na Figura 23). Ela é composta por uma bandeja horizontal revestida com a cor azul, onde os grãos são depositados, sob condições controladas de luz. A bandeja é iluminada por um conjunto de lâmpadas de LED e uma câmera de vídeo é posicionada cerca de $60 \mathrm{~cm}$ acima dela. A câmera é do modelo GC1020C ${ }^{1}$, da marca AVT. Ela é do tipo IP acessível por uma interface Gigabit Ethernet. As imagens são capturadas e armazenadas no formato bitmap com resolução de $1024 \times 768$ pixels.



Figura 23 - Estrutura interna do aparato de captura de imagens

\subsection{Segmentação e Individualização}

A primeira etapa do método é a identificação de grãos e impurezas presentes na amostra. $\mathrm{O}$ fundo de cor azul foi escolhido devido ao fato de nenhuma das classes apresentarem tonalidades próximas a essa cor, como pode ser observado na Figura 21, de forma a facilitar a segmentação 
da imagem. Analisando-se o espaço de cor RGB, percebe-se que as tonalidades de azul apresentam valores de B significativamente maiores que de R e G. Definiu-se então a seguinte função de segmentação:
SE $\quad B \geq X^{*} R$ e $B \geq X^{*} G$
ENTÃO é um pixel de fundo.
SENÃO é um pixel de objeto.

Sendo que R, G e B são as componentes de cor do pixel a ser avaliado e X é um parâmetro a ser encontrado empiricamente.

A função de segmentação foi testada para diversos valores de X, avaliando-se visualmente o resultado obtido. Os testes foram realizados utilizando-se amostras que apresentassem objetos de diferentes colorações, desde grãos muito escuros a grãos mais claros e com tonalidades diversificadas (pedras, paus, grãos marinheiro, etc.). O valor de $\mathrm{X}$ que apresentou os melhores resultados foi 3,3 .

Tendo os objetos sido separados do fundo, a imagem é binarizada para que os outros algoritmos possam ser aplicados. A partir da imagem binarizada é finalmente executado um algoritmo para rotular as diferentes formas. A rotulação é feita pelo método das componentes conexas, o qual agrupa os pixels de acordo com as suas conectividades. Existem duas variantes que definem a conectividade dos pixels: a vizinhança-de-4 e a vizinhança-de- 8 . A primeira considera que dois pixels são vizinhos somente se estiverem conectados pelos eixos vertical ou horizontal, enquanto a segunda, adotada neste trabalho, também considera os diagonais. Uma componente conexa é um grupo de pixels que compartilham da propriedade de que existe um caminho de ligação (uma sucessão de vizinhos) entre quaisquer dois deles (Costa e Cesar, 2000). Uma vez definidas as componentes conexas, cada uma delas e seus respectivos pixels são rotulados, representando um objeto diferente. Depois de rotuladas todas as formas presentes na imagem, é trivial se extrair os pixels de seus contornos.

Finalmente, são descartados os objetos compostos por menos que 40 pixels, por eles serem muito pequenos para representar um objeto de interesse, provavelmente sendo resultado de ruído da imagem ou uma falha no algoritmo de identificação.

Na Figura 24 pode ser visualizada uma imagem de saída do processo de identificação de grãos. Nesta imagem, os contornos dos grãos foram pintados de verde e numerados sequencialmente. 


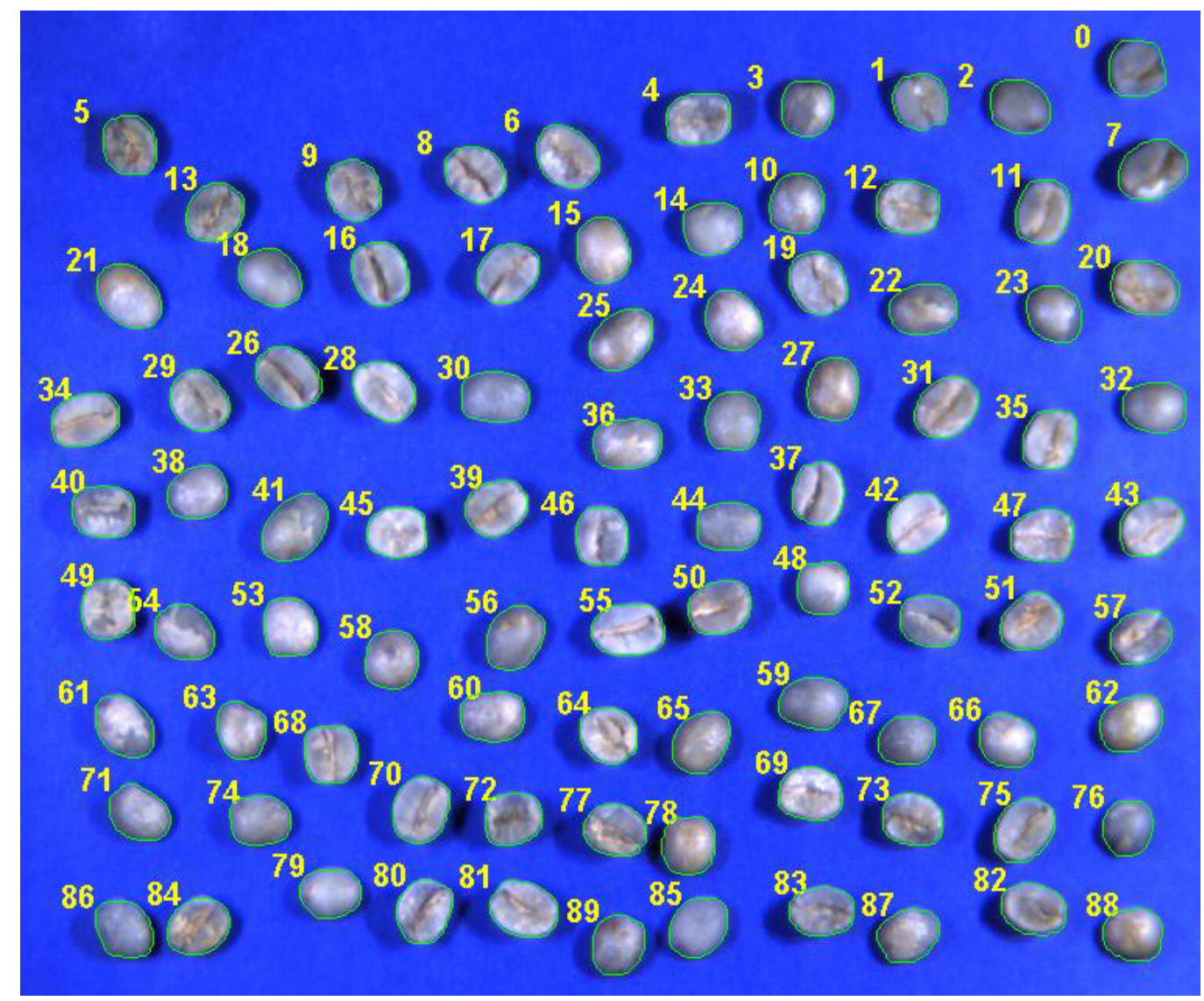

Figura 24 - Grãos identificados e rotulados

\subsection{Criação de um Banco de Dados de Amostras}

As amostras descritas na Seção 3.2 foram digitalizadas e individualizadas pelo método descrito na Seção 3.7. Cada um dos objetos de interesse (grãos ou impurezas) foi armazenado em um banco de dados JAVA DB ${ }^{1}$, o qual oferece suporte a consultas SQL. Para cada objeto foram armazenadas as seguintes informações: sua classe, a escala da imagem (pixels/mm) e informações sobre cada um de seus pixels componentes. Cada um desses pixels apresentam as seguintes informações: suas coordenadas $\mathrm{X}$ e $\mathrm{Y}$ em relação a sua imagem de origem, seus valores R, G e B e também a informação se este pixel pertence ou não à borda do objeto. Essa última informação é necessária para se recuperar os contornos dos objetos.

${ }^{1}$ Mais informações em: http://www.oracle.com/technetwork/java/javadb/overview/index.html (Acessado em $16 / 05 / 2014)$ 


\subsection{Caracterização dos Atributos}

Esta seção apresentará os atributos adotados neste estudo, juntamente com os parâmetros utilizados para calculá-los. Os atributos são divididos em três naturezas: atributos morfológicos, atributos de cor e atributos de textura. Os atributos descritos nas próximas subsseções foram calculados para cada uma das amostras presentes no banco de dados descrito na Seção 3.8. Foram definidos cinco banco de dados para comportarem os atributos calculados:

Bancom: banco de dados contendo os atributos morfológicos das amostras do banco de amostras.

Bancoc: banco de dados contendo os atributos de cor das amostras do banco de amostras.

Bancoт: banco de dados contendo os atributos de textura das amostras do banco de amostras.

Bancoст: Banco $_{\text {С }}$ Ваnсот.

Bancoмст: Ваnсом $\bowtie$ Bancoc $\bowtie$ Ваnсот.

Onde $\bowtie$ representa a operação JOIN da álgebra relacional aplicada sobre o número identificador da amostra.

Cada um desses bancos está associado a uma das análises apresentadas na Seção 3.3. De forma que os atributos contidos no Bancom foram utilizados pela análise $\mathrm{A}_{\mathrm{M}}$ (após o processo de seleção de atributos descrito na Seção 3.11), e assim por diante.

\subsubsection{Atributos Morfológicos}

Os conceitos e o cálculo dos atributos morfológicos foram apresentados na Seção 2.3. Neste trabalho foram utilizados os atributos a seguir: 39 Descritores de Fourier de menor ordem, calculados a partir da assinatura dada pelas distâncias da borda ao centroide; 28 DGFs, referentes a 4 diferentes frequências radiais $(R=m=4)$ e 7 diferentes frequências angulares ( $\mathrm{T}=\mathrm{N}=7$ ), parâmetros esses determinados por avaliações conduzidas por Oyama, Rodrigues e Jorge (2012); elementos do Modelo Autorregressivo até ordem $10\left(\mathrm{~N}_{\mathrm{R}}=10\right)$, calculados utilizando 60 raios $\left(\mathrm{N}_{\mathrm{AR}}=60\right)$, resultando em 11 atributos; Momentos de Zernike até ordem 20 $\left(n_{Z}=20\right)$, com todas as suas repetições, resultando em 121 valores; e os 12 atributos unitários 
( área, perímetro, eixo maior, eixo menor, excentricidade, spread, slenderness, $\mathrm{A}_{1}, \mathrm{~A}_{2}, \mathrm{~A}_{3}, \mathrm{~A}_{4}$ e A5). Portanto, contou-se com um total de 211 atributos morfológicos.

Esses 211 atributos foram calculados para cada uma das amostras do banco de amostras e os valores foram inseridos no Bancom.

\subsubsection{Atributos de Cor}

Dois conjuntos de atributos foram comparados na definição dos atributos de cor: histogramas de frequências normalizadas de cores, e atributos estatísticos extraídos desses histogramas. Os atributos e sua avaliação são apresentadas a seguir.

\subsubsection{Histograma de Frequências Normalizadas de Cores}

Nas etapas iniciais do trabalho avaliou-se o uso de histogramas de frequências normalizadas das cores dos pixels dos grãos como atributos de cor. As frequências dos histogramas de um dado espaço de cor foram utilizadas como atributos da amostra no processo de classificação. Histogramas de vários espaços de cor foram avaliados.

Como o número de cores possíveis de serem representadas pelos espaços de cor adotados é muito elevado, da ordem de dezenas de milhões, os espaços de cor precisaram ser quantizados para tornar viável o cálculo dos histogramas e sua utilização como um conjunto de atributos. A quantização foi feita linearmente, de modo que cada um dos novos valores quantizados acomodasse o mesmo número de cores do modelo original. A quantização de um canal de um espaço de cor feita segundo a Equação (3.6):

$$
Q\left(\mathrm{~V}_{c}\right)= \begin{cases}N_{v a l}-1 & \text { se } V_{C}=V_{\max , C} \\ \text { ARREDONDA }\left(N_{\text {val }} \frac{V_{C}-V_{\min , C}}{V_{\max , C}-V_{\min , C}}\right), & \text { caso contrário }\end{cases}
$$

Sendo que $\mathrm{Q}\left(\mathrm{V}_{\mathrm{C}}\right)$ é o valor quantizado, $\mathrm{V}_{\mathrm{C}}$ é o valor do modelo de cor original, cujo domínio é limitado por $V_{\min , C}$ e $V_{\max , C}$. O índice $\mathrm{C}$ determina o canal do espaço de cor que está sendo quantizado. A função ARREDONDA(x) arredonda x para o inteiro de menor valor. O canal quantizado apresentará $\mathrm{N}_{\text {val }}$ possíveis valores, situados no intervalo discreto [0, $\left.\mathrm{N}_{\text {val }}-1\right]$. 
Como no banco de amostra estão armazenados os valores $\mathrm{R}, \mathrm{G}$ e B de cada pixel de uma amostra, o cálculo dos histogramas para cada canal do espaço RGB é facilmente feito. Além dos histogramas do espaço RGB, foram avaliados os histogramas dos seguintes espaços de cor: YUV, YIQ, YDbDr, YPbPr, YCbCr, CIE XYZ, CIELAB, HSV, RGB normalizado (rgb) e $\mathrm{I}_{1} \mathrm{I}_{2} \mathrm{I}_{3}$. A conversão do espaço RGB para outros espaços de cor é dada pelas equações apresentadas na Seção 2.2.

Todos os histogramas foram calculados quantizando cada canal dos espaços de cor em 10 valores $\left(\mathrm{N}_{\mathrm{val}}=10\right)$. As 30 frequências provenientes dos histogramas dos canais de um mesmo espaço de cor foram utilizadas como vetor de característica para classificar os grãos. Ou seja, 12 conjuntos de atributos foram avaliados, um para cada espaço de cor. A avaliação de cada conjunto de atributos se deu pelo método da validação cruzada com 10 folds, utilizando as instâncias do banco de amostras para derivar os atributos e adotando redes neurais PMC como classificadores, conforme a configuração apresentada na Seção 3.5.

Nesta avaliação preliminar dos atributos foram utilizadas somente classes caracterizadas por sua cor. Das classes apresentadas na Figura 21 foram selecionadas 17 com essa característica: perfeito, pedra, melado, branco, concha, casca, preto-verde, barrento, coco, preto, pau, ardido, marinheiro, brocado, velho, verde e casca de marinheiro. E visto que o par de classes coco e casca representam essencialmente a mesma classe no que diz respeito à cor, já que ambos têm a mesma composição externa, porém com interiores diferentes, sendo diferenciáveis somente por forma, essas duas classes foram condensadas em uma só. A mesma situação é observada com as classes marinheiro e casca de marinheiro, as quais também foram englobadas em uma classe só. Portanto, apenas as classes 'cabeça', 'triângulo', 'chocho' e ‘quebrado' foram excluídas e 15 classes foram utilizadas na avaliação, que foi promovida com 12.537 amostras.

Os resultados das avaliações são apresentados na Tabela 3, com o melhor desempenho destacado. Esses resultados serão melhor discutidos na Seção 4.1. 
Tabela 3 - Acurácias para cada espaço de cor, das classificações utilizando histogramas de frequências normalizadas das cores do grão como vetor de características

\begin{tabular}{cc}
\hline Espaço de Cor & Acurácia (\%) \\
\hline RGB & 69,92 \\
$\mathrm{HSV}$ & 74,33 \\
$\mathrm{YCbCr}$ & 69,93 \\
YCgCr & 67,06 \\
$\mathrm{YIQ}$ & 68,98 \\
$\mathrm{YPbPr}$ & 69,87 \\
$\mathrm{YUV}$ & 69,79 \\
$\mathrm{YDbDr}$ & 69,88 \\
$\mathrm{CIE} \mathrm{XYZ}$ & 58,63 \\
$\mathrm{CIELAB}$ & 74,23 \\
rgb & 63,71 \\
$\mathrm{I}_{1} \mathrm{I}_{2} \mathrm{I}_{3}$ & 70,99 \\
\hline
\end{tabular}

\subsubsection{Atributos Estatísticos de Histogramas}

A fim de se melhorar a etapa de classificação por cor, avaliou-se o uso de outros atributos em um novo experimento. Acreditando que as informações de cor estavam muito dispersas pelas frequências dos histogramas, e que uma técnica para condensá-las em um menor número de atributos poderia melhorar a acurácia, optou-se por extrair atributos estatísticos dos histogramas e utilizá-los como descritores. Os atributos utilizados foram: média, variância, obliquidade, curtose, energia, entropia e suavidade. A forma de calculá-los é apresentada pelas equações abaixo.

Tendo um histograma dividido em I intervalos, e sendo $F(i) \in[0,1]$ a frequência normalizada associada ao intervalo i, calculamos seus atributos estatísticos como abaixo (MALIK; BAHARUDIN, 2013):

$$
\begin{gathered}
\text { Média }=\sum_{i=1}^{I} i F(i) \\
\text { Desvio Padrão }=\sqrt{\sum_{i=1}^{I}(i-M e ́ d i a)^{2} F(i)}
\end{gathered}
$$




$$
\begin{gathered}
\text { Obliquidade }=\frac{1}{(\text { Desvio Padrão })^{3}} \sum_{i=1}^{I}(i-\text { Média })^{3} F(i) \\
\text { Curtose }=\frac{1}{(\text { Desvio Padrão })^{4}} \sum_{i=1}^{I}(i-\text { Média })^{4} F(i) \\
\text { Energia }=\sum_{i=1}^{I}(F(i))^{2} \\
\text { Entropia }=-\sum_{i=1}^{I}\left[F(i) \log _{2} F(i)\right] \\
\text { Suavidade }=1-\frac{1}{1+(\text { Desvio Padrão })^{2}}
\end{gathered}
$$

Analisando os resultados da Tabela 3, nota-se três espaços de cor que se destacaram positivamente - HSV, CIELAB e $\mathrm{I}_{1} \mathrm{I}_{2} \mathrm{I}_{3}$ - e dois que se destacaram negativamente - rgb e CIE XYZ. O restante apresentou resultados razoáveis e muito parecidos. Então, para avaliar o segunda abordagem de atributos de cor, foram escolhidos os três espaços que se destacaram positivamente e um dos que apresentaram resultados medianos, o RGB. Assim, para esta nova avaliação foram utilizados os espaços de cor HSV, CIELAB e $\mathrm{I}_{1} \mathrm{I}_{2} \mathrm{I}_{3}$ e RGB.

Cada um dos sete atributos estatísticos foi calculado para cada um dos canais dos quatro espaços de cor. Os atributos foram extraídos de histogramas de 100 intervalos $(I=100)$, os quais foram calculados quantizando os espaços de cor segundo a Equação (3.6) para $\mathrm{N}_{\text {val }}=100$. Todos os atributos extraídos foram utilizados em conjunto como vetor de características, o qual contou, portanto, com 84 elementos. Esse vetor de características foi submetido à mesma avaliação que os vetores formados por histogramas, pela validação cruzada com 10 folds e redes PMC. As mesmas classes e o mesmo banco de amostras foram utilizados.

O resultado dessa avaliação proporcionou uma acurácia de 80,09\%, enquanto que a melhor classificação, também sob o critério da validação cruzada, utilizando histogramas de frequências normalizadas, teve a acurácia de 74,33\%. 


\subsubsection{Atributos de Cor Selecionados}

Pelos resultados apresentados, nota-se que um considerável ganho de acurácia foi obtido pela abordagem da extração de atributos estatísticos em relação a utilização dos histogramas diretamente, e assim, os atributos selecionados para a análise de cor, e para posterior seleção de atributos, foram os 84 atributos estatísticos: média, variância, obliquidade, curtose, energia, entropia e suavidade extraídos de cada um dos histogramas (com 100 intervalos cada) dos canais dos espaços de cor HSV, CIELAB e $\mathrm{I}_{1} \mathrm{I}_{2} \mathrm{I}_{3}$ e RGB.

Esses 84 atributos foram calculados para cada uma das amostras do banco de amostras e os valores foram armazenados no Bancoc.

\subsubsection{Atributos de Textura}

Para se definir os atributos a serem utilizados na análise de textura avaliaram-se os descritores de Haralick calculados para diferentes espaços de cor. A fim de se obter melhores resultados uma modificação nesses descritores foi proposta. Os resultados foram comparados e então definiu-se o conjunto de atributos para a análise.

\subsubsection{Descritores de Haralick}

Primeiramente avaliaram-se os descritores de Haralick como vetor de características para a análise por textura. Assim, como foi feito para os atributos de cor, vários espaços de cor foram avaliados. Os descritores de Haralick foram calculados com suas GLCMs sendo computadas em relação a todos os pixels de um grão. Os quatro possíveis ângulos de vizinhança $\left(\theta=0^{\circ}, 45^{\circ}\right.$, $90^{\circ}$ e $135^{\circ}$ ) foram utilizados ao mesmo tempo para o cálculo da mesma GLCM, com a distância do pixel vizinho sendo $d=1$. Os cálculos foram feitos com os pixels tendo 32 valores diferentes $\left(\mathrm{N}_{\mathrm{NC}}=32\right)$, sendo que esses valores não necessariamente representam níveis de cinza, mas diferentes valores de um canal do espaço de cor. A quantização dos espaços de cor, para que cada canal tenha 32 valores, foi feita pela aplicação da Equação (3.6) com $\mathrm{N}_{\mathrm{val}}=32$.

Foram avaliados os seguintes espaços de cor para o cálculo dos descritores: RGB, RGB normalizado (rgb), $\mathrm{I}_{1} \mathrm{I}_{2} \mathrm{I}_{3}$, HSV e CIELAB. Além destes foi avaliado o espaço de cor de níveis 
de cinza, o qual possui apenas um canal, e pode ser calculado dos valores RGB pela Equação (3.15).

$$
\mathrm{C}=0,29894 \mathrm{R}+0,58704 \mathrm{G}+0,11402 \mathrm{~B}
$$

Para cada um dos espaços de cor foram avaliados 4 vetores de característica:

$$
\begin{gathered}
v_{1}^{E}=\{14 \text { descritores de Haralick do canal } 1 \text { de E }\} \\
v_{2}^{E}=\{14 \text { descritores de Haralick do canal } 2 \text { de E }\} \\
v_{3}^{E}=\{14 \text { descritores de Haralick do canal } 3 \text { de E }\} \\
v_{4}^{E}=v_{1}^{E} \cup v_{2}^{E} \cup v_{3}^{E}
\end{gathered}
$$

Sendo E um espaço de cor. Excepcionalmente para espaço de cor de níveis de cinza apenas o vetor $v_{1}^{E}$ foi avaliado, já que ele conta apenas com um canal.

Do mesmo modo pelo qual foram avaliados os atributos de cor, foram avaliados os descritores de Haralick: pelo método da validação cruzada com 10 folds, com o uso de redes PMC. O mesmo banco de amostras foi utilizado para calcular os descritores e as mesmas classes foram definidas. $\mathrm{O}$ resultado das avaliações é apresentado na Tabela 4.

Tabela 4 - Acurácias (em \%), para cada vetor de características avaliado, das classificações utilizando descritores de Haralick

\begin{tabular}{ccccc}
\hline $\mathbf{E}$ & $\boldsymbol{v}_{\mathbf{1}}^{\boldsymbol{E}}$ & $\boldsymbol{v}_{\mathbf{2}}^{\boldsymbol{E}}$ & $\boldsymbol{v}_{\mathbf{3}}^{\boldsymbol{E}}$ & $\boldsymbol{v}_{\mathbf{4}}^{\boldsymbol{E}}$ \\
\hline CIELAB & $\mathrm{L}: 45,98$ & $\mathrm{a}^{*}: 56,13$ & $\mathrm{~b}^{*}: 47,28$ & 59,81 \\
HSV & $\mathrm{H}: 45,38$ & $\mathrm{~S}: 38,57$ & $\mathrm{~V}: 23,59$ & 53,66 \\
rgb & r: 59,01 & $\mathrm{~g}: 64,54$ & $\mathrm{~b}: 61,62$ & 78,95 \\
RGB & $\mathrm{R}: 58,34$ & $\mathrm{G}: 60,54$ & $\mathrm{~B}: 59,89$ & 79,08 \\
$\mathrm{I}_{1} \mathrm{I}_{2} \mathrm{I}_{3}$ & $\mathrm{I}_{1}: 59,02$ & $\mathrm{I}_{2}: 65,07$ & $\mathrm{I}_{3}: 62,14$ & 80,98 \\
Níveis de & $\mathrm{C}: 60,11$ & - & - & - \\
Cinza & & & & \\
\hline
\end{tabular}




\subsubsection{Modificação dos Descritores de Haralick}

Com o intuito de se realizar uma análise de macrotextura de imagens, modificaram-se os descritores de Haralick para utilizar dois pixels de referência, ao invés de um, no cálculo da GLCM. O segundo pixel de referência é tido como aquele posicionado logo abaixo do primeiro pixel de referência, como ilustrado na Figura 25.

\begin{tabular}{|l|l|l|}
\hline PV_8 & PV_9 & PV_0 \\
\hline PV_7 & PR_1 & PV_1 \\
\hline PV_6 & PR_2 & PV_2 \\
\hline PV_5 & PV_4 & PV_3 \\
\hline
\end{tabular}

Figura 25 - Utilização de dois pixels de referência para o cálculo da GLCM Sendo PR_1 o primeiro pixel de referência e PR_2 o segundo

Portanto, a GLCM passa a ser uma matriz de três dimensões, sendo a primeira dimensão o valor do pixel de referência 1 (PR_1), a segunda o valor do pixel de referência 2 (PR_2), e a terceira o pixel vizinho (PV). Dessa forma, o elemento $\boldsymbol{V}_{\boldsymbol{i}, \boldsymbol{j}, \boldsymbol{k}}$ da GLCM indica quantas ocorrências de PR_1 com nível de cinza i, tendo PR_2 com nível de cinza $\mathbf{j}$ e tendo um PV que apresenta nível de cinza $\mathbf{k}$ há na imagem. A Figura 26 ilustra uma GLCM para dois pixels de referência para uma imagem em preto e branco (com 2 níveis de cinza). 


\begin{tabular}{|c|c|c|c|c|c|}
\hline \multirow{2}{*}{\multicolumn{2}{|c|}{$\frac{V^{\text {VPR1* }}{ }^{->}}{\text {VPR2* }}$}} & \multicolumn{2}{|c|}{0} & \multicolumn{2}{|c|}{1} \\
\hline & & 0 & 1 & 0 & 1 \\
\hline$\frac{\grave{\jmath}}{\mathrm{O}}$ & 0 & $\mathrm{~V}(0,0,0)$ & $V(0,1,0)$ & $\mathrm{V}(1,0,0)$ & $V(1,1,0)$ \\
\hline$\frac{\text { N. }}{\frac{N}{\bar{V}}}$ & 1 & $\mathrm{~V}(0,0,1)$ & $\mathrm{V}(0,1,1)$ & $V(1,0,1)$ & $V(1,1,1)$ \\
\hline
\end{tabular}

Figura 26 - GLCM para 2 níveis de cinza utilizando a abordagem de dois pixels de referência.

* VPR1: Valor do pixel de referência 1; VPR2: Valor do pixel de referência 2

A normalização da GLCM em probabilidades $\boldsymbol{P}_{\boldsymbol{i}, \boldsymbol{j}, \boldsymbol{k}}$ é dada, então, segundo a equação (3.16), para $\mathrm{N}_{\mathrm{NC}}$ níveis de cinza.

$$
P_{i, j, k}=\frac{V_{i, j, k}}{\sum_{p=0}^{N_{N C}-1} \sum_{q=0}^{N_{N C}-1} \sum_{r=0}^{N_{N C}-1} V_{p, q, r}}
$$

Uma peculiaridade que surge quando tomamos dois pixels como referência é que deixa-se de ter uma simetria radial dos pixels vizinhos em relação à referência. Para o caso de um único pixel de referência, a ocorrência de um pixel vizinho na posição $\left(\mathrm{d}=\mathrm{d}_{0}\right.$ e $\left.\theta=0^{\circ}\right)$ com nível de cinza $\mathbf{x}$ e a ocorrência de outro pixel vizinho na posição $\left(d=d_{0}\right.$ e $\left.\theta=45^{\circ}\right)$ com o mesmo nível de cinza $\mathbf{x}$ representam a mesma relação entre pixel de referência e pixel vizinho, porém vistos de perspectivas diferentes (com uma rotação de $45^{\circ}$, neste caso), como se vê na Figura 27a. O mesmo não ocorre quando dois pixels são tomados como referência, pois ocorrências do mesmo nível de cinza em posições diferentes podem representar relações que não diferem por uma simples rotação, como fica claro na Figura 27b. Ainda assim, pode-se estabelecer relações de simetria em três configurações diferentes: para pixels vizinhos em posições diagonais em relação aos pixels de referência, para pixels vizinhos em posições horizontais em relação aos pixels de referência, e para pixels vizinhos em posições verticais em relação aos pixels de referência. Essas três configurações são mostradas na Figura 28. Sendo assim, podem ser calculadas três GLCMs, uma para cada uma dessas configurações. São definidas, então, três GLCMs: diagonal, vertical e horizontal, cujos elementos são definidos, respectivamente, como $V_{i, j, k}^{D}, V_{i, j, k}^{V}$ e $V_{i, j, k}^{H}$. 


\begin{tabular}{|c|c|c|}
\hline $\begin{array}{c}\mathrm{PV}_{3} \\
\left(d=1, \theta=135^{\circ}\right)\end{array}$ & $\begin{array}{c}\mathrm{PV}_{2} \\
\left(d=1, \theta=90^{\circ}\right)\end{array}$ & $\begin{array}{c}\mathrm{PV}_{1} \\
\left(\mathrm{~d}=1, \theta=45^{\circ}\right)\end{array}$ \\
\hline $\begin{array}{c}P V_{4} \\
\left(d=1, \theta=0^{\circ}\right)\end{array}$ & $\mathrm{PR}$ & $\begin{array}{c}\mathrm{PV}_{0} \\
\left(d=1, \theta=0^{\circ}\right)\end{array}$ \\
\hline $\begin{array}{c}\mathrm{PV}_{5} \\
\left(d=1, \theta=45^{\circ}\right)\end{array}$ & $\begin{array}{c}\left(\mathrm{PV}=1, \theta=90^{\circ}\right) \\
\left(d=1, \theta=135^{\circ}\right)\end{array}$ \\
\hline
\end{tabular}

\begin{tabular}{|c|c|c|}
\hline $\begin{array}{c}\mathrm{PV}_{3} \\
\left(d=1, \theta=135^{\circ}\right)\end{array}$ & $\begin{array}{c}\mathrm{PV}_{2} \\
\left(d=1, \theta=90^{\circ}\right)\end{array}$ & $\begin{array}{c}\mathrm{PV}_{1} \\
\left(d=1, \theta=45^{\circ}\right)\end{array}$ \\
\hline $\begin{array}{c}P V_{4} \\
\left(d=1, \theta=0^{\circ}\right)\end{array}$ & $\mathrm{PR}$ & $\begin{array}{c}\mathrm{PV}_{0} \\
\left(d=1, \theta=0^{\circ}\right)\end{array}$ \\
\hline $\begin{array}{c}P V_{5} \\
\left(d=1, \theta=45^{\circ}\right)\end{array}$ & $\mathrm{PV}_{6}$ & $\begin{array}{c}\mathrm{PV}_{7} \\
\left(\mathrm{~d}=1, \theta=90^{\circ}\right)\end{array}$ \\
$\left(\mathrm{d}=1, \theta=135^{\circ}\right)$ \\
\hline
\end{tabular}

a)

\begin{tabular}{|c|c|c|}
\hline PV_8 & PV_9 & PV_0 \\
\hline PV_7 & PR_1 & PV_1 \\
\hline PV_6 & PR_2 & PV_2 \\
\hline PV_5 & PV_4 & PV_3 \\
\hline
\end{tabular}

\begin{tabular}{|c|c|c|}
\hline PV_8 & PV_9 & PV_0 \\
\hline PV_7 & PR_1 & PV_1 \\
\hline PV_6 & PR_2 & PV_2 \\
\hline PV_5 & PV_4 & PV_3 \\
\hline
\end{tabular}

b)

Figura 27 - Comparação de simetrias no cálculo das GLCM.

Simetria radial presente em a), mas ausente em b)

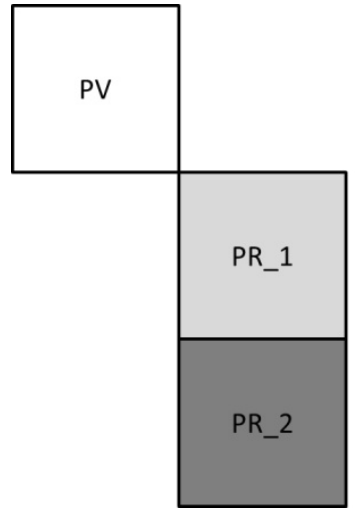

a)

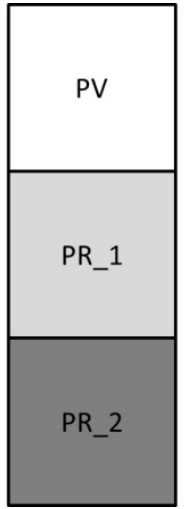

b)

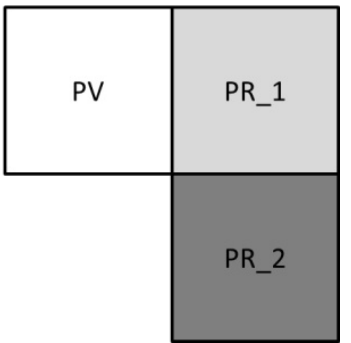

c)

Figura 28 - As três configurações de simetria para a GLCM utilizando dois pixels de referência. a) diagonal b) vertical e c) horizontal 
Tomando como referência a Figura 25, a GLCM diagonal é computada para os pixels vizinhos PV_0, PV_3, PV_5 e PV_8; a GLCM vertical é computada para os pixels vizinhos PV_4, e PV_9; e a GLCM horizontal é computada para os pixels vizinhos PV_1, PV_2, PV_6 e PV_7. A Figura 29 ilustra a simetria para a configuração diagonal. Deve-se atentar que para certos pixels vizinhos, os pixels de referência aparecem invertidos em relação às configurações apresentadas na Figura 28, como pode ser observado na Figura 29, e esta inversão deve ser levada em conta na atualização da GLCM.


Figura 29 - Simetria diagonal para os pixels PV_8, PV_0, PV_3 e PV_5

Portanto, a Tabela 5 mostra para cada um dos pixels vizinhos, como é feita a atualização das GLCMs.

Tabela 5 - Atualização da GLCM para cada posição do pixel vizinho

Para pixel de referência 1 com nível de cinza i, pixel de referência 2 com nível de cinza j e pixel vizinho com nível de cinza $k$

\begin{tabular}{cc||cc||cc}
\hline Pixel Vizinho & $\begin{array}{c}\text { Elemento a } \\
\text { ser } \\
\text { incrementado }\end{array}$ & Pixel Vizinho & $\begin{array}{c}\text { Elemento a } \\
\text { ser } \\
\text { incrementado }\end{array}$ & Pixel Vizinho & $\begin{array}{c}\text { Elemento a } \\
\text { ser } \\
\text { incrementado }\end{array}$ \\
\hline$P V_{-} 0$ & $V_{i, j, k}^{D}$ & $P V_{-} 1$ & $V_{i, j, k}^{H}$ & $P V_{-} 9$ & $V_{i, j, k}^{V}$ \\
$P V_{-} 8$ & $P V_{-} 7$ & & & \\
& & & & & \\
$P V_{-} 3$ & $V_{j, i, k}^{D}$ & $P V_{-} 2$ & $V_{j, i, k}^{H}$ & & $V_{j, i, k}^{V}$ \\
$P V_{-} 5$ & & & & \\
\hline
\end{tabular}


Havendo três GLCMs diferentes, a modificação proposta gera 42 descritores (14 para cada uma das matrizes). Os cálculos dos descritores também devem ser modificados para poderem comportar a nova abordagem. Os 14 descritores (de $f_{1}$ a $f_{14}$ ) foram definidos conforme as equações abaixo, com $\mathrm{N}_{\mathrm{NC}}$ sendo o número de níveis de cinza da imagem.

$$
\begin{aligned}
& P_{x}(i, j)=\sum_{k=0}^{N_{N C}-1} P_{i, j, k} \\
& P_{y}(k)=\sum_{i=0}^{N_{N C^{-1}}} \sum_{j=0}^{N_{N C^{-1}}} P_{i, j, k} \\
& P_{x+y}(a, b)=\sum_{i=1}^{N_{N C}} \sum_{j=1}^{N_{N C}} \sum_{k=1}^{N_{N C}} P_{i, j, k}, \\
& \left\{\begin{array}{c}
i+k=a \\
j+k=b \\
a=2, \ldots, 2 N_{N C} \\
b=2, \ldots, 2 N_{N C}
\end{array}\right. \\
& P_{x-y}(a, b)=\sum_{i=1}^{N_{N C}} \sum_{j=1}^{N_{N C}} \sum_{k=1}^{N_{N C}} P_{i, j, k}, \\
& \left\{\begin{array}{c}
|i-k|=a \\
|j-k|=b \\
a=0, \ldots, N_{N C}-1 \\
b=0, \ldots, N_{N C}-1
\end{array}\right. \\
& \text { segundo momento angular }=f_{1}=\sum_{i=0}^{N_{N C^{-1}}} \sum_{j=0}^{N_{N C^{-1}}} \sum_{k=0}^{N_{N C^{-1}}} P_{i, j, k}{ }^{2} \\
& \text { contraste }=f_{2}=\sum_{i=0}^{N_{N C}-1} \sum_{j=0}^{N_{N C}-1}\left(i^{2}+j^{2}\right) P_{x-y}(i, j) \\
& \text { correlação }=f_{3}=\frac{r_{a b}-r_{a c} r_{b c}}{\sqrt{\left(1-r_{a c}^{2}\right)\left(1-r_{b c}^{2}\right)}}
\end{aligned}
$$

Onde 


$$
\begin{gathered}
P_{a}(i)=\sum_{j=0}^{N_{N C}-1} \sum_{k=0}^{N_{N C}-1} P_{i, j, k} \\
P_{b}(j)=\sum_{i=0}^{N_{N C}-1} \sum_{k=0}^{N_{N C}-1} P_{i, j, k} \\
P_{c}(k)=\sum_{i=0}^{N_{N C}-1} \sum_{j=0}^{N_{N C^{-1}}} P_{i, j, k} \\
r_{a b} \frac{\sum_{i=0}^{N_{N C}-1}\left(P_{a}(i)-\mu_{a}\right)\left(P_{b}(i)-\mu_{b}\right)}{\sigma_{a} \sigma_{b}} \\
r_{a c} \frac{\sum_{i=0}^{N_{N C}-1}\left(P_{a}(i)-\mu_{a}\right)\left(P_{c}(i)-\mu_{c}\right)}{\sigma_{a} \sigma_{c}} \\
r_{b c} \frac{\sum_{i=0}^{N_{N C}-1}\left(P_{b}(i)-\mu_{b}\right)\left(P_{c}(i)-\mu_{c}\right)}{\sigma_{b} \sigma_{c}}
\end{gathered}
$$

Sendo $\mu_{a}, \mu_{b}$ e $\mu_{c}$ as médias de $P_{a}, P_{b}$ e $P_{c}$, respectivamente, e $\sigma_{a}, \sigma_{b}$ e $\sigma_{c}$ as variâncias de $P_{a}, P_{b}$ e $P_{c}$, respectivamente.

$$
\text { variância }=f_{4}=\sum_{i=0}^{N_{N C}-1} \sum_{j=0}^{N_{N C^{-1}}} \sum_{k=0}^{N_{N C}-1}\left(|i-j|-\mu_{d i f}\right)^{2} P_{i, j, k}
$$

Onde $\mu_{d i f}$ é a média da diferença entre níveis de cinza do pixel de referência 1 e o pixel de referência 2.

$$
\begin{gathered}
\text { momento inverso da diferença }=f_{5}=\sum_{i=0}^{N_{N C^{-1}}} \sum_{j=0}^{N_{N C^{-1}}} \sum_{k=0}^{N_{N C^{-1}}} \frac{P_{i, j, k}}{\left(1+(i-k)^{2}+(j-k)^{2}\right)} \\
\text { média da soma }=f_{6}=\sum_{i=0}^{2 N_{N C}-1} \sum_{j=0}^{2 N_{N C^{-1}}}(i+j) P_{x+y}(i, j)
\end{gathered}
$$




$$
\begin{gathered}
\text { variância da soma }=f_{7}=\sum_{i=0}^{2 N_{N C^{-1}}} \sum_{j=0}^{2 N_{N C^{-1}}}\left(i+j-f_{8}\right)^{2} P_{x+y}(i, j) \\
\text { entropia da soma }=f_{8}=-\sum_{i=0}^{2 N_{N C^{-1}}} \sum_{j=0}^{2 N_{N C^{-1}}} P_{x+y}(i, j) \log \left(P_{x+y}(i, j)+\varepsilon\right)
\end{gathered}
$$

,sendo $\varepsilon$ um número positivo pequeno, para evitar a ocorrência da indefinição $\log (0)$.

$$
\text { entropia }=f_{9}=-\sum_{i=0}^{N_{N C^{-1}}} \sum_{j=0}^{N_{N C^{-1}}} \sum_{k=0}^{N_{N C^{-1}}} P_{i, j, k} \log \left(P_{i, j, k}+\epsilon\right)
$$

$$
\text { diferença da variância }=f_{10}=\text { variância de } P_{x-y}
$$

$$
\text { entropia da diferença }=f_{11}=-\sum_{i=0}^{N_{N C^{-1}}} \sum_{j=0}^{N_{N C^{-1}}} P_{x-y}(\mathrm{i}, \mathrm{j}) \log \left(P_{x-y}(\mathrm{i}, \mathrm{j})+\epsilon\right)
$$

$$
\text { medida de correlação } 1=f_{12}=\frac{f_{9}-H X Y 1}{\max \{H X, H Y\}}
$$

$$
\text { medida de correlação } 2=f_{13}=\sqrt{1-e^{-2\left(H X Y 2-f_{9}\right)}}
$$

Sendo

$$
\begin{gathered}
\mathrm{HX}=-\sum_{i=0}^{N_{N C}-1} \sum_{j=0}^{N_{N C^{-1}}} P_{x}(\mathrm{i}, \mathrm{j}) \log \left(P_{x}(\mathrm{i}, \mathrm{j})+\epsilon\right) \\
\mathrm{HY}=-\sum_{i=0}^{N_{N C}-1} \sum_{j=0}^{N_{N C^{-1}}} P_{y}(\mathrm{i}) \log \left(P_{y}(\mathrm{i})+\epsilon\right) \\
\mathrm{HXY1}=-\sum_{i=0}^{N_{N C}-1} \sum_{j=0}^{N_{N C}-1} \sum_{k=0}^{N_{N C}-1} P_{i, j, k} \log \left(P_{x}(i, j) P_{y}(k)+\epsilon\right)
\end{gathered}
$$




$$
\mathrm{HXY} 2=-\sum_{i=0}^{N_{N C^{-1}}} \sum_{j=0}^{N_{N C^{-1}}} \sum_{k=0}^{N_{N C^{-1}}} P_{x}(i, j) P_{y}(\mathrm{k}) \log \left(P_{x}(i, j) P_{y}(k)+\epsilon\right)
$$

Na proposta original de Haralick o descritor de máximo coeficiente de correlação $\left(f_{14}\right)$ exige o cálculo dos autovalores da matriz de coocorrência. Para evitar se calcular autovalores em uma matriz de três dimensões, cuja abstração não é trivial, somente o pixel de referência 1 é utilizado em seu cálculo:

$$
\begin{gathered}
\text { máximo coeficiente de correlação }=f_{14}=(\text { segundo maior autovalor de } Q)^{\frac{1}{2}} \\
Q_{i, k}=\frac{P_{i, j}^{P R 1} P_{k, j}^{P R 1}}{P_{x}^{P R 1}(i) P_{y}(k)}
\end{gathered}
$$

Onde:

$$
\begin{gathered}
P_{i, k}^{P R 1}=\sum_{j=0}^{N_{N C^{-1}}} P_{i, j, k} \\
P_{x}^{P R 1}(i)=\sum_{j=0}^{N_{N C^{-1}}} \sum_{k=0}^{N_{N C^{-1}}} P_{i, j, k}
\end{gathered}
$$

Para se avaliar os efeitos da modificação, os descritores de Haralick calculados com dois pixels de referência foram submetidos aos mesmos procedimentos utilizados para avaliar os descritores de Haralick originais, conforme descrito anteriormente nesta seção. Desta vez foram avaliado três espaços de cor: RGB, $I_{1} I_{2} I_{3}$ e níveis de cinza. Sendo que os dois primeiros foram os que obtiveram os melhores resultados para os descritores de Haralick com um pixel de referência e o último é o espaço abordado pela concepção original dos descritores. Os resultados obtidos são apresentados e comparados com os respectivos valores dos descritores originais na Tabela 6 (o melhor deles aparece destacado). Uma análise sobre esses resultados será realizada na Seção 4.2. 
Tabela 6 - Acurácias (em \%), para cada vetor de características avaliado, das classificações utilizando descritores de Haralick com 2 pixels de referência. Comparadas com as respectivas acurácias dos descritores calculados com 1

\begin{tabular}{cccccc}
\multicolumn{6}{c}{ pixel de referência } \\
\hline Método & $\mathbf{E}$ & $\boldsymbol{v}_{\mathbf{1}}^{\boldsymbol{E}}$ & $\boldsymbol{v}_{\mathbf{2}}^{\boldsymbol{E}}$ & $\boldsymbol{v}_{\mathbf{3}}^{\boldsymbol{E}}$ & $\boldsymbol{v}_{\mathbf{4}}^{\boldsymbol{E}}$ \\
\hline 1 pixel & $\mathrm{RGB}$ & $\mathrm{R}: 58,34$ & $\mathrm{G}: 60,54$ & $\mathrm{~B}: 59,89$ & 79,08 \\
2 pixels & $\mathrm{RGB}$ & $\mathrm{R}: 59,14$ & $\mathrm{G}: 60,68$ & $\mathrm{~B}: 59,10$ & 80,02 \\
1 pixel & $\mathrm{I}_{1} \mathrm{I}_{2} \mathrm{I}_{3}$ & $\mathrm{I}_{1}: 59,02$ & $\mathrm{I}_{2}: 65,07$ & $\mathrm{I}_{3}: 62,14$ & 80,98 \\
2 pixels & $\mathrm{I}_{1} \mathrm{I}_{2} \mathrm{I}_{3}$ & $\mathrm{I}_{1}: 61,35$ & $\mathrm{I}_{2}: 64,87$ & $\mathrm{I}_{3}: 63,92$ & 82,32 \\
1 pixel & Níveis de cinza & 60,11 & - & - & - \\
2 pixels & Níveis de cinza & 61,73 & - & - & - \\
\hline
\end{tabular}

\subsubsection{3. $\quad$ Atributos de Textura Selecionados}

Constata-se que a modificação proposta superou a original em 7 das 9 classificações, ainda que de forma singela, conferindo a melhor classificação para análise de textura quando empregada sobre o espaço de cor $I_{1} I_{2} I_{3}$. Sendo assim, os atributos selecionados para compor a análise de textura foram os descritores de Haralick computados com 2 pixels de referência calculados para cada um dos canais do espaço de cor $I_{1} I_{2} I_{3}$, num total de 126 atributos.

Os 126 atributos foram calculados para cada uma das amostras do banco de amostras e os valores foram armazenados no Bancoт.

\subsection{Definição das Classes}

Na determinação dos atributos utilizados em cada uma das análises, as classificações foram realizadas incluindo somente as classes de grãos e objetos discrimináveis para cada etapa de análise. Por exemplo, a classe de grão quebrado foi omitida das classificações que determinaram os atributos da análise por cor, pois ela não é discriminável por sua coloração, mas sim por sua forma. No entanto, ao se realizar uma análise não se tem a informação de antemão se um objeto é pertencente a uma dessas classes omitidas. Dessa forma, o objeto deve ser classificado de acordo com os critérios da análise em questão (mesmo que esta classificação não determine sua classe real), e sua classe real deve ser determinada pela análise que tiver poder de discriminá-la (a análise morfológica, no caso, da classe ‘quebrado' citada no exemplo). Apesar de certas classes não serem discrimináveis por uma dada análise, amostras pertencentes 
a elas devem ter uma classificação esperada em tal análise, e a rede neural responsável por ela deve utilizar instancias dessas classes em seus treinamentos, a fim de evitar saídas inesperadas. A Tabela 7 relacionada quais classes são discrimináveis pelo aspecto avaliado em cada análise.

Tabela 7 - Relação das classes discrimináveis em cada análise

\begin{tabular}{|c|c|c|c|}
\hline Classe & $A_{M}$ & $A_{c}, A_{T}, A_{C T}$ & $\mathrm{~A}_{M C T}$ \\
\hline Perfeito & $\checkmark$ & $\checkmark$ & $\checkmark$ \\
\hline Ardido & & $\checkmark$ & $\checkmark$ \\
\hline Barrento & & $\checkmark$ & $\checkmark$ \\
\hline Branco & & $\checkmark$ & $\checkmark$ \\
\hline Brocado & & $\checkmark$ & $\checkmark$ \\
\hline Cabeça & $\checkmark$ & & $\checkmark$ \\
\hline Casca & $\checkmark$ & $\checkmark$ & $\checkmark$ \\
\hline Casca de marinheiro & $\checkmark$ & $\checkmark$ & $\checkmark$ \\
\hline Chocho & $\checkmark$ & & $\checkmark$ \\
\hline Coco & $\checkmark$ & $\checkmark$ & $\checkmark$ \\
\hline Concha & $\checkmark$ & $\checkmark$ & $\checkmark$ \\
\hline Marinheiro & & $\checkmark$ & $\checkmark$ \\
\hline Melado & & $\checkmark$ & $\checkmark$ \\
\hline Pau & $\checkmark$ & $\checkmark$ & $\checkmark$ \\
\hline Pedra & $\checkmark$ & $\checkmark$ & $\checkmark$ \\
\hline Preto & & $\checkmark$ & $\checkmark$ \\
\hline Preto Verde & & $\checkmark$ & $\checkmark$ \\
\hline Quebrado & $\checkmark$ & & $\checkmark$ \\
\hline Triângulo & $\checkmark$ & & $\checkmark$ \\
\hline Velho & & $\checkmark$ & $\checkmark$ \\
\hline Verde & & $\checkmark$ & $\checkmark$ \\
\hline
\end{tabular}

Dada esta situação, foi decidido fundir classes não discrimináveis com classes discrimináveis. Após a análise visual das amostras, determinou-se quais as classes aparentavam ser quase indistinguíveis entre si sob o aspecto avaliado por uma dada análise e essas classes foram fundidas. Por exemplo, é difícil distinguir as classes 'casca' e 'coco' ao se analisar somente sua cor e textura, já que elas são compostas pelo mesmo material. Então as classes 'casca' e 'coco' foram fundidas em uma só: $\overline{c a s c a}$. O resultado dessas fusões é apresentado na Tabela 8. A Tabela 9 mostra as classes definidas para cada uma das análises. 
Tabela 8 - Classes fundidas para cada análise

\begin{tabular}{|c|c|c|}
\hline Análises & $\begin{array}{l}\text { Classe } \\
\text { Fundida }\end{array}$ & Classes Originais \\
\hline $\mathrm{A}_{\mathrm{C}}, \mathrm{A}_{\mathrm{T}}, \mathrm{A}_{\mathrm{CT}}$ & $\overline{\text { Perfecto }}$ & $\{$ Perfeito, Cabeça, Chocho, Quebrado, Triângulo\} \\
\hline $\mathrm{A}_{\mathrm{C}}, \mathrm{A}_{\mathrm{T}}, \mathrm{A}_{\mathrm{CT}}$ & $\overline{\operatorname{Casca}}$ & $\{$ Casca, Coco $\}$ \\
\hline $\mathrm{A}_{\mathrm{C}}, \mathrm{A}_{\mathrm{T}}, \mathrm{A}_{\mathrm{CT}}$ & $\overline{\text { Marınhelro }}$ & $\{$ Marinheiro, Casca de Marinheiro $\}$ \\
\hline $\mathrm{A}_{\mathrm{M}}$ & Oval & $\begin{array}{c}\text { \{Ardido, Barrento, Branco, Coco, Marinheiro, Melado, Preto, Preto- } \\
\text { Verde, Velho, Verde, Perfeito }\}\end{array}$ \\
\hline $\mathrm{A}_{\mathrm{M}}$ & Irregular & \{Quebrado, Brocado, Casca, Casca de Marinheiro, Concha\} \\
\hline & & Tabela 9 - Classes de cada análise \\
\hline Análises & & Classes \\
\hline $\mathrm{A}_{\mathrm{C}}, \mathrm{A}_{\mathrm{T}}, \mathrm{A}_{\mathrm{CT}}$ & A Ardido, & $\begin{array}{l}\text { Barrento, Branco, Brocado, } \overline{\text { Casca }} \text {, Concha, } \overline{\text { Marınhelro }}, \text { Melado, Pau, } \\
\text { Pedra, } \overline{\text { Perfelto }} \text {, Preto, Preto-verde, Velho, Verde }\}\end{array}$ \\
\hline $\mathrm{A}_{\mathrm{M}}$ & & $\{$ Cabeça, Chocho, Irregular, Oval, Pau, Pedra, Triângulo $\}$ \\
\hline $\mathrm{A}_{\mathrm{MCT}}$ & $\begin{array}{l}\text { \{Ardido, } \mathrm{E} \\
\text { Coco, Conch }\end{array}$ & $\begin{array}{l}\text { arrento, Branco, Brocado, Cabeça, Casca, Casca de marinheiro, Chocho, } \\
\text {, Marinheiro, Melado, Pau, Pedra, Perfeito, Preto, Preto-verde, Quebrado, } \\
\text { Triângulo, Velho, Verde }\}\end{array}$ \\
\hline
\end{tabular}

Com a fusão das classes, houve um grande desbalanceamento no número de instâncias de cada classe, o que poderia acabar influenciando negativamente no treinamento das redes neurais e na avaliação dos resultados de classificações teste. Portanto, fez-se necessário um procedimento de balanceamento do número de instâncias por classes, tanto das classes fundidas, quanto das classes originais. Este procedimento consistiu em descartar amostras aleatoriamente, de modo que restasse somente o número esperado de instâncias por classe. A distribuição resultante, tanto do ponto de vista das classes originais, quanto do ponto de vista das classes fundidas, e da distribuição por peneiras (para os grãos perfeitos), é apresentada abaixo para os bancos de dados utilizados nas análises.

Após a execução do procedimento a situação do banco de dados de atributos morfológicos (Bancom) é apresentada nos Gráficos 3-6. A distribuição de amostras por classe é apresentada no Gráfico 3. A composição das amostras da classe fundida 'Ovalado' por classes originais é mostrada no Gráfico 4. A distribuição de peneiras nas amostras da classe 'Perfeito' é 
apresentada no Gráfico 5. No Gráfico 6 é dada a distribuição de amostras da classe fundida 'Irregular' pelas classes originais.

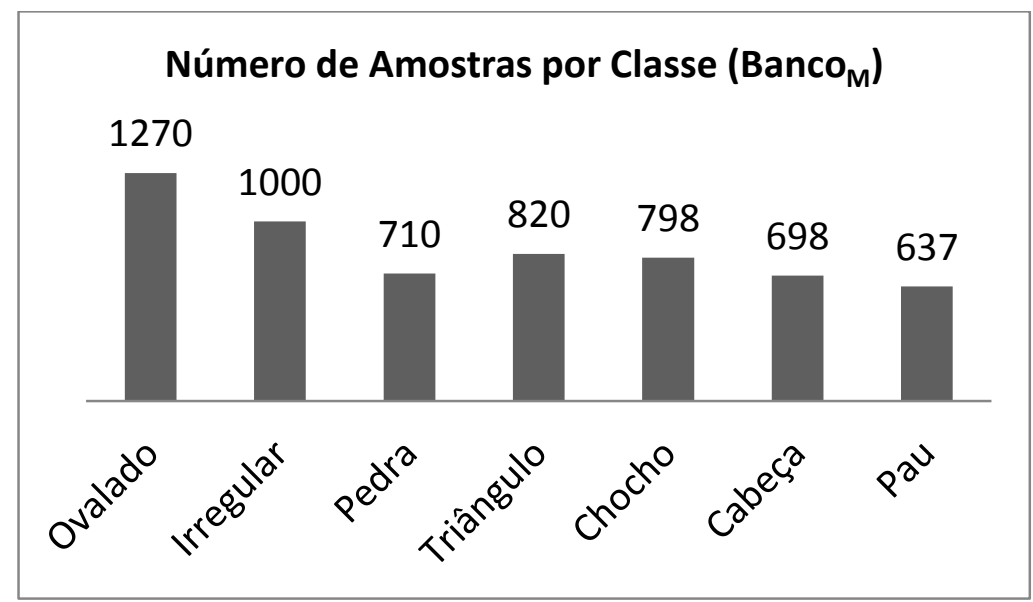

Gráfico 3 - Distribuição das amostras por classe, para o banco de atributos morfológicos

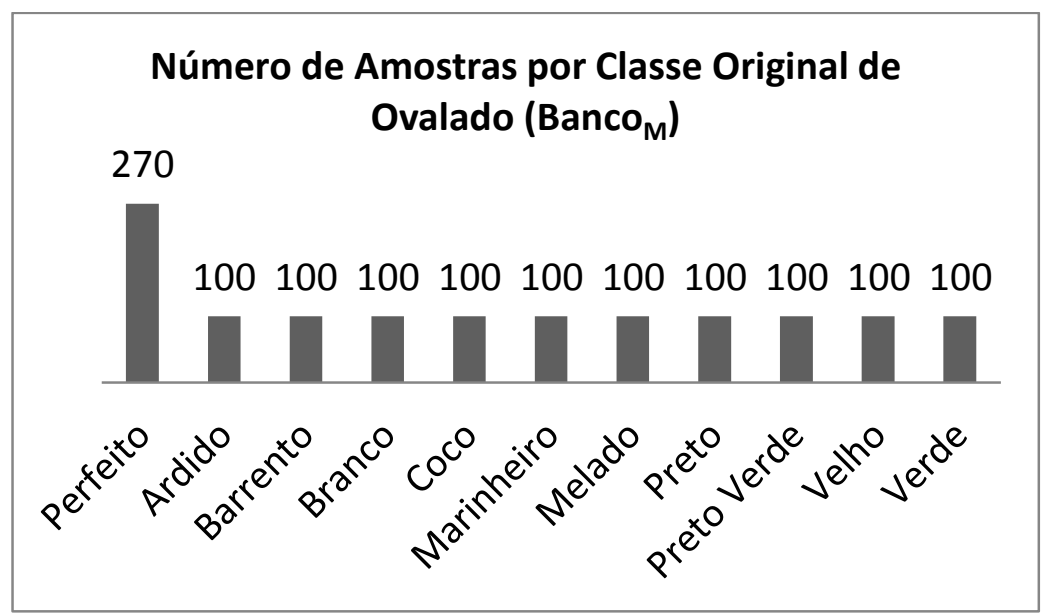

Gráfico 4 - Distribuição das amostras da classe Ovalado por classe original, para o banco de atributos morfológicos

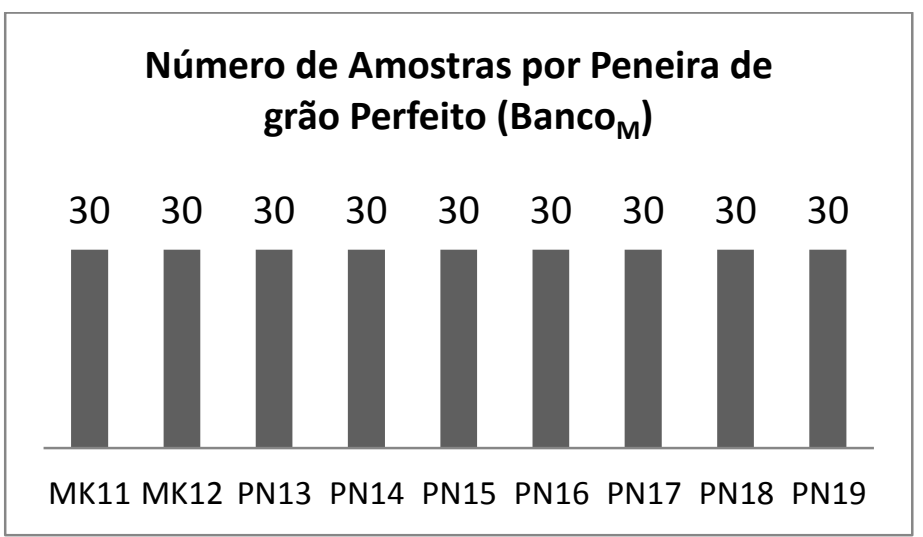

Gráfico 5 - Distribuição das amostras da classe Perfeito por peneira, para o banco de atributos morfológicos 


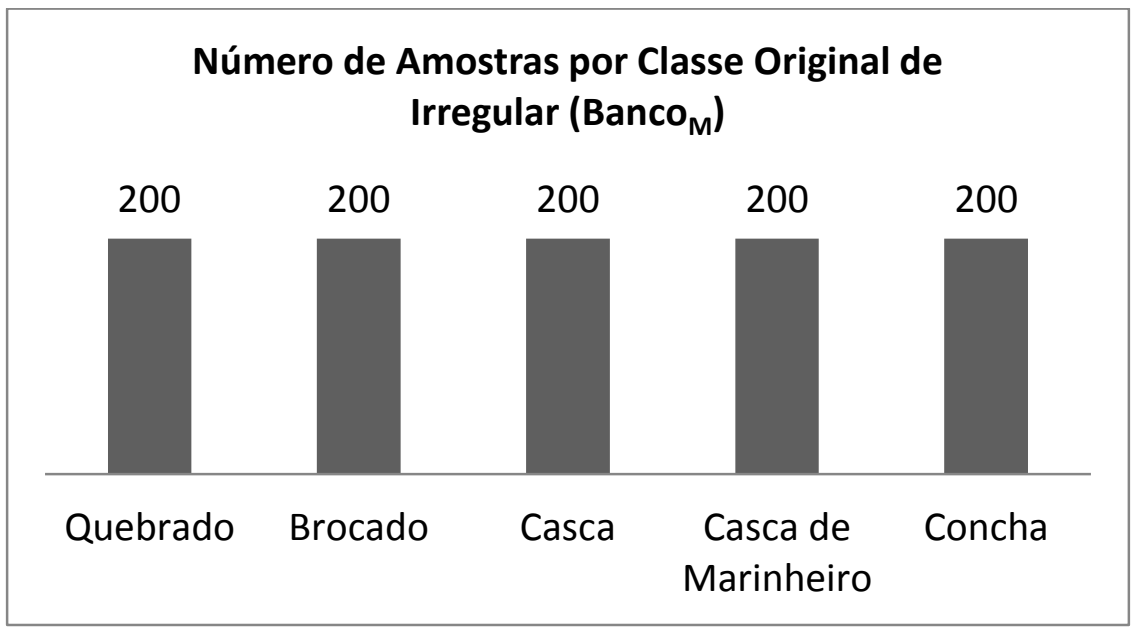

Gráfico 6 - Distribuição das amostras da classe Irregular por classe original, para o banco de atributos morfológicos

Os bancos de dados de atributos de cor $\left(\right.$ Banco $\left._{\mathrm{C}}\right)$, textura $\left(\right.$ Ваnсо $\left._{\mathrm{T}}\right)$ e cor-textura $\left(\right.$ Banco $\left._{\mathrm{CT}}\right)$ apresentaram a mesma distribuição de amostras, a qual é apresentada nos Gráficos 7-9. A distribuição de amostras por classe é apresentada no Gráfico 7. A composição das amostras da classe fundida ' $\overline{\text { Perfelto' }}$ ' pelas classes originais e por peneiras de grãos 'Perfeito' é mostrada no Gráfico 8. A composição das amostras das classes fundidas ' $\overline{\text { Marınhelro }}$ ' e ' $\overline{\text { Casca }}$ ' por classes originais é apresentada no Gráfico 9.

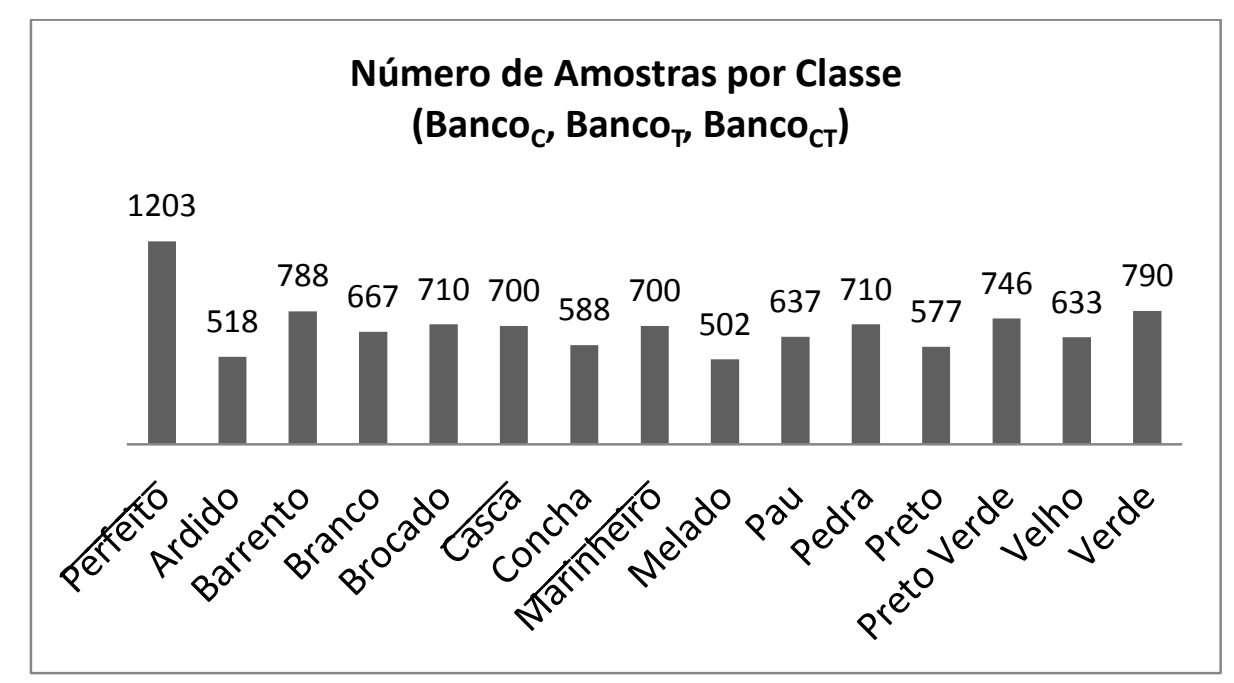

Gráfico 7 - Distribuição das amostras por classe, para os bancos de cor e textura 


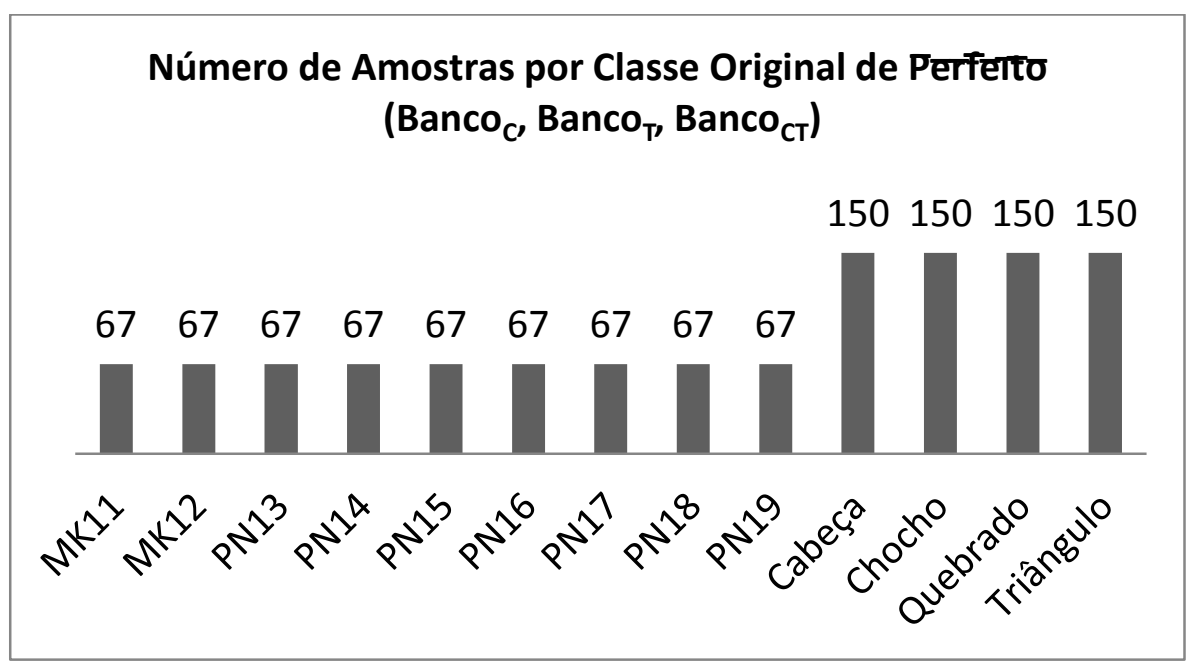

Gráfico 8 - Distribuição das amostras da classe fundida $\overline{\text { Perfeıto }}$ por classe original e peneira, para os bancos de cor e textura



Gráfico 9 - Distribuição das amostras das classes fundidas $\overline{\text { Marınheıro } ~} \overline{\text { Casca }}$ por classe original, para os bancos de cor e textura

Mesmo que para a análise $\mathrm{A}_{\mathrm{MCT}}$ não tenha havido fusão de classes, a distribuição das amostras do banco de atributos Banco é apresentada no Gráfico 10 e a distribuição da classe 'Perfeito' por peneira é mostrada no Gráfico 11. 


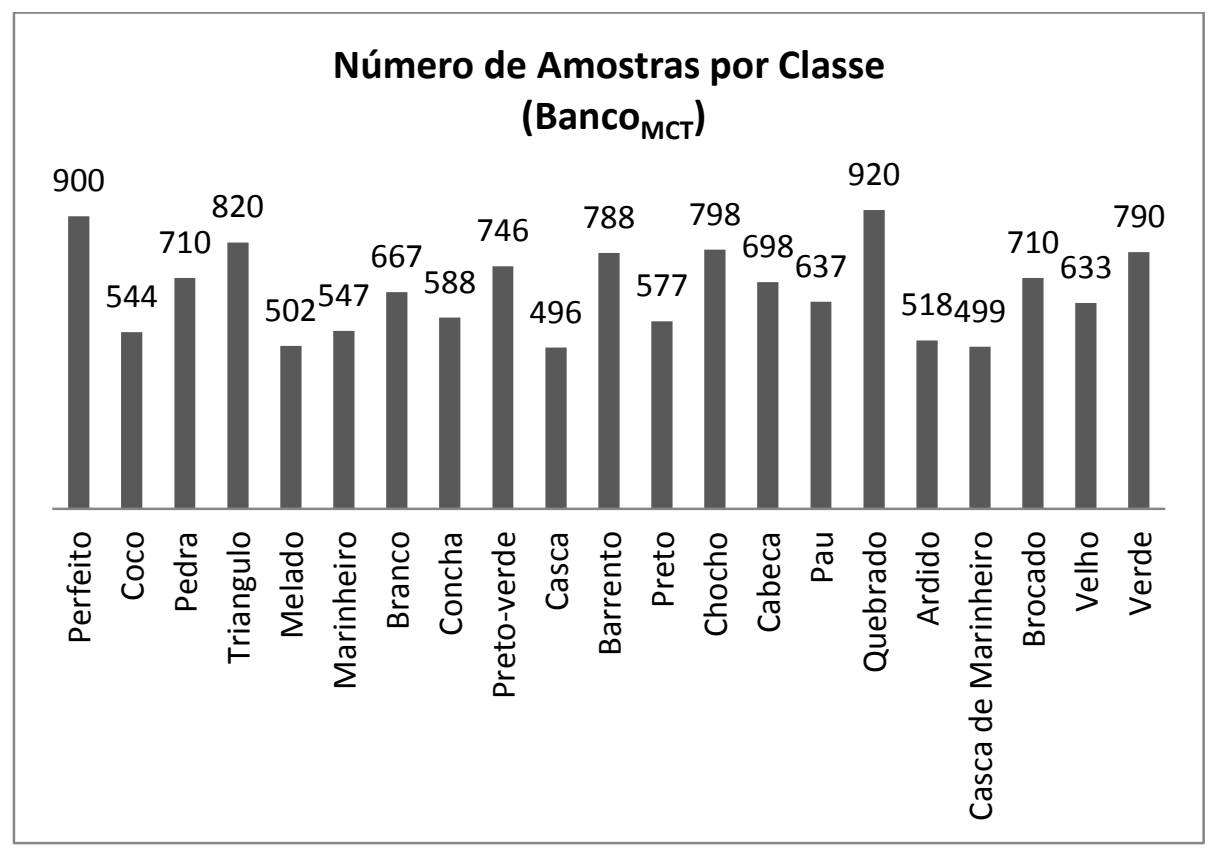

Gráfico 10 - Distribuição das amostras por classe, para o banco de atributos morfológicos, de cor e de textura

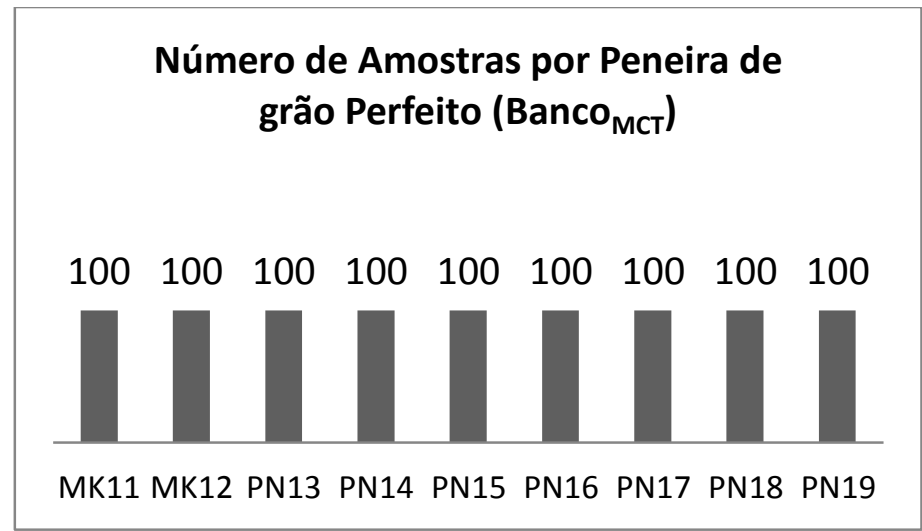

Gráfico 11 - Distribuição das amostras da classe Perfeito por peneira, para o banco de atributos morfológicos, de cor e de textura

O número de amostras disponíveis para o processo de treinamento e avaliação de cada análise está resumido na Tabela 10.

Tabela 10 - Número de amostras disponíveis para cada análise

\begin{tabular}{cc}
\hline Análises & $\begin{array}{c}\text { Número de } \\
\text { amostras }\end{array}$ \\
\hline $\mathrm{A}_{\mathrm{M}}$ & 5933 \\
$\mathrm{~A}_{\mathrm{C}}, \mathrm{A}_{\mathrm{T}}, \mathrm{A}_{\mathrm{CT}}$ & 10469 \\
$\mathrm{~A}_{\mathrm{CMT}}$ & 14088 \\
\hline
\end{tabular}




\subsection{Seleção de Atributos}

Uma vez definidas as configurações dos atributos e das classes para abordar o problema e tendo sido uniformizadas as distribuições de classes das bases de dados, técnicas de seleção de atributos foram aplicadas sobre as instâncias dos bancos de dados a fim de diminuir redundâncias de informação entre os atributos, e consequentemente, melhorar sua eficácia. Três técnicas foram utilizadas independentemente: ordenação dos atributos por ganho de informação, ordenação dos atributos por chi-quadrado e aplicação da PCA, seguida de ordenação por variância. A discretização dos valores dos atributos, necessária para o cálculo do ganho de informação e do chi-quadrado foi feita pelo método Minimum Description Length (FAYYAD; IRANI; BAJCSY, 1993).

Após as ordenações classificações teste foram executadas para variados números de atributos.

Para cada um dos cinco banco de dados definidos (Bancom, Bancoc, Bancot, Bancoct e Banсомст) foi realizado o seguinte procedimento:

1. Determinou-se o número de atributos $\left(\mathrm{N}_{\mathrm{at}}\right)$ do banco de dados.

2. Ordenou-se os atributos do banco de dados de forma independente por cada uma das três técnicas. Sendo que a técnica T definiu a ordenação $O^{T}=\left\{A_{1}^{T}, A_{2}^{T}, \ldots, A_{N_{a t}}^{T}\right\}$, onde $\left\{A_{i}^{T}\right\}$ são atributos (ou componentes principais, no caso da PCA), de modo que $\operatorname{critério}^{T}\left(A_{i}^{T}\right) \geq \operatorname{critério}^{T}\left(A_{i+1}^{T}\right), \forall i<N_{a t}$. Dado que $\operatorname{critério}^{T}(\cdot)$ é o valor do critério de avaliação utilizado pela técnica $\mathrm{T}$ para ordenar os atributos, ou seja, quanto maior critério $^{T}(A)$, mais bem avaliado é o atributo A.

3. Para cada técnica T foram realizadas classificações de teste, pelo método da validação cruzada com 10 folds, de acordo com os parâmetros definidos na Seção 3.5, variandose o número atributos. Em um teste com $\mathrm{k}$ atributos, estes foram dados por $\left\{A_{j}^{T}\right\}, j=$ $1, \ldots, k$, ou seja, foram utilizados somente os $\mathrm{k}$ atributos mais bem avaliados. O número de testes realizados foi escolhido levando em consideração $\mathrm{N}_{\text {at }}$ e o tempo de processamento envolvido. Nenhum critério específico foi definido na determinação do número de atributos utilizados em cada teste.

4. Os conjuntos de atributos que proporcionaram os melhores resultados para as técnicas de ordenação por ganho de informação e por chi-quadrado foram transformados pela PCA, a fim de se reduzir as covariâncias dos atributos, e os conjuntos de componentes 
principais resultantes, sem nenhuma exclusão, foram submetidos ao mesmo processo de avaliação.

Após a execução do procedimento em todos os bancos de dados, os resultados foram comparados e os melhores conjuntos de atributos foram definidos como os vetores de características para cada uma das análises.

\subsection{Definição do Processo Classificatório}

Conforme citado na Seção 3.3, propôs-se avaliar três processos classificatórios. O primeiro deles $\left(P_{M C T}\right)$ está bem definido, e nada mais é do que a própria análise $\mathrm{A}_{\mathrm{MCT}}$ : utilizar uma rede neural que toma como entradas atributos selecionados das três naturezas (morfológicos, de cor e de textura) e a classificação do grão é dada diretamente por essa rede neural. O segundo processo classificatório $\left(P_{M+C+T}\right)$ propõe realizar as análises intermediárias de cor $\left(\mathrm{A}_{\mathrm{C}}\right)$, morfológica $\left(\mathrm{A}_{\mathrm{M}}\right)$ e de textura $\left(\mathrm{A}_{\mathrm{T}}\right)$ paralelamente, e definir um procedimento para cruzar os resultados e gerar a classificação final. $\mathrm{O}$ terceiro $\left(P_{F+C T}\right)$ é análogo ao segundo, porém as análises intermediárias são a morfológica $\left(\mathrm{A}_{\mathrm{M}}\right)$ e a de cor-textura $\left(\mathrm{A}_{\mathrm{CT}}\right)$. A seguir será definido o processo classificatório $P_{M+C+T}$, que por analogia também caracteriza o $P_{M+C T}$.

Cada uma das análises foi refinada pelos vários procedimentos apresentados, porém os seus resultados (com exceção da análise $\mathrm{A}_{\mathrm{MCT}}$ ) determinam, individualmente, somente um dos aspectos da aparência dos objetos e pode atribuir uma classificação ambígua para um grão (uma classe fundida). Dessa forma se fez necessário um procedimento para unificar as análises e atribuir ao objeto em questão uma classe, que indique que tipo de defeito ou impureza ele representa, ou se é um grão perfeito. Definiu-se, então, que a geração dos resultados finais seria realizada a partir das saídas das análises parciais, também pelo uso de redes neurais PMC. O processo de classificação de um grão ou impureza foi definido como passos a seguir: após o grão ter sido segmentado e individualizado, todas as características a serem utilizadas pelas três análises - morfológica, de cor e de textura - são extraídas. As características são agrupadas para formar os vetores de características destinados a cada análise, os quais foram definidos no processo apresentado na Seção 3.11. Os vetores de características são submetidos à classificação de redes neurais pré-treinadas. Cada uma das redes neurais gera um vetor de probabilidades, indicando a probabilidade do objeto de pertencer a cada uma das classes 
definidas pela rede neural em questão. Têm-se então três vetores de probabilidade, conforme apresentado abaixo:

$$
\begin{gathered}
V_{\text {cor }}=\left\{P C C_{i}\right\}, \mathrm{i}=1, \ldots, N_{c c} \\
V_{\text {morfologia }}=\left\{P C M_{j}\right\}, \mathrm{j}=1, \ldots, N_{c m} \\
V_{\text {textura }}=\left\{P C T_{k}\right\}, \mathrm{k}=1, \ldots, N_{c t}
\end{gathered}
$$

Sendo $N_{c c}, N_{c m}$ e $N_{c t}$ os números de classes utilizadas nas análises de cor, forma e textura, respectivamente, conforme definido na Seção 3.10. $P C C_{i}$ é a probabilidade de o grão pertencer à i-ésima classe de cor, $P C M_{j}$ a probabilidade de o grão pertencer à j-ésima classe de forma e $P C T_{k}$ a probabilidade de o grão pertencer à k-ésima classe de textura.

Esses vetores são então concatenados para se formar um vetor de características único:

$$
V_{\text {concatenado }}=V_{\text {cor }} \cup V_{\text {morfologia }} \cup V_{\text {textura }}
$$

O vetor concatenado é então submetido a mais uma rede neural pré-treinada, a qual definirá a classe final do objeto. Essa abordagem visa não somente diferenciar as classificações intermediárias não conclusivas proveniente da fusão de classes, mas também lidar com incertezas recorrentes. O procedimento é ilustrado na Figura 30. 


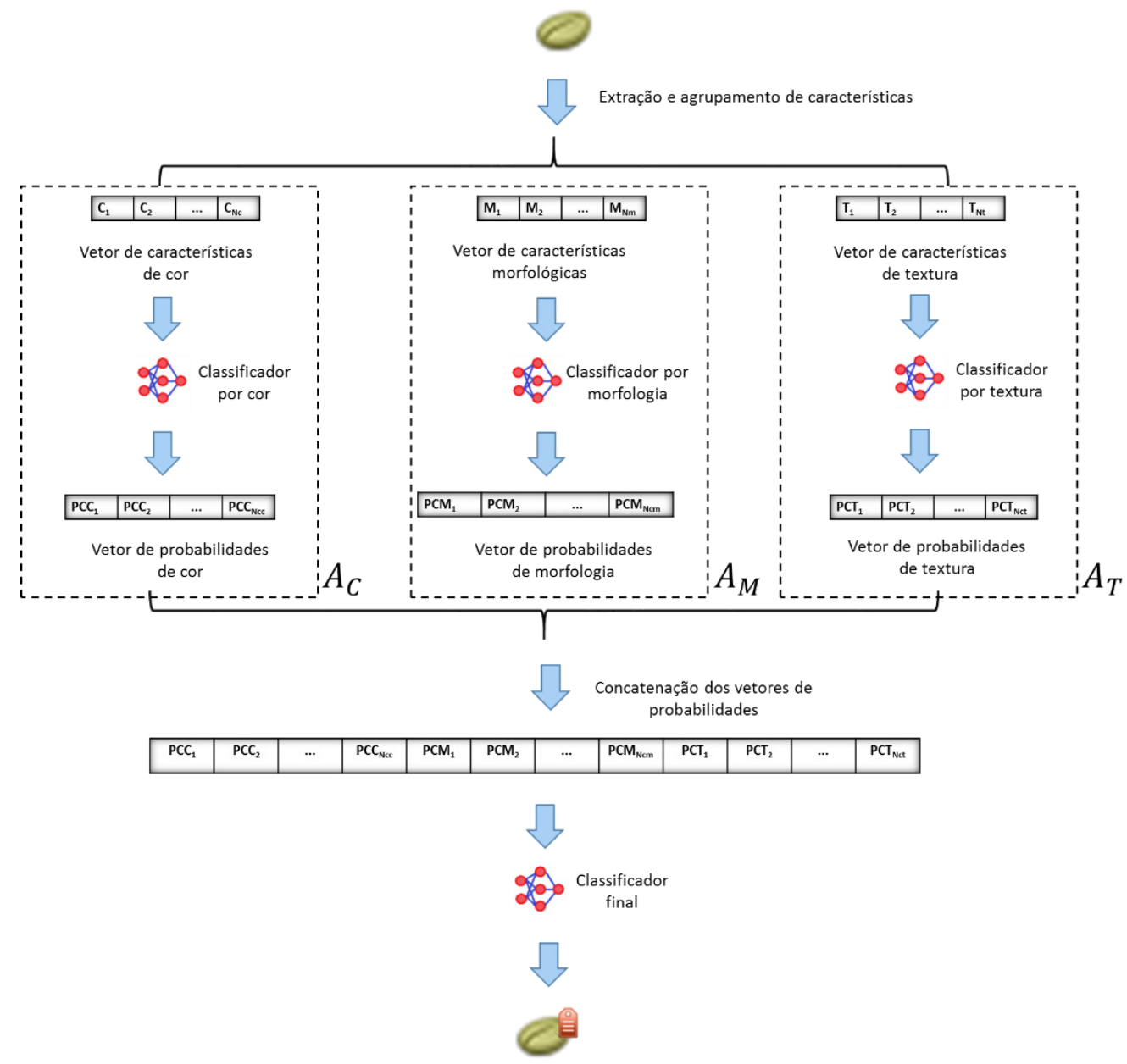

Figura 30 - Processo classificatório envolvendo análises paralelas de cor, morfologia e textura

Os processos classificatórios $P_{M+C+T}$ e $P_{M+C T}$ envolvem classificações em dois níveis, ou seja, é preciso treinar redes neurais do primeiro nível, para então aplicá-las em um conjunto de dados a fim de se obter vetores de probabilidades, os quais são utilizados como conjunto de treinamento para a rede neural do segundo nível. Essa dinâmica de classificação não permite a aplicação direta dos métodos de validação cruzada disponíveis nas ferramentas utilizadas, sendo necessário modificá-las ou implementar uma ferramenta própria. Para contornar o problema foi utilizado um procedimento alternativo para treinamento e avaliação dos processos classificatórios, o qual é ilustrado na Figura 31 para o $P_{M+C+T}$. Dividiu-se cada banco de dados em dois conjuntos, um para treinamento e outro para teste dos classificadores (Figura 31a). As redes neurais responsáveis pelas análises intermediárias foram treinadas pelo conjunto de treinamento (Figura 31b). Essas redes foram utilizadas para classificar as instâncias do conjunto de treinamento, gerando um conjunto de vetores de probabilidade (Figura 31c). Os vetores foram concatenados e utilizados no treinamento da rede neural responsável pela classificação 
final (Figura 31d). Finalmente, as instâncias do conjunto de testes foram classificadas pelas redes neurais das análises intermediárias, gerando vetores de probabilidade (Figura 31e), os quais foram concatenados e passados como entrada para o classificador final (Figura 31f), que gera a avaliação final. Para efeitos de comparação o processo classificatório $P_{M C T}$ também teve que ser avaliado treinando sua rede neural com o conjunto de treinamento para então utilizá-la na classificação do conjunto de teste. Os bancos de dados foram então divididos da seguinte forma: $60 \%$ das instâncias foram destinadas a formar o conjunto de treinamento, e os $40 \%$ restantes para o conjunto de testes.

(a)

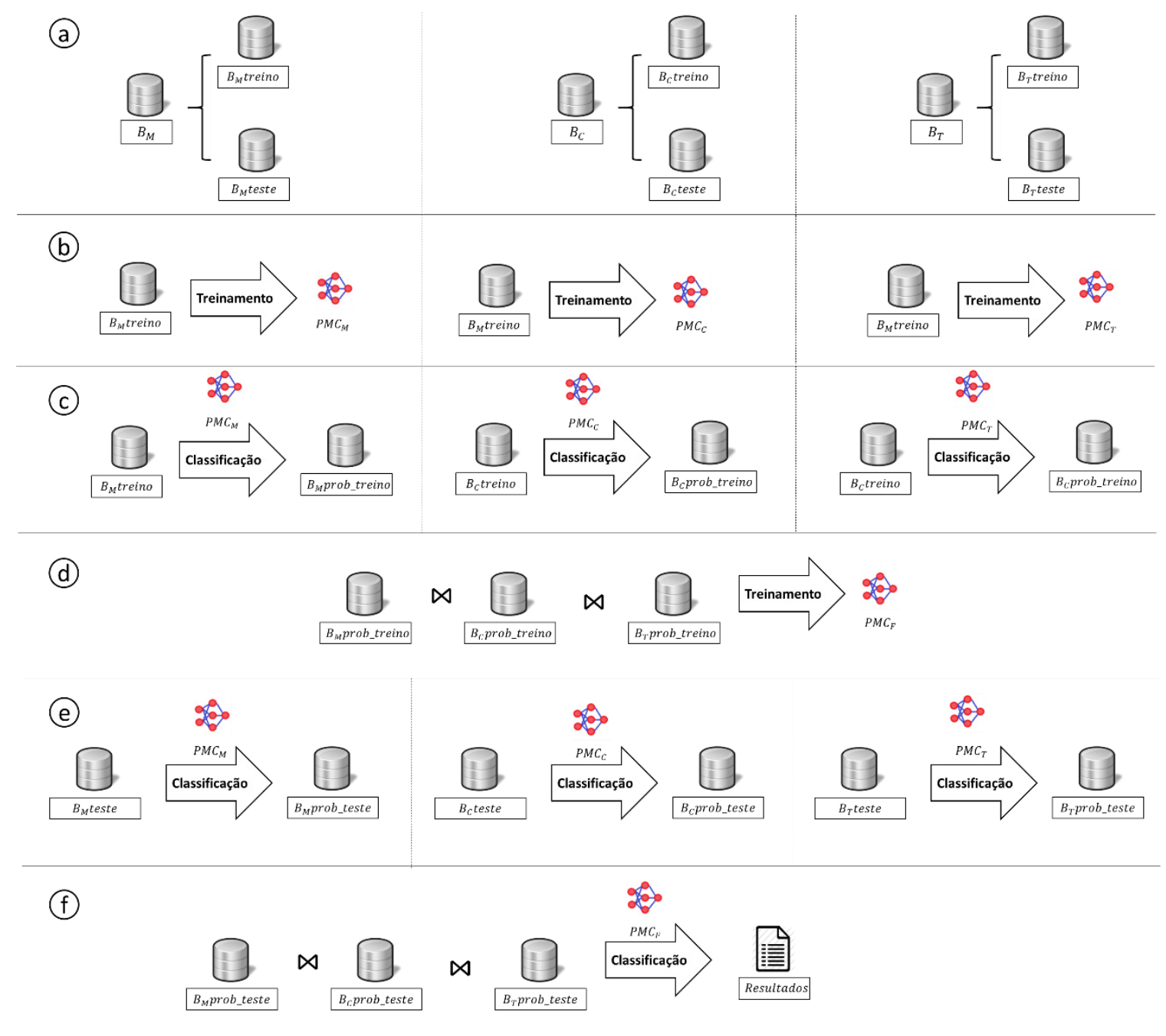





\section{RESULTADOS E DISCUSSÃO}

Neste capítulo serão apresentados e discutidos os resultados obtidos. Detalhes sobre os critérios de avaliação (acurácia, precisão, recall e F-Measure) foram apresentados na Seção 3.4 .

\subsection{Classificação por Histogramas de Frequências Normalizadas de Cores}

Os resultados das classificações por histogramas de frequências normalizadas de cor foram apresentados brevemente na Seção 3.9.2.1 e serão discutidos mais profundamente nesta seção. As acurácias obtidas pela submissão dos histogramas oriundos de diferentes espaços de cor ao método da validação cruzada são reapresentadas na Tabela 11.

\begin{tabular}{|c|c|}
\hline Espaço de Cor & Acurácia (\%) \\
\hline RGB & 69,92 \\
\hline HSV & 74,33 \\
\hline $\mathrm{YCbCr}$ & 69,93 \\
\hline $\mathrm{YCgCr}$ & 67,06 \\
\hline YIQ & 68,98 \\
\hline YPbPr & 69,87 \\
\hline YUV & 69,79 \\
\hline YDbDr & 69,88 \\
\hline CIE XYZ & 58,63 \\
\hline CIELAB & 74,23 \\
\hline $\mathrm{rgb}$ & 63,71 \\
\hline $\mathrm{I}_{1} \mathrm{I}_{2} \mathrm{I}_{3}$ & 70,99 \\
\hline
\end{tabular}

Nota-se que as diferenças entre os resultados são muito pequenas, com exceção dos modelos CIE XYZ, rgb, CIELAB e HSV. Sendo que os dois primeiros apresentaram resultados muito inferiores ao dos outros, enquanto os dois últimos apresentaram valores muito semelhantes, com significativa superioridade em relação aos outros modelos. 
Supõe-se que a boa vantagem obtida pelo espaço de cor HSV se deva pelo fato de ele descorrelacionar informações bem distintas e com significados concretos - matiz, saturação e brilho - entre os canais. Essa separação pode ter deixado a classificação mais robusta em relação a variações da distribuição de luz pelo sistema de iluminação, por exemplo. Como a câmara de captura de imagens não conta com um sistema de iluminação totalmente homogênea, os grãos de uma mesma imagem não são iluminados da mesma forma.

Acredita-se que o bom desempenho do CIELAB se deva por ele ser perceptualmente uniforme, de modo que as grandes diferenças de cor que poderiam ser percebidas por classificadores humanos seriam transcritas numericamente pelo sistema de cor em grandes diferenças de valor, e pequenas diferenças que passariam desapercebidas por humanos seriam representadas por pequenas diferenças de valores.

Constata-se que com exceção do HSV, CIELAB e rgb, todos os espaços de cor avaliados são combinações lineares do RGB. Acredita-se que essa seja a razão pela qual os espaços de cor obtiveram resultados muito semelhantes, sendo justamente as exceções os espaços que proporcionaram acurácias destoantes. Das combinações lineares, apenas o CIE XYZ apresentou resultados muito distintos.

\subsection{Modificação dos Descritores de Haralick}

Os resultados obtidos nas classificações com os descritores de Haralick modificados para serem utilizados dois pixels de referência no cômputo das GLCM serão discutidos e comparados aqui com os resultados dos descritores em sua concepção original.

Os critérios de classificação adotados nesta comparação são: acurácia, precisão média, recall médio e F-Measure média. As Equações (3.2)-(3.4) apresentam o cálculo dos critérios para uma única classe. Seus valores médios são calculados pela média aritmética simples entre os valores obtidos para cada classe.

Nove ensaios foram realizados para cada uma das duas abordagens, sendo que em cada ensaio diferentes bandas de espaços de cor foram utilizadas para calcular os descritores, conforme descrito na Seção 3.9.3.2. As acurácias, as precisões médias, os recalls médios e as F-Measures médias são apresentadas nas Tabelas 12-15. Em cada tabela o melhor resultado de cada ensaio é destacado e é apresentado a diferença, em porcentagem, entre o melhor e o pior resultado $($ Diferença $=($ Melhor - Pior $) /$ Pior $)$. 
Tabela 12 - Comparação das acurácias obtidas pelas duas abordagens de cálculo dos descritores de Haralick: com 1 e 2 pixels de referência

\begin{tabular}{ccccccccccc}
\hline & RGB & $\mathrm{R}$ & $\mathrm{G}$ & $\mathrm{B}$ & $\mathrm{I}_{1} \mathrm{I}_{2} \mathrm{I}_{3}$ & $\mathrm{I}_{1}$ & $\mathrm{I}_{2}$ & $\mathrm{I}_{3}$ & $\begin{array}{c}\text { Níveis de } \\
\text { Cinza }\end{array}$ \\
\hline 1 pixel & $79,08 \%$ & $58,34 \%$ & $60,54 \%$ & $59,89 \%$ & $80,98 \%$ & $59,02 \%$ & $65,07 \%$ & $62,14 \%$ & $60,11 \%$ \\
2 pixels & $80,02 \%$ & $59,14 \%$ & $60,68 \%$ & $59,10 \%$ & $82,32 \%$ & $61,35 \%$ & $64,87 \%$ & $63,92 \%$ & $61,73 \%$ \\
Diferença & $1,19 \%$ & $1,37 \%$ & $0,23 \%$ & $1,34 \%$ & $1,65 \%$ & $3,95 \%$ & $0,31 \%$ & $2,86 \%$ & $2,69 \%$ \\
\hline
\end{tabular}

Tabela 13 - Comparação das precisões médias obtidas pelas duas abordagens de cálculo dos descritores de Haralick: com 1 e 2 pixels de referência

\begin{tabular}{|c|c|c|c|c|c|c|c|c|c|}
\hline & RGB & $\mathrm{R}$ & G & B & $\mathrm{I}_{1} \mathrm{I}_{2} \mathrm{I}_{3}$ & $\mathrm{I}_{1}$ & $\mathrm{I}_{2}$ & $\mathrm{I}_{3}$ & $\begin{array}{c}\text { Níveis de } \\
\text { Cinza }\end{array}$ \\
\hline 1 pixel & $77,97 \%$ & $56,55 \%$ & $57,42 \%$ & $56,67 \%$ & $79,72 \%$ & $55,77 \%$ & $62,33 \%$ & $60,66 \%$ & $56,92 \%$ \\
\hline 2 pixels & $78,73 \%$ & $57,83 \%$ & $58,43 \%$ & $56,61 \%$ & $81,59 \%$ & $59,23 \%$ & $63,22 \%$ & $63,76 \%$ & $59,53 \%$ \\
\hline Diferença & $0,97 \%$ & $2,25 \%$ & $1,75 \%$ & $0,11 \%$ & $2,35 \%$ & $6,20 \%$ & $1,43 \%$ & $5,11 \%$ & $4,59 \%$ \\
\hline
\end{tabular}

Tabela 14 - Comparação dos recalls médios obtidos pelas duas abordagens de cálculo dos descritores de Haralick: com 1 e 2 pixels de referência

\begin{tabular}{cccccccccc}
\hline & RGB & $\mathrm{R}$ & $\mathrm{G}$ & $\mathrm{B}$ & $\mathrm{I}_{1} \mathrm{I}_{2} \mathrm{I}_{3}$ & $\mathrm{I}_{1}$ & $\mathrm{I}_{2}$ & $\mathrm{I}_{3}$ & $\begin{array}{c}\text { Níveis de } \\
\text { Cinza }\end{array}$ \\
\hline 1 pixel & $76,73 \%$ & $53,74 \%$ & $55,18 \%$ & $53,83 \%$ & $79,03 \%$ & $53,28 \%$ & $60,23 \%$ & $57,67 \%$ & $54,43 \%$ \\
2 pixels & $78,00 \%$ & $55,23 \%$ & $56,19 \%$ & $53,55 \%$ & $80,69 \%$ & $56,75 \%$ & $60,36 \%$ & $60,55 \%$ & $57,47 \%$ \\
\hline Diferença & $1,65 \%$ & $2,78 \%$ & $1,84 \%$ & $0,54 \%$ & $2,11 \%$ & $6,52 \%$ & $0,22 \%$ & $5,01 \%$ & $5,59 \%$ \\
\hline
\end{tabular}

Tabela 15 - Comparação das F-Measures médias obtidas pelas duas abordagens de cálculo dos descritores de Haralick: com 1 e 2 pixels de referência

\begin{tabular}{ccccccccccc}
\hline & RGB & $\mathrm{R}$ & $\mathrm{G}$ & $\mathrm{B}$ & $\mathrm{I}_{1} \mathrm{I}_{2} \mathrm{I}_{3}$ & $\mathrm{I}_{1}$ & $\mathrm{I}_{2}$ & $\mathrm{I}_{3}$ & $\begin{array}{c}\text { Níveis de } \\
\text { Cinza }\end{array}$ \\
\hline 1 pixel & $77,35 \%$ & $55,11 \%$ & $56,28 \%$ & $55,21 \%$ & $79,37 \%$ & $54,49 \%$ & $61,26 \%$ & $59,13 \%$ & $55,65 \%$ \\
2 pixels & $78,36 \%$ & $56,50 \%$ & $57,29 \%$ & $55,03 \%$ & $\mathbf{5 1 , 1 4 \%}$ & $\mathbf{5 7 , 9 6 \%}$ & $\mathbf{6 1 , 7 6 \%}$ & $\mathbf{6 2 , 1 2 \%}$ & $58,48 \%$ \\
\hline Diferença & $1,31 \%$ & $2,52 \%$ & $1,80 \%$ & $0,33 \%$ & $2,23 \%$ & $6,37 \%$ & $0,81 \%$ & $5,06 \%$ & $5,10 \%$ \\
\hline
\end{tabular}

Dos nove ensaios realizados a utilização dos descritores com 2 pixels de referência obteve melhor acurácia em sete. Apenas com os canais $\mathrm{B}$ e $\mathrm{I}_{2}$ os descritores originais apresentaram melhor acurácia. Para todos os outros critérios (precisão média, recall médio e F-Measure médias) a versão modificada dos descritores apresentou melhores resultados em todos os ensaios com exceção daquele em que o canal B foi utilizado. Para todos os critérios, a média das diferenças dos resultados dos ensaios em que a versão modificada foi melhor é superior a média das diferenças dos resultados dos ensaios em que a versão modificada foi pior. Para o caso mais extremo, da precisão média: a diferença média quando o descritor modificado foi 
superior foi de $3,08 \%$, enquanto a diferença média quando o descritor original foi superior foi de $0,11 \%$.

Dadas as informações apresentadas, e contando que todos os ensaios foram realizados utilizando o método da validação cruzada de 10 folds, utilizando um número considerável de amostras (12.537), pode-se concluir que a modificação realizada nos descritores de Haralick conseguiu uma melhora de desempenho em relação a sua versão original, para os espaços de cor avaliados e sendo aplicado ao problema aqui tratado.

\subsection{Seleção de Atributos}

Esta seção apresentará os resultados obtidos no processo de seleção de atributos detalhado na Seção 3.11. Para cada uma das cinco análises ( $A_{M}, A_{C}, A_{T}, A_{C T}$ e $\left.A_{M C T}\right)$ será apresentada uma tabela contendo os resultados das classificações teste conduzidas para seus atributos. Os conjuntos de atributos selecionados pelas técnicas chi-quadrado e ganho de informação reavaliados após a aplicação da PCA terão seus resultados apresentados entre parênteses. O melhor resultado da tabela aparecerá destacado. Os valores da tabela (com exceção dos reavaliados após a PCA) serão mostrados em um gráfico para uma melhor visualização.

Os 15 primeiros atributos das ordenações por chi-quadrado e ganho de informação para cada uma das cinco análises estão listados na Tabela 16. As ordenações completas são listadas no Apêndice.

Tabela 16 - Quinze primeiros atributos das ordenações por chi-quadrado e por ganho de informação (G.I.) para cada análise.

Os atributos aparecem em ordem decrescente de classificação, com os mais bem avaliados no topo. Os atributos morfológicos são apresentados segundo a notação utilizada na Seção 2.3. Os atributos de cor são: média (MED), variância (VAR), suavidade (SVD), energia (ENG), entropia (ENT). E $f_{i}^{X}(C)$ é o descritor de Haralick $f_{i}$ calculado pela GLCM de simetria X (X $\epsilon\{H, V, D\}$. H: Horizontal, V: Vertical, D: Diagonal) para o canal de cor C.

\begin{tabular}{|c|c|c|c|c|c|c|c|c|c|}
\hline \multicolumn{2}{|c|}{$A_{M}$} & \multicolumn{2}{|c|}{$A_{C}$} & \multicolumn{2}{|c|}{$A_{T}$} & \multicolumn{2}{|c|}{$A_{C T}$} & \multicolumn{2}{|c|}{$A_{M C T}$} \\
\hline $\mathrm{Chi}^{2}$ & G.I. & $\mathrm{Chi}^{2}$ & G.I. & $\mathrm{Chi}^{2}$ & G.I. & $\mathrm{Chi}^{2}$ & G.I. & $\mathrm{Chi}^{2}$ & G.I. \\
\hline Perímetro & Perímetro & $\operatorname{MED}\left(I_{1}\right)$ & $\operatorname{MED}\left(I_{1}\right)$ & $f_{7}^{H}\left(I_{1}\right)$ & $f_{7}^{H}\left(I_{1}\right)$ & $\operatorname{MED}\left(I_{1}\right)$ & $\operatorname{MED}\left(I_{1}\right)$ & $\operatorname{MED}\left(I_{1}\right)$ & $\operatorname{MED}\left(I_{1}\right)$ \\
\hline Spread & Spread & $\operatorname{MED}(\mathrm{V})$ & $\operatorname{MED}(\mathrm{V})$ & $f_{7}^{V}\left(I_{1}\right)$ & $f_{7}^{V}\left(I_{1}\right)$ & $\operatorname{MED}(\mathrm{V})$ & $\operatorname{MED}(\mathrm{V})$ & $\operatorname{MED}(\mathrm{V})$ & $\operatorname{MED}(\mathrm{V})$ \\
\hline$Z_{0,0}$ & $Z_{0,0}$ & $\operatorname{MED}(\mathrm{S})$ & $\operatorname{MED}(\mathrm{L})$ & $f_{7}^{D}\left(I_{1}\right)$ & $f_{7}^{D}\left(I_{1}\right)$ & $\operatorname{MED}(\mathrm{S})$ & $f_{7}^{H}\left(I_{1}\right)$ & $\operatorname{MED}(\mathrm{S})$ & $f_{7}^{H}\left(I_{1}\right)$ \\
\hline Área & Área & ENG(R) & $\operatorname{MED}(S)$ & $f_{6}^{H}\left(I_{1}\right)$ & $f_{6}^{H}\left(I_{1}\right)$ & $f_{7}^{H}\left(I_{1}\right)$ & $f_{7}^{V}\left(I_{1}\right)$ & $f_{7}^{H}\left(I_{1}\right)$ & $f_{7}^{V}\left(I_{1}\right)$ \\
\hline$Z_{2,0}$ & $Z_{2,0}$ & $\mathrm{ENG}(\mathrm{G})$ & VAR(R) & $f_{6}^{V}\left(I_{1}\right)$ & $f_{6}^{V}\left(I_{1}\right)$ & $f_{7}^{V}\left(I_{1}\right)$ & $f_{7}^{D}\left(I_{1}\right)$ & $f_{7}^{V}\left(I_{1}\right)$ & $f_{7}^{D}\left(I_{1}\right)$ \\
\hline $\mathrm{F}(0)$ & $\mathrm{F}(0)$ & VAR(G) & $\mathrm{SVD}(\mathrm{R})$ & $f_{6}^{D}\left(I_{1}\right)$ & $f_{6}^{D}\left(I_{1}\right)$ & $f_{7}^{D}\left(I_{1}\right)$ & $f_{6}^{H}\left(I_{1}\right)$ & $f_{7}^{D}\left(I_{1}\right)$ & $f_{6}^{H}\left(I_{1}\right)$ \\
\hline $\operatorname{DGF}(0,2)$ & $Z_{6,0}$ & $\operatorname{SVD}(G)$ & ENG(R) & $f_{2}^{D}\left(I_{1}\right)$ & $f_{2}^{D}\left(I_{1}\right)$ & ENG(R) & $f_{6}^{V}\left(I_{1}\right)$ & ENG(R) & $f_{6}^{V}\left(I_{1}\right)$ \\
\hline
\end{tabular}




\begin{tabular}{|c|c|c|c|c|c|c|c|c|c|}
\hline$Z_{6,0}$ & Slenderness & SVD (R) & $\operatorname{MED}(G)$ & $f_{2}^{V}\left(I_{1}\right)$ & $f_{2}^{V}\left(I_{1}\right)$ & ENG(G) & $f_{6}^{D}\left(I_{1}\right)$ & ENG(G) & $f_{6}^{D}\left(I_{1}\right)$ \\
\hline Slenderness & $\operatorname{DGF}(0,2)$ & $\operatorname{VAR}(\mathrm{R})$ & $\operatorname{VAR}(G)$ & $f_{2}^{H}\left(I_{1}\right)$ & $f_{2}^{H}\left(I_{1}\right)$ & $\mathrm{SVD}(\mathrm{R})$ & $\operatorname{MED}\left(L^{*}\right)$ & $\operatorname{SVD}(G)$ & $\operatorname{MED}\left(L^{*}\right)$ \\
\hline $\mathrm{F}(2)$ & $Z_{10,0}$ & $\operatorname{MED}(L)$ & $\operatorname{SVD}(G)$ & $f_{7}^{V}\left(I_{2}\right)$ & $f_{7}^{V}\left(I_{2}\right)$ & $\operatorname{VAR}(\mathrm{R})$ & $\operatorname{MED}(\mathrm{S})$ & $\operatorname{VAR}(\mathrm{R})$ & $\operatorname{MED}(G)$ \\
\hline $\mathrm{D}_{3}$ & $\mathrm{~A}_{1}$ & $\operatorname{MED}(\mathrm{G})$ & $\mathrm{ENG}(\mathrm{G})$ & $f_{2}^{V}\left(I_{2}\right)$ & $f_{2}^{V}\left(I_{2}\right)$ & $f_{6}^{V}\left(I_{1}\right)$ & $\operatorname{SVD}(\mathrm{R})$ & $\operatorname{SVD}(\mathrm{R})$ & $\operatorname{SVD}(\mathrm{R})$ \\
\hline $\operatorname{DGF}(0,1)$ & Eixo maior & $\operatorname{MED}(B)$ & $\operatorname{MED}(\mathrm{R})$ & $f_{7}^{D}\left(I_{2}\right)$ & $f_{7}^{D}\left(I_{2}\right)$ & VAR(G) & VAR(R) & VAR(G) & VAR(R) \\
\hline$Z_{10,0}$ & $\mathrm{~A}_{3}$ & VAR(L) & VAR(L) & $f_{6}^{H}\left(I_{2}\right)$ & $f_{6}^{H}\left(I_{2}\right)$ & $\operatorname{SVD}(G)$ & ENG(R) & $f_{6}^{H}\left(I_{2}\right)$ & $\operatorname{MED}(\mathrm{S})$ \\
\hline $\mathrm{A}_{1}$ & $\operatorname{DGF}(0,0)$ & SVD(L) & $\operatorname{SVD}(\mathrm{L})$ & $f_{6}^{D}\left(I_{2}\right)$ & $f_{6}^{D}\left(I_{2}\right)$ & $f_{6}^{D}\left(I_{1}\right)$ & $\operatorname{MED}(G)$ & $f_{6}^{D}\left(I_{2}\right)$ & ENG(R) \\
\hline Eixo maior & $\operatorname{DGF}(0,1)$ & $\operatorname{ENT}(G)$ & $\operatorname{VAR}\left(I_{3}\right)$ & $f_{7}^{H}\left(I_{2}\right)$ & $f_{7}^{H}\left(I_{2}\right)$ & $f_{6}^{H}\left(I_{1}\right)$ & $\operatorname{VAR}(\mathrm{G})$ & $f_{7}^{H}\left(I_{2}\right)$ & VAR(G) \\
\hline
\end{tabular}

Os resultados da seleção de atributos da análise morfológica $\left(\mathrm{A}_{M}\right)$ são apresentados na Tabela 17 e no Gráfico 12.

Tabela 17 - Acurácias (em \%) das classificações utilizando os melhores atributos de cada técnica de seleção de atributos para a análise $\mathbf{A}_{\mathrm{M}}$.

Os resultados da reavaliações após a aplicação da PCA são dadas entre parênteses

\begin{tabular}{cccc}
\hline Número de Atributos & Ganho de Informação & $\mathbf{C h i}^{\mathbf{2}}$ & PCA \\
\hline 10 & 62,95 & 63,24 & 62,92 \\
15 & 64,15 & 64,32 & 64,60 \\
20 & 64,27 & $64,82(64,62)$ & 63,95 \\
25 & 63,34 & 64,57 & 63,95 \\
30 & 64,28 & 64,45 & 61,98 \\
35 & $64,79(64,30)$ & 64,25 & 60,76 \\
40 & 63,36 & 63,34 & 59,33 \\
45 & 63,54 & 62,87 & 57,91 \\
50 & 63,05 & 63,16 & 57,37 \\
55 & 63,24 & 62,45 & 56,67 \\
60 & 62,73 & 62,41 & 56,85 \\
90 & 61,94 & 60,96 & 56,99 \\
120 & 60,95 & 61,82 & 57,88 \\
150 & 61,52 & 61,00 & 59,41 \\
180 & 62,19 & 62,08 & 58,37 \\
211 & 62,14 & 62,14 & 60,51 \\
\hline
\end{tabular}




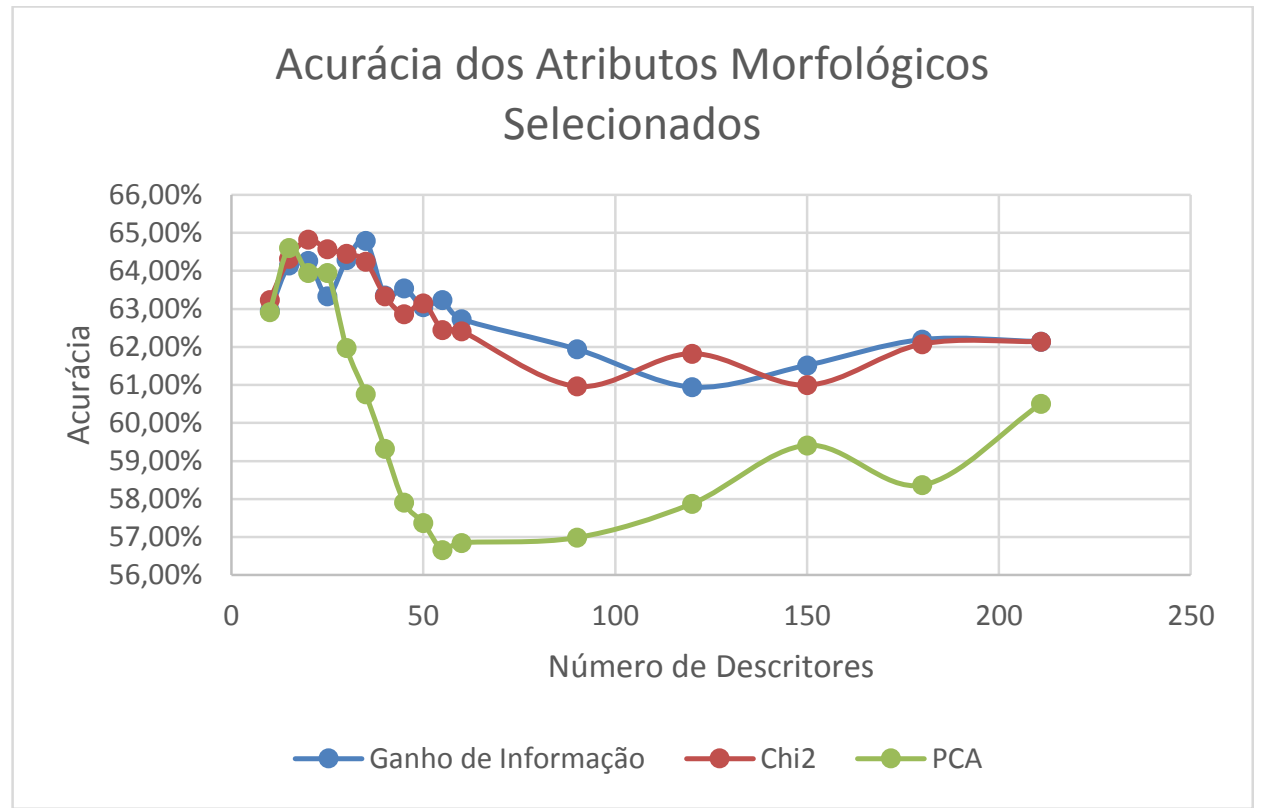

Gráfico 12 - Acurácias das classificações utilizando os melhores atributos de cada técnica de seleção de atributos para a análise $A_{M}$

Assim, para a análise morfológica foram selecionados 20 atributos, obtidos pela ordenação por chi-quadrado. Esses atributos são: 9 atributos unitários (perímetro, spread, área, slenderness, eixo maior, $\mathrm{A}_{1}, \mathrm{~A}_{2}, \mathrm{~A}_{3}$ e $\mathrm{A}_{4}$ ), 6 Momentos de Zernike, 2 Descritores de Fourier (frequências 0 e 2) e 3 DGF (todos com frequência radial 0). O Descritor de Fourier de frequência zero, também conhecido como componente DC, coincide com o valor médio do sinal. Portanto, como a assinatura utilizada no cálculo dos descritores de Fourier foram as distâncias dos pixels da borda do grão ao seu centroide, a componente DC nada mais é do que a distância média da borda ao centroide. O Modelo Autorregressivo foi o único atributo a ficar de fora da seleção de atributos morfológicos e a melhor colocação de um de seus elementos nas ordenações da seleção de atributos foi $66^{\circ}$. Assim, conclui-se que o atributo não é apropriado para o problema tratado.

Dos 12 atributos unitários avaliados, 9 foram selecionados, mostrando certa superioridade em relação aos outros. Diferentemente dos outros atributos, que decompõem a representação de forma em um conjunto de elementos, os descritores unitários extraem da forma informações específicas, geralmente contendo significados físicos bem definidos (área, perímetro, etc.). Assim, acredita-se que informações importantes se condensam no atributo, contribuindo para uma melhor diferenciação pela rede neural. Os outros atributos possuem um grande número de elementos, mas cada um deles, separadamente, carrega poucas informações significantes sobre 
a forma, não conseguindo filtrar as características realmente importantes na discriminação das classes de grãos de café.

A baixa acurácia obtida pelos atributos morfológicos (64,82\% no melhor caso) mostra a deficiência em reconhecer as diferenças nos contornos dos objetos que separaram as classes. Essa deficiência pode ser devida a limitações dos atributos utilizados ou à própria dificuldade inerente ao problema ser elevada. Apesar de um número significativo de atributos terem sido avaliados, estudos mais profundos são necessários para comprovar ou refutar qualquer uma das hipóteses. Além disso, o modo como as classes foram fundidas e o número reduzido de amostras utilizadas no treinamento podem ter influenciado negativamente o desempenho.

Os resultados da seleção de atributos da análise de cor $\left(\mathrm{A}_{\mathrm{C}}\right)$ são apresentados na Tabela 18 e no Gráfico 13. Os resultados para a análise de textura $\left(\mathrm{A}_{\mathrm{T}}\right)$ são dados pela Tabela 19 e pelo Gráfico 14. E os resultados para análise de cor-textura (ACT) são apresentados na Tabela 20 e no Gráfico 15.

Tabela 18 - Acurácias (em \%) das classificações utilizando os melhores atributos de cada técnica de seleção de atributos para a análise $A_{C}$.

Os resultados da reavaliações após a aplicação da PCA são dadas entre parênteses

\begin{tabular}{cccc}
\hline Número de Atributos & Ganho de Informação & Chi $^{\mathbf{2}}$ & PCA \\
\hline 15 & 70,83 & 68,21 & 72,64 \\
25 & 73,80 & 74,85 & 75,58 \\
35 & 75,56 & 75,78 & 75,44 \\
45 & 75,73 & 76,42 & 76,09 \\
55 & 76,88 & 76,51 & 76,58 \\
65 & 76,96 & 76,74 & 78,09 \\
75 & $77,08(78,66)$ & $77,51(78,90)$ & 79,10 \\
84 & 77,77 & 77,77 & 78,63 \\
\hline
\end{tabular}




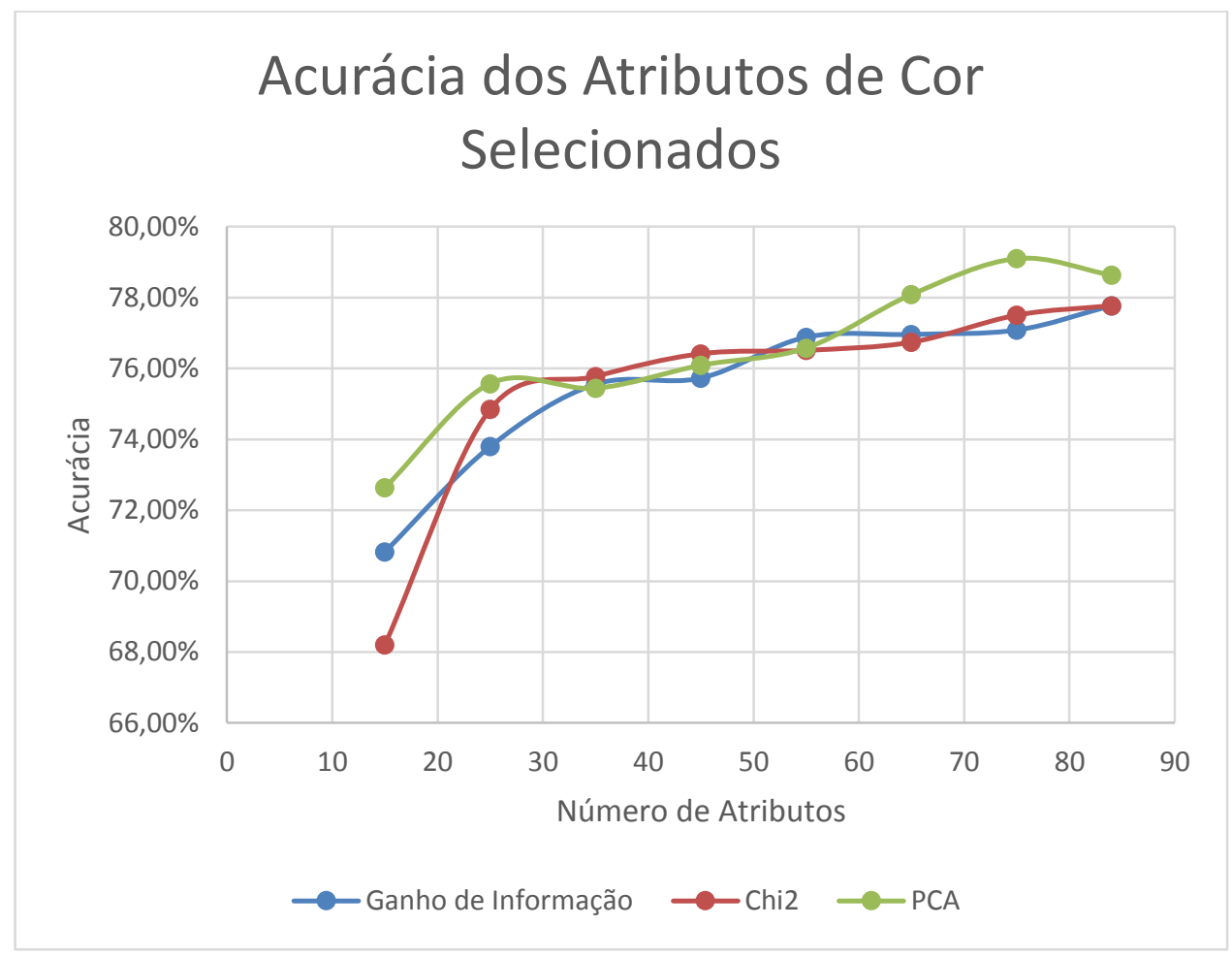

Gráfico 13 - Acurácias das classificações utilizando os melhores atributos de cada técnica de seleção de atributos para a análise $A_{C}$

O melhor vetor de características para análise de cor, com acurácia de 79,10\%, foi composto por 75 das 84 componentes principais. Como cada uma das componentes principais é uma combinação linear dos atributos inicialmente propostos, tem-se que cada um dos atributos teve uma contribuição para a classificação.

Constata-se pelo Gráfico 13 que a acurácia das classificações foram evoluindo conforme novos atributos foram adicionados ao vetor de características, mesmo que os atributos adicionados já estivessem presentes, porém calculados por outros espaços de cor. Deve-se notar que os diferentes espaços de cor são apenas representações diferentes da mesma propriedade física. Então, acredita-se que a adição de atributos calculados por outros espaços de cor possam melhorar o desempenho da análise.

Ao se analisar a ordenação gerada pelo algoritmo chi-quadrado para os atributos de cor, constata-se que os seis piores classificados são curtoses, e todas as doze curtoses estão classificadas entre os 24 piores atributos. Resultados similares são observados na ordenação pelo ganho de informação. Sob a óptica oposta, nota-se que os três melhores classificados pelo chi-quadrado são médias e que todas as doze médias encontram-se entre os 30 melhores atributos. Novamente, observa-se uma situação parecida para a ordenação por ganho de informação. Como esses dois atributos estatísticos são as duas situações extremas a serem 
destacadas ao se analisar as ordenações, conclui-se que a média é o atributo com mais informações discriminantes do histograma de cor para o problema abordado, enquanto que a curtose é a menos discriminante.

Tabela 19 - Acurácias (em \%) das classificações utilizando os melhores atributos de cada técnica de seleção de atributos para a análise $\mathrm{A}_{\mathrm{T}}$.

Os resultados da reavaliações após a aplicação da PCA são dadas entre parênteses

\begin{tabular}{cccc}
\hline Número de Atributos & Ganho de Informação & Chi $^{\mathbf{2}}$ & PCA \\
\hline 10 & 55,94 & 55,80 & 72,39 \\
30 & 75,06 & 76,92 & 78,52 \\
50 & 77,17 & 76,49 & 79,27 \\
70 & 77,77 & 79,33 & 80,44 \\
90 & 80,49 & 79,84 & 81,12 \\
100 & 80,35 & 80,56 & 81,13 \\
110 & 80,49 & 81,02 & 82,40 \\
120 & $81,20(83,09)$ & $81,16(82,97)$ & 82,26 \\
126 & 81,52 & 81,52 & 83,67 \\
\hline
\end{tabular}

\section{Acurácia dos Atributos de Textura Selecionados}



Gráfico 14 - Acurácias das classificações utilizando os melhores atributos de cada técnica de seleção de atributos para a análise $\mathbf{A}_{\mathrm{T}}$

O melhor resultado para a análise de textura (acurácia de $83,67 \%$ ) foi obtido com a utilização de todas as 126 componentes principais, sem nenhuma exclusão. É possível notar 
pela Tabela 16 (e pela sua extensão no Apêndice) que os descritores de Haralick que diferem apenas pela simetria utilizada para calcular GLCM são geralmente ordenados em posições contiguas, sugerindo uma alta correlação entre eles. Essa hipótese é de fato confirmada quando as correlações são calculadas. Acredita-se que esse é o motivo por que a PCA obteve bons resultados em melhorar a acurácia quando havia atributos de textura envolvidos, sobretudo nas análises $A_{T}$ e $A_{C T}$, em que esses atributos compunham a maioria dos elementos do vetor de característica. Apesar de a alta correlação não estar presente em todos os descritores de Haralick, escolher apenas uma simetria para compor o conjunto de atributos de textura pode melhorar não só a acurácia da classificação, como também reduzir sobremaneira o tempo de processamento.

Tabela 20 - Acurácias (em \%) das classificações utilizando os melhores atributos de cada técnica de seleção de atributos para a análise $\mathbf{A C T}_{\mathrm{CT}}$

Os resultados da reavaliações após a aplicação da PCA são dadas entre parênteses

\begin{tabular}{cccc}
\hline Número de Atributos & Ganho de Informação & Chi $^{2}$ & PCA \\
\hline 30 & 74,10 & 75,54 & 78,94 \\
60 & 77,59 & 77,75 & 81,87 \\
90 & 79,32 & 79,62 & 84,02 \\
120 & 81,17 & 82,96 & 85,01 \\
150 & 83,47 & 83,61 & 86,01 \\
160 & 83,61 & 83,69 & 86,01 \\
170 & 83,89 & 83,72 & 85,89 \\
180 & 84,22 & 84,43 & 86,08 \\
190 & 84,73 & $84,47(86,41)$ & 86,11 \\
200 & $84,90(86,59)$ & 84,30 & 86,51 \\
210 & 84,72 & 84,72 & 86,09 \\
\hline
\end{tabular}




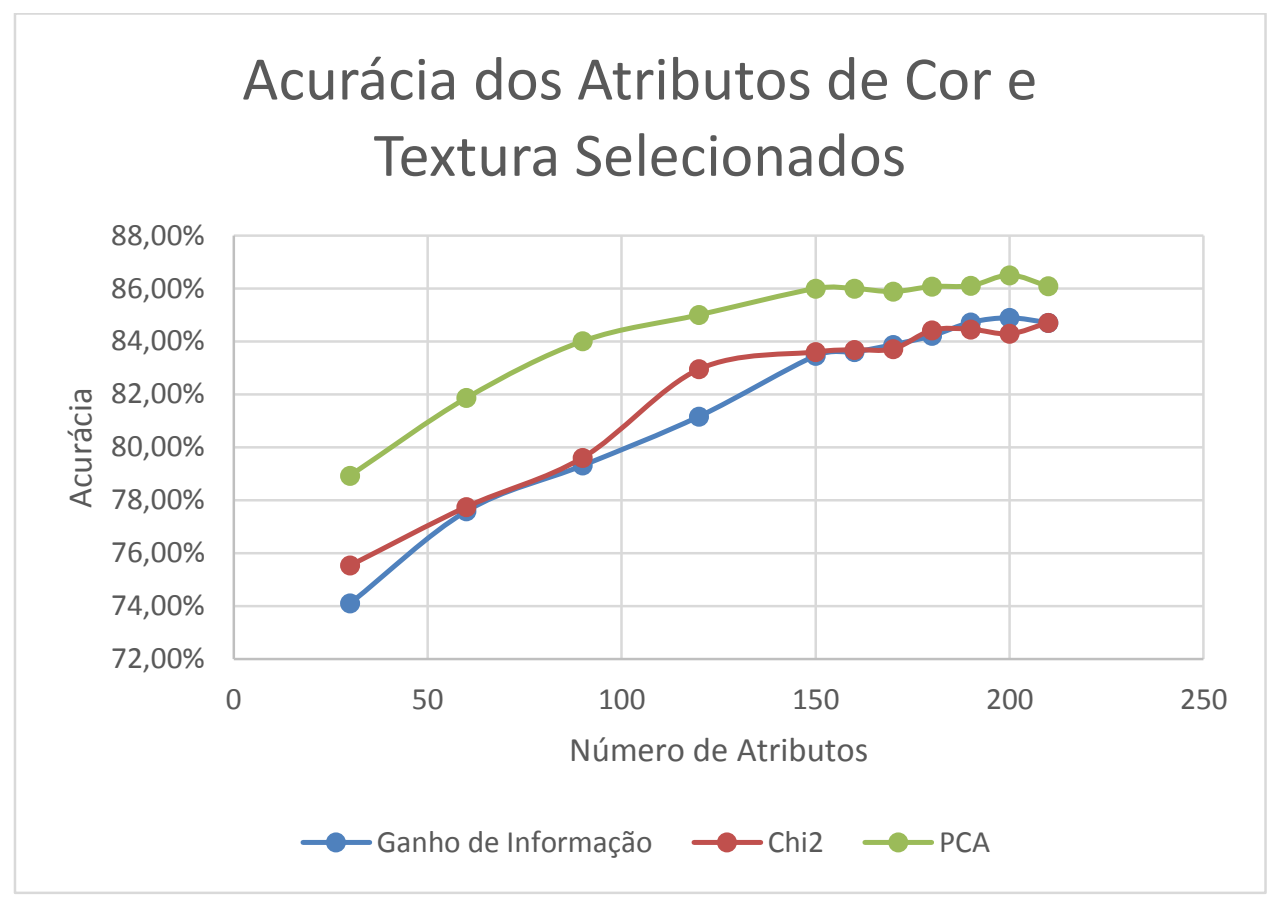

Gráfico 15 - Acurácias das classificações utilizando os melhores atributos de cada técnica de seleção de atributos para a análise AcT

Como a maioria das classes é visualmente caracterizada por aspectos envolvendo coloração, era esperado que os atributos de cor e textura tivessem melhor poder discriminante, como de fato foi corroborado pelos resultados. Tendo em vista que as análises $A_{C}, A_{T}$ e $A_{C T}$ foram conduzidas utilizando exatamente o mesmo conjunto de amostras e com as mesmas classes fundidas, torna-se apropriado comparar seus resultados. Os atributos de textura selecionados para a Análise $\mathrm{A}_{\mathrm{T}}$ superaram os atributos de cor selecionados para análise $\mathrm{A}_{\mathrm{C}}$ em 5,78\%, ao se comparar as acurácias obtidas, com os primeiros classificando corretamente $83,67 \%$ das amostras e os últimos 79,10\%. Portanto, o padrão com que as cores são distribuídas pelos grãos é mais discriminante que o aspecto geral da coloração do grão. A união dos atributos de cor e textura proporcionou melhor eficácia do que a utilização de qualquer um dos dois separadamente, de modo que a acurácia obtida com essa união foi de $86,59 \%$, superando os atributos de textura em 3,49\%. Esse resultado coincide com as conclusões apresentadas por Majumdar e Jayas (2000d), trabalho envolvendo classificação de grãos de trigo, em que os resultados da utilização de atributos de diferentes naturezas - cor, morfologia e textura superaram significativamente o emprego de atributos exclusivos de uma natureza. 
Tabela 21 - Acurácias (em \%) das classificações utilizando os melhores atributos de cada técnica de seleção de atributos para a análise AMCT.

Os resultados da reavaliações após a aplicação da PCA são dadas entre parênteses

\begin{tabular}{cccc}
\hline Número de Atributos & Ganho de Informação & $\mathbf{C h i}^{\mathbf{2}}$ & PCA \\
\hline 50 & 79,11 & 77,80 & 76,24 \\
100 & 80,42 & 80,34 & 76,40 \\
150 & 81,45 & 81,12 & 78,27 \\
200 & 82,47 & 82,62 & 80,83 \\
250 & $82,97(85,08)$ & 83,17 & 81,96 \\
300 & 79,43 & $83,71(84,74)$ & 82,71 \\
\hline
\end{tabular}

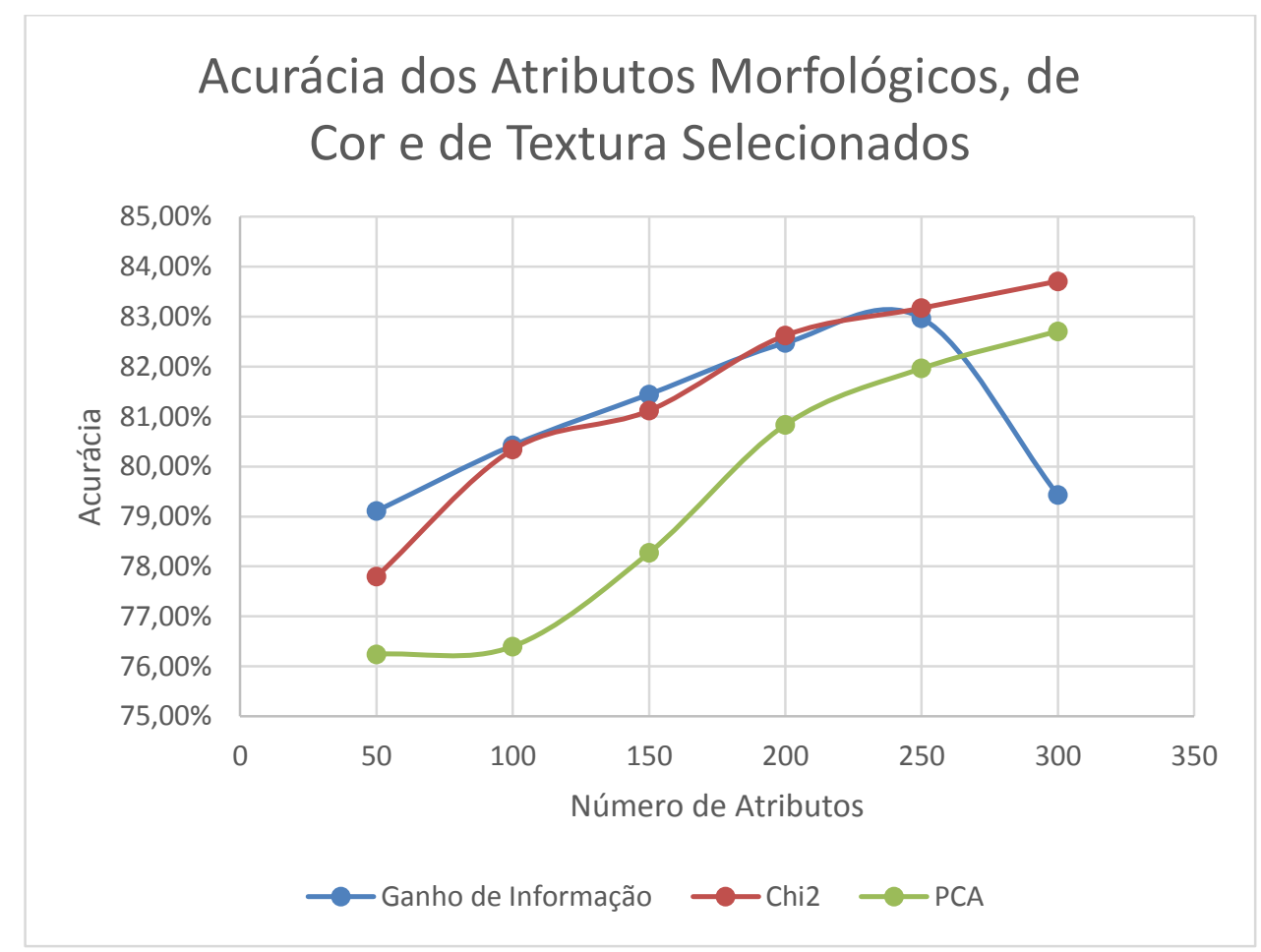

Figura 32 - Acurácias das classificações utilizando os melhores atributos de cada técnica de seleção de atributos para a análise $\mathbf{A M C T}_{\mathrm{MCT}}$

Os atributos selecionados para a análise $\mathrm{A}_{\mathrm{MCT}}$, os quais proporcionaram a acurácia de $85,08 \%$, foram o conjunto das componentes principais resultantes da aplicação da PCA nos 250 atributos mais bem avaliados sendo o critério chi-quadrado. Os 250 atributos selecionados pelo chi-quadrado foram: 111 atributos de textura (88,10\% dos atributos de textura avaliados), 82 atributos de cor $(97,62 \%$ dos atributos de cor avaliados) e 57 atributos morfológicos $(27,01 \%$ dos atributos morfológicos avaliados). Esses dados reforçam o baixo desempenho dos atributos morfológicos e sugere que apesar de os atributos de textura serem mais discriminantes como 
um todo, individualmente os atributos de cor são mais poderosos, já que quase todos eles foram selecionados para compor essa análise. Para reforçar essa ideia, pode ser verificado que na análise $\mathrm{A}_{\mathrm{CT}}$, dos 10 atributos excluídos, apenas 2 são de cor. Esses dois atributos são curtoses, que é o atributo estatístico que extraiu menos informações dos histogramas de cor.

Deve-se notar que o número de atributos da análise $\mathrm{A}_{\mathrm{MCT}}$ submetidos ao processo de seleção foi de 421, mas as avaliações utilizaram no máximo 300 deles. As avaliações não foram além devido ao longo tempo de processamento envolvido, que chegou a ser de semanas, quando 300 atributos foram utilizados com o método da validação cruzada. As técnicas de seleção de atributos, com exceção da ordenação por ganho de informação, apresentaram curvas crescentes de acurácia em função do número de atributos, sugerindo que os resultados poderiam ser melhorados caso mais atributos fossem incorporados ao vetor de características.

A melhor acurácia da análise $\mathrm{A}_{\mathrm{CT}}(86,59 \%)$ foi maior que a melhor acurácia da análise $\mathrm{A}_{\mathrm{MCT}}$ (85,08\%), entretanto, como os conjuntos de classes das análises não são os mesmos (a análise $A_{C T}$ teve seu problema simplificado ao fundir algumas das classes) não cabe comparação entre os resultados.

A Tabela 22 resume os resultados apresentados nesta seção. Por ela constata-se que a máxima disparidade entre a acurácia e o recall médio provenientes das classificações geradas com os atributos selecionados foi de 2,42\%. Portanto, pode se dizer que o desbalanceamento da distribuição das amostras entre as classes não afetou os treinamentos ao ponto de produzir classificações muito enviesadas, gerando acurácias enganosas. Assim sendo, os resultados dos experimentos foram utilizados para definir os vetores de características adotados por cada análise.

Tabela 22 - Resumo do processo de seleção de atributos

\begin{tabular}{|c|c|c|c|c|c|c|}
\hline Análise & $\begin{array}{l}\text { Números de atributos do vetor de características } \\
\text { avaliados }\end{array}$ & $\begin{array}{c}\text { Número } \\
\text { de } \\
\text { amostras }\end{array}$ & $\begin{array}{l}\text { Número de } \\
\text { atributos } \\
\text { com melhor } \\
\text { acurácia }\end{array}$ & $\begin{array}{c}\text { Melhor } \\
\text { Acurácia } \\
\text { (\%) }\end{array}$ & $\begin{array}{l}\text { Respectivo } \\
\text { Recall } \\
\text { Médio (\%) }\end{array}$ & $\begin{array}{l}\text { Técnica do } \\
\text { Melhor } \\
\text { Resultado }\end{array}$ \\
\hline$A_{M}$ & $\begin{array}{c}10,15,20,25,30,35,40,45,50,55,60,90 \\
120,150,180,211\end{array}$ & 5933 & 20 & 64.82 & 66.39 & $\mathrm{Chi}^{2}$ \\
\hline$A_{C}$ & $15,25,35,45,55,65,75,84$ & 10469 & 75 & 79.10 & 78.98 & PCA \\
\hline$A_{T}$ & $10,30,50,70,90,100,110,120,126$ & 10469 & 126 & 83.67 & 83.69 & PCA \\
\hline
\end{tabular}




\begin{tabular}{|c|c|c|c|c|c|c|}
\hline$A_{C T}$ & $30,60,90,120,150,160,170,180,190,200,210$ & 10469 & 200 & 86.59 & 86.69 & $\begin{array}{c}\text { Ganho de } \\
\text { informação } \\
\text { seguido de } \\
\text { PCA }\end{array}$ \\
\hline$A_{M C T}$ & $50,100,150,200,250,300$ & 14088 & 250 & 85.08 & 85.62 & $\begin{array}{c}\text { Ganho de } \\
\text { informação } \\
\text { seguido de } \\
\text { PCA }\end{array}$ \\
\hline
\end{tabular}

\subsection{Definição do Processo Classificatório}

As avaliações dos processos classificatórios foram conduzidas com os vetores de características de cada análise definidos pelos resultados apresentados na seção anterior. Os resultados das classificações de cada processo são apresentadas na Tabela 23. São dados os recalls por classe (com os melhores destacados), a acurácia, o recall médio e a melhoria obtida pelo melhor resultado em comparação ao segundo melhor.

Tabela 23 - Recalls das classes dos Processos Classificatórios

\begin{tabular}{|c|c|c|c|c|}
\hline Classe & $P_{M+C+T}$ & $P_{M+C T}$ & $P_{M C T}$ & Melhoria \\
\hline Perfeito & $69.0 \%$ & $70.7 \%$ & $85.3 \%$ & $20.65 \%$ \\
\hline Coco & $80.3 \%$ & $65.6 \%$ & $87.2 \%$ & $8.59 \%$ \\
\hline Pedra & $71.1 \%$ & $72.5 \%$ & $81.0 \%$ & $11.72 \%$ \\
\hline Triangulo & $58.2 \%$ & $58.8 \%$ & $62.8 \%$ & $6.80 \%$ \\
\hline Melado & $90.0 \%$ & $86.0 \%$ & $92.5 \%$ & $2.78 \%$ \\
\hline Marinheiro & $91.3 \%$ & $91.8 \%$ & $95.4 \%$ & $3.92 \%$ \\
\hline Branco & $84.3 \%$ & $84.6 \%$ & $90.3 \%$ & $6.74 \%$ \\
\hline Concha & $72.8 \%$ & $68.9 \%$ & $87.7 \%$ & $20.47 \%$ \\
\hline Preto-Verde & $80.6 \%$ & $85.3 \%$ & $88.6 \%$ & $3.87 \%$ \\
\hline Casca & $61.6 \%$ & $64.1 \%$ & $86.4 \%$ & $34.79 \%$ \\
\hline Barrento & $85.4 \%$ & $76.2 \%$ & $88.6 \%$ & $3.75 \%$ \\
\hline Preto & $82.7 \%$ & $84.8 \%$ & $90.0 \%$ & $6.13 \%$ \\
\hline Chocho & $63.9 \%$ & $59.9 \%$ & \begin{tabular}{|l|}
$76.8 \%$ \\
\end{tabular} & $20.19 \%$ \\
\hline Cabeça & $81.4 \%$ & $82.8 \%$ & $87.8 \%$ & $6.04 \%$ \\
\hline $\mathrm{Pau}$ & $68.6 \%$ & $78.8 \%$ & $75.3 \%$ & $4.65 \%$ \\
\hline Quebrado & $56.0 \%$ & $55.2 \%$ & $75.8 \%$ & $35.36 \%$ \\
\hline Ardido & $72.0 \%$ & $74.9 \%$ & $74.4 \%$ & $0.67 \%$ \\
\hline $\begin{array}{l}\text { Casca de } \\
\text { Marinheiro }\end{array}$ & $67.0 \%$ & $69.5 \%$ & $74.0 \%$ & $6.47 \%$ \\
\hline Brocado & $54.9 \%$ & $58.5 \%$ & $71.8 \%$ & $22.74 \%$ \\
\hline Velho & $69.2 \%$ & $74.7 \%$ & $83.0 \%$ & $11.11 \%$ \\
\hline Verde & $75.0 \%$ & $80.4 \%$ & $88.0 \%$ & $9.45 \%$ \\
\hline Recall Médio & $73.11 \%$ & $73.52 \%$ & $82.99 \%$ & $12.87 \%$ \\
\hline Acurácia & $72.01 \%$ & $72.61 \%$ & $82.85 \%$ & $14.10 \%$ \\
\hline
\end{tabular}


A classificação utilizando um único passo, com a utilização de atributos de todas as naturezas de uma vez, conseguiu o melhor resultado para quase todos os recalls comparados, sendo superada na classificação em apenas duas das 21 classes ('Pau' e 'Ardido'). É importante que todas as classes sejam corretamente discriminadas, pois, como citado na Introdução, cada tipo de impureza e defeito deprecia a qualidade da bebida produzia de forma diferente, tendo, portanto, diferentes pesos na avaliação da amostra, variando de acordo com o critério de avaliação adotado. $\mathrm{O}$ processo $\mathrm{P}_{\mathrm{MCT}}$ não só obteve significante vantagem na acurácia, mas também apresentou larga superioridade no recall de algumas classes específicas, como 'Quebrado', para a qual foi observada uma melhoria de 35,36\% em relação aos outros processos. Das sete classes com recall inferior a $80 \%$, quatro não podem ser distinguidas sem uma análise morfológica: ‘Triângulo', ‘Quebrado’ e 'Chocho’ (que nada mais são do que grãos perfeitos, porém com contornos característicos que os torna impróprios) e 'Casca de Marinheiro' (que é a casca do defeito 'Marinheiro', geralmente encontrada em pedaços e com um formato muito irregular). Essa observação reforça que o reconhecimento da forma do grão é o principal desafio da classificação.

A abordagem de realizar classificações em duas etapas se mostrou inferior à abordagem com uma classificação única e direta. Os processos classificatórios que utilizam a primeira abordagem, $\mathrm{P}_{\mathrm{M}+\mathrm{C}+\mathrm{T}}$ e $\mathrm{P}_{\mathrm{M}+\mathrm{CT}}$, obtiveram acurácias similares $\quad(72,01 \%$ e $72,61 \%$, respectivamente), enquanto a segunda abordagem, dada pelo processo $\mathrm{P}_{\mathrm{MCT}}$, superou a acurácia do melhor dos processos anteriores em $14,10 \%$, proporcionando o valor de $82,85 \%$. Portanto, pode-se inferir que é desenvolvida uma sinergia quando os atributos em questão são empregados em conjunto. A perda dessa sinergia pela utilização dos atributos separadamente não é compensada na união dos resultados das classificações intermediárias.

O processo classificatório $\mathrm{P}_{\mathrm{MCT}}$ nada mais é do que a própria análise $\mathrm{A}_{\mathrm{MCT}}$, cujos resultados foram apresentados na seção anterior. Como a análise $\mathrm{A}_{\mathrm{MCT}}$ foi avaliada com um conjunto mais completo de amostras e pelo método da validação cruzada, seu resultado é mais confiável e será entendido como o resultado do método proposto neste trabalho. A matriz de confusão da análise $\mathrm{A}_{\mathrm{MCT}}$, ou seja do processo classificatório $\mathrm{P}_{\mathrm{MCT}}$, é apresentada na Tabela 24 e os recalls obtidos são dados na

Tabela 25. Assim, a acurácia de $85,08 \%$ e o recall médio de $85,62 \%$ serão utilizados para comparar a eficácia do método de classificação deste estudo com trabalhos correlatos. 
Tabela 24 - Matriz de confusão do processo classificatório proposto.

Os valores destacados são o número de classificações corretas. a) perfeito, b) coco, c) pedra, d) triângulo, e) melado, f) marinheiro, g) branco, h) concha, i) preto-verde, j) casca, k) barrento, l) preto, m) chocho, n) cabeça, o) pau, p) quebrado, q) ardido, r) casca de marinheiro, s) brocado, t) velho, u) verde

\begin{tabular}{|c|c|c|c|c|c|c|c|c|c|c|c|c|c|c|c|c|c|c|c|c|c|c|}
\hline & \multicolumn{21}{|c|}{ Classe atribuída } \\
\hline & & a & b & c & d & $\mathbf{e}$ & $\mathbf{f}$ & g & $\mathbf{h}$ & $\mathbf{i}$ & $\mathbf{j}$ & $\mathbf{k}$ & 1 & $\mathbf{m}$ & $\mathbf{n}$ & $\mathbf{o}$ & $\mathbf{p}$ & $\mathbf{q}$ & $\mathbf{r}$ & $\mathbf{s}$ & $\mathbf{t}$ & $\mathbf{u}$ \\
\hline \multirow{21}{*}{ 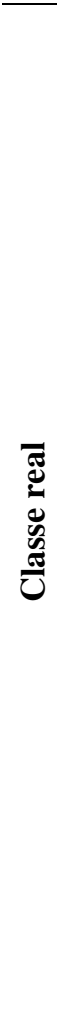 } & $\mathbf{a}$ & 671 & 0 & 0 & 53 & 1 & 0 & 4 & 11 & 0 & 0 & 7 & 0 & 48 & 37 & 0 & 15 & 2 & 1 & 22 & 8 & 20 \\
\hline & b & 0 & 485 & 0 & 0 & 0 & 1 & 0 & 0 & 37 & 0 & 0 & 19 & 0 & 0 & 0 & 0 & 0 & 1 & 0 & 0 & 1 \\
\hline & c & 1 & 2 & 611 & 0 & 5 & 0 & 1 & 2 & 0 & 17 & 8 & 0 & 2 & 0 & 36 & 8 & 8 & 5 & 4 & 0 & 0 \\
\hline & d & 54 & 0 & 1 & 618 & 0 & 0 & 7 & 17 & 0 & 0 & 5 & 0 & 14 & 0 & 4 & 65 & 2 & 3 & 8 & 6 & 16 \\
\hline & e & 0 & 0 & 0 & 0 & 464 & 2 & 1 & 3 & 0 & 3 & 7 & 0 & 0 & 2 & 1 & 0 & 8 & 1 & 0 & 10 & 0 \\
\hline & $\mathbf{f}$ & 0 & 0 & 0 & 0 & 2 & 518 & 2 & 0 & 0 & 4 & 0 & 0 & 0 & 1 & 1 & 0 & 0 & 5 & 2 & 12 & 0 \\
\hline & $\mathbf{g}$ & 9 & 0 & 0 & 5 & 0 & 5 & 614 & 1 & 0 & 0 & 0 & 0 & 1 & 6 & 6 & 1 & 0 & 1 & 4 & 14 & 0 \\
\hline & $\mathbf{h}$ & 17 & 0 & 3 & 9 & 2 & 0 & 0 & 516 & 0 & 0 & 5 & 1 & 1 & 2 & 3 & 3 & 8 & 5 & 6 & 5 & 2 \\
\hline & $\mathbf{i}$ & 1 & 24 & 1 & 0 & 0 & 0 & 0 & 0 & 673 & 1 & 0 & 43 & 0 & 0 & 1 & 0 & 0 & 1 & 0 & 0 & 1 \\
\hline & $\mathbf{j}$ & 0 & 2 & 10 & 0 & 8 & 1 & 0 & 1 & 0 & 442 & 3 & 0 & 0 & 0 & 7 & 0 & 11 & 11 & 0 & 0 & 0 \\
\hline & $\mathbf{k}$ & 5 & 0 & 7 & 2 & 8 & 0 & 0 & 3 & 0 & 2 & 7 & 0 & 2 & 2 & 7 & 4 & 8 & 5 & 2 & 17 & 4 \\
\hline & I & 0 & 16 & 0 & 0 & 0 & 0 & 0 & 0 & 36 & 0 & 0 & 525 & 0 & 0 & 0 & 0 & 0 & 0 & 0 & 0 & 0 \\
\hline & $\mathbf{m}$ & 46 & 0 & 1 & 22 & 0 & 0 & 1 & 3 & 0 & 0 & 7 & 0 & 656 & 0 & 1 & 31 & 0 & 1 & 11 & 7 & 11 \\
\hline & $\mathbf{n}$ & 24 & 0 & 0 & 1 & 0 & 1 & 4 & 2 & 0 & 0 & 1 & 0 & 0 & 654 & 0 & 0 & 2 & 0 & 3 & 1 & 5 \\
\hline & o & 0 & 0 & 41 & 3 & 2 & 1 & 8 & 0 & 1 & 18 & 8 & 0 & 2 & 1 & 505 & 5 & 3 & 28 & 4 & 6 & 1 \\
\hline & $\mathbf{p}$ & 16 & 1 & 7 & 62 & 0 & 0 & 3 & 11 & 1 & 0 & 3 & 0 & 54 & 0 & 1 & $\overline{727}$ & 0 & 7 & 26 & 0 & 1 \\
\hline & $\mathbf{q}$ & 1 & 0 & 7 & 1 & 5 & 0 & 0 & 18 & 0 & 14 & 19 & 3 & 0 & 1 & 4 & 0 & $4 \longdiv { 4 3 1 }$ & 1 & 9 & 1 & 3 \\
\hline & $\mathbf{r}$ & 0 & 2 & 7 & 6 & 3 & 11 & 0 & 2 & 1 & 3 & 6 & 0 & 0 & 3 & 29 & 15 & 2 & 395 & 6 & 8 & 0 \\
\hline & $\mathbf{s}$ & 35 & 0 & 6 & 17 & 0 & 0 & 3 & 11 & 0 & 1 & 6 & 0 & 15 & 2 & 6 & 37 & 15 & 3 & 528 & 5 & 20 \\
\hline & $\mathbf{t}$ & 2 & 0 & 1 & 8 & 6 & 12 & 6 & 5 & 0 & 1 & 17 & 0 & 20 & 2 & 5 & 1 & 0 & 4 & 1 & 542 & 0 \\
\hline & $\mathbf{u}$ & 19 & 0 & 0 & 21 & 2 & 1 & 2 & 1 & 2 & 0 & 4 & 0 & 7 & 5 & 0 & 2 & 5 & 1 & 16 & 1 & $\longdiv { 7 0 1 }$ \\
\hline
\end{tabular}

Tabela 25 - Recalls do processo classificatório proposto.

\begin{tabular}{cl}
\hline Classe & Recall \\
\hline Perfeito & $74,6 \%$ \\
Coco & $89,2 \%$ \\
Pedra & $86,1 \%$ \\
Triangulo & $75,4 \%$ \\
Melado & $92,4 \%$ \\
Marinheiro & $94,7 \%$ \\
Branco & $92,1 \%$ \\
Concha & $87,8 \%$ \\
Preto-Verde & $90,2 \%$ \\
Casca & $89,1 \%$
\end{tabular}




\begin{tabular}{cc} 
Barrento & $90,1 \%$ \\
Preto & $91,0 \%$ \\
Chocho & $82,2 \%$ \\
Cabeça & $93,7 \%$ \\
Pau & $79,3 \%$ \\
Quebrado & $79,0 \%$ \\
Ardido & $83,2 \%$ \\
Casca de & $79,2 \%$ \\
Marinheiro & $74,4 \%$ \\
Brocado & $85,6 \%$ \\
Velho & $88,7 \%$ \\
Verde & \\
Recall Médio & $85.62 \%$ \\
Acurácia & $85.08 \%$ \\
\hline
\end{tabular}

Da matriz de confusão identificaram-se as 10 maiores confusões cometidas pela classificação, ou seja, as mais frequentes ocorrências de um grão de uma dada classe ser classificado como sendo de outra classe específica. Essas confusões são apresentadas na Tabela 26.

Tabela 26 - Dez maiores confusões entre classes

Apresenta a porcentagem de grãos da classe real que foram classificados com a classe atribuída

\begin{tabular}{ccc}
\hline Classe real & Classe atribuída & \% \\
\hline Triângulo & Quebrado & 7,93 \\
Coco & Preto-verde & 6,80 \\
Quebrado & Triângulo & 6,74 \\
Triângulo & Perfeito & 6,59 \\
Pau & Pedra & 6,44 \\
Preto & Preto-verde & 6,24 \\
Perfeito & Triângulo & 5,89 \\
Quebrado & Chocho & 5,87 \\
Casca de Marinheiro & Pau & 5,81 \\
Chocho & Perfeito \\
\hline
\end{tabular}

Nota-se que a maior confusão se dá entre as classes 'triângulo' e 'quebrado', sendo que 7,93\% dos grãos 'triângulo' foram classificados como 'quebrado' e 6,74\% dos grãos 'quebrado' foram classificados como 'triângulo'. Constata-se que 6 das 10 confusões são em classes que teriam que ser distinguidas pela sua morfologia, reforçando que atributos capazes de identificar satisfatoriamente diferenças morfológicas são vitais para obter uma melhora no processo de classificação. 
Como constatado na Seção 1.2, não há muitos trabalhos acadêmicos publicados em que o problema aqui tratado é abordado. Os trabalho de Carrillo e Penãloza (2009) e Ahmad et al. (2010) são dois deles, em que são tratados problemas similares, mas em versões mais simples. No primeiro o recall médio de $67,7 \%$ foi obtido ao se classificar sete classes de grãos e impurezas, e no segundo a acurácia foi de 78,32\% e o número de classes envolvidas era quatro. Como os problemas não são exatamente os mesmos e não há como se determinar se há classes coincidentes, não é possível realizar uma comparação quantitativa, e mesmo uma comparação qualitativa pode ser grosseira. Entretanto, como há uma disparidade muito grande nos números de classes, é razoável se considerar que a acurácia significativamente superior obtida neste trabalho representa um progresso na busca de um método capaz de classificar grãos de café sem erros. Este avanço, em relação aos trabalhos comparados, pode ser creditado à incorporação de atributos de textura e à exploração de mais espaços de cor na análise, à avaliação de um vasto conjunto de atributos, os quais utilizam abordagens bem distintas para extração e representação de informação, e à seleção dos atributos mais promissores por técnicas bem consolidadas. 


\section{CONCLUSÕES}

Na busca por um método para classificação de amostras de grãos de café, 421 atributos 211 morfológicos, 126 de textura e 84 relacionados a cor - foram reunidos e organizados em cinco subconjuntos definidos pelas naturezas de seus elementos (morfologia, cor, textura, cortextura e morfologia-cor-textura). Cada um dos subconjuntos teve seus elementos submetidos a um processo de seleção em que foram descartados aqueles que não contribuíam para uma boa classificação. Os elementos selecionados foram utilizados como entrada para três processos classificatórios propostos, os quais foram submetidos a avaliações visando determinar o mais efetivo.

Com o intuito de se melhorar a análise por textura dos grãos, os descritores de Haralick foram modificados, proporcionando um aumento do desempenho dos classificadores na maioria dos casos testados. Apesar de a comparação dos resultados das duas versões dos descritores (original e modificada) terem sido feitas especificamente para alguns poucos espaços de cor, e para algumas classificações no problema abordado neste trabalho, a modificação proposta pode indicar um caminho a ser explorado na busca de melhores formas de descrever textura, e assim uma contribuição foi dada nessa área.

Um vasto conjunto de atributos foi avaliado, e selecionaram-se os mais promissores por uma série de classificações-teste conduzidas pelo método da validação cruzada. Esse processo de seleção mostrou que cor e textura são os aspectos mais importantes a serem considerados para se distinguir as classes do problema aqui tratado. Também foi mostrado que, apesar de espaços de cor serem apenas diferentes representações de uma mesma característica física, utilizar várias versões de um mesmo atributo, sendo cada uma proveniente de um espaço de cor distinto, em um vetor de características pode ser vantajoso. Após todas as avaliações, e tendo sido determinada a melhor configuração, o processo classificatório selecionado proporcionou a acurácia de $85,08 \%$, atestada pelo método da validação cruzada, com recalls das classes variando de $62,80 \%$ a $95,4 \%$, superando resultados obtidos em trabalhos correlatos que abordam versões mais simples do problema tratado.

A principal deficiência do método de classificação proposta é a dificuldade em identificar as nuances de forma que separam certas classes. Acredita-se que um esforço para superar essa dificuldade melhoraria significantemente o desempenho da classificação e é a direção sugerida para futuros trabalhos. Sugere-se a exploração de novos atributos que visem extrair 
características especificas da forma (como é o caso do perímetro, e da excentricidade, por exemplo), em detrimento de atributos que se caracterizam por apresentar maneiras alternativas de representar formas ou contornos (como é o caso do modelo autorregressivo, por exemplo), já que atributos do primeiro tipo apresentaram melhor poder discriminante nas classificações conduzidas.

Assim, foi dada uma contribuição para a busca de uma técnica de classificação automática de café, rápida e livre de erros e subjetividade, podendo ajudar o setor de café a vencer importantes gargalos atualmente presentes no ciclo de vida do produto, que tem significante importância para o país. Essa contribuição pode também ser estendida para problemas similares de classificação de outros tipos de grãos. 


\section{TRABALHOS PUBLICADOS}

Os trabalhos publicados em mídias e eventos científicos frutos desta pesquisa de mestrado foram os seguintes:

- Capítulos de Livro:

1. JORGE, L.A.C; GONCALVES, D. S. ; OYAMA, P. I. C. . Uso de sistemas de imagem para classificação de frutas e hortaliças. Tecnologias pós-colheita em frutas e hortaliças. Tecnologias pós-colheita em frutas e hortaliças. 1ed.São Carlos/SP: Embrapa Instrumentação, 2011, v. 1, pp. 125-157.

2. OYAMA, P. I. C.; Jorge, L.A.C ; RODRIGUES, E. L. L. ; GOMES, C.C.. Sistema para Classificação Automática de Café em Grãos por Cor e Forma Através de Imagens Digitais. Avanços em Visão Computacional. Omnipax. Curitiba/PR, 2012, v.1, pp. 119-139.

- Trabalhos completos publicados em anais de congressos

1. OYAMA, P. I. C.; Jorge, L. A. C. ; RODRIGUES, E. L. L. . Comparação de Descritores de Forma aplicados na Classificação de Grãos de Café. In: VIII Workshop de Visão Computacional, 2012, Goiânia-GO. VIII Workshop de Visão Computacional, 2012.

2. OYAMA, P. I. C.; Rodrigues, Evandro Luis Linhari ; Jorge, L.A.C.. Metodologia para classificação de café em grãos utilizando imagens digitais. In: IV Jornada Científica Embrapa - São Carlos, 2012, São Carlos/SP. Anais da IV Jornada Científica Embrapa - São Carlos, 2012.

3. OYAMA, P. I. C.; Rodrigues, Evandro Luis Linhari ; Jorge, L.A.C..In: .Desenvolvimento de uma metodologia de visão computacional para classificação de grãos de café. In: V Workshop de Pós-Graduação em Engenharia Elétrica, 2012, São Carlos-SP. V Workshop de Pós-Graduação em Engenharia Elétrica, 2012.

4. OYAMA, P. I. C.; Jorge, L. A. C. ; RODRIGUES, E. L. L. . Methodology to Classify Coffee Beans Samples through Shape, Colour and Texture Descriptors. In: IX Workshop de Visão Computacional, 2013, Rio de Janeiro-RJ. IX Workshop de Visão Computacional, 2013.

5. OYAMA, P. I. C.; Jorge, L. A. C. ; RODRIGUES, E. L. L. . Computer Vision System to Identify Impurities amongst Coffee Beans: Fuzzy and Neural Approaches. In: IX Workshop de Visão Computacional, 2013, Rio de Janeiro-RJ. IX Workshop de Visão Computacional, 2013. 



\section{REFERÊNCIAS BIBLIOGRÁFICAS ${ }^{1}$}

AHMAD, I. et al. Color classifier for symptomatic soybean seeds using image processing. Plant Disease, v. 83, n. 4, p. 320-327, APR 1999 1999. ISSN 0191-2917.

AHMAD, U. et al. The Development of Automatic Coffee Sorting System Based on Image Processing and Artificial Neural Network. 2010.

AREFI, A.; MOTLAGH, A.; TEIMOURLOU, R. Wheat class identification using computer vision system and artificial neural networks. International Agrophysics, v. 25, n. 4, p. 319-325, 20112011 . ISSN 0236-8722.

BILLMEYER, F. W.; SALTZMAN, M. Describing Colors. In: (Ed.). Principles of color technology. 2nd. New York ; Chichester: Wiley, 1981. cap. 2, p.25-66. ISBN 047103052X : ${ }^{1} 20.00$.

BROGAN, W. L.; EDISON, A. R. Automatic classification of grains via pattern recognition techniques. Pattern Recognition, v. 6, n. 2, p. 97-103, 1974. ISSN 0031-3203.

BROWN, D. A.; CRAW, I.; LEWTHWAITE, J. A SOM based approach to skin detection with application in real time systems. BMVC, 2001, Citeseer. p.491-500.

CARRILLO, E.; PEÑALOZA, A. A. Artificial vision to assure coffee-Excelso beans quality. Proceedings of the 2009 Euro American Conference on Telematics and Information Systems: New Opportunities to increase Digital Citizenship, 2009, ACM. p.35.

CARTER, R.; YAN, Y.; TOMLINS, K. Digital imaging based classification and authentication of granular food products. Measurement Science \& Technology, v. 17, n. 2, p. 235-240, FEB 2006 2006. ISSN 0957-0233.

CHAVES-GONZALEZ, J. et al. Detecting skin in face recognition systems: A colour spaces study. Digital Signal Processing, v. 20, n. 3, p. 806-823, MAY 2010 2010. ISSN 1051-2004.

CHEN, X. et al. Combining discriminant analysis and neural networks for corn variety identification. Computers and Electronics in Agriculture, v. 71, p. S48-S53, APR 2010 2010. ISSN 0168-1699.

CHOUDHARY, R.; PALIWAL, J.; JAYAS, D. Classification of cereal grains using wavelet, morphological, colour, and textural features of non-touching kernel images. Biosystems Engineering, v. 99, n. 3, p. 330-337, MAR 2008 2008. ISSN 1537-5110.

CHTIOUI, Y. et al. Identification of seeds by colour imaging : comparison of discriminant analysis and artificial neural network. Journal of the Science of Food and Agriculture, v. 71, p. 433-441, 1996.

COSTA, L. D. F.; CESAR, R. M. Shape analysis and classification : theory and practice. Boca Raton, FL: CRC Press, 2000. ISBN 0849334934 (alk. paper)

CIP entry.

COX, E. et al. The Fuzzy Systems Handkbook with Cdrom. Academic Press, Inc., 1998. ISBN 0121944557.

DE DIOS, J. J.; GARCÍA, N. Face detection based on a new color space YCgCr. Image Processing, 2003. ICIP 2003. Proceedings. 2003 International Conference on, 2003, IEEE. p.III-909-12 vol. 2.

\footnotetext{
${ }^{1}$ De acordo com a Associação Brasileira de Normas Técnicas. NBR 6023/2002.
} 
DELWICHE, S.; YANG, I.; GRAYBOSCH, R. Multiple view image analysis of freefalling U.S. wheat grains for damage assessment. Computers and Electronics in Agriculture, v. 98, p. 62-73, OCT 2013 2013. ISSN 0168-1699.

DUBOIS, S.; GLANZ, F. An autoregressive model approach to two-dimensional shape classification. Ieee Transactions on Pattern Analysis and Machine Intelligence, v. 8, n. 1, p. 55-66, JAN 1986 1986. ISSN 0162-8828.

FARIDAH, F.; PARIKESIT, G. O.; FERDIANSJAH, F. Coffee bean grade determination based on image parameter. TELKOMNIKA (Telecommunication, Computing, Electronics and Control), v. 9, n. 3, p. 547554, 2013. ISSN 2302-9293.

FAYYAD, U.; IRANI, K.; BAJCSY, R. Multi-interval discretization of continuous-valued attributes for classification learning. Ijcai-93, Vols 1 and 2, p. 1022-1027, 19931993.

FORD, A.; ROBERTS, A. Colour space conversions. Westminster University, London, 1998.

GALlOWAY, M. M. Texture analysis using gray level run lengths. Computer graphics and image processing, v. 4, n. 2, p. 172-179, 1975. ISSN 0146-664X.

GONZALEZ, R. C.; WOODS, R. E. Digital image processing. In: (Ed.). 3rd. Upper Saddle River, NJ ; Harlow: Pearson/Prentice Hall, 2008a. cap. Wavelets and Multiresolution Processing, p.xxii, 954 p. ISBN 9780131687288 (hbk.)

013168728X (hbk.).

Digital image processing. 3rd ed. Upper Saddle River, N.J. ; Harlow: Pearson/Prentice Hall, 2008b. ISBN 9780131687288 (hbk.) : ${ }^{1} 46.99$

$013168728 \mathrm{X}$ (hbk.) : ${ }^{1} 46.99$.

HARALICK, R.; SHANMUGA.K; DINSTEIN, I. TEXTURAL FEATURES FOR IMAGE CLASSIFICATION. Ieee Transactions on Systems Man and Cybernetics, v. SMC3, n. 6, p. 610-621, 1973 1973. ISSN 0018-9472.

HASTIE, T.; TIBSHIRANI, R.; FRIEDMAN, J. H. Model assessment and selection. In: (Ed.). The elements of statistical learning : data mining, inference, and prediction. 2nd ed. New York: Springer, 2009. cap. 7, p.219-260. ISBN 9780387848570 (hbk.) : ${ }^{1} 55.99$

0387848576 (hbk.) : ${ }^{1} 55.99$.

HAYKIN, S. S. Neural networks : a comprehensive foundation. In: (Ed.). 2nd. Upper Saddle River, N.J.: Prentice Hall, 1999. cap. Multilayer Perceptrons, p.xxi, 842 p. ISBN 0132733501.

INTERNATIONAL COFFEE ORGANIZATION. Exporting countries: total production. 2014a

. Exports by exporting countries to all destinations. 2014b

JACK, K. Video demystified a handbook for the digital engineer. Amsterdam ; Boston: Newnes/Elsevier,: 944 p. 2007.

JACOBS, R. Increased rates of convergence through learning rate adaptation. Neural Networks, v. 1, n. 4, p. 295-307, 1988 1988. ISSN 0893-6080.

JAIN, A. K. Fundamentals of digital image processing. Englewood Cliffs, NJ: Prentice Hall, 1989. ISBN 0133361659.

JOLLIFFE, I. Principal component analysis. Wiley Online Library, 2005. ISBN 0470013192. 
JORGE, L. A. C. et al. Uso de sistemas de imagem para classificação de frutas e hortaliças. In: FERREIRA, M. D. (Ed.). Tecnologias Pós-Colheita em Frutas e Hortaliças. São Carlos, SP: Embrapa Instrumentação, 2011. cap. 7, p.127-153.

KHATCHATOURIAN, O.; PADILHA, F. R. Reconhecimento de variedades de soja por meio do processamento de imagens digitais usando redes neurais artificiais. Eng Agric Jaboticabal, v. 28, n. 4, p. 759-69, 2008.

KUHL, F.; GIARDINA, C. Elliptic fourier features of a closed contour. Computer Graphics and Image Processing, v. 18, n. 3, p. 236-258, 1982 1982. ISSN 0148-664X.

MACKAY, D. J. C. Information theory, inference and learning algorithms. Cambridge: Cambridge University Press, 2003. ISBN 0521642981 : No price. Disponível em: < Publisher description http://www.loc.gov/catdir/description/cam032/2003055133.html >.Disponível em: < Table of contents http://www.loc.gov/catdir/toc/cam031/2003055133.html >.

MAHALANOBIS, P. C. On the generalized distance in statistics. Proceedings of the National Institute of Sciences (Calcutta), v. 2, p. 49-55, 1936.

MAJUMDAR, S.; JAYAS, D. Classification of cereal grains using machine vision: I. Morphology models. Transactions of the Asae, v. 43, n. 6, p. 1669-1675, NOV-DEC 2000 2000a. ISSN 0001-2351.

. Classification of cereal grains using machine vision: II. Color models. Transactions of the Asae, v. 43, n. 6, p. 1677-1680, NOV-DEC 2000 2000b. ISSN 0001-2351.

. Classification of cereal grains using machine vision: III. Texture models. Transactions of the Asae, v. 43, n. 6, p. 1681-1687, NOV-DEC 2000 2000c. ISSN 0001-2351.

Classification of cereal grains using machine vision: IV. Combined morphology, color, and texture models. Transactions of the Asae, v. 43, n. 6, p. 1689-1694, NOV-DEC 2000 2000d. ISSN 0001-2351.

MALIK, F.; BAHARUDIN, B. The statistical quantized histogram texture features analysis for image retrieval based on median and laplacian filters in the DCT domain. International Arab Journal of Information Technology, v. 10, n. 6, p. 616-624, NOV 2013 2013. ISSN 1683-3198.

MCLACHLAN, G. J. Discriminant analysis and statistical pattern recognition. Hoboken, N.J.: WileyInterscience, 2004. ISBN 9780471691150 (pbk.)

0471691151 (pbk.) : No price.

MENDENHALL, W.; BEAVER, R. J.; BEAVER, B. M. Analysis of Categorical Data. In: (Ed.). Introduction to probability and statistics. 14th ed. [Pacific Grove, Calif.]: Brooks/Cole, 2013. cap. 14, p.574-605. ISBN 9781133111504 (pbk.) : ${ }^{1} 44.99$

1133111505 (pbk.) : ${ }^{1} 44.99$.

NEUMAN, M. et al. Wheat-grain color analysis by digital image-processing .1. methodology. Journal of Cereal Science, v. 10, n. 3, p. 175-182, NOV 1989 1989a. ISSN 0733-5210.

Wheat-grain color analysis by digital image-processing .2. wheat class discrimination. Journal of Cereal Science, v. 10, n. 3, p. 183-188, NOV 1989 1989b. ISSN 0733-5210.

OHTA, Y.; KANADE, T.; SAKAI, T. Color information for region-segmentation. Computer Graphics and Image Processing, v. 13, n. 3, p. 222-241, 1980 1980. ISSN 0148-664X.

OLIVER, N.; ROSARIO, B.; PENTLAND, A. A Bayesian computer vision system for modeling human interactions. Ieee Transactions on Pattern Analysis and Machine Intelligence, v. 22, n. 8, p. 831-843, AUG 2000 2000. ISSN 0162-8828.

OYAMA, P. I. C.; RODRIGUES, E. L. L.; JORGE, L. A. C. Comparação de descritores de forma aplicados na classificação de grãos de café. VIII Workshop de Visão Computacional. Goiância, GO 2012. 
PRATT, W. K. Digital image processing : PIKS Scientific inside. 4th ed., Newly updated and rev. ed. New York ; Chichester: Wiley-Interscience, 2007. ISBN 9780471767770 (hbk.) : ${ }^{173.95}$

0471767778 (hbk.) : ${ }^{1} 73.95$.

RAO, K. R.; YIP, P. C. Karhunen-Loève Transform. In: (Ed.). The transform and data compression handbook. Boca Raton; London: CRC Press, 2001. cap. 1, ISBN 0849336929 : No price.

RUMELHART, D. E.; HINTON, G. E.; WILLIAMS, R. J. Learning internal representations by error propagation. DTIC Document. 1985

SETIONO, R.; LIU, H. Improving backpropagation learning with feature selection. Applied Intelligence, v. 6, n. 2, p. 129-139, APR 1996 1996. ISSN 0924-669X.

SHI, Y. Q.; SUN, H. Image and video compression for multimedia engineering : fundamentals, algorithms, and standards. 2nd ed. Boca Raton, Fla.: CRC ; London : Taylor \& Francis [distributor], 2008. ISBN 9780849373640 (hbk.) : ${ }^{1} 44.99$

0849373646 (hbk.) : ${ }^{1} 44.99$.

SHOUCHE, S. et al. Shape analysis of grains of Indian wheat varieties. Computers and Electronics in Agriculture, v. 33, n. 1, p. 55-76, 2001. ISSN 0168-1699.

SILVA, I. N.; SPATTI, D. H.; FLAUZINO, R. A. Redes neurais artificiais para engenharia e ciências aplicadas. São Paulo: Artliber, 2010.

SYMONS, S. J.; FULCHER, R. Determination of wheat kernel morphological variation by digital image analysis: I. Variation in Eastern Canadian milling quality wheats. Journal of cereal science, v. 8, n. 3, p. 211218, 1988. ISSN 0733-5210.

TEAGUE, M. Image analysis via the general-theory of moments. Journal of the Optical Society of America, v. 69, n. 10, p. 1468-1468, 1979 1979. ISSN 0030-3941.

VALIENTE-GONZALEZ, J. et al. Automatic corn (Zea mays) kernel inspection system using novelty detection based on principal component analysis. Biosystems Engineering, v. 117, p. 94-103, JAN 2014 2014. ISSN 1537-5110.

WALCK, C. Handbook on statistical distributions for experimentalists: University of Stockholm Internal Report SUF-PFY/96-01, available from www. physto. se/ walck 2007.

WITTEN, I. H.; FRANK, E.; HALL, M. A. Data mining : practical machine learning tools and techniques. 3rd ed. / Ian H. Witten, Eibe Frank, Mark A. Hall. San Francisco, Calif. ; London: Morgan Kaufmann, 2011. ISBN 9780123748560 (pbk.) : ${ }^{1} 42.99$

0123748569 (pbk.) : ${ }^{1} 42.99$.

ZHANG, D.; LU, G. Generic Fourier descriptor for shape-based image retrieval. Ieee International Conference on Multimedia and Expo, Vol I and Ii, Proceedings, p. 425-428, 20022002.

. Review of shape representation and description techniques. Pattern Recognition, v. 37, n. 1, p. 1-19, JAN 2004 2004. ISSN 0031-3203. 


\section{APÊNDICE}

Nas Tabelas 28-32 são apresentadas as ordenações dos atributos pelos algoritmos de ganho de informação e chi-quadrado para as diferentes análises. A notação utilizada nas tabelas é apresentada na Tabela 27.

Tabela 27 - Notação dos atributos utilizada nas tabelas de ordenações

\begin{tabular}{|c|c|}
\hline Atributo & Descrição \\
\hline Fu & Descritor de Fourier de frequência $\mathbf{u}$ \\
\hline DGF_Rp_A $\boldsymbol{\varphi}$ & $\begin{array}{c}\text { Descritor genérico de Fourier de frequência radial } \rho \mathrm{e} \\
\text { frequência angular } \boldsymbol{\varphi}\end{array}$ \\
\hline AR_SN & Razão sinal-ruído do modelo autorregressivo \\
\hline AR_i & i-ésimo parâmetro do modelo autorregressivo \\
\hline Zernike_On_Rm & Momento de Zernike de ordem $\mathbf{n}$ e repetição $\mathbf{m}$ \\
\hline $\mathrm{A} \mathbf{i}$ & i-ésimo atributo derivado $\left(\mathrm{A}_{\mathrm{i}}\right)$ \\
\hline C_média & Média do histograma do canal de cor $\mathbf{C}$ \\
\hline C_variância & Variância do histograma do canal de cor $\mathbf{C}$ \\
\hline C_suavidade & Suavidade do histograma do canal de cor $\mathbf{C}$ \\
\hline C_energia & Energia do histograma do canal de cor $\mathbf{C}$ \\
\hline C_obliquidade & Obliquidade do histograma do canal de cor $\mathbf{C}$ \\
\hline C_entropia & Entropia do histograma do canal de cor $\mathbf{C}$ \\
\hline C_curtose & Curtose do histograma do canal de cor $\mathbf{C}$ \\
\hline F_C_i(Horizontal) & $\begin{array}{l}\text { i-ésimo descritor de Haralick modificado calculado } \\
\text { para o canal de cor } \mathbf{C} \text { e simetria horizontal }\end{array}$ \\
\hline F_C_i(Vertical) & $\begin{array}{l}\text { i-ésimo descritor de Haralick modificado calculado } \\
\text { para o canal de cor } \mathbf{C} \text { e simetria vertical }\end{array}$ \\
\hline F_C_i(Diagonal) & $\begin{array}{l}\text { i-ésimo descritor de Haralick modificado calculado } \\
\text { para o canal de cor } \mathbf{C} \text { e simetria diagonal }\end{array}$ \\
\hline
\end{tabular}


Tabela 28 - Ordenação dos atributos da análise $A_{M}$ pelos algoritmos Ganho de Informação e chi-quadrado

\begin{tabular}{|c|c|c|c|c|c|}
\hline Posição & $\begin{array}{c}\text { Ganho de } \\
\text { Informação }\end{array}$ & Chi-quadrado & Posição & $\begin{array}{l}\text { Ganho de } \\
\text { Informação }\end{array}$ & Chi-quadrado \\
\hline 1 & Perímetro & Perímetro & 107 & Zernike_O1_R1 & Zernike_O20_R0 \\
\hline 2 & Spread & Spread & 108 & Zernike_O7_R5 & Zernike_O15_R13 \\
\hline 3 & Zernike_O0_R0 & Zernike_O0_R0 & 109 & Zernike_O17_R15 & Zernike_O7_R1 \\
\hline 4 & Área & Área & 110 & Zernike_O5_R5 & Zernike_O13_R11 \\
\hline 5 & Zernike_O2_R0 & Zernike_O2_R0 & 111 & F3 & Zernike_O19_R7 \\
\hline 6 & F0 & F0 & 112 & Zernike_O19_R5 & Zernike_O17_R11 \\
\hline 7 & Zernike_O6_R0 & DGF_R0_A2 & 113 & DGF_R2_A6 & Zernike_O8_R2 \\
\hline 8 & DGF_R0_A2 & Zernike_O6_R0 & 114 & Zernike_O20_R0 & Zernike_O19_R5 \\
\hline 9 & Slenderness & Slenderness & 115 & Zernike_O12_R2 & Zernike_O5_R5 \\
\hline 10 & Zernike_O10_R0 & $\mathrm{F} 2$ & 116 & Zernike_O19_R7 & Zernike_O7_R5 \\
\hline 11 & $\mathrm{~A} 1$ & A3 & 117 & Zernike_O13_R11 & Zernike_O1_R1 \\
\hline 12 & $\mathrm{~F} 2$ & DGF_R0_A1 & 118 & Zernike_O17_R11 & Zernike_O14_R6 \\
\hline 13 & A3 & Zernike_O10_R0 & 119 & Zernike_O9_R7 & Zernike_O11_R9 \\
\hline 14 & Eixo maior & A1 & 120 & Zernike_O9_R3 & Zernike_O9_R7 \\
\hline 15 & DGF_R0_A1 & Eixo maior & 121 & Zernike_O11_R3 & Zernike_O17_R5 \\
\hline 16 & DGF_R0_A0 & DGF_R0_A0 & 122 & Zernike_O11_R9 & AR_SN \\
\hline 17 & A4 & A4 & 123 & Zernike_O15_R13 & Zernike_O11_R3 \\
\hline 18 & A2 & A2 & 124 & Zernike_O17_R5 & F3 \\
\hline 19 & Eixo menor & Zernike_O6_R4 & 125 & Zernike_O14_R6 & Zernike_O9_R3 \\
\hline 20 & Zernike_O14_R0 & Zernike_O10_R4 & 126 & Zernike_O3_R3 & Zernike_O19_R13 \\
\hline 21 & Zernike_O6_R4 & Zernike_O14_R0 & 127 & Zernike_O20_R4 & Zernike_O12_R2 \\
\hline 22 & Zernike_O10_R4 & Zernike_O4_R4 & 128 & Zernike_O19_R3 & Zernike_O19_R3 \\
\hline 23 & Zernike_O4_R4 & Eixo menor & 129 & Zernike_O20_R2 & Zernike_O20_R4 \\
\hline 24 & DGF_R1_A5 & Excentricidade & 130 & Zernike_O15_R3 & Zernike_O3_R3 \\
\hline 25 & Excentricidade & DGF_R0_A3 & 131 & Zernike_O16_R2 & Zernike_O15_R3 \\
\hline 26 & DGF_R0_A3 & Zernike_O4_R2 & 132 & AR_SN & Zernike_O13_R9 \\
\hline 27 & Zernike_O4_R2 & Zernike_O2_R2 & 133 & Zernike_O19_R13 & Zernike_O20_R2 \\
\hline 28 & Zernike_O14_R4 & DGF_R1_A5 & 134 & Zernike_O13_R9 & Zernike_O20_R8 \\
\hline 29 & Zernike_O18_R0 & Zernike_O14_R8 & 135 & Zernike_O13_R3 & DGF_R2_A3 \\
\hline 30 & DGF_R1_A6 & Zernike_O8_R8 & 136 & AR_1 & Zernike_O16_R2 \\
\hline 31 & Zernike_O14_R8 & Zernike_O6_R6 & 137 & Zernike_O20_R8 & AR_1 \\
\hline 32 & Zernike_O8_R8 & Zernike_O10_R8 & 138 & Zernike_O17_R3 & Zernike_O15_R11 \\
\hline 33 & Zernike_O18_R4 & Zernike_O8_R6 & 139 & Zernike_O11_R1 & Zernike_O13_R3 \\
\hline 34 & Zernike_O2_R2 & DGF_R3_A6 & 140 & Zernike_O5_R1 & DGF_R3_A0 \\
\hline 35 & DGF_R1_A4 & Zernike_O12_R6 & 141 & Zernike_O15_R11 & DGF_R1_A0 \\
\hline 36 & Zernike_O4_R0 & Zernike_O4_R0 & 142 & Zernike_O19_R1 & DGF_R2_A2 \\
\hline 37 & Zernike_O20_R20 & DGF_R1_A6 & 143 & F5 & DGF_R2_A1 \\
\hline 38 & Zernike_O12_R12 & Zernike_O10_R10 & 144 & Zernike_O9_R1 & Zernike_O18_R6 \\
\hline 39 & Zernike_O18_R18 & Zernike_O12_R12 & 145 & Zernike_O17_R13 & Zernike_O5_R1 \\
\hline 40 & Zernike_O16_R16 & Zernike_O18_R0 & 146 & Zernike_O18_R6 & DGF_R2_A0 \\
\hline
\end{tabular}




\begin{tabular}{|c|c|c|c|c|c|}
\hline Posição & $\begin{array}{c}\text { Ganho de } \\
\text { Informação }\end{array}$ & Chi-quadrado & Posição & $\begin{array}{c}\text { Ganho de } \\
\text { Informação }\end{array}$ & Chi-quadrado \\
\hline 41 & Zernike_O6_R6 & DGF_R1_A4 & 147 & Zernike_O15_R1 & Zernike_O11_R1 \\
\hline 42 & Zernike_O10_R10 & Zernike_O14_R4 & 148 & DGF_R2_A3 & Zernike_O17_R13 \\
\hline 43 & DGF_R3_A6 & Zernike_O16_R16 & 149 & Zernike_O13_R1 & Zernike_O17_R3 \\
\hline 44 & Zernike_O12_R6 & Zernike_O20_R20 & 150 & A5 & Zernike_O19_R15 \\
\hline 45 & Zernike_O8_R6 & Zernike_O18_R18 & 151 & Zernike_O19_R15 & F5 \\
\hline 46 & Zernike_O10_R6 & DGF_R0_A4 & 152 & DGF_R2_A2 & Zernike_O19_R1 \\
\hline 47 & Zernike_O10_R8 & Zernike_O14_R14 & 153 & DGF_R2_A1 & Zernike_O9_R1 \\
\hline 48 & Zernike_O14_R14 & Zernike_O16_R10 & 154 & Zernike_O17_R1 & DGF_R1_A1 \\
\hline 49 & Zernike_O18_R2 & Zernike_O18_R8 & 155 & DGF_R2_A5 & DGF_R3_A1 \\
\hline 50 & Zernike_O3_R1 & Zernike_O10_R6 & 156 & Zernike_O12_R4 & DGF_R2_A4 \\
\hline 51 & Zernike_O14_R2 & Zernike_O18_R2 & 157 & DGF_R2_A0 & Zernike_O15_R1 \\
\hline 52 & Zernike_O18_R8 & Zernike_O12_R10 & 158 & DGF_R1_A0 & Zernike_O12_R4 \\
\hline 53 & Zernike_O19_R19 & Zernike_O18_R4 & 159 & F4 & Zernike_O13_R1 \\
\hline 54 & Zernike_O15_R15 & DGF_R0_A5 & 160 & DGF_R3_A0 & A5 \\
\hline 55 & Zernike_O17_R17 & Zernike_O14_R2 & 161 & DGF_R2_A4 & DGF_R2_A5 \\
\hline 56 & Zernike_O8_R0 & Zernike_O14_R12 & 162 & Zernike_O16_R4 & DGF_R1_A3 \\
\hline 57 & Zernike_O16_R6 & Zernike_O16_R6 & 163 & DGF_R1_A1 & Zernike_O17_R1 \\
\hline 58 & Zernike_O11_R11 & Zernike_O12_R8 & 164 & F7 & $\mathrm{F} 4$ \\
\hline 59 & Zernike_O12_R8 & Zernike_O20_R18 & 165 & DGF_R1_A3 & Zernike_O16_R4 \\
\hline 60 & Zernike_O16_R10 & Zernike_O8_R0 & 166 & DGF_R3_A1 & F7 \\
\hline 61 & Zernike_O13_R13 & Zernike_O18_R12 & 167 & DGF_R3_A4 & DGF_R1_A2 \\
\hline 62 & DGF_R0_A4 & Zernike_O19_R19 & 168 & DGF_R1_A2 & DGF_R3_A4 \\
\hline 63 & AR_0 & Zernike_O20_R10 & 169 & F6 & DGF_R3_A2 \\
\hline 64 & Zernike_O9_R5 & Zernike_O15_R15 & 170 & F8 & F6 \\
\hline 65 & Zernike_O12_R10 & Zernike_O17_R17 & 171 & F10 & F8 \\
\hline 66 & Zernike_O20_R6 & AR_0 & 172 & F9 & DGF_R3_A3 \\
\hline 67 & Zernike_O20_R10 & Zernike_O3_R1 & 173 & DGF_R3_A2 & F10 \\
\hline 68 & Zernike_O14_R12 & Zernike_O18_R16 & 174 & DGF_R3_A3 & F9 \\
\hline 69 & Zernike_O13_R7 & Zernike_O13_R13 & 175 & F11 & F11 \\
\hline 70 & DGF_R0_A5 & Zernike_O16_R12 & 176 & $\mathrm{~F} 12$ & F38 \\
\hline 71 & Zernike_O9_R9 & Zernike_O16_R14 & 177 & $\mathrm{~F} 38$ & F12 \\
\hline 72 & Zernike_O10_R2 & Zernike_O14_R10 & 178 & F35 & F35 \\
\hline 73 & Zernike_O8_R4 & Zernike_O11_R11 & 179 & F29 & $\mathrm{F} 29$ \\
\hline 74 & Zernike_O18_R12 & DGF_R0_A6 & 180 & AR_9 & AR_9 \\
\hline 75 & Zernike_O7_R7 & Zernike_O20_R14 & 181 & F31 & F14 \\
\hline 76 & Zernike_O14_R10 & Zernike_O18_R14 & 182 & $\mathrm{~F} 1$ & $\mathrm{~F} 31$ \\
\hline 77 & Zernike_O17_R9 & Zernike_O9_R5 & 183 & F14 & F13 \\
\hline 78 & Zernike_O11_R5 & Zernike_O20_R16 & 184 & $\mathrm{~F} 13$ & $\mathrm{~F} 25$ \\
\hline 79 & Zernike_O20_R12 & Zernike_O17_R9 & 185 & F25 & F32 \\
\hline 80 & Zernike_O20_R18 & Zernike_O13_R7 & 186 & F32 & F28 \\
\hline 81 & Zernike_O7_R3 & Zernike_O8_R4 & 187 & $\mathrm{~F} 28$ & F37 \\
\hline 82 & Zernike_O18_R10 & Zernike_O20_R6 & 188 & F37 & F27 \\
\hline 83 & Zernike_O16_R8 & Zernike_O20_R12 & 189 & F34 & $\mathrm{F} 1$ \\
\hline 84 & Zernike_O16_R12 & Zernike_O10_R2 & 190 & F27 & F34 \\
\hline
\end{tabular}




\begin{tabular}{|c|c|c|c|c|c|}
\hline Posição & $\begin{array}{c}\text { Ganho de } \\
\text { Informação }\end{array}$ & Chi-quadrado & Posição & $\begin{array}{c}\text { Ganho de } \\
\text { Informação }\end{array}$ & Chi-quadrado \\
\hline 85 & Zernike_O7_R1 & DGF_R3_A5 & 191 & F33 & F23 \\
\hline 86 & Zernike_O17_R7 & Zernike_O16_R8 & 192 & $\mathrm{~F} 23$ & AR_4 \\
\hline 87 & Zernike_O5_R3 & Zernike_O6_R2 & 193 & F36 & F24 \\
\hline 88 & Zernike_O18_R16 & Zernike_O9_R9 & 194 & F24 & F33 \\
\hline 89 & Zernike_O15_R9 & Zernike_O18_R10 & 195 & $\mathrm{~F} 21$ & F36 \\
\hline 90 & Zernike_O12_R0 & Zernike_O11_R5 & 196 & F26 & $\mathrm{F} 21$ \\
\hline 91 & Zernike_O18_R14 & Zernike_O19_R9 & 197 & AR_4 & F26 \\
\hline 92 & Zernike_O20_R14 & Zernike_O19_R17 & 198 & AR_2 & AR_2 \\
\hline 93 & Zernike_O6_R2 & Zernike_O17_R7 & 199 & F22 & F22 \\
\hline 94 & Zernike_O13_R5 & Zernike_O12_R0 & 200 & F20 & F20 \\
\hline 95 & Zernike_O19_R9 & Zernike_O7_R7 & 201 & F30 & F30 \\
\hline 96 & Zernike_O15_R7 & Zernike_O7_R3 & 202 & F16 & F19 \\
\hline 97 & Zernike_O11_R7 & Zernike_O15_R7 & 203 & F19 & AR_3 \\
\hline 98 & Zernike_O15_R5 & Zernike_O15_R9 & 204 & AR_3 & F16 \\
\hline 99 & Zernike_O19_R11 & Zernike_O19_R11 & 205 & AR_8 & AR_8 \\
\hline 100 & DGF_R3_A5 & Zernike_O16_R0 & 206 & AR_6 & F15 \\
\hline 101 & Zernike_O16_R14 & Zernike_O17_R15 & 207 & F15 & F18 \\
\hline 102 & Zernike_O19_R17 & DGF_R2_A6 & 208 & F17 & AR_6 \\
\hline 103 & Zernike_O20_R16 & Zernike_O13_R5 & 209 & AR_7 & AR_7 \\
\hline 104 & DGF_R0_A6 & Zernike_O11_R7 & 210 & F18 & AR_5 \\
\hline 105 & Zernike_O16_R0 & Zernike_O5_R3 & 211 & AR_5 & F17 \\
\hline 106 & Zernike_O8_R2 & Zernike_O15_R5 & & & \\
\hline
\end{tabular}

Tabela 29 - Ordenação dos atributos da análise Ac pelos algoritmos Ganho de Informação e chi-quadrado

\begin{tabular}{|c|c|c|c|c|c|}
\hline Posição & $\begin{array}{c}\text { Ganho de } \\
\text { Informação }\end{array}$ & Chi-quadrado & Posição & $\begin{array}{c}\text { Ganho de } \\
\text { Informação }\end{array}$ & Chi-quadrado \\
\hline 1 & I1_média & I1_média & 43 & I2_suavidade & CIE-b_suavidade \\
\hline 2 & V_média & V_média & 44 & I2_variância & I2_variância \\
\hline 3 & CIE-L_média & S_média & 45 & V_energia & I2_suavidade \\
\hline 4 & S_média & R_energia & 46 & H_energia & H_suavidade \\
\hline 5 & R_variância & G_energia & 47 & CIE-a_entropia & H_variância \\
\hline 6 & R_suavidade & G_variância & 48 & I2_energia & CIE-L_entropia \\
\hline 7 & R_energia & G_suavidade & 49 & R_obliquidade & S_obliquidade \\
\hline 8 & G_média & R_suavidade & 50 & I2_entropia & I2_energia \\
\hline 9 & G_variância & R_variância & 51 & H_entropia & H_energia \\
\hline 10 & G_suavidade & CIE-L_média & 52 & V_entropia & S_variância \\
\hline 11 & G_energia & G_média & 53 & S_energia & I1_entropia \\
\hline 12 & R_média & B_média & 54 & G_obliquidade & S_suavidade \\
\hline 13 & CIE-L_suavidade & CIE-L_variância & 55 & S_entropia & H_entropia \\
\hline 14 & CIE-L_variância & CIE-L_suavidade & 56 & S_variância & B_obliquidade \\
\hline 15 & I3_variância & G_entropia & 57 & S_suavidade & CIE-a_entropia \\
\hline 16 & I3_suavidade & R_média & 58 & CIE-a_energia & CIE-b_energia \\
\hline
\end{tabular}




\begin{tabular}{|c|c|c|c|c|c|}
\hline Posição & $\begin{array}{c}\text { Ganho de } \\
\text { Informação }\end{array}$ & Chi-quadrado & Posição & $\begin{array}{c}\text { Ganho de } \\
\text { Informação }\end{array}$ & Chi-quadrado \\
\hline 17 & B_média & B_energia & 59 & B_curtose & I2_entropia \\
\hline 18 & I2_média & H_média & 60 & CIE-b_energia & CIE-a_energia \\
\hline 19 & CIE-a_suavidade & I3_variância & 61 & CIE-b_entropia & B_curtose \\
\hline 20 & CIE-a_variância & I3_suavidade & 62 & CIE-L_obliquidade & B_suavidade \\
\hline 21 & G_entropia & I2_média & 63 & B_variância & B_variância \\
\hline 22 & H_média & V_obliquidade & 64 & B_suavidade & I1_obliquidade \\
\hline 23 & B_energia & R_entropia & 65 & I1_obliquidade & CIE-L_obliquidade \\
\hline 24 & CIE-L_energia & CIE-b_média & 66 & S_curtose & CIE-b_entropia \\
\hline 25 & V_obliquidade & CIE-L_energia & 67 & B_obliquidade & S_curtose \\
\hline 26 & I3_média & CIE-a_média & 68 & H_curtose & V_curtose \\
\hline 27 & CIE-b_média & V_energia & 69 & V_curtose & H_curtose \\
\hline 28 & I3_entropia & CIE-a_suavidade & 70 & I2_curtose & I2_curtose \\
\hline 29 & I1_variância & CIE-a_variância & 71 & I2_obliquidade & I2_obliquidade \\
\hline 30 & I1_suavidade & I3_média & 72 & H_obliquidade & CIE-b_curtose \\
\hline 31 & R_entropia & B_entropia & 73 & R_curtose & H_obliquidade \\
\hline 32 & CIE-a_média & I3_entropia & 74 & CIE-b_curtose & CIE-b_obliquidade \\
\hline 33 & I1_energia & S_energia & 75 & CIE-b_obliquidade & CIE-a_obliquidade \\
\hline 34 & CIE-L_entropia & R_obliquidade & 76 & CIE-a_obliquidade & V_variância \\
\hline 35 & H_suavidade & V_entropia & 77 & V_suavidade & V_suavidade \\
\hline 36 & H_variância & S_entropia & 78 & V_variância & I3_obliquidade \\
\hline 37 & I3_energia & I1_variância & 79 & I3_obliquidade & R_curtose \\
\hline 38 & I1_entropia & I1_suavidade & 80 & G_curtose & CIE-a_curtose \\
\hline 39 & B_entropia & I1_energia & 81 & CIE-a_curtose & I3_curtose \\
\hline 40 & S_obliquidade & I3_energia & 82 & I3_curtose & G_curtose \\
\hline 41 & CIE-b_variância & G_obliquidade & 83 & CIE-L_curtose & CIE-L_curtose \\
\hline 42 & CIE-b_suavidade & CIE-b_variância & 84 & I1_curtose & I1_curtose \\
\hline
\end{tabular}

Tabela 30 - Ordenação dos atributos da análise Aт pelos algoritmos Ganho de Informação e chi-quadrado

\begin{tabular}{ccc||ccc}
\hline Posição & Ganho de Informação & Chi-quadrado & Posição & $\begin{array}{c}\text { Ganho de } \\
\text { Informação }\end{array}$ & Chi-quadrado \\
\hline 1 & F_I1_7(Horizontal) & F_I1_7(Horizontal) & 64 & F_I3_10(Horizontal) & F_I2_10(Horizontal) \\
2 & F_I1_7(Vertical) & F_I1_7(Vertical) & 65 & F_I2_5(Diagonal) & F_I3_11(Vertical) \\
3 & F_I1_7(Diagonal) & F_I1_7(Diagonal) & 66 & F_I3_5(Vertical) & F_I3_1(Diagonal) \\
4 & F_I1_6(Vertical) & F_I1_6(Vertical) & 67 & F_I2_1(Horizontal) & F_I3_10(Diagonal) \\
5 & F_I1_6(Diagonal) & F_I1_6(Horizontal) & 68 & F_I2_9(Horizontal) & F_I2_11(Horizontal) \\
6 & F_I1_6(Horizontal) & F_I1_6(Diagonal) & 69 & F_I2_2(Vertical) & F_I2_2(Diagonal) \\
7 & F_I1_2(Diagonal) & F_I1_2(Diagonal) & 70 & F_I2_1(Diagonal) & F_I3_1(Vertical) \\
8 & F_I1_2(Horizontal) & F_I1_2(Horizontal) & 71 & F_I2_9(Diagonal) & F_I2_11(Diagonal) \\
9 & F_I1_2(Vertical) & F_I1_2(Vertical) & 72 & F_I3_10(Vertical) & F_I3_10(Horizontal) \\
10 & F_I2_7(Vertical) & F_I2_7(Vertical) & 73 & F_I2_8(Horizontal) & F_I2_5(Diagonal) \\
11 & F_I2_6(Horizontal) & F_I2_6(Horizontal) & 74 & F_I2_2(Horizontal) & F_12_10(Diagonal) \\
12 & F_I2_6(Vertical) & F_I2_6(Vertical) & 75 & F_I2_9(Vertical) & F_13_5(Vertical) \\
13 & F_I2_6(Diagonal) & F_I2_6(Diagonal) & 76 & F_I2_1(Vertical) & F_I2_9(Horizontal) \\
\hline
\end{tabular}




\begin{tabular}{|c|c|c|c|c|c|}
\hline Posição & Ganho de Informação & Chi-quadrado & Posição & $\begin{array}{c}\text { Ganho de } \\
\text { Informaçãa }\end{array}$ & Chi-quadrado \\
\hline 14 & F_I2_7(Diagonal) & F_I2_7(Horizontal) & 77 & F_I2_8(Vertical) & F_I2_2(Horizontal) \\
\hline 15 & F_I2_7(Horizontal) & F_I2_7(Diagonal) & 78 & F_I2_11(Vertical) & F_I2_1(Diagonal) \\
\hline 16 & F_I1_11(Diagonal) & F_I3_6(Diagonal) & 79 & F_I2_8(Diagonal) & F_I3_10(Vertical) \\
\hline 17 & F_I3_6(Diagonal) & F_I3_6(Horizontal) & 80 & F_I2_10(Vertical) & F_I2_1(Horizontal) \\
\hline 18 & F_I3_7(Vertical) & F_I3_6(Vertical) & 81 & F_I2_5(Vertical) & F_I2_9(Diagonal) \\
\hline 19 & F_I3_6(Horizontal) & F_I3_7(Vertical) & 82 & F_I2_4(Horizontal) & F_I2_2(Vertical) \\
\hline 20 & F_I3_7(Horizontal) & F_I3_7(Diagonal) & 83 & F_I2_4(Diagonal) & F_I2_9(Vertical) \\
\hline 21 & F_I3_7(Diagonal) & F_I3_7(Horizontal) & 84 & F_I2_4(Vertical) & F_I2_8(Horizontal) \\
\hline 22 & F_I3_6(Vertical) & F_I1_11(Diagonal) & 85 & F_I3_4(Horizontal) & F_I2_1(Vertical) \\
\hline 23 & F_I1_11(Horizontal) & F_I1_11(Horizontal) & 86 & F_I3_4(Diagonal) & F_I2_11(Vertical) \\
\hline 24 & F_I1_9(Horizontal) & F_I1_11(Vertical) & 87 & F_I3_4(Vertical) & F_I2_8(Vertical) \\
\hline 25 & F_I1_8(Horizontal) & F_I3_8(Vertical) & 88 & F_I1_4(Vertical) & F_I2_8(Diagonal) \\
\hline 26 & F_I1_8(Vertical) & F_I3_2(Diagonal) & 89 & F_I1_4(Diagonal) & F_I3_13(Diagonal) \\
\hline 27 & F_I1_8(Diagonal) & F_I3_8(Horizontal) & 90 & F_I1_4(Horizontal) & F_I2_10(Vertical) \\
\hline 28 & F_I1_9(Diagonal) & F_I3_8(Diagonal) & 91 & F_I1_13(Vertical) & F_I2_5(Vertical) \\
\hline 29 & F_I1_9(Vertical) & F_I3_9(Horizontal) & 92 & F_I2_13(Vertical) & F_I3_13(Vertical) \\
\hline 30 & F_I1_5(Diagonal) & F_I3_9(Diagonal) & 93 & F_I3_13(Diagonal) & F_I2_13(Vertical) \\
\hline 31 & F_I1_11(Vertical) & F_I1_9(Horizontal) & 94 & F_I3_13(Vertical) & F_I3_13(Horizontal) \\
\hline 32 & F_I1_5(Horizontal) & F_I1_5(Diagonal) & 95 & F_I2_13(Diagonal) & F_I2_13(Diagonal) \\
\hline 33 & F_I1_10(Diagonal) & F_I1_8(Horizontal) & 96 & F_I3_13(Horizontal) & F_I1_13(Vertical) \\
\hline 34 & F_I1_1(Diagonal) & F_I1_9(Diagonal) & 97 & F_I2_13(Horizontal) & F_I2_13(Horizontal) \\
\hline 35 & F_I1_1(Horizontal) & F_I3_9(Vertical) & 98 & F_I2_3(Vertical) & F_I2_3(Vertical) \\
\hline 36 & F_I1_1(Vertical) & F_I1_8(Vertical) & 99 & F_I1_3(Vertical) & F_I1_3(Vertical) \\
\hline 37 & F_I1_10(Horizontal) & F_I1_9(Vertical) & 100 & F_I1_13(Diagonal) & F_I3_12(Diagonal) \\
\hline 38 & F_I3_8(Vertical) & F_I1_8(Diagonal) & 101 & F_I2_14(Diagonal) & F_I3_14(Diagonal) \\
\hline 39 & F_I3_8(Horizontal) & F_I2_4(Diagonal) & 102 & F_I3_14(Vertical) & F_I2_14(Diagonal) \\
\hline 40 & F_I3_8(Diagonal) & F_I2_4(Horizontal) & 103 & F_I2_14(Vertical) & F_I3_14(Vertical) \\
\hline 41 & F_I1_5(Vertical) & F_I1_10(Diagonal) & 104 & F_I1_3(Horizontal) & F_I3_3(Vertical) \\
\hline 42 & F_I3_2(Diagonal) & F_I2_4(Vertical) & 105 & F_I3_12(Diagonal) & F_I2_14(Vertical) \\
\hline 43 & F_I3_9(Horizontal) & F_I3_2(Vertical) & 106 & F_I1_13(Horizontal) & F_I1_13(Diagonal) \\
\hline 44 & F_I1_10(Vertical) & F_I3_4(Horizontal) & 107 & F_I3_14(Diagonal) & F_I2_12(Diagonal) \\
\hline 45 & F_13_9(Diagonal) & F_I3_4(Vertical) & 108 & F_I2_14(Horizontal) & F_I3_12(Vertical) \\
\hline 46 & F_I3_9(Vertical) & F_I3_4(Diagonal) & 109 & F_I2_12(Diagonal) & F_I2_14(Horizontal) \\
\hline 47 & F_I3_2(Vertical) & F_I1_1(Diagonal) & 110 & F_I3_3(Vertical) & F_I3_12(Horizontal) \\
\hline 48 & F_I3_11(Diagonal) & F_I1_1(Horizontal) & 111 & F_I3_12(Vertical) & F_I1_3(Horizontal) \\
\hline 49 & F_I3_1(Horizontal) & F_I1_5(Horizontal) & 112 & F_I3_12(Horizontal) & F_I1_13(Horizontal) \\
\hline 50 & F_I3_2(Horizontal) & F_I1_10(Horizontal) & 113 & F_I1_12(Horizontal) & F_I2_12(Vertical) \\
\hline 51 & F_I3_1(Diagonal) & F_I1_1(Vertical) & 114 & F_I2_12(Vertical) & F_I1_12(Horizontal) \\
\hline 52 & F_I3_11(Horizontal) & F_I3_2(Horizontal) & 115 & F_I2_12(Horizontal) & F_I2_12(Horizontal) \\
\hline 53 & F_I3_1(Vertical) & F_I3_11(Diagonal) & 116 & F_I3_14(Horizontal) & F_I3_14(Horizontal) \\
\hline 54 & F_I2_10(Horizontal) & F_I2_5(Horizontal) & 117 & F_I1_14(Vertical) & F_I2_3(Diagonal) \\
\hline 55 & F_I3_11(Vertical) & F_I1_4(Horizontal) & 118 & F_I2_3(Diagonal) & F_I1_12(Diagonal) \\
\hline 56 & F_I3_5(Diagonal) & F_I1_4(Vertical) & 119 & F_I1_12(Diagonal) & F_I1_14(Vertical) \\
\hline 57 & F_I2_5(Horizontal) & F_I3_5(Horizontal) & 120 & F_I1_14(Horizontal) & F_I1_14(Horizontal) \\
\hline
\end{tabular}




\begin{tabular}{ccc||ccc}
\hline Posição & Ganho de Informação & Chi-quadrado & Posição & $\begin{array}{c}\text { Ganho de } \\
\text { Informação }\end{array}$ & Chi-quadrado \\
\hline 58 & F_I2_11(Horizontal) & F_I1_4(Diagonal) & 121 & F_I1_14(Diagonal) & F_I2_3(Horizontal) \\
59 & F_I2_2(Diagonal) & F_I3_5(Diagonal) & 122 & F_I2_3(Horizontal) & F_I1_14(Diagonal) \\
60 & F_I3_5(Horizontal) & F_I3_1(Horizontal) & 123 & F_I1_12(Vertical) & F_I3_3(Diagonal) \\
61 & F_I2_11(Diagonal) & F_I1_10(Vertical) & 124 & F_I1_3(Diagonal) & F_I1_12(Vertical) \\
62 & F_I3_10(Diagonal) & F_I1_5(Vertical) & 125 & F_I3_3(Diagonal) & F_I1_3(Diagonal) \\
63 & F_I2_10(Diagonal) & F_I3_11(Horizontal) & 126 & F_I3_3(Horizontal) & F_I3_3(Horizontal) \\
\hline
\end{tabular}

Tabela 31 - Ordenação dos atributos da análise ACт pelos algoritmos Ganho de Informação e chi-quadrado

\begin{tabular}{|c|c|c|c|c|c|}
\hline Posição & Ganho de Informação & Chi-quadrado & Posição & $\begin{array}{c}\text { Ganho de } \\
\text { Informação }\end{array}$ & Chi-quadrado \\
\hline 1 & I1_média & I1_média & 106 & F_I3_10(Diagonal) & S_obliquidade \\
\hline 2 & V_média & V_média & 107 & F_I2_5(Horizontal) & F_I2_4(Vertical) \\
\hline 3 & F_I1_7(Horizontal) & S_média & 108 & F_I2_10(Diagonal) & F_I2_11(Horizontal) \\
\hline 4 & F_I1_7(Vertical) & F_I1_7(Horizontal) & 109 & F_I3_10(Horizontal) & F_I3_1(Horizontal) \\
\hline 5 & F_I1_7(Diagonal) & F_I1_7(Vertical) & 110 & H_energia & F_I3_1(Diagonal) \\
\hline 6 & F_I1_6(Vertical) & F_I1_7(Diagonal) & 111 & F_I2_1(Horizontal) & F_I2_4(Diagonal) \\
\hline 7 & F_I1_6(Horizontal) & R_energia & 112 & F_I2_9(Diagonal) & F_I2_5(Horizontal) \\
\hline 8 & F_I1_6(Diagonal) & G_energia & 113 & F_I2_8(Vertical) & F_I3_10(Diagonal) \\
\hline 9 & CIE-L_média & R_suavidade & 114 & F_I2_9(Horizontal) & F_I3_11(Vertical) \\
\hline 10 & S_média & R_variância & 115 & F_I2_9(Vertical) & F_I2_2(Diagonal) \\
\hline 11 & R_suavidade & F_I1_6(Vertical) & 116 & F_I2_5(Diagonal) & F_I2_11(Diagonal) \\
\hline 12 & R_variância & G_variância & 117 & CIE-a_entropia & F_I3_10(Horizontal) \\
\hline 13 & R_energia & G_suavidade & 118 & F_I2_1(Diagonal) & F_I2_10(Horizontal) \\
\hline 14 & G_média & F_I1_6(Diagonal) & 119 & F_I2_8(Horizontal) & I2_energia \\
\hline 15 & G_variância & F_I1_6(Horizontal) & 120 & F_I3_5(Vertical) & F_I2_9(Horizontal) \\
\hline 16 & G_suavidade & CIE-L_média & 121 & F_I2_1(Vertical) & F_I1_4(Vertical) \\
\hline 17 & G_energia & F_I1_2(Diagonal) & 122 & F_I2_8(Diagonal) & F_I1_4(Diagonal) \\
\hline 18 & R_média & F_I1_2(Vertical) & 123 & I2_energia & F_I2_2(Horizontal) \\
\hline 19 & F_I1_2(Diagonal) & F_I1_2(Horizontal) & 124 & F_I3_10(Vertical) & F_I1_4(Horizontal) \\
\hline 20 & F_I1_2(Vertical) & G_média & 125 & F_I2_2(Horizontal) & F_I2_10(Diagonal) \\
\hline 21 & F_I1_2(Horizontal) & B_média & 126 & I2_entropia & F_I3_5(Vertical) \\
\hline 22 & CIE-L_variância & CIE-L_variância & 127 & F_I2_2(Vertical) & H_energia \\
\hline 23 & CIE-L_suavidade & CIE-L_suavidade & 128 & R_obliquidade & F_I2_1(Diagonal) \\
\hline 24 & B_média & R_média & 129 & H_entropia & F_I2_5(Diagonal) \\
\hline 25 & I3_variância & G_entropia & 130 & F_I2_11(Vertical) & F_I2_1(Horizontal) \\
\hline 26 & I3_suavidade & B_energia & 131 & V_entropia & F_I2_9(Vertical) \\
\hline 27 & F_I2_7(Vertical) & I3_suavidade & 132 & S_energia & F_I2_9(Diagonal) \\
\hline 28 & CIE-a_suavidade & I3_variância & 133 & F_I2_10(Vertical) & S_variância \\
\hline 29 & CIE-a_variância & H_média & 134 & S_entropia & S_suavidade \\
\hline 30 & F_I2_7(Diagonal) & F_I2_7(Vertical) & 135 & CIE-a_energia & F_I3_10(Vertical) \\
\hline 31 & F_I2_6(Horizontal) & F_I2_7(Diagonal) & 136 & G_obliquidade & F_I2_8(Vertical) \\
\hline 32 & F_I2_6(Diagonal) & F_I2_6(Horizontal) & 137 & F_I2_5(Vertical) & F_I2_2(Vertical) \\
\hline 33 & I2_média & F_I2_6(Diagonal) & 138 & CIE-b_entropia & F_I2_1(Vertical) \\
\hline
\end{tabular}




\begin{tabular}{|c|c|c|c|c|c|}
\hline Posição & Ganho de Informação & Chi-quadrado & Posição & $\begin{array}{c}\text { Ganho de } \\
\text { Informação }\end{array}$ & Chi-quadrado \\
\hline 34 & G_entropia & R_entropia & 139 & S_variância & I1_entropia \\
\hline 35 & F_I2_6(Vertical) & F_I2_6(Vertical) & 140 & CIE-b_energia & CIE-a_entropia \\
\hline 36 & F_12_7(Horizontal) & I2_média & 141 & S_suavidade & F_I2_8(Horizontal) \\
\hline 37 & H_média & F_I2_7(Horizontal) & 142 & B_curtose & CIE-b_energia \\
\hline 38 & F_I1_11(Diagonal) & V_obliquidade & 143 & B_variância & B_obliquidade \\
\hline 39 & B_energia & CIE-L_energia & 144 & B_suavidade & F_I2_8(Diagonal) \\
\hline 40 & CIE-L_energia & CIE-b_média & 145 & CIE-L_obliquidade & I2_entropia \\
\hline 41 & F_I3_6(Horizontal) & CIE-a_média & 146 & I1_obliquidade & H_entropia \\
\hline 42 & F_I1_11(Horizontal) & CIE-a_suavidade & 147 & F_I1_13(Vertical) & CIE-a_energia \\
\hline 43 & F_I3_6(Vertical) & CIE-a_variância & 148 & F_I2_13(Vertical) & F_I2_11(Vertical) \\
\hline 44 & F_I3_6(Diagonal) & F_I3_6(Horizontal) & 149 & F_I3_4(Diagonal) & B_curtose \\
\hline 45 & F_I3_7(Vertical) & F_I3_6(Vertical) & 150 & F_I3_4(Horizontal) & B_variância \\
\hline 46 & F_I3_7(Horizontal) & F_I3_6(Diagonal) & 151 & F_I3_4(Vertical) & B_suavidade \\
\hline 47 & V_obliquidade & V_energia & 152 & F_I2_4(Horizontal) & F_I2_5(Vertical) \\
\hline 48 & F_I3_7(Diagonal) & F_I3_7(Vertical) & 153 & F_I2_4(Vertical) & F_I2_10(Vertical) \\
\hline 49 & F_I1_8(Vertical) & F_I3_7(Horizontal) & 154 & F_I2_4(Diagonal) & I1_obliquidade \\
\hline 50 & I3_média & F_I3_7(Diagonal) & 155 & F_I3_13(Diagonal) & F_I3_13(Diagonal) \\
\hline 51 & F_I1_8(Horizontal) & F_I1_11(Diagonal) & 156 & B_obliquidade & CIE-b_entropia \\
\hline 52 & F_I1_9(Horizontal) & B_entropia & 157 & S_curtose & CIE-L_obliquidade \\
\hline 53 & F_I1_8(Diagonal) & I3_média & 158 & F_I1_4(Vertical) & F_I3_13(Vertical) \\
\hline 54 & I3_entropia & F_I1_11(Horizontal) & 159 & F_I1_4(Horizontal) & F_I2_13(Vertical) \\
\hline 55 & F_I1_9(Vertical) & I3_entropia & 160 & F_I1_4(Diagonal) & F_I3_13(Horizontal) \\
\hline 56 & F_I1_9(Diagonal) & S_energia & 161 & F_I3_13(Vertical) & F_I2_13(Diagonal) \\
\hline 57 & CIE-b_média & F_I3_8(Vertical) & 162 & F_I2_13(Diagonal) & S_curtose \\
\hline 58 & I1_suavidade & F_I1_11(Vertical) & 163 & V_curtose & F_I1_13(Vertical) \\
\hline 59 & I1_variância & F_I3_8(Horizontal) & 164 & H_curtose & F_I2_13(Horizontal) \\
\hline 60 & R_entropia & F_I3_8(Diagonal) & 165 & F_I3_13(Horizontal) & V_curtose \\
\hline 61 & F_I1_10(Diagonal) & F_I3_2(Diagonal) & 166 & F_I2_13(Horizontal) & I2_curtose \\
\hline 62 & F_I1_5(Diagonal) & F_I3_9(Horizontal) & 167 & I2_curtose & H_curtose \\
\hline 63 & F_I1_11(Vertical) & F_I3_9(Diagonal) & 168 & F_I2_3(Vertical) & I2_obliquidade \\
\hline 64 & F_I1_1(Vertical) & F_I1_8(Vertical) & 169 & H_obliquidade & F_I2_3(Vertical) \\
\hline 65 & CIE-a_média & V_entropia & 170 & F_I1_3(Vertical) & CIE-b_curtose \\
\hline 66 & F_I1_1(Diagonal) & F_I1_8(Horizontal) & 171 & I2_obliquidade & F_I3_12(Diagonal) \\
\hline 67 & F_I1_5(Horizontal) & F_I1_9(Horizontal) & 172 & F_I2_14(Diagonal) & F_I1_3(Vertical) \\
\hline 68 & F_I1_10(Horizontal) & F_I1_8(Diagonal) & 173 & F_I1_13(Diagonal) & F_I2_14(Diagonal) \\
\hline 69 & F_I1_1(Horizontal) & F_I3_9(Vertical) & 174 & F_I3_14(Vertical) & H_obliquidade \\
\hline 70 & F_I1_5(Vertical) & F_I1_9(Diagonal) & 175 & CIE-b_curtose & CIE-b_obliquidade \\
\hline 71 & F_I3_8(Vertical) & R_obliquidade & 176 & CIE-b_obliquidade & F_I3_14(Diagonal) \\
\hline 72 & I1_energia & F_I1_9(Vertical) & 177 & R_curtose & V_suavidade \\
\hline 73 & F_I3_8(Diagonal) & I3_energia & 178 & F_I2_14(Vertical) & V_variância \\
\hline 74 & F_I3_8(Horizontal) & S_entropia & 179 & V_variância & F_I3_14(Vertical) \\
\hline 75 & CIE-L_entropia & I1_energia & 180 & V_suavidade & CIE-a_obliquidade \\
\hline 76 & I3_energia & I1_suavidade & 181 & CIE-a_obliquidade & F_I1_13(Diagonal) \\
\hline 77 & F_I3_9(Horizontal) & I1_variância & 182 & F_I1_3(Horizontal) & I3_obliquidade \\
\hline
\end{tabular}




\begin{tabular}{|c|c|c|c|c|c|}
\hline Posição & Ganho de Informação & Chi-quadrado & Posição & $\begin{array}{c}\text { Ganho de } \\
\text { Informação }\end{array}$ & Chi-quadrado \\
\hline 78 & H_variância & CIE-b_variância & 183 & F_I3_12(Diagonal) & F_I2_14(Vertical) \\
\hline 79 & H_suavidade & CIE-b_suavidade & 184 & I3_obliquidade & F_I3_3(Vertical) \\
\hline 80 & F_I3_2(Diagonal) & F_I1_10(Diagonal) & 185 & F_I3_14(Diagonal) & F_I2_12(Diagonal) \\
\hline 81 & F_I3_9(Diagonal) & I2_suavidade & 186 & F_I1_13(Horizontal) & R_curtose \\
\hline 82 & F_I1_10(Vertical) & I2_variância & 187 & F_I2_14(Horizontal) & F_I2_14(Horizontal) \\
\hline 83 & F_I3_9(Vertical) & F_I1_5(Diagonal) & 188 & F_I2_12(Diagonal) & F_I3_12(Vertical) \\
\hline 84 & B_entropia & F_I3_2(Vertical) & 189 & G_curtose & I3_curtose \\
\hline 85 & I1_entropia & F_I1_10(Horizontal) & 190 & CIE-a_curtose & F_I2_12(Vertical) \\
\hline 86 & CIE-b_variância & F_I1_1(Vertical) & 191 & F_I3_3(Vertical) & CIE-a_curtose \\
\hline 87 & CIE-b_suavidade & F_I1_1(Diagonal) & 192 & F_I2_12(Vertical) & F_I3_12(Horizontal) \\
\hline 88 & S_obliquidade & F_I1_5(Horizontal) & 193 & I3_curtose & F_I1_3(Horizontal) \\
\hline 89 & F_I3_2(Vertical) & G_obliquidade & 194 & F_I1_12(Horizontal) & F_I1_12(Horizontal) \\
\hline 90 & I2_variância & F_I1_1(Horizontal) & 195 & F_I3_12(Horizontal) & F_I1_13(Horizontal) \\
\hline 91 & I2_suavidade & F_I3_11(Diagonal) & 196 & F_I3_12(Vertical) & G_curtose \\
\hline 92 & F_I3_11(Diagonal) & H_variância & 197 & F_I3_14(Horizontal) & F_I3_14(Horizontal) \\
\hline 93 & F_I3_11(Horizontal) & H_suavidade & 198 & F_I2_12(Horizontal) & F_I2_12(Horizontal) \\
\hline 94 & V_energia & F_I3_5(Horizontal) & 199 & F_I1_14(Vertical) & F_I1_14(Vertical) \\
\hline 95 & F_I3_1(Diagonal) & F_I1_5(Vertical) & 200 & F_I1_14(Horizontal) & F_I1_12(Diagonal) \\
\hline 96 & F_I3_1(Horizontal) & F_I3_5(Diagonal) & 201 & F_I1_12(Diagonal) & F_12_3(Diagonal) \\
\hline 97 & F_I3_1(Vertical) & F_I3_11(Horizontal) & 202 & F_I2_3(Diagonal) & F_I1_14(Horizontal) \\
\hline 98 & F_I3_2(Horizontal) & F_I1_10(Vertical) & 203 & F_I1_14(Diagonal) & F_I1_14(Diagonal) \\
\hline 99 & F_I3_11(Vertical) & F_I3_2(Horizontal) & 204 & CIE-L_curtose & CIE-L_curtose \\
\hline 100 & F_I3_5(Horizontal) & F_I3_4(Vertical) & 205 & F_I1_12(Vertical) & F_I2_3(Horizontal) \\
\hline 101 & F_I2_11(Horizontal) & F_I3_4(Diagonal) & 206 & F_I1_3(Diagonal) & F_I1_12(Vertical) \\
\hline 102 & F_I3_5(Diagonal) & F_I2_4(Horizontal) & 207 & F_I2_3(Horizontal) & F_I1_3(Diagonal) \\
\hline 103 & F_I2_10(Horizontal) & F_I3_4(Horizontal) & 208 & I1_curtose & I1_curtose \\
\hline 104 & F_I2_11(Diagonal) & CIE-L_entropia & 209 & F_I3_3(Diagonal) & F_I3_3(Diagonal) \\
\hline 105 & F_I2_2(Diagonal) & F_I3_1(Vertical) & 210 & F_I3_3(Horizontal) & F_I3_3(Horizontal) \\
\hline
\end{tabular}

Tabela 32 - Ordenação dos atributos da análise AMCт pelos algoritmos Ganho de Informação e chi-quadrado

\begin{tabular}{ccc||ccc}
\hline Posição & Ganho de Informação & Chi-quadrado & Posição & $\begin{array}{c}\text { Ganho de } \\
\text { Informação }\end{array}$ & Chi-quadrado \\
\hline 1 & I1_média & I1_média & 212 & Zernike_O16_R16 & Zernike_O14_R14 \\
2 & V_média & V_média & 213 & F_I3_12(Diagonal) & Zernike_O20_R20 \\
3 & F_I1_7(Horizontal) & S_média & 214 & Zernike_O8_R8 & F_I3_12(Vertical) \\
4 & F_I1_7(Vertical) & F_I1_7(Horizontal) & 215 & Zernike_O12_R12 & Zernike_O2_R2 \\
5 & F_I1_7(Diagonal) & F_I1_7(Vertical) & 216 & Zernike_O14_R14 & Zernike_O4_R2 \\
6 & F_I1_6(Horizontal) & F_I1_7(Diagonal) & 217 & F_I1_3(Horizontal) & I3_curtose \\
7 & F_I1_6(Vertical) & R_energia & 218 & F_I3_14(Vertical) & Zernike_O10_R8 \\
8 & F_I1_6(Diagonal) & G_energia & 219 & Zernike_O4_R0 & DGF_R1_A6 \\
9 & CIE-L_média & R_variância & 220 & Zernike_O10_R10 & Zernike_O4_R0 \\
10 & G_média & R_suavidade & 221 & Zernike_O19_R19 & CIE-a_curtose \\
11 & R_suavidade & G_suavidade & 222 & F_I1_13(Diagonal) & Zernike_O14_R8 \\
\hline
\end{tabular}




\begin{tabular}{|c|c|c|c|c|c|}
\hline Posição & Ganho de Informação & Chi-quadrado & Posição & $\begin{array}{l}\text { Ganho de } \\
\text { Informação }\end{array}$ & Chi-quadrado \\
\hline 12 & R_variância & G_variância & 223 & Zernike_O15_R15 & Zernike_O18_R2 \\
\hline 13 & S_média & F_I1_6(Vertical) & 224 & Zernike_O17_R17 & Zernike_O8_R6 \\
\hline 14 & R_energia & F_I1_6(Horizontal) & 225 & Excentricidade & DGF_R1_A5 \\
\hline 15 & G_variância & F_I1_6(Diagonal) & 226 & Zernike_O13_R13 & Zernike_O18_R0 \\
\hline 16 & G_suavidade & CIE-L_média & 227 & DGF_R0_A3 & Zernike_O12_R6 \\
\hline 17 & G_energia & F_I1_2(Diagonal) & 228 & Zernike_O11_R11 & Zernike_O14_R2 \\
\hline 18 & R_média & Spread & 229 & F_I2_14(Vertical) & F_I2_14(Horizontal) \\
\hline 19 & CIE-a_suavidade & F_I1_2(Vertical) & 230 & F_I3_12(Vertical) & F_I2_12(Diagonal) \\
\hline 20 & CIE-a_variância & F_I1_2(Horizontal) & 231 & F_I3_14(Diagonal) & F_I3_14(Vertical) \\
\hline 21 & Spread & Perímetro & 232 & Zernike_O8_R0 & F_I2_14(Vertical) \\
\hline 22 & F0 & Área & 233 & F_I2_12(Diagonal) & H_obliquidade \\
\hline 23 & Área & Zernike_O0_R0 & 234 & F_I2_14(Horizontal) & DGF_R0_A4 \\
\hline 24 & Zernike_O0_R0 & G_média & 235 & AR_0 & Zernike_O19_R19 \\
\hline 25 & Perímetro & F0 & 236 & Zernike_O6_R6 & Zernike_O15_R15 \\
\hline 26 & F_I1_2(Diagonal) & I2_média & 237 & Zernike_O3_R1 & Zernike_O12_R10 \\
\hline 27 & I3_suavidade & I3_variância & 238 & R_curtose & Zernike_O17_R17 \\
\hline 28 & I3_variância & I3_suavidade & 239 & V_suavidade & Zernike_O14_R12 \\
\hline 29 & I2_média & Zernike_O2_R0 & 240 & V_variância & Zernike_O16_R10 \\
\hline 30 & Zernike_O2_R0 & CIE-a_suavidade & 241 & Zernike_O2_R2 & Zernike_O16_R14 \\
\hline 31 & Zernike_O6_R0 & CIE-a_variância & 242 & Zernike_O14_R8 & V_variância \\
\hline 32 & F_I2_6(Vertical) & F_I2_6(Vertical) & 243 & Zernike_O10_R6 & V_suavidade \\
\hline 33 & F_I1_2(Horizontal) & F_I2_7(Horizontal) & 244 & Zernike_O12_R8 & DGF_R3_A6 \\
\hline 34 & F_I2_7(Horizontal) & F_I2_7(Diagonal) & 245 & F_I2_3(Diagonal) & Zernike_O12_R8 \\
\hline 35 & F_I2_6(Horizontal) & CIE-b_média & 246 & Zernike_O12_R6 & Zernike_O13_R13 \\
\hline 36 & F_I2_7(Diagonal) & F_I2_6(Horizontal) & 247 & Zernike_O10_R8 & Zernike_O11_R11 \\
\hline 37 & F_I1_2(Vertical) & F_I2_7(Vertical) & 248 & G_curtose & AR_0 \\
\hline 38 & F_I2_6(Diagonal) & F_I2_6(Diagonal) & 249 & Zernike_O8_R6 & Zernike_O18_R16 \\
\hline 39 & F_I2_7(Vertical) & R_média & 250 & Zernike_O12_R0 & F_I3_12(Horizontal) \\
\hline 40 & CIE-L_suavidade & H_média & 251 & Zernike_O4_R2 & Zernike_O18_R12 \\
\hline 41 & CIE-L_variância & Zernike_O6_R0 & 252 & F_I3_12(Horizontal) & Zernike_O10_R6 \\
\hline 42 & CIE-b_média & CIE-L_variância & 253 & Zernike_O9_R9 & Zernike_O18_R8 \\
\hline 43 & I3_média & CIE-L_suavidade & 254 & Zernike_O20_R6 & F_I2_12(Vertical) \\
\hline 44 & F_I3_7(Horizontal) & G_entropia & 255 & Zernike_O20_R4 & DGF_R0_A5 \\
\hline 45 & F_I3_6(Horizontal) & F_I3_6(Vertical) & 256 & F_I1_12(Horizontal) & DGF_R1_A4 \\
\hline 46 & F_I3_7(Diagonal) & F_I3_6(Horizontal) & 257 & Zernike_O9_R5 & Zernike_O3_R1 \\
\hline 47 & F_I3_6(Vertical) & CIE-a_média & 258 & Zernike_O7_R7 & Zernike_O8_R0 \\
\hline 48 & F_I3_7(Vertical) & I3_média & 259 & Zernike_O10_R2 & Zernike_O18_R14 \\
\hline 49 & F_I3_6(Diagonal) & B_média & 260 & Zernike_O16_R6 & Zernike_O20_R16 \\
\hline 50 & F_I1_11(Diagonal) & F_13_6(Diagonal) & 261 & DGF_R1_A4 & Zernike_O20_R18 \\
\hline 51 & I3_entropia & F_I3_7(Diagonal) & 262 & F_I1_13(Horizontal) & Zernike_O16_R12 \\
\hline 52 & F_I1_11(Horizontal) & B_energia & 263 & F_I2_12(Vertical) & Zernike_O12_R0 \\
\hline 53 & F_I1_5(Diagonal) & F_I3_7(Horizontal) & 264 & F_I3_14(Horizontal) & F_I1_13(Diagonal) \\
\hline 54 & F_I1_9(Horizontal) & F_I3_7(Vertical) & 265 & Zernike_O18_R8 & F_I1_3(Horizontal) \\
\hline 55 & F_I1_8(Vertical) & V_obliquidade & 266 & Zernike_O16_R0 & DGF_R0_A6 \\
\hline
\end{tabular}




\begin{tabular}{|c|c|c|c|c|c|}
\hline Posição & Ganho de Informação & Chi-quadrado & Posição & $\begin{array}{c}\text { Ganho de } \\
\text { Informação }\end{array}$ & Chi-quadrado \\
\hline 56 & H_média & CIE-L_energia & 267 & DGF_R3_A6 & Zernike_O14_R10 \\
\hline 57 & F_I1_9(Vertical) & DGF_R0_A2 & 268 & Zernike_O16_R10 & Zernike_O9_R9 \\
\hline 58 & F_I1_9(Diagonal) & R_entropia & 269 & Zernike_O13_R7 & R_curtose \\
\hline 59 & CIE-L_energia & I3_entropia & 270 & Zernike_O12_R10 & Zernike_O9_R5 \\
\hline 60 & F_I1_8(Horizontal) & F_I1_11(Diagonal) & 271 & Zernike_O14_R12 & Zernike_O20_R14 \\
\hline 61 & F_I1_5(Horizontal) & V_energia & 272 & DGF_R0_A4 & Zernike_O16_R6 \\
\hline 62 & B_média & F_I1_11(Horizontal) & 273 & Zernike_O7_R1 & Zernike_O7_R7 \\
\hline 63 & F_I1_10(Diagonal) & CIE-b_suavidade & 274 & Zernike_O18_R16 & Zernike_O20_R10 \\
\hline 64 & F_I1_8(Diagonal) & CIE-b_variância & 275 & Zernike_O20_R0 & Zernike_O13_R7 \\
\hline 65 & CIE-a_média & B_entropia & 276 & Zernike_O18_R12 & F_I3_14(Horizontal) \\
\hline 66 & G_entropia & F_I3_8(Vertical) & 277 & F_I2_12(Horizontal) & Zernike_O17_R15 \\
\hline 67 & F_I1_10(Horizontal) & F_I3_8(Diagonal) & 278 & Zernike_O15_R9 & Zernike_O16_R0 \\
\hline 68 & V_obliquidade & F_I3_2(Diagonal) & 279 & F3 & Zernike_O17_R9 \\
\hline 69 & F_I1_1(Horizontal) & F_I3_8(Horizontal) & 280 & Zernike_O16_R14 & Zernike_O15_R9 \\
\hline 70 & F_I1_1(Diagonal) & Zernike_O10_R0 & 281 & Zernike_O20_R12 & Zernike_O20_R6 \\
\hline 71 & F_I1_1(Vertical) & I3_energia & 282 & Zernike_O11_R7 & F_I2_3(Diagonal) \\
\hline 72 & F_I3_2(Diagonal) & S_energia & 283 & Zernike_O20_R18 & Zernike_O20_R4 \\
\hline 73 & I3_energia & F_I1_11(Vertical) & 284 & Zernike_O11_R5 & Zernike_O6_R2 \\
\hline 74 & I1_variância & F_I1_5(Diagonal) & 285 & Zernike_O18_R10 & F_I1_12(Horizontal) \\
\hline 75 & I1_suavidade & F_I3_9(Diagonal) & 286 & F_I2_3(Horizontal) & Zernike_O20_R12 \\
\hline 76 & F_I3_8(Vertical) & Slenderness & 287 & Zernike_O17_R9 & Zernike_O19_R17 \\
\hline 77 & F_I3_8(Diagonal) & I2_variância & 288 & Zernike_O14_R10 & Zernike_O18_R10 \\
\hline 78 & F_I3_8(Horizontal) & I2_suavidade & 289 & Zernike_O5_R5 & Zernike_O19_R11 \\
\hline 79 & Zernike_O10_R0 & F_I3_9(Horizontal) & 290 & Zernike_O5_R3 & Zernike_O10_R2 \\
\hline 80 & F_I1_11(Vertical) & F_I2_4(Horizontal) & 291 & Zernike_O19_R11 & Zernike_O11_R5 \\
\hline 81 & B_energia & F_I2_4(Diagonal) & 292 & Zernike_O16_R2 & G_curtose \\
\hline 82 & F_I1_5(Vertical) & F_I2_4(Vertical) & 293 & Zernike_O7_R5 & Zernike_O15_R13 \\
\hline 83 & CIE-L_entropia & F_I1_9(Horizontal) & 294 & Zernike_O17_R15 & Zernike_O20_R0 \\
\hline 84 & F_I3_9(Horizontal) & F_I3_13(Diagonal) & 295 & Zernike_O7_R3 & Zernike_O16_R8 \\
\hline 85 & I1_energia & F_I1_9(Vertical) & 296 & Zernike_O16_R12 & Zernike_O5_R5 \\
\hline 86 & F_I3_9(Diagonal) & F_I2_5(Horizontal) & 297 & Zernike_O20_R10 & Zernike_O11_R7 \\
\hline 87 & S_obliquidade & F_I1_8(Vertical) & 298 & Zernike_O1_R1 & Zernike_O7_R3 \\
\hline 88 & CIE-b_variância & F_I1_9(Diagonal) & 299 & Zernike_O16_R8 & Zernike_O15_R7 \\
\hline 89 & CIE-b_suavidade & F_I1_10(Diagonal) & 300 & Zernike_O8_R4 & Zernike_O5_R3 \\
\hline 90 & CIE-a_entropia & F_I3_4(Vertical) & 301 & Zernike_O17_R11 & DGF_R2_A6 \\
\hline 91 & F_I2_5(Horizontal) & F_I3_4(Diagonal) & 302 & Zernike_O18_R14 & Zernike_O13_R11 \\
\hline 92 & F_I1_10(Vertical) & F_I1_4(Vertical) & 303 & Zernike_O17_R7 & Zernike_O17_R7 \\
\hline 93 & B_entropia & F_I1_4(Diagonal) & 304 & Zernike_O19_R17 & Zernike_O7_R1 \\
\hline 94 & F_I3_9(Vertical) & S_entropia & 305 & F_I3_3(Diagonal) & Zernike_O19_R9 \\
\hline 95 & F_I3_2(Vertical) & F_I1_4(Horizontal) & 306 & Zernike_O6_R2 & Zernike_O17_R11 \\
\hline 96 & F_I2_10(Horizontal) & F_I3_9(Vertical) & 307 & Zernike_O15_R13 & Zernike_O7_R5 \\
\hline 97 & F_I2_11(Diagonal) & F_I1_8(Horizontal) & 308 & Zernike_O15_R5 & Zernike_O16_R2 \\
\hline 98 & F_I3_11(Diagonal) & F_I1_5(Horizontal) & 309 & Zernike_O3_R3 & Zernike_O1_R1 \\
\hline 99 & I1_entropia & I1_energia & 310 & Zernike_O20_R16 & F_I2_12(Horizontal) \\
\hline
\end{tabular}




\begin{tabular}{|c|c|c|c|c|c|}
\hline Posição & Ganho de Informação & Chi-quadrado & Posição & $\begin{array}{c}\text { Ganho de } \\
\text { Informação }\end{array}$ & Chi-quadrado \\
\hline 100 & DGF_R0_A2 & F_I3_4(Horizontal) & 311 & Zernike_O9_R7 & Zernike_O9_R7 \\
\hline 101 & F_I3_1(Horizontal) & CIE-a_entropia & 312 & Zernike_O20_R14 & F3 \\
\hline 102 & F_I2_10(Diagonal) & F_I3_2(Vertical) & 313 & Zernike_O9_R3 & F_I1_13(Horizontal) \\
\hline 103 & F_I3_1(Vertical) & F_I1_8(Diagonal) & 314 & Zernike_O15_R7 & Zernike_O8_R4 \\
\hline 104 & F_I3_11(Horizontal) & F_I1_10(Horizontal) & 315 & Zernike_O19_R9 & Zernike_O3_R3 \\
\hline 105 & F_I2_11(Horizontal) & V_entropia & 316 & DGF_R0_A5 & Zernike_O15_R5 \\
\hline 106 & F_I3_1(Diagonal) & F_I1_1(Horizontal) & 317 & Zernike_O13_R11 & DGF_R3_A5 \\
\hline 107 & F_I3_5(Diagonal) & S_obliquidade & 318 & Zernike_O12_R2 & Zernike_O9_R3 \\
\hline 108 & F_I2_5(Diagonal) & F_I2_11(Horizontal) & 319 & F_I1_14(Vertical) & Zernike_O13_R5 \\
\hline 109 & R_entropia & F_I2_11(Diagonal) & 320 & Zernike_O20_R2 & AR_SN \\
\hline 110 & F_I3_2(Horizontal) & F_I3_13(Vertical) & 321 & F_I1_3(Diagonal) & Zernike_O11_R9 \\
\hline 111 & I2_suavidade & F_I1_1(Vertical) & 322 & F_I3_3(Horizontal) & Zernike_O20_R2 \\
\hline 112 & I2_variância & F_I2_10(Horizontal) & 323 & Zernike_O13_R5 & Zernike_O11_R3 \\
\hline 113 & F_I3_5(Horizontal) & F_I1_1(Diagonal) & 324 & F_I1_12(Diagonal) & F_I2_3(Horizontal) \\
\hline 114 & F_I2_2(Diagonal) & F_I3_5(Diagonal) & 325 & AR_1 & Zernike_O12_R2 \\
\hline 115 & H_variância & F_I2_2(Diagonal) & 326 & F5 & Zernike_O19_R13 \\
\hline 116 & H_suavidade & F_I3_5(Horizontal) & 327 & Zernike_O11_R9 & Zernike_O19_R5 \\
\hline 117 & F_I3_10(Diagonal) & I1_suavidade & 328 & DGF_R0_A6 & F_I3_3(Diagonal) \\
\hline 118 & F_I3_11(Vertical) & I1_variância & 329 & F_I1_14(Horizontal) & Zernike_O19_R7 \\
\hline 119 & F_I2_2(Vertical) & F_I3_11(Diagonal) & 330 & Zernike_O8_R2 & DGF_R1_A0 \\
\hline 120 & F_I3_10(Horizontal) & F_I3_2(Horizontal) & 331 & Zernike_O11_R3 & Zernike_O14_R6 \\
\hline 121 & F_I2_4(Diagonal) & F_I3_1(Vertical) & 332 & Zernike_O19_R5 & F5 \\
\hline 122 & F_I2_4(Horizontal) & F_I1_5(Vertical) & 333 & F_I1_14(Diagonal) & F_I1_12(Diagonal) \\
\hline 123 & F_I2_4(Vertical) & F_I3_11(Horizontal) & 334 & AR_SN & AR_1 \\
\hline 124 & F_I3_10(Vertical) & F_I3_1(Horizontal) & 335 & Zernike_O15_R3 & Zernike_O15_R3 \\
\hline 125 & F_I3_5(Vertical) & F_I2_5(Diagonal) & 336 & DGF_R2_A6 & Zernike_O13_R9 \\
\hline 126 & F_I2_2(Horizontal) & F_I2_10(Diagonal) & 337 & Zernike_O19_R13 & Zernike_O15_R11 \\
\hline 127 & F_I3_4(Diagonal) & F_I3_1(Diagonal) & 338 & CIE-L_curtose & Zernike_O5_R1 \\
\hline 128 & F_I3_4(Vertical) & F_I1_10(Vertical) & 339 & Zernike_O13_R9 & F_I3_3(Horizontal) \\
\hline 129 & F_I2_1(Horizontal) & F_I3_10(Diagonal) & 340 & Zernike_O19_R3 & Zernike_O8_R2 \\
\hline 130 & I2_energia & I2_energia & 341 & Zernike_O14_R6 & Zernike_O19_R3 \\
\hline 131 & CIE-a_energia & F_I3_11(Vertical) & 342 & Zernike_O15_R11 & F_I1_3(Diagonal) \\
\hline 132 & F_I2_1(Diagonal) & CIE-L_entropia & 343 & Zernike_O13_R3 & DGF_R2_A3 \\
\hline 133 & F_I2_8(Horizontal) & A3 & 344 & Zernike_O19_R7 & Zernike_O17_R5 \\
\hline 134 & F_I1_4(Vertical) & F_I2_2(Vertical) & 345 & DGF_R3_A5 & F_I1_14(Vertical) \\
\hline 135 & F_I1_4(Diagonal) & CIE-a_energia & 346 & Zernike_O11_R1 & Zernike_O13_R3 \\
\hline 136 & F_I1_4(Horizontal) & R_obliquidade & 347 & Zernike_O17_R5 & Zernike_O9_R1 \\
\hline 137 & F_I3_4(Horizontal) & F_I3_10(Horizontal) & 348 & I1_curtose & Zernike_O19_R15 \\
\hline 138 & F_I2_9(Diagonal) & F_I2_2(Horizontal) & 349 & Zernike_O5_R1 & Zernike_O11_R1 \\
\hline 139 & F_I2_1(Vertical) & F_I2_9(Horizontal) & 350 & Zernike_O9_R1 & CIE-L_curtose \\
\hline 140 & F_I2_9(Horizontal) & S_suavidade & 351 & Zernike_O17_R3 & Zernike_O20_R8 \\
\hline 141 & F_I2_8(Vertical) & S_variância & 352 & A5 & Zernike_O17_R13 \\
\hline 142 & F_I2_8(Diagonal) & F_I2_9(Diagonal) & 353 & Zernike_O17_R13 & F_I1_14(Horizontal) \\
\hline 143 & F_I2_9(Vertical) & F_I2_8(Horizontal) & 354 & F_I1_12(Vertical) & F_I1_14(Diagonal) \\
\hline
\end{tabular}




\begin{tabular}{|c|c|c|c|c|c|}
\hline Posição & Ganho de Informação & Chi-quadrado & Posição & $\begin{array}{c}\text { Ganho de } \\
\text { Informação }\end{array}$ & Chi-quadrado \\
\hline 144 & F_I2_10(Vertical) & F_I2_8(Vertical) & 355 & Zernike_O19_R1 & DGF_R2_A0 \\
\hline 145 & F_I2_11(Vertical) & Eixo maior & 356 & Zernike_O20_R8 & DGF_R3_A0 \\
\hline 146 & Slenderness & F_I3_10(Vertical) & 357 & Zernike_O19_R15 & I1_curtose \\
\hline 147 & I2_entropia & F_I2_8(Diagonal) & 358 & Zernike_O13_R1 & DGF_R2_A1 \\
\hline 148 & S_variância & CIE-b_energia & 359 & F7 & Zernike_O17_R3 \\
\hline 149 & S_suavidade & F_I3_5(Vertical) & 360 & Zernike_O16_R4 & A5 \\
\hline 150 & F_I2_5(Vertical) & H_variância & 361 & Zernike_O15_R1 & DGF_R2_A5 \\
\hline 151 & V_energia & H_suavidade & 362 & Zernike_O17_R1 & DGF_R2_A2 \\
\hline 152 & Eixo maior & F_I2_1(Horizontal) & 363 & DGF_R1_A0 & F7 \\
\hline 153 & A1 & F_I2_1(Diagonal) & 364 & DGF_R2_A5 & Zernike_O19_R1 \\
\hline 154 & B_curtose & $\mathrm{A} 1$ & 365 & DGF_R2_A3 & DGF_R2_A4 \\
\hline 155 & H_energia & F_I2_9(Vertical) & 366 & Zernike_O12_R4 & F_I1_12(Vertical) \\
\hline 156 & CIE-b_energia & G_obliquidade & 367 & DGF_R2_A1 & Zernike_O13_R1 \\
\hline 157 & CIE-b_entropia & F_I2_1(Vertical) & 368 & $\mathrm{~F} 4$ & Zernike_O16_R4 \\
\hline 158 & F_I3_13(Diagonal) & F_I2_13(Vertical) & 369 & Zernike_O18_R6 & Zernike_O15_R1 \\
\hline 159 & $\mathrm{~A} 3$ & I1_entropia & 370 & DGF_R2_A0 & Zernike_O17_R1 \\
\hline 160 & CIE-L_obliquidade & I2_entropia & 371 & DGF_R2_A4 & DGF_R3_A1 \\
\hline 161 & $\mathrm{~A} 2$ & $\mathrm{~F} 2$ & 372 & F8 & DGF_R1_A1 \\
\hline 162 & F_I3_13(Vertical) & F_I3_13(Horizontal) & 373 & DGF_R2_A2 & Zernike_O12_R4 \\
\hline 163 & S_entropia & F_I2_11(Vertical) & 374 & DGF_R3_A0 & Zernike_O18_R6 \\
\hline 164 & Zernike_O14_R0 & F_I2_10(Vertical) & 375 & DGF_R1_A3 & DGF_R1_A3 \\
\hline 165 & S_curtose & DGF_R0_A0 & 376 & DGF_R1_A1 & $\mathrm{F} 4$ \\
\hline 166 & F_I2_13(Vertical) & B_curtose & 377 & F9 & DGF_R1_A2 \\
\hline 167 & H_entropia & DGF_R0_A1 & 378 & DGF_R1_A2 & F8 \\
\hline 168 & B_variância & F_I2_5(Vertical) & 379 & DGF_R3_A4 & DGF_R3_A2 \\
\hline 169 & B_suavidade & B_obliquidade & 380 & F10 & DGF_R3_A4 \\
\hline 170 & DGF_R0_A0 & CIE-b_entropia & 381 & F6 & F9 \\
\hline 171 & V_entropia & A4 & 382 & DGF_R3_A1 & F10 \\
\hline 172 & S_energia & F_I2_13(Diagonal) & 383 & F11 & F6 \\
\hline 173 & I2_curtose & H_energia & 384 & F13 & F13 \\
\hline 174 & Eixo menor & I2_curtose & 385 & $\mathrm{~F} 12$ & F11 \\
\hline 175 & R_obliquidade & CIE-L_obliquidade & 386 & DGF_R3_A3 & DGF_R3_A3 \\
\hline 176 & I1_obliquidade & B_suavidade & 387 & DGF_R3_A2 & $\mathrm{F} 12$ \\
\hline 177 & F_I1_13(Vertical) & B_variância & 388 & F14 & F14 \\
\hline 178 & G_obliquidade & $\mathrm{A} 2$ & 389 & F16 & $\mathrm{F} 1$ \\
\hline 179 & CIE-b_curtose & H_entropia & 390 & F15 & F38 \\
\hline 180 & B_obliquidade & S_curtose & 391 & $\mathrm{~F} 1$ & F16 \\
\hline 181 & DGF_R0_A1 & I1_obliquidade & 392 & F38 & F15 \\
\hline 182 & F_I2_3(Vertical) & Zernike_O14_R0 & 393 & F17 & F17 \\
\hline 183 & F_I2_13(Diagonal) & CIE-b_curtose & 394 & F35 & F35 \\
\hline 184 & A4 & F_I2_13(Horizontal) & 395 & $\mathrm{~F} 21$ & $\mathrm{~F} 21$ \\
\hline 185 & F_I3_13(Horizontal) & Eixo menor & 396 & F29 & F18 \\
\hline 186 & V_curtose & F_I2_3(Vertical) & 397 & $\mathrm{~F} 20$ & F19 \\
\hline 187 & $\mathrm{~F} 2$ & I2_obliquidade & 398 & $\mathrm{~F} 18$ & $\mathrm{~F} 20$ \\
\hline
\end{tabular}




\begin{tabular}{|c|c|c|c|c|c|}
\hline Posição & Ganho de Informação & Chi-quadrado & Posição & $\begin{array}{c}\text { Ganho de } \\
\text { Informação }\end{array}$ & Chi-quadrado \\
\hline 188 & I2_obliquidade & F_I1_13(Vertical) & 399 & F19 & F29 \\
\hline 189 & H_curtose & F_I3_12(Diagonal) & 400 & F37 & F37 \\
\hline 190 & F_I1_3(Vertical) & V_curtose & 401 & F28 & F28 \\
\hline 191 & F_I2_13(Horizontal) & Zernike_O4_R4 & 402 & F25 & F27 \\
\hline 192 & CIE-b_obliquidade & Zernike_O6_R4 & 403 & F27 & F22 \\
\hline 193 & Zernike_O18_R4 & CIE-b_obliquidade & 404 & F22 & F25 \\
\hline 194 & CIE-a_obliquidade & Zernike_O10_R4 & 405 & F34 & F24 \\
\hline 195 & Zernike_O14_R4 & CIE-a_obliquidade & 406 & F24 & F34 \\
\hline 196 & CIE-a_curtose & H_curtose & 407 & AR_2 & F33 \\
\hline 197 & F_I3_3(Vertical) & F_I1_3(Vertical) & 408 & AR_6 & F31 \\
\hline 198 & I3_curtose & Zernike_O8_R8 & 409 & AR_5 & F32 \\
\hline 199 & Zernike_O10_R4 & DGF_R0_A3 & 410 & F36 & AR_9 \\
\hline 200 & H_obliquidade & F_I2_14(Diagonal) & 411 & F32 & F30 \\
\hline 201 & Zernike_O18_R0 & Excentricidade & 412 & AR_7 & F26 \\
\hline 202 & F_I2_14(Diagonal) & Zernike_O10_R10 & 413 & F33 & F23 \\
\hline 203 & DGF_R1_A5 & I3_obliquidade & 414 & F31 & AR_7 \\
\hline 204 & I3_obliquidade & F_I3_3(Vertical) & 415 & AR_3 & AR_8 \\
\hline 205 & Zernike_O18_R2 & Zernike_O18_R4 & 416 & AR_8 & AR_6 \\
\hline 206 & Zernike_O6_R4 & Zernike_O12_R12 & 417 & F26 & AR_2 \\
\hline 207 & DGF_R1_A6 & F_I3_14(Diagonal) & 418 & AR_4 & AR_3 \\
\hline 208 & Zernike_O18_R18 & Zernike_O14_R4 & 419 & F30 & AR_4 \\
\hline 209 & Zernike_O20_R20 & Zernike_O18_R18 & 420 & $\mathrm{~F} 23$ & AR_5 \\
\hline 210 & Zernike_O4_R4 & Zernike_O6_R6 & 421 & AR_9 & F36 \\
\hline 211 & Zernike_O14_R2 & Zernike_O16_R16 & & & \\
\hline
\end{tabular}

